\title{
2016 European Guidelines on cardiovascular disease prevention in clinical practice
}

\section{The Sixth Joint Task Force of the European Society of Cardiology and Other Societies on Cardiovascular Disease Prevention in Clinical Practice (constituted by representatives of 10 societies and by invited experts)}

\section{Developed with the special contribution of the European Association for Cardiovascular Prevention \& Rehabilitation (EACPR)}

Authors/Task Force Members: Massimo F. Piepoli* (Chairperson) (Italy), Arno W. Hoes* (Co-Chairperson) (The Netherlands), Stefan Agewall (Norway) ${ }^{1}$, Christian Albus (Germany) ${ }^{9}$, Carlos Brotons (Spain) ${ }^{\mathbf{1 0}}$, Alberico L. Catapano (Italy) ${ }^{3}$, Marie-Therese Cooney (Ireland) ${ }^{1}$, Ugo Corrà (Italy) ${ }^{1}$, Bernard Cosyns (Belgium) ${ }^{1}$, Christi Deaton (UK) ${ }^{1}$, lan Graham (Ireland) ${ }^{1}$, Michael Stephen Hall (UK) ${ }^{7}$, F. D. Richard Hobbs (UK) ${ }^{10}$, Maja-Lisa Løchen (Norway) ${ }^{1}$, Herbert Löllgen (Germany) $^{8}$, Pedro Marques-Vidal (Switzerland) ${ }^{1}$, Joep Perk (Sweden) ${ }^{1}$, Eva Prescott (Denmark) ${ }^{1}$, Josep Redon (Spain) ${ }^{5}$, Dimitrios J. Richter (Greece) ${ }^{1}$, Naveed Sattar $(\mathrm{UK})^{2}$, Yvo Smulders (The Netherlands) ${ }^{1}$, Monica Tiberi (Italy) ${ }^{1}$, H. Bart van der Worp (The Netherlands) ${ }^{6}$, Ineke van Dis (The Netherlands) ${ }^{4}$, W. M. Monique Verschuren (The Netherlands) ${ }^{1}$

Additional Contributor: Simone Binno (Italy)

* Corresponding authors: Massimo F. Piepoli, Heart Failure Unit, Cardiology Department, Polichirurgico Hospital G. Da Saliceto, Cantone Del Cristo, 29121 Piacenza, Emilia Romagna, Italy, Tel: +390523 3032 17, Fax: +390523 3032 20, E-mail: m.piepoli@alice.it, m.piepoli@imperial.ac.uk.

Arno W. Hoes, Julius Center for Health Sciences and Primary Care, University Medical Center Utrecht, PO Box 85500 (HP Str. 6.131), 3508 GA Utrecht, The Netherlands, Tel: +31 88756 8193, Fax: +31 88756 8099, E-mail: a.w.hoes@umcutrecht.nl.

ESC Committee for Practice Guidelines (CPG) and National Cardiac Societies document reviewers: listed in the Appendix.

ESC entities having participated in the development of this document:

Associations: European Association for Cardiovascular Prevention \& Rehabilitation (EACPR), European Association of Cardiovascular Imaging (EACVI), European Association of Percutaneous Cardiovascular Interventions (EAPCI), Heart Failure Association (HFA).

Councils: Council on Cardiovascular Nursing and Allied Professions, Council for Cardiology Practice, Council on Cardiovascular Primary Care.

Working Groups: Cardiovascular Pharmacotherapy

The content of these European Society of Cardiology (ESC) Guidelines has been published for personal and educational use only. No commercial use is authorized. No part of the ESC Guidelines may be translated or reproduced in any form without written permission from the ESC. Permission can be obtained upon submission of a written request to Oxford University Press, the publisher of the European Heart Journal and the party authorized to handle such permissions on behalf of the ESC.

Disclaimer. The ESC Guidelines represent the views of the ESC and were produced after careful consideration of the scientific and medical knowledge and the evidence available at the time of their publication. The ESC is not responsible in the event of any contradiction, discrepancy and/or ambiguity between the ESC Guidelines and any other official recommendations or guidelines issued by the relevant public health authorities, in particular in relation to good use of healthcare or therapeutic strategies. Health professionals are encouraged to take the ESC Guidelines fully into account when exercising their clinical judgment, as well as in the determination and the implementation of preventive, diagnostic or therapeutic medical strategies; however, the ESC Guidelines do not override, in any way whatsoever, the individual responsibility of health professionals to make appropriate and accurate decisions in consideration of each patient's health condition and in consultation with that patient and, where appropriate and/or necessary, the patient's caregiver. Nor do the ESC Guidelines exempt health professionals from taking into full and careful consideration the relevant official updated recommendations or guidelines issued by the competent public health authorities, in order to manage each patient's case in light of the scientifically accepted data pursuant to their respective ethical and professional obligations. It is also the health professional's responsibility to verify the applicable rules and regulations relating to drugs and medical devices at the time of prescription. 
Document Reviewers: Guy De Backer (CPG Review Coordinator) (Belgium), Marco Roffi (CPG Review Coordinator) (Switzerland), Victor Aboyans (France) ${ }^{\mathbf{1}}$, Norbert Bachl (Austria) ${ }^{\mathbf{8}}$, Héctor Bueno (Spain) ${ }^{\mathbf{1}}$, Scipione Carerj (Italy) ${ }^{\mathbf{1}}$, Leslie Cho (USA) ${ }^{1}$, John Cox (Ireland) ${ }^{10}$, Johan De Sutter (Belgium) ${ }^{1}$, Günther Egidi (Germany) ${ }^{1}$, Miles Fisher (UK) ${ }^{2}$, Donna Fitzsimons (UK) ${ }^{1}$, Oscar H. Franco (The Netherlands) ${ }^{1}$, Maxime Guenoun (France) ${ }^{1}$, Catriona Jennings (UK) ${ }^{1}$, Borut Jug (Slovenia) ${ }^{4}$, Paulus Kirchhof (UK/Germany) ${ }^{1}$, Kornelia Kotseva (UK) ${ }^{1}$, Gregory Y.H. Lip (UK) ${ }^{1}$, François Mach (Switzerland) ${ }^{1}$, Giuseppe Mancia (Italy) ${ }^{5}$, Franz Martin Bermudo (Spain) ${ }^{7}$, Alessandro Mezzani (Italy) ${ }^{1}$, Alexander Niessner (Austria) ${ }^{1}$, Piotr Ponikowski (Poland) ${ }^{1}$, Bernhard Rauch (Germany) ${ }^{1}$, Lars Rydén (Sweden) ${ }^{1}$, Adrienne Stauder (Hungary) ${ }^{9}$, Guillaume Turc (France) ${ }^{6}$, Olov Wiklund (Sweden) ${ }^{3}$, Stephan Windecker (Switzerland) ${ }^{1}$, Jose Luis Zamorano (Spain) ${ }^{1}$

Societies: ${ }^{1}$ European Society of Cardiology (ESC); ${ }^{2}$ European Association for the Study of Diabetes (EASD); ${ }^{3}$ European Atherosclerosis Society (EAS); ${ }^{4}$ European Heart Network (EHN); ${ }^{5}$ European Society of Hypertension (ESH); ${ }^{6}$ European Stroke Organisation (ESO); International Diabetes Federation European Region (IDF Europe); ${ }^{8}$ International Federation of Sport Medicine (FIMS); ${ }^{9}$ International Society of Behavioural Medicine (ISBM); ${ }^{10}$ WONCA Europe.

The disclosure forms of all experts involved in the development of these guidelines are available on the ESC website http://www.escardio.org/guidelines.

Online publish-ahead-of-print 23 May 2016

Keywords

Guidelines • Blood pressure • Clinical settings • Diabetes • Healthy lifestyle • Lipid • Nutrition • Physical activity - Population - Prevention - Primary care - Psychosocial factors • Rehabilitation • Risk assessment • Risk management • Smoking • Stakeholder

\section{Table of Contents}

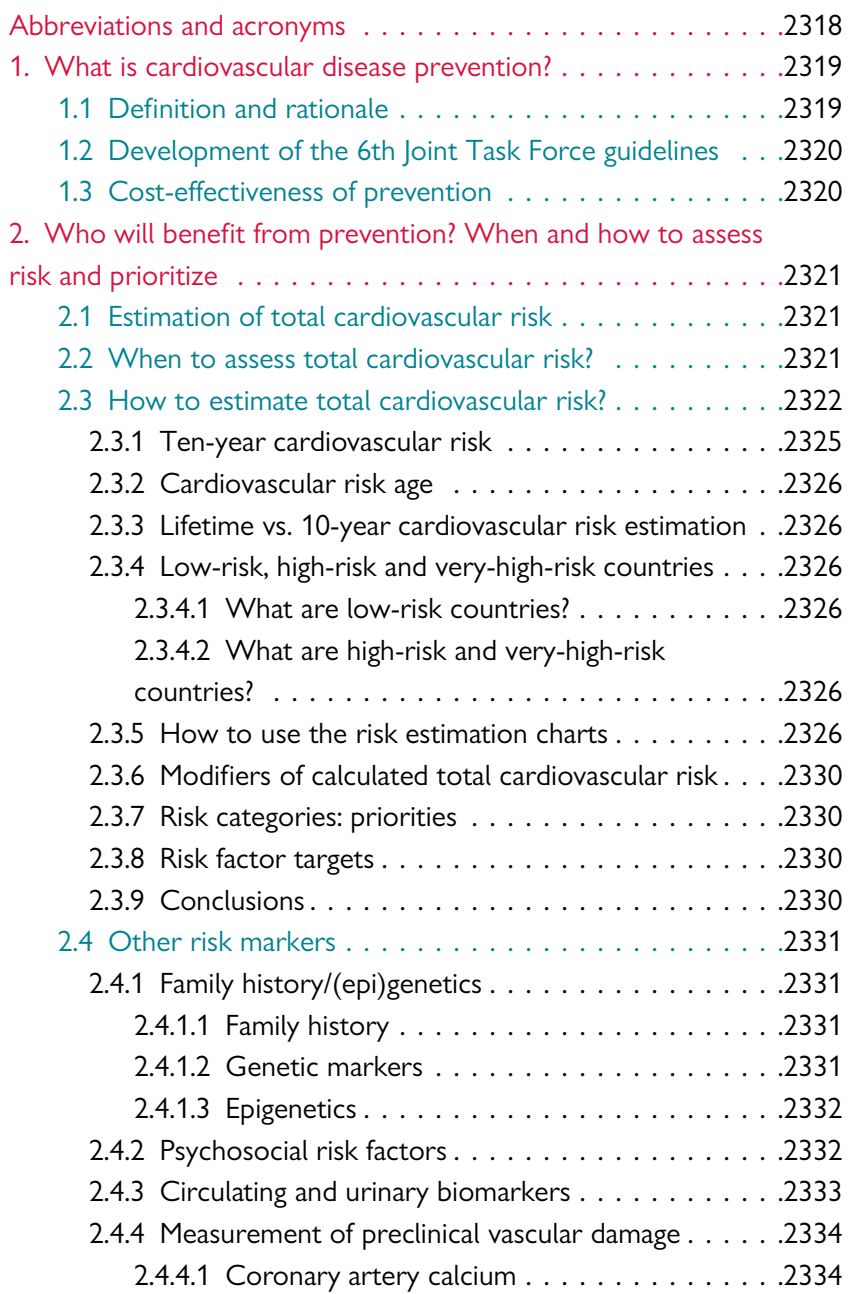

2.4.4.2 Carotid ultrasound . . . . . . . . . . . 2335

2.4.4.3 Arterial stiffness . . . . . . . . . . . . . . . . . . . . . . . . . . . . . . . . . . . . . . . . . .

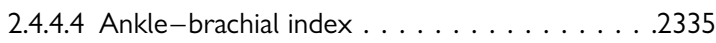

2.4.4.5 Echocardiography . . . . . . . . . . . . . . 2335

2.4.5 Clinical conditions affecting cardiovascular disease risk .2335

2.4.5.1 Chronic kidney disease . . . . . . . . . . . . . 2335

2.4.5.2 Influenza . . . . . . . . . . . 2336

2.4.5.3 Periodontitis. . . . . . . . . . . . . . . . 2336

2.4.5.4 Patients treated for cancer . . . . . . . . . . . . . . . . . . . . . . . . . . .

2.4.5.5 Autoimmune disease . . . . . . . . . . . . . . 2337

2.4.5.6 Obstructive sleep apnoea syndrome . . . . . . . . . . . . . . . . . . . . . . . . .

2.4.5.7 Erectile dysfunction . . . . . . . . . . . . . 2338

2.5 Relevant groups . . . . . . . . . . . . . . . . . . . 2338

2.5.1 Individuals $<50$ years of age . . . . . . . . . . 2338

2.5.1.1 Assessing cardiovascular disease risk in people

$<50$ years of age . . . . . . . . . . . . . . . 2338

2.5.1.2 Management of cardiovascular disease risk in

people $<50$ years of age . . . . . . . . . . . . . . . . . . . . . . . . . . . . . . . . . . .

2.5 .2 Elderly . . . . . . . . . . . . . . . . . . . . . . . 2339

2.5.2.1 Hypertension . . . . . . . . . . . . . . . . . . 2339

2.5.2.2 Diabetes mellitus . . . . . . . . . . . . . . . . . 2339

2.5.2.3 Hyperlipidaemia . . . . . . . . . . . . . . . . . 2339

2.5.3 Female-specific conditions . . . . . . . . . . . . . . 2339

2.5.3.1 Obstetric conditions . . . . . . . . . . . . . 2339

2.5.3.2 Non-obstetric conditions . . . . . . . . . . . 2340

2.5 .4 Ethnic minorities. . . . . . . . . . . . . . . . . . 2340

3a. How to intervene at the individual level: risk factor

intervention . . . . . . . . . . . . . . . . . . . . . . . . . 2341

3a.1 Behaviour change . . . . . . . . . . . . . . . . . 2341

3a.2 Psychosocial factors. . . . . . . . . . . . . . . . . . . . 2342

3a.3 Sedentary behaviour and physical activity . . . . . . . . 2343

3a.3.1 Introduction . . . . . . . . . . . . . . . . . . . . . .2343 
3a.3.2 Physical activity prescription . . . . . . . . . . . 2344

3a.3.2.1 Aerobic physical activity . . . . . . . . . . . . 2344

3a.3.2.2 Muscle strength/resistance physical activity . .2344

3a.3.2.3 Neuromotor physical activity . . . . . . . . . . 2345

3a.3.2.4 Phases and progression of physical activity . .2345

3a.3.3 Risk assessment . . . . . . . . . . . . . . . . 2345

3a.4 Smoking intervention . . . . . . . . . . . . . . . . . . . . . . . . . . . . . . . . . . . .

3a.4.1 Introduction . . . . . . . . . . . . . . . . . . . 2345

3a.4.2 Dosage and type . . . . . . . . . . . . . . . . . . . . . . . . . . . . . . . . . .

3a.4.3 Passive smoking . . . . . . . . . . . . . . 2346

3a.4.4 Mechanisms by which tobacco smoking increases

risk . . . . . . . . . . . . . . . . . . . 2346

3a.4.5 Smoking cessation . . . . . . . . . . . . . . . 2346

3a.4.6 Evidence-based drug interventions . . . . . . . . . . . . . . . . . . . . . . . .

3a.4.7 Electronic cigarettes. . . . . . . . . . . . . . . . . 2347

3a.4.8 Other smoking cessation interventions . . . . . . 2347

3a.5 Nutrition. . . . . . . . . . . . . . . . . . . . . . . . 2347

3a.5.1 Introduction . . . . . . . . . . . . . . . . . . . 2347

3a.5.2 Fatty acids . . . . . . . . . . . . . . . . . . 2347

3a.5.3 Minerals . . . . . . . . . . . . . . . . . . . 2348

3a.5.4 Vitamins . . . . . . . . . . . . . . . 2348

3a.5.5 Fibre. . . . . . . . . . . . . . . . . . . . 2348

3a.5.6 Foods and food groups . . . . . . . . . . . . . . . . . . . . . . . . . . . . . .

3a.5.6.1 Fruits and vegetables . . . . . . . . . . . . 2349

3a.5.6.2 Nuts . . . . . . . . . . . . . . . . . . . . . . . 2349

3a.5.6.3 Fish . . . . . . . . . . . . . . . . . . . . . . 2349

3a.5.6.4 Alcoholic beverages . . . . . . . . . . . . . . . 2349

3a.5.6.5 Soft drinks and sugar . . . . . . . . . . . . . .2349

3a.5.7 Functional foods . . . . . . . . . . . . . . . . . . . 2349

3a.5.8 Dietary patterns . . . . . . . . . . . . . . . . . 2349

3a.6 Body weight. . . . . . . . . . . . . . . . . . . . . . . 2349

3a.6.1 Introduction . . . . . . . . . . . . . . . . . . 2350

3a.6.2 Which index of obesity is the best predictor of

cardiovascular risk? . . . . . . . . . . . . . . . . . 2350

3a.6.3 Does 'metabolically healthy obesity' exist? . . . . . . 2350

3a.6.4 The obesity paradox in established heart disease . .2350

3a.6.5 Treatment goals and modalities . . . . . . . . . 2350

3a.7 Lipid control . . . . . . . . . . . . . . . . . . . . . . . . . . . . . . . . . . . . .

3a.7.1 Introduction . . . . . . . . . . . . . . . . . . 2351

3a.7.2 Total and low-density lipoprotein cholesterol . . . .2351

3a.7.3 Apolipoprotein B . . . . . . . . . . . . . . . . . . . . . . . . . . . . . . . . . .

3a.7.4 Triglycerides . . . . . . . . . . . . . . . . . 2351

3a.7.5 High-density lipoprotein cholesterol . . . . . . . . 2351

3a.7.6 Lipoprotein(a) . . . . . . . . . . . . . . . . . 2352

3a.7.7 Apolipoprotein B/apolipoprotein A1 ratio . . . . . 2352

3a.7.8 Calculated lipoprotein variables . . . . . . . . . . 2352

3a.7.8.1 Low-density lipoprotein cholesterol . . . . . . 2352

3a.7.8.2 Non-high-density lipoprotein cholesterol

(accurate in non-fasting samples) . . . . . . . . . . . 2352 . . . . . . . .

3a.7.8.3 Remnant cholesterol. . . . . . . . . . . . . . 2352

3a.7.9 Exclusion of secondary and familial dyslipidaemia . .2352 3a.7.10 Who should be treated and what are the goals? . 2352

3a.7.11 Patients with kidney disease . . . . . . . . . . . . . . . . . . . . . . . . . . . . . . .

3a.7.12 Drugs . . . . . . . . . . . . . . . . . 2353

3a.7.13 Drug combinations . . . . . . . . . . . . . . 2354

3a.8 Diabetes mellitus (type 2 and type 1) . . . . . . . . . 2355

3a.8.1 Lifestyle intervention . . . . . . . . . . . . . 2356

3a.8.2 Cardiovascular risk . . . . . . . . . . . . . . . 2356

3a.8.3 Glucose control . . . . . . . . . . . . . . . . . 2356 3a.8.4 Blood pressure . . . . . . . . . . . . . . . . . 2356

3a.8.5 Lipid-lowering therapy . . . . . . . . . . . . . . . . 2356 . . . . . . . . . . . . . . . . . .

3a.8.6 Antithrombotic therapy . . . . . . . . . . . . . . . . . . . . . . . . . . . . . . . . . . . . . .

3a.8.7 Microalbuminuria . . . . . . . . . . . . . . . . . . .2357

3a.8.8 Type 1 diabetes . . . . . . . . . . . . . . . . . . . . . . . . . . . . . . . . . . . . . . . . . . . . . . .

3a.9 Hypertension . . . . . . . . . . . . . . . . . . . . . 2358

3a.9.1 Introduction . . . . . . . . . . . . . . . . . . . . 2359

3a.9.2 Definition and classifications of hypertension . . . . 2359

3a.9.3 Blood pressure measurement . . . . . . . . . . . 2359

3a.9.4 Office or clinic blood pressure measurement . . . . 2359

3a.9.5 Out-of-office blood pressure monitoring . . . . . . 2359

3a.9.6 Diagnostic evaluation in hypertensive patients . . . . 2359

3a.9.7 Risk stratification in hypertension . . . . . . . . . 2360

3a.9.8 Who to treat, and when to initiate antihypertensive

treatment . . . . . . . . . . . . . . . . . . . . . . . . . .2360

3a.9.9 How to treat . . . . . . . . . . . . . . . . 2360

3a.9.9.1 Lifestyle changes . . . . . . . . . . . . . . . . 2360

3a.9.9.2 Blood pressure-lowering drugs . . . . . . . . . 2360

3a.9.9.3 Combination treatment . . . . . . . . . . . . 2361

3a.9.10 Blood pressure goals . . . . . . . . . . . . . . . 2361 . . . . . . . . . . .

3a.9.11 Hypertension in special groups . . . . . . . . . . . 2362

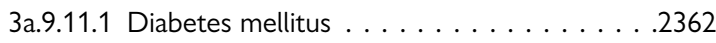

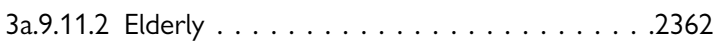

3a.9.12 Resistant hypertension . . . . . . . . . . . . . . 2362 . . . . . . . . . .

3a.9.13 Duration of treatment and follow-up . . . . . . . 2362

3a.10 Antiplatelet therapy . . . . . . . . . . . . . . . . 2363

3a.10.1 Antiplatelet therapy in individuals without

cardiovascular disease . . . . . . . . . . . . . . . . 2363

3a.10.2 Antiplatelet therapy in individuals with

cardiovascular or cerebrovascular disease . . . . . . . . . 2363

3a.11 Adherence to medication . . . . . . . . . . . . . . 2364

3a.11.1 Polypill . . . . . . . . . . . . . . . . . . . . 2365

3b. How to intervene at the individual level: disease-specific

intervention - atrial fibrillation, coronary artery disease, chronic heart failure, cerebrovascular disease, peripheral artery disease (web addenda) . . . . . . . . . . . . . . . . . . 2365

3c. How to intervene at the population level . . . . . . . . 2365

3c.1 Introduction (healthy lifestyle promotion) . . . . . . . 2365

3c.2 Population-based approaches to diet . . . . . . . . . 2366

3c.3 Population-based approaches to physical activity . . . . 2367

3c.4 Population-based approaches to smoking and other

tobacco use . . . . . . . . . . . . . . . . . . . . . . . . . 2369

3c.5 Alcohol abuse protection . . . . . . . . . . . . . 2370

3c.6 Healthy environment . . . . . . . . . . . . . . . . 2371

4a. Where to intervene at the individual level . . . . . . . . . 2371

4a.1 Clinical settings and stakeholders . . . . . . . . . . . 2371

4a.1.1 Cardiovascular disease prevention in primary care .2371

4a.1.2 Acute hospital admission setting . . . . . . . . . . 2372 . . . 2372

4a.1.3 Specialized prevention programmes . . . . . . . . . . . . . . 2372

4a.1.4 Alternative rehabilitation models . . . . . . . . . . . . . . . . . . . . . . . . .

4a.1.4.1 Telerehabilitation . . . . . . . . . . . . . . . 2373

4a.1.5 Maintaining lifestyle changes. . . . . . . . . . . . . 2373

4a.2 How to monitor preventive activities . . . . . . . . . 2373

4b. Where to intervene at the population level . . . . . . . . 2374

4 b.1 Government and public health. . . . . . . . . . . 60

4b.2 Non-governmental organizations . . . . . . . . . . 2374

5. To do and not to do messages from the Guidelines . . . . . 2375

6. Appendix . . . . . . . . . . . . . . . . . . . 2376

7. References . . . . . . . . . . . . . . . . . . . . . . . . . . 2377 


\section{Abbreviations and acronyms}

\section{$A B I$ \\ ABPM \\ ACCORD \\ ACE-I \\ ACS}

ADVANCE

AF

AMI

apoA1

apoB

$A R B$

BEUC

$\mathrm{BMI}$

$\mathrm{BP}$

CAC

CAD

CAPRIE

CARDS

CHANCE

CHARISMA

$\mathrm{Cl}$

CKD

CR

CT

CTT

CURE

\section{$\mathrm{CV}$}

CVD

DALYS

DASH

DBP

DCCT

DHA

DM

DPP-4

eGFR

ECDA

ECG

ED

EHN

EMA

EPA

EPIC

EPODE

ESC

EU ankle-brachial (blood pressure) index

ambulatory blood pressure monitoring

Action to Control Cardiovascular Risk in Diabetes angiotensin-converting enzyme inhibitor

acute coronary syndromes

Action in Diabetes and Vascular disease: PreterAx and Diamicron MR Controlled Evaluation

atrial fibrillation

acute myocardial infarction

apolipoprotein A1

apolipoprotein B

angiotensin receptor blocker

Bureau Européen des Unions de Consommateurs

body mass index (weight $(\mathrm{kg}) /$ height $\left(\mathrm{m}^{2}\right)$ )

blood pressure

coronary artery calcium

coronary artery disease

Clopidogrel versus Aspirin in Patients at Risk for Ischaemic Events

Collaborative Atorvastatin Diabetes Study

Clopidogrel in High-risk patients with Acute Non-disabling Cerebrovascular Events

Clopidogrel for High Atherothrombotic Risk and Ischemic Stabilisation, Management, and Avoidance

confidence interval

chronic kidney disease

cardiac rehabilitation

computed tomography

Cholesterol Treatment Trialists' Collaboration

Clopidogrel vs. Placebo in Patients with ACS

without ST-segment elevation

cardiovascular

cardiovascular disease

disability-adjusted life years

Dietary Approaches to Stop Hypertension

diastolic blood pressure

Diabetes Control and Complications Trial

docosahexaenoic acid

diabetes mellitus

dipeptidyl peptidase-4

estimated glomerular filtration rate

European Chronic Disease Alliance

electrocardiogram

erectile dysfunction

European Heart Network

European Medicines Agency

eicosapentaenoic acid

European Prospective Investigation into Cancer and Nutrition

Ensemble Prévenons l'Obésité des Enfants

European Society of Cardiology

European Union

$\begin{array}{ll}\text { FDA } & \text { Food and Drug Administration (USA) } \\ \text { FDC } & \text { fixed dose combination } \\ \text { FH } & \text { familial hypercholesterolaemia } \\ \text { GLP-1 } & \text { glucagon-like peptide 1 } \\ \text { GP } & \text { general practitioner }\end{array}$

GOSPEL Global Secondary Prevention Strategies to Limit Event Recurrence After Myocardial Infarction

HbA1c glycated haemoglobin

HBPM home blood pressure measurements

HDL-C high-density lipoprotein cholesterol

HF heart failure

HF-ACTION Heart Failure: A Controlled Trial Investigating Outcomes of Exercise Training

HOPE Heart Outcomes Prevention Evaluation

HPS Heart Protection Study

HRQoL health-related quality of life

HR heart rate

hsCRP high-sensitivity C-reactive protein

HYVET Hypertension in the Very Elderly Trial

ICD

IMT International Classification of Diseases

INVEST International Verapamil-Trandolapril Study

LDL-C low-density lipoprotein cholesterol

$\operatorname{Lp}(\mathrm{a})$

LV

lipoprotein(a)

left ventricle/left ventricular

$\mathrm{LVH}$

MET

$\mathrm{MHO}$

$\mathrm{MI}$

MUFA

NGO

NHS

NICE

NNT

$\mathrm{NRI}$

NRT

OASIS

ONTARGET ONgoing Telmisartan Alone and in combination with Ramipril Global Endpoint Trial

OSAS obstructive sleep apnoea syndrome

OR

PA

PAD

PLATO

PCOS

PCSK9

PROactive odds ratio

physical activity

peripheral artery disease

Ticagrelor vs. Clopidogrel in Patients with ACS with and without ST-segment elevation

polycystic ovary syndrome proprotein convertase subtilisin/kexin type 9

PROGRESS Perindopril Protection Against Recurrent Stroke Study

PROCAM Prospective Cardiovascular Munster Study

PWV pulse wave velocity

RA rheumatoid arthritis 
RCT randomized controlled trial

RESPONSE Randomised Evaluation of Secondary Prevention by Outpatient Nurse Specialists

RM repetition maximum

ROS reactive oxygen species

RPE rating of perceived exertion

$\mathrm{RR} \quad$ relative risk

SAVOR-TIMI Saxagliptin Assessment of Vascular Outcomes 53

SBP

SGLT2

SNP

SCORE

SPARCL

TIA

TRITON

UKPDS

VADT

VALUE

VLDL

$\dot{\mathrm{VO}} 2$

$\mathrm{WHO}$
Recorded in Patients with Diabetes Mellitus -

Trombolysis in Myocardial Infarction

systolic blood pressure

sodium-glucose co-transporter 2

single nucleotide polymorphism

Systematic Coronary Risk Estimation

Stroke Prevention by Aggressive Reduction in Cholesterol Levels

transient ischaemic attack

Prasugrel vs. Clopidogrel in Patients with ACS

Veterans Affairs Diabetes Trial

Valsartan Antihypertensive Long-Term Use

Evaluation

very low-density lipoprotein

oxygen uptake

World Health Organization
United Kingdom Prospective Diabetes Study

\section{What is cardiovascular disease prevention?}

\subsection{Definition and rationale}

Cardiovascular disease (CVD) prevention is defined as a coordinated set of actions, at the population level or targeted at an individual, that are aimed at eliminating or minimizing the impact of CVDs and their related disabilities. ${ }^{1}$ CVD remains a leading cause of morbidity and mortality, despite improvements in outcomes. Age-adjusted coronary artery disease (CAD) mortality has declined since the 1980s, particularly in high-income regions. ${ }^{2}$ CAD rates are now less than half what they were in the early 1980s in many countries in Europe, due to preventive measures including the success of smoking legislation. However, inequalities between countries persist and many risk factors, particularly obesity ${ }^{3}$ and diabetes mellitus (DM), ${ }^{4}$ have been increasing substantially. If prevention was practised as instructed it

\section{Level of evidence}

\begin{tabular}{|l|l|}
\hline $\begin{array}{l}\text { Level of } \\
\text { evidence A }\end{array}$ & $\begin{array}{l}\text { Data derived from multiple randomized } \\
\text { clinical trials or meta-analyses. }\end{array}$ \\
\hline $\begin{array}{l}\text { Level of } \\
\text { evidence B }\end{array}$ & $\begin{array}{l}\text { Data derived from a single randomized } \\
\text { clinical trial or large non-randomized } \\
\text { studies. }\end{array}$ \\
\hline Level of \\
evidence C & $\begin{array}{l}\text { Consensus of opinion of the experts and/ } \\
\text { registries. }\end{array}$ \\
\hline
\end{tabular}

\section{Classes of recommendations}

\begin{tabular}{|c|c|c|}
\hline $\begin{array}{l}\text { Classes of } \\
\text { recommendations }\end{array}$ & Definition & $\begin{array}{c}\text { Suggested wording to } \\
\text { use }\end{array}$ \\
\hline Class I & $\begin{array}{l}\text { Evidence and/or general agreement } \\
\text { that a given treatment or } \\
\text { procedure is beneficial, useful, } \\
\text { effective. }\end{array}$ & $\begin{array}{l}\text { Is recommended/is } \\
\text { indicated }\end{array}$ \\
\hline Class II & $\begin{array}{l}\text { Conflicting evidence and/or a } \\
\text { divergence of opinion about the } \\
\text { usefulness/efficacy of the given } \\
\text { treatment or procedure. }\end{array}$ & \\
\hline Class IIa & $\begin{array}{l}\text { Weight of evidence/opinion is in } \\
\text { favour of usefulness/efficacy. }\end{array}$ & Should be considered \\
\hline Class IIb & $\begin{array}{l}\text { Usefulness/efficacy is less well } \\
\text { established by evidence/opinion. }\end{array}$ & May be considered \\
\hline Class III & $\begin{array}{l}\text { Evidence or general agreement that } \\
\text { the given treatment or procedure } \\
\text { is not useful/effective, and in some } \\
\text { cases may be harmful. }\end{array}$ & Is not recommended \\
\hline
\end{tabular}


would markedly reduce the prevalence of CVD. It is thus not only prevailing risk factors that are of concern, but poor implementation of preventive measures as well. ${ }^{5,6}$ Prevention should be delivered (i) at the general population level by promoting healthy lifestyle behaviour $^{7}$ and (ii) at the individual level, i.e. in those subjects at moderate to high risk of CVD or patients with established CVD, by tackling unhealthy lifestyles (e.g. poor-quality diet, physical inactivity, smoking) and by optimising risk factors. Prevention is effective: the elimination of health risk behaviours would make it possible to prevent at least $80 \%$ of CVDs and even $40 \%$ of cancers. ${ }^{8,9}$

\subsection{Development of the 6th Joint Task Force guidelines}

The present guidelines represent an evidence-based consensus of the 6th European Joint Task Force involving 10 professional societies.

By appraising the current evidence and identifying remaining knowledge gaps in managing CVD prevention, the Task Force formulated recommendations to guide actions to prevent CVD in clinical practice. The Task Force followed the quality criteria for development of guidelines, which can be found at http://www. escardio.org/Guidelines-\&-Education/Clinical-Practice-Guidelines/ Guidelines-development/Writing-ESC-Guidelines. For simplification and in keeping with other European Society of Cardiology (ESC) guidelines, the ESC grading system based on classes of recommendation and levels of evidence has been maintained, recognising that this may be less suitable to measure the impact of prevention strategies, particularly those related to behavioural issues and population-based interventions.

This document has been developed to support healthcare professionals communicating with individuals about their cardiovascular (CV) risk and the benefits of a healthy lifestyle and early modification of their CV risk. In addition, the guidelines provide tools for healthcare professionals to promote population-based strategies and integrate these into national or regional prevention frameworks and to translate these in locally delivered healthcare services, in line with the recommendations of the World Health Organization (WHO) global status report on non-communicable diseases $2010 .^{10}$

As in the present guidelines, the model presented in the previous document from the Fifth European Joint Task Force ${ }^{11}$ has been structured around four core questions: (i) What is CVD prevention? (ii) Who will benefit from prevention? (iii) How to intervene? (iv) Where to intervene?

Compared with the previous guidelines, greater emphasis has been placed on a population-based approach, on disease-specific interventions and on female-specific conditions, younger individuals and ethnic minorities. Due to space restrictions for the paper version, the chapter on disease-specific intervention is on the web, together with a few tables and figures (for more detail see web addenda).

A lifetime approach to CV risk is important since both CV risk and prevention are dynamic and continuous as patients age and/or accumulate co-morbidities. This implies that, apart from improving lifestyle and reducing risk factor levels in patients with established CVD and those at increased risk of developing CVD, healthy people of all ages should be encouraged to adopt a healthy lifestyle. Healthcare professionals play an important role in achieving this in their clinical practice.

\subsection{Cost-effectiveness of prevention}

\section{Key messages}

- Prevention of CVD, either by implementation of lifestyle changes or use of medication, is cost effective in many scenarios, including population-based approaches and actions directed at high-risk individuals.

- Cost-effectiveness depends on several factors, including baseline CV risk, cost of drugs or other interventions, reimbursement procedures and implementation of preventive strategies.

\section{Recommendation for cost-effective prevention of cardiovascular disease}

\begin{tabular}{|l|c|c|c|}
\hline Recommendation & Class $^{\mathbf{a}}$ & Level $^{\mathrm{b}}$ & Ref $^{\mathrm{c}}$ \\
\hline $\begin{array}{l}\text { Measures aimed at promoting healthy } \\
\text { lifestyles at the population level } \\
\text { should be considered. }\end{array}$ & Ila & B & 12,13 \\
\hline
\end{tabular}

${ }^{\mathrm{a} C}$ Class of recommendation.

bLevel of evidence.

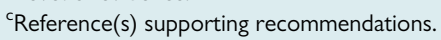

In 2009, costs related to CVD amounted to $€ 106$ billion, representing $\sim 9 \%$ of the total healthcare expenditure across the European Union (EU). ${ }^{14}$ Thus, CVD represents a considerable economic burden to society and effective preventive measures are necessary. There is consensus in favour of an approach combining strategies to improve $\mathrm{CV}$ health across the population at large from childhood onward, with specific actions to improve CV health in individuals at increased risk of CVD or with established CVD.

Most studies assessing the cost-effectiveness of CVD prevention combine evidence from clinical research with simulation approaches, while cost-effectiveness data from randomized controlled trials (RCTs) are relatively scarce. ${ }^{15,16}$ Cost-effectiveness strongly depends on parameters such as the target population's age, the overall population risk of CVD and the cost of interventions. Hence, results obtained in one country may not be valid in another. Furthermore, changes such as the introduction of generic drugs can considerably change cost-effectiveness. ${ }^{17}$ According to the $\mathrm{WHO}$, policy and environmental changes could reduce CVD in all countries for less than US\$1/person/year. ${ }^{18} \mathrm{~A}$ report from the National Institute for Health and Care Excellence (NICE) estimated that a UK national programme reducing population $\mathrm{CV}$ risk by $1 \%$ would prevent 25000 CVD cases and generate savings of $€ 40$ million/year. CAD mortality rates could be halved by only modest risk factor reductions and it has been suggested that eight dietary priorities alone could halve CVD death. ${ }^{13}$

In the last three decades, more than half of the reduction in $\mathrm{CV}$ mortality has been attributed to changes in risk factor levels in the population, primarily the reduction in cholesterol and blood pressure (BP) levels and smoking. This favourable trend is partly offset by an increase in other risk factors, mainly obesity and type 2 DM. ${ }^{19,20}$ Aging of the population also increases CVD events. ${ }^{21}$

Several population interventions have efficiently modified the lifestyle of individuals. For example, increased awareness of how healthy lifestyles prevent CVD has helped to reduce smoking and cholesterol 
levels. Lifestyle interventions act on several CV risk factors and should be applied prior to or in conjunction with drug therapies. Also, legislation aimed at decreasing salt and the trans fatty acid content of foods and smoking habits is cost effective in preventing CVD. ${ }^{12,13,19}$

Cholesterol lowering using statins ${ }^{15,16}$ and improvement in BP control are cost effective if targeted at persons with high CV risk. $^{22}$ Importantly, a sizable portion of patients on lipid-lowering or BP-lowering drug treatment fails to take their treatment adequately or to reach therapeutic goals, ${ }^{23,24}$ with clinical and economic consequences.

\section{Gap in evidence}

- Most cost-effectiveness studies rely on simulation. More data, mainly from RCTs, are needed.

\section{Who will benefit from prevention? When and how to assess risk and prioritize}

\subsection{Estimation of total cardiovascular risk}

All current guidelines on the prevention of CVD in clinical practice recommend the assessment of total CVD risk since atherosclerosis is usually the product of a number of risk factors. Prevention of CVD in an individual should be adapted to his or her total CV risk: the higher the risk, the more intense the action should be.

The importance of total risk estimation in apparently healthy people before management decisions are made is illustrated in supplementary Figure A (see web addenda) and in Table 1 derived from the high-risk Systemic Coronary Risk Estimation (SCORE) chart (http://www.escardio.org/Guidelines-\&-Education/Practice-tools/ CVD-prevention-toolbox/SCORE-Risk-Charts). This shows that a person with a cholesterol level of $7 \mathrm{mmol} / \mathrm{L}$ can be at 10 times lower risk than someone with a cholesterol level of $5 \mathrm{mmol} / \mathrm{L}$ if the former is a female and the latter is a male hypertensive smoker.

A recent meta-analysis on $\mathrm{CV}$ risk reduction by treatment with BP-lowering drugs does, however, support the concept that absolute risk reduction is larger in those individuals at higher baseline risk. $^{25}$ This was confirmed in a further meta-analysis that also

\section{Table I Impact of combinations of risk factors on risk}

\begin{tabular}{|c|c|c|c|c|c|}
\hline Gender & $\begin{array}{c}\text { Age } \\
\text { (years) }\end{array}$ & $\begin{array}{c}\text { Cholesterol } \\
(\mathrm{mmol} / \mathrm{L})\end{array}$ & $\begin{array}{c}\text { SBP } \\
(\mathrm{mmHg})\end{array}$ & Smoker & $\begin{array}{c}\text { Risk (I0 } \\
\text { year risk of } \\
\text { fatal CVD) }\end{array}$ \\
\hline F & 60 & 7 & 120 & No & $2 \%$ \\
\hline F & 60 & 7 & 140 & Yes & $5 \%$ \\
\hline M & 60 & 6 & 160 & No & $9 \%$ \\
\hline M & 60 & 5 & 180 & Yes & $21 \%$ \\
\hline
\end{tabular}

$\mathrm{CVD}=$ cardiovascular disease; $F=$ female; $M=$ male; $S B P=$ systolic blood pressure. showed a greater residual risk during treatment in those at higher baseline risk, supporting earlier intervention. ${ }^{26,27}$

Although clinicians often ask for decisional thresholds to trigger intervention, this is problematic since risk is a continuum and there is no exact point above which, for example, a drug is automatically indicated nor below which lifestyle advice may not usefully be offered.

The risk categories presented later in this section are to assist the physician in dealing with individual people. They acknowledge that although individuals at the highest levels of risk gain most from risk factor interventions, most deaths in a community come from those at lower levels of risk, simply because they are more numerous compared with high-risk individuals. Thus a strategy for individuals at high risk must be complemented by public health measures to encourage a healthy lifestyle and to reduce population levels of $\mathrm{CV}$ risk factors.

It is essential for clinicians to be able to assess CV risk rapidly and with sufficient accuracy. This realization led to the development of the risk chart used in the 1994 and 1998 Guidelines. This chart, developed from a concept pioneered by Anderson, ${ }^{28}$ used age, sex, smoking status, blood cholesterol and systolic BP (SBP) to estimate the 10- year risk of a first fatal or non-fatal CAD event. There were several problems with this chart, which are outlined in the Fourth Joint European Guidelines on prevention. ${ }^{11,29}$ This led to the presently recommended SCORE system, estimating an individual's 10 year risk of fatal CVD. ${ }^{30}$ The SCORE charts have been developed to estimate risk in both high- and low-risk European populations; its applicability to non-Caucasian populations has not been examined.

\subsection{When to assess total cardiovascular risk?}

\section{Recommendations for cardiovascular risk assessment}

\begin{tabular}{|l|c|c|}
\hline Recommendations & Class $^{\mathrm{a}}$ & Level $^{\mathrm{b}}$ \\
\hline Systematic CV risk assessment is recommended & & \\
in individuals at increased CV risk, i.e. with & & \\
family history of premature CVD, familial & & \\
hyperlipidaemia, major CV risk factors (such as & $\mathrm{I}$ & $\mathrm{C}$ \\
smoking, high BP, DM or raised lipid levels) or & & \\
comorbidities increasing CV risk. & & \\
\hline
\end{tabular}

$\mathrm{BP}=$ blood pressure; $\mathrm{CV}=$ cardiovascular; $\mathrm{CVD}=$ cardiovascular disease; $\mathrm{DM}=$ diabetes mellitus.

${ }^{a}$ Class of recommendation.

bevel of evidence.

Screening is the identification of unrecognized disease or, in this case, of an unknown increased risk of CVD in individuals without 
symptoms. CV risk assessment or screening can be done opportunistically or systematically. Opportunistic screening means without a predefined strategy, but is done when the opportunity arises [e.g. when the individual is consulting his or her general practitioner (GP) for some other reason]. Systematic screening can be done in the general population as part of a screening programme or in targeted subpopulations, such as subjects with a family history of premature CVD or familial hyperlipidaemia.

While the ideal scenario would be for all adults to have their risk assessed, this is not practical in many societies. The decision about who to screen must be made by individual countries and will be resource dependent.

In a meta-analysis, GP-based health checks on cholesterol, BP, body mass index (BMI) and smoking were effective in improving surrogate outcomes, especially in high-risk patients. ${ }^{31} \mathrm{~A}$ large study of $\mathrm{CV}$ risk assessment in the general population found that although there were overall improvements in risk factors, there was no impact on CV outcomes at the population level. ${ }^{32} \mathrm{~A}$ Cochrane review of RCTs using counselling or education to modify CV risk factors in adults from the general population, occupational groups or those with specific risk factors (i.e. DM, hypertension) concluded that risk factor improvements were modest and interventions did not reduce total or $\mathrm{CV}$ mortality in general populations, but reduced mortality in highrisk hypertensive and DM populations. ${ }^{33}$ Although the benefits of treating asymptomatic conditions such as hypertension, DM and dyslipidaemia on morbidity and mortality outcomes have been documented, a Cochrane review of the existing trials concluded that general health checks (including screening for these conditions) do not reduce all-cause or CV morbidity or mortality. ${ }^{34}$ However, most studies were performed three to four decades ago, and thus risk factor interventions were not contemporary. Perhaps application of medical treatment in addition to the lifestyle interventions that were the core component of most trials would improve efficacy.

Most guidelines recommend a mixture of opportunistic and systematic screening. ${ }^{11,35-38}$ Screening in people at relatively low risk of CVD is not particularly effective in reducing the risk of CV events. The costs of such screening interventions are high and these resources may be better used in people at higher CV risk or with established CVD. In many countries, GPs have a unique role in identifying individuals at risk of but without established CVD and assessing their eligibility for intervention (see section 4a.1.1). A modelling study based on the European Prospective Investigation of Cancer-Norfolk (EPIC-Norfolk) cohort data concluded that, compared with the $\mathrm{Na}$ tional Health Service (NHS) national strategy to screen all adults 4074 years of age for CV risk, inviting the $60 \%$ of the population at the highest risk according to an integrated risk score was equally effective in preventing new cases of CVD and had potential cost savings. ${ }^{39}$

A general concern in screening, including $C V$ risk assessment, is its potential to do harm. False positive results can cause unnecessary concern and medical treatment. Conversely, false negative results may lead to inappropriate reassurance and a lack of lifestyle changes. However, current data suggest that participating in CV screening in general does not cause worry in those who are screened. ${ }^{40-43}$ More research is needed on how certain subgroups, such as older people, the socially deprived and ethnic minorities, react to screening.

Despite limited evidence, these guidelines recommend a systematic approach to $C V$ risk assessment targeting populations likely to be at higher $\mathrm{CV}$ risk, such as those with a family history of premature
CVD. Thus systematic CV risk assessment in men $<40$ years of age and women $<50$ years of age with no known $C V$ risk factors is not recommended. Additionally, screening of specific groups with jobs that place other people at risk, e.g. bus drivers and pilots, may be reasonable, as is screening for $\mathrm{CV}$ risk factors in women before prescribing combined oral contraception, although there are no data to support the beneficial effects. Beyond this, systematic CV risk assessment in adults $<40$ years of age with no known $\mathrm{CV}$ risk factors is not recommended as a main strategy due to the low cost-effectiveness. Systematic CV assessment may be considered in adult men $>40$ years of age and in women $>50$ years of age or post-menopausal with no known CV risk factors. Risk assessment is not a one-time event; it should be repeated, for example, every 5 years.

\subsection{How to estimate total cardiovascular risk?}

\section{Key messages}

- In apparently healthy persons, CV risk in general is the result of multiple, interacting risk factors. This is the basis for the total CV risk approach to prevention.

- SCORE, which estimates the 10 year risk of fatal CVD, is recommended for risk assessment and can assist in making logical management decisions and may help to avoid both under- and overtreatment. Validated local risk estimation systems are useful alternatives to SCORE.

- Individuals automatically at high to very high CV risk (Table 5) do not need the use of a risk score and require immediate attention to risk factors.

- In younger persons, a low absolute risk may conceal a very high relative risk and use of the relative risk chart or calculation of their "risk age" may help in advising them of the need for intensive preventive efforts.

- While women are at lower CV risk than men, their risk is deferred by $\sim 10$ years rather than avoided.

- The total risk approach allows flexibility; if perfection cannot be achieved with one risk factor, trying harder with others can still reduce risk.

\section{Recommendation for how to estimate cardiovascular risk}

\begin{tabular}{|l|l|l|l|}
\hline Recommendation & Class $^{\mathbf{a}}$ & Level $^{\mathbf{b}}$ & Ref $^{\mathbf{c}}$ \\
\hline $\begin{array}{l}\text { Total CV risk estimation, using a risk } \\
\text { estimation system such as SCORE, is } \\
\text { recommended for adults }>40 \text { years } \\
\text { of age, unless they are automatically } \\
\text { categorised as being at high-risk or } \\
\text { very high-risk based on documented } \\
\text { CVD, DM (>40 years of age), kidney } \\
\text { disease or highly elevated single risk } \\
\text { factor (Table 5). }\end{array}$ & & & \\
\hline
\end{tabular}

$\mathrm{CV}=$ cardiovascular; $\mathrm{DM}=$ diabetes mellitus; $\mathrm{SCORE}=$ Systematic Coronary Risk Estimation.

${ }^{a}$ Class of recommendation.

bevel of evidence.

'Reference(s) supporting recommendations. 
Table 2 Current cardiovascular disease risk estimation systems for use in apparently healthy persons, updated from ${ }^{59,60}$

\begin{tabular}{|c|c|c|c|c|c|c|c|c|}
\hline & Framingham $^{44}$ & SCORE $^{30}$ & ASSIGN - SCORE & QRISKI ${ }^{46}$ \& QRISK2 $2^{47}$ & PROCAM $^{48}$ & $\begin{array}{l}\text { Pooled Cohort } \\
\text { Studies Equations }\end{array}$ & CUORE ${ }^{49}$ & Globorisk $^{52}$ \\
\hline Data & $\begin{array}{l}\text { Prospective studies: } \\
\text { Framingham Heart } \\
\text { Study and Framingham } \\
\text { offspring study. } \\
\text { Latest version includes } \\
\text { both }\end{array}$ & $\begin{array}{l}\text { I2 pooled prospective } \\
\text { studies }\end{array}$ & $\begin{array}{l}\text { SHHEC Prospective } \\
\text { study }\end{array}$ & QRESEARCH database & Prospective study & $\begin{array}{l}4 \text { Pooled prospective } \\
\text { studies } \\
\text { ARIC } \\
\text { CHS } \\
\text { CARDIA } \\
\text { Framingham (original } \\
\text { and offspring studies) }\end{array}$ & CUORE & $\begin{array}{l}\text { Derivation cohort: } 8 \text { pooled } \\
\text { prospective studies - Atherosclerosis } \\
\text { Risk in Communities, Cardiovascular } \\
\text { Health Study, Framingham Heart Study } \\
\text { original cohort and offspring cohort, } \\
\text { Honolulu Program, Multiple Risk } \\
\text { Factor Intervention Trial, Puerto Rico } \\
\text { Heart Health Program, and Women's } \\
\text { Health Initiative Clinical Trial }\end{array}$ \\
\hline Population & $\begin{array}{l}\text { General population, } \\
\text { Framingham, } \\
\text { Massachusetts, USA. } \\
\text { Baselines: 1968-197I, } \\
\text { 1971-1975, 1984-1987 }\end{array}$ & $\begin{array}{l}\text { I2 prospective studies } \\
\text { from II European } \\
\text { countries. } \\
\text { Baselines: } \\
\text { |972-199| }\end{array}$ & $\begin{array}{l}\text { Random sample from } \\
\text { general population } \\
\text { in Scotland, baseline: } \\
\text { 1984-1987 }\end{array}$ & $\begin{array}{l}\text { Data collected from } \\
1993-2008 \text { from GP } \\
\text { databases - imputation } \\
\text { of missing data }\end{array}$ & $\begin{array}{l}\text { Healthy employees. } \\
\text { Baseline: } \\
\text { 1978-1995 }\end{array}$ & $\begin{array}{l}\text { Baselines 1987-89 } \\
\text { (ARIC), I990 and } \\
\text { 1992-3 (CHS), 1985-6 } \\
\text { (CARDIA), I968-197I, } \\
\text { 197I-I975, 1984-1987 } \\
\text { (Framingham) }\end{array}$ & 1980 s and 1990 s & $\begin{array}{l}8 \text { prospective studies from North } \\
\text { America. } \\
\text { Baselines: } 1948-1993\end{array}$ \\
\hline Sample size & $\begin{array}{l}3969 \text { men and } \\
4522 \text { women }\end{array}$ & $\begin{array}{l}117098 \text { men and } \\
88080 \text { women }\end{array}$ & $\begin{array}{l}6540 \text { men and } 6757 \\
\text { women }\end{array}$ & $\begin{array}{l}1.28 \text { million (QRISKI) } \\
2.29 \text { million (QRISK2) }\end{array}$ & $\begin{array}{l}18460 \text { men and } \\
8515 \text { women }\end{array}$ & $\begin{array}{l}\text { II } 240 \text { white women, } \\
9098 \text { white men, } 264 \mid \\
\text { African-American } \\
\text { women and } 1647 \\
\text { African-American men }\end{array}$ & $\begin{array}{l}7520 \text { men and } \mathrm{I} 3 \mathrm{I} 27 \\
\text { women }\end{array}$ & 33323 men and 16806 women \\
\hline Calculates & $\begin{array}{l}\text { 10-year risk of CAD } \\
\text { eventsoriginally. } \\
\text { Latest version: } \\
\text { I0-year risk of CVD } \\
\text { events } \\
\text { NCEP ATP III version: } \\
\text { I0-year risk of hard } \\
\text { coronary events }\end{array}$ & $\begin{array}{l}10 \text {-year risk of CVD } \\
\text { mortality }\end{array}$ & $\begin{array}{l}\text { 10-year risk of CVD } \\
\text { events }\end{array}$ & $\begin{array}{l}\text { 10-year risk of CVD } \\
\text { events. } \\
\text { Lifetime risk }\end{array}$ & $\begin{array}{l}\text { Two separate scores } \\
\text { calculate } 10 \text {-year } \\
\text { risks of major } \\
\text { coronary events } \\
\text { and cerebral } \\
\text { ischaemic events }\end{array}$ & $\begin{array}{l}\text { I0-year risk for a } \\
\text { first atherosclerotic } \\
\text { CVD event. } \\
\text { Lifetime risk }\end{array}$ & $\begin{array}{l}\text { 10-year probability } \\
\text { of developing a } \\
\text { first major CV } \\
\text { event (myocardial } \\
\text { infarction or } \\
\text { stroke) }\end{array}$ & $\begin{array}{l}10 \text { year risk of fatal cardiovascular } \\
\text { disease }\end{array}$ \\
\hline $\begin{array}{l}\text { Age range } \\
\text { (years) }\end{array}$ & $30-75$ & $40-65$ & $30-74$ & $35-74$ & $20-75$ & $20-79$ & $35-69$ & $40-84$ \\
\hline Variables & $\begin{array}{l}\text { Sex, age, total } \\
\text { cholesterol, } \\
\text { HDL-C, SBP, } \\
\text { smoking status, DM, } \\
\text { hypertensive treatment }\end{array}$ & $\begin{array}{l}\text { Sex, age, total } \\
\text { cholesterol } \\
\text { or total cholesterol/ } \\
\text { HDL-C ratio, SBP, } \\
\text { smoking status. } \\
\text { Versions for use in } \\
\text { high and low-risk } \\
\text { countries }\end{array}$ & $\begin{array}{l}\text { Sex, age, total } \\
\text { cholesterol, HDL-C, } \\
\text { SBP, smoking - no. } \\
\text { cigs, DM, area based } \\
\text { index of deprivation, } \\
\text { family history }\end{array}$ & $\begin{array}{l}\text { QRISKI - sex, age, } \\
\text { total cholesterol to } \\
\text { HDL-C ratio, SBP, } \\
\text { smoking status, DM, } \\
\text { area based index of } \\
\text { deprivation, family } \\
\text { history, BMI, BP } \\
\text { treatment, ethnicity } \\
\text { and chronic diseases }\end{array}$ & $\begin{array}{l}\text { Age, sex, LDL-C, } \\
\text { HDL-C, DM, } \\
\text { smoking, SBP }\end{array}$ & $\begin{array}{l}\text { Age, sex, race (white } \\
\text { or other/African } \\
\text { American), total } \\
\text { cholesterol, HDL-C, } \\
\text { SBP, antihypertensive } \\
\text { treatment, DM, } \\
\text { smoking }\end{array}$ & $\begin{array}{l}\text { Age, sex, SBP, total } \\
\text { cholesterol, HDL-C, } \\
\text { antihypertensive } \\
\text { therapy and smoking } \\
\text { habit }\end{array}$ & $\begin{array}{l}\text { Age, sex, smoking, total cholesterol, } \\
\text { DM, systolic BP }\end{array}$ \\
\hline
\end{tabular}




\section{Table 2 (continued)}

\begin{tabular}{|c|c|c|c|c|c|c|c|c|}
\hline & Framingham ${ }^{44}$ & SCORE ${ }^{30}$ & ASSIGN - SCORE 45 & $\begin{array}{l}\text { QRISK 146\& } \\
\text { QRISK2 }{ }^{47}\end{array}$ & PROCAM $^{48}$ & $\begin{array}{l}\text { Pooled Cohort } \\
\text { Studies Equations }\end{array}$ & CUORE ${ }^{49}$ & Globorisk ${ }^{52}$ \\
\hline $\begin{array}{l}\text { Comments/ } \\
\text { developments }\end{array}$ & \begin{tabular}{|l} 
Latest version includes \\
version based on \\
non-laboratory values \\
only, \\
substituting BMI from \\
lipid measurements
\end{tabular} & $\begin{array}{l}\text { National, updated } \\
\text { recalibrations }\end{array}$ & & $\begin{array}{l}\text { QRISK2 includes } \\
\text { interaction terms } \\
\text { to adjust for the } \\
\text { interactions between } \\
\text { age and some of the } \\
\text { variables }\end{array}$ & $\begin{array}{l}\text { Recent change in the } \\
\text { methods (Weibull) } \\
\text { allows extension of } \\
\text { risk estimation to } \\
\text { women and broader } \\
\text { age range }\end{array}$ & $\begin{array}{l}\text { Race specific beta } \\
\text { coefficients for } \\
\text { risk factors have } \\
\text { been incorporated. } \\
\text { Calculator shown to } \\
\text { overestimate risk in } \\
\text { external validations - } \\
\text { this may indicate the } \\
\text { need for recalibration } \\
\text { in certain populations }\end{array}$ & & $\begin{array}{l}\text { Recalibrations have been undertaken } \\
\text { for II countries }\end{array}$ \\
\hline $\begin{array}{l}\text { Recommended } \\
\text { by guidelines }\end{array}$ & $\begin{array}{l}\text { NCEP guidelines, } \\
\text { Canadian CV }^{54} \\
\text { guidelines, } \text {,5 }^{55} \text { other } \\
\text { national guidelines } \\
\text { recommend adapted } \\
\text { versions including New } \\
\text { Zealand }{ }^{56}\end{array}$ & $\begin{array}{l}\text { European Guidelines } \\
\text { on CVD Prevention }{ }^{29}\end{array}$ & $\mathrm{SIGN}^{37}$ & $\begin{array}{l}\text { NICE guidelines on } \\
\text { lipid modification, }, \\
\text { QRISK Lifetime } \\
\text { recommended by } \\
\text { JBS3 guidelines }^{58}\end{array}$ & $\begin{array}{l}\text { International Task } \\
\text { Force for Prevention } \\
\text { of Coronary Disease } \\
\text { Guidelines }\end{array}$ & $\begin{array}{l}2013 \text { AHA ACC } \\
\text { Guideline on the } \\
\text { assessment of CVD } \\
\text { risk }^{50}\end{array}$ & & \\
\hline
\end{tabular}

$\mathrm{ACC}=$ American College of Cardiology; AHA = American Heart Association; ARIC = Atherosclerosis Risk in Communities; ATP $=$ Adult Treatment Panel; BMI = body mass index; BP = blood pressure; $\mathrm{CAD}=$ coronary artery disease; CARDIA = Coronary Artery Risk Development in Young Adults; CHS = Cardiovascular Health Study; CVD = cardiovascular disease; DM = diabetes mellitus; HDL-C = high-density lipoprotein cholesterol; JBS = Joint British Societies; LDL-C = low-density lipoprotein cholesterol; NCEP = National Cholesterol Education Program; NICE = National Institute for Health and Care Excellence; no. cigs = number of cigarettes; PROCAM = Prospective Cardiovascular Munster Study; SBP = systolic blood pressure; SIGN = Scottish Intercollegiate Guidelines Network; SHHEC = Scottish Heart Health Extended Cohort. 


\subsubsection{Ten-year cardiovascular risk}

Many CV risk assessment systems are available for use in apparently healthy individuals (Table 2), including Framingham, ${ }^{44}$ SCORE, ${ }^{30}$ ASSIGN (CV risk estimation model from the Scottish Intercollegiate Guidelines Network), ${ }^{45}$ Q-Risk, ${ }^{46,47}$ PROCAM (Prospective Cardiovascular Munster Study), ${ }^{48}$ CUORE, ${ }^{49}$ the Pooled Cohort equations, ${ }^{50}$ Arriba $^{51}$ and Globorisk. ${ }^{52}$ In practice, most risk estimation systems perform rather similarly when applied to populations recognizably comparable to those from which the risk estimation system was derived. Since 2003, the European Guidelines on CVD prevention in clinical practice recommend use of the SCORE system, because it is based on large, representative European cohort datasets. The SCORE risk function has been externally validated. ${ }^{53}$

Table 3 lists the advantages of the SCORE risk charts.

The SCORE system estimates the 10 year risk of a first fatal atherosclerotic event. All International Classification of Diseases (ICD) codes that could reasonably be assumed to be atherosclerotic are included, including CAD, stroke and aneurysm of the abdominal aorta. Traditionally most systems estimated CAD risk only; however, more recently a number of risk estimation systems have changed to estimate the risk of all CVDs. ${ }^{44,47,50,58}$

The choice of CV mortality rather than total (fatal plus non-fatal) events was deliberate, although not universally popular. Non-fatal event rates are critically dependent upon definitions and the methods used in their ascertainment. Critically, the use of mortality allows recalibration to allow for time trends in CV mortality. Any risk estimation system will overpredict in countries in which mortality has fallen and underpredict in those in which it has risen. Recalibration to allow for secular changes can be undertaken if good quality, up-to-date mortality and risk factor prevalence data are available. Data quality does not permit this for non-fatal events. For these reasons, the CV mortality charts were produced and have been recalibrated for a number of European countries.

Naturally, the risk of total fatal and non-fatal events is higher, and clinicians frequently ask for this to be quantified. The SCORE data indicate that the total $C V$ event risk is about three times higher than the risk of fatal CVD for men, so that a SCORE risk of fatal CVD of 5\% translates into a fatal plus non-fatal CV risk of $\sim 15 \%$; the multiplier is about four in women and somewhat lower than three in older persons, in whom a first event is more likely to be fatal. ${ }^{61}$

As noted in the introduction, thresholds to trigger certain interventions are problematic since risk is a continuum and there is no threshold at which, for example, a drug is automatically indicated. Obviously, decisions on whether treatment is initiated should also be based on patient preferences.

A particular problem relates to young people with high levels of risk factors, where a low absolute risk may conceal a very high relative risk requiring intensive lifestyle advice. Several approaches to communicating about risk to younger people are presented below (refer also to section 2.5.1). These include use of the relative risk chart or 'risk age' or 'lifetime risk'. The aim is to communicate that lifestyle changes can reduce the relative risk substantially as well as reduce the increase in risk that occurs with ageing.

Another problem relates to older people. In some age categories, the vast majority, especially of men, will have estimated CV death risks exceeding the 5-10\% level, based on age (and gender) only, even when other $\mathrm{CV}$ risk factor levels are low. This could lead to

\section{Table 3 Advantages and limitations in using the} SCORE risk charts

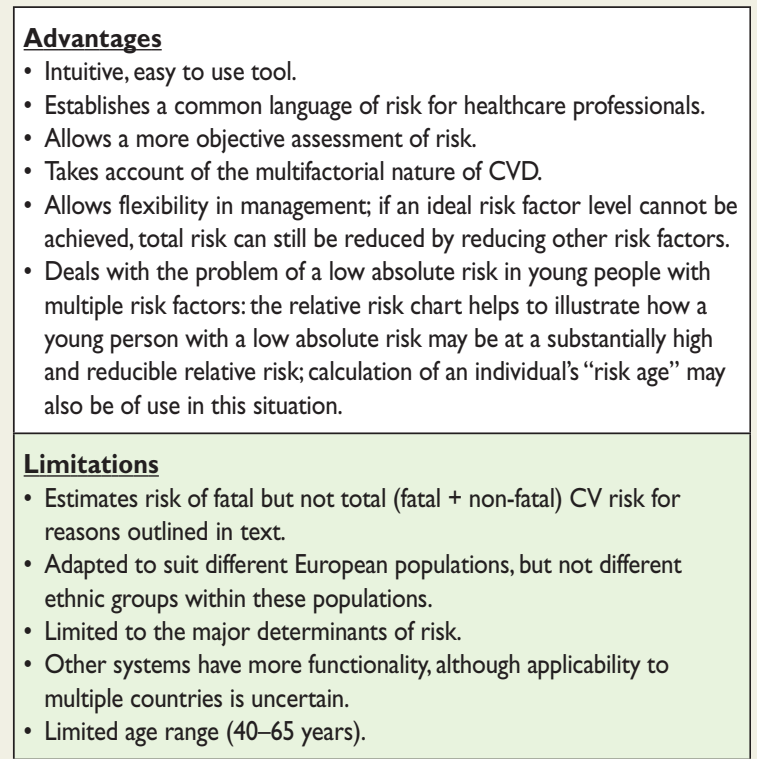

CVD = cardiovascular disease SCORE = Systematic Coronary Risk Estimation

excessive use of drugs in the elderly. This issue is dealt with later (see section 2.3.5). It should be noted that RCT evidence to guide drug treatments in older persons is limited (refer to section 2.5.2).

The role of high-density lipoprotein cholesterol (HDL-C) in risk estimation has been systematically re-examined using the SCORE database. ${ }^{62-64}$ Overall HDL-C has a modest but useful effect in redefining risk estimation, ${ }^{63,64}$ but this may not be seen in some low-risk populations. ${ }^{65}$ Assessing HDL-C is particularly important at levels of risk just below the threshold for intensive risk modification of $5 \%$, where many of these subjects will qualify for intensive advice if their HDL-C is low. ${ }^{63}$ SCORE charts incorporating HDL-C are illustrated in supplementary Figures B-I (see web addenda). In these charts, HDL-C is used categorically. The electronic version of SCORE, HeartScore (http://www.HeartScore.org), has been modified to take HDL-C into account on a continuous basis and is therefore more accurate.

The role of a plasma triglyceride as a predictor of CVD has been debated for many years. Fasting triglycerides relate to risk in univariable analyses, but the effect is attenuated by adjustment for other factors, especially HDL-C. ${ }^{66}$

Dealing with the impact of additional risk factors such as body weight, family history and newer risk markers is difficult within the constraint of a paper chart. It should be stressed, however, that although many other risk factors have been identified, their contribution is generally very modest to both absolute CV risk estimations and in terms of reclassification of an individual to another risk category $^{67}$ (Table 4).

The SCORE risk charts are shown in Figures 1-4, including a chart of relative risks (Figure 3). Instructions on their use follow.

Please note that Figure 3 shows relative not absolute risk. Thus a person in the top right-hand box, with multiple CV risk factors, has a risk that is 12 times greater than a person in the bottom left with normal risk 
Table 4 Examples of risk modifiers that are likely to have reclassification potential (see following sections for details)

Socio-economic status, social isolation, or lack of social support.

Family history of premature CVD.

$\mathrm{BMl}$ and central obesity.

CT coronary calcium score.

Atherosclerotic plaques determined by carotid artery scanning.

$\mathrm{ABI}$.

$\mathrm{ABI}=$ ankle-brachial blood pressure index; $\mathrm{BMI}=$ body mass index; $\mathrm{CVD}=$ cardiovascular disease; $\mathrm{CT}=$ computed tomography.

factor levels. This may be helpful when advising a young person with a low absolute but high relative risk of the need for lifestyle change.

\subsubsection{Cardiovascular risk age}

The risk age of a person with several $\mathrm{CV}$ risk factors is the age of a person of the same gender with the same level of risk but with ideal levels of risk factors. Thus a 40 -year-old with high levels of some risk factors may have the risk age of a 60 -year-old (Figure 4), because the risk equals that of a 60 -year-old with ideal risk factor levels (i.e. nonsmoking, total cholesterol of $4 \mathrm{mmol} / \mathrm{L}$ and BP of $120 \mathrm{mmHg}$ ) ${ }^{68}$ Risk age is an intuitive and easily understood way of illustrating the likely reduction in life expectancy that a young person with a low absolute but high relative risk of CVD will be exposed to if preventive measures are not adopted. ${ }^{68}$ Table $A$ showing different risk factor combinations is included in the web addenda to provide a more accurate estimation of risk ages. Risk age is also automatically calculated as part of the latest revision of HeartScore.

Risk age has been shown to be independent of the $\mathrm{CV}$ endpoint used, ${ }^{68}$ which bypasses the dilemma of whether to use a risk estimation system based on CV mortality or on total CV events. Risk age can be used in any population regardless of baseline risk and secular changes in mortality, and therefore avoids the need for recalibration. ${ }^{69}$ At present, risk age is recommended to help communicate about risk, especially to younger people with a low absolute risk but a high relative risk.

\subsubsection{Lifetime vs. 10-year cardiovascular risk estimation}

Conventional $\mathrm{CV}$ risk prediction schemes estimate the 10 year risk of $\mathrm{CV}$ events. Lifetime $\mathrm{CV}$ risk prediction models identify high-risk individuals both in the short and long term. Such models account for predicted risk in the context of competing risks from other diseases over the remaining expected lifespan of an individual.

Notably, 10 year risk identifies individuals who are most likely to benefit from drug therapy in the near term. Drug treatment starts to work quite rapidly, and drug treatment can be largely informed by short-term risk, such as 10 year risk. One problem with short-term risk is that it is mostly governed by age and consequently few younger individuals, in particular women, reach treatment thresholds. It has therefore been argued that lifetime risk estimation may enhance risk communication, particularly among younger individuals and women.

Evidence for the role of lifetime risk in treatment decisions is lacking. Sufficient data for robust lifetime risk estimations, as well as meaningful risk categorization thresholds, are also lacking. Providing lifetime $\mathrm{CV}$ risk estimates for some groups at high risk of mortality due to competing non-CVD causes can be difficult to interpret. Importantly, evidence of the benefits of lifelong preventive therapy (e.g. BP- or lipid-lowering drugs) in younger individuals with low short-term but higher lifetime risks is lacking. For these reasons, we do not recommend that risk stratification for treatment decisions be based on lifetime risk. However, like risk age and relative risk, it may be a useful tool in communicating about risk to individuals with high risk factor levels but who are at a low 10 year absolute risk of CV events, such as some younger people. Whatever approach is used, if absolute risk is low, a high relative risk or risk age signals the need for active lifestyle advice and awareness that drug treatment may need consideration as the person ages. Both risk age and lifetime risk are closer to relative than absolute risk, and none provides an evidence base for drug treatment decisions.

\subsubsection{Low-risk, high-risk and very-high-risk countries}

The countries considered here are those with national cardiology societies that belong to the ESC, both European and non-European.

\subsubsection{What are low-risk countries?}

The fact that CVD mortality has declined in many European countries means that more now fall into the low-risk category. While any cut-off point is arbitrary and open to debate, in these guidelines the cut-off points for calling a country 'low risk' are based on age-adjusted 2012 CVD mortality rates in those 45-74 years of age $(<225 / 100000 \text { in men and }<175 / 100000 \text { in women })^{70}$ Thus the following countries are defined as low risk: Andorra, Austria, Belgium, Cyprus, Denmark, Finland, France, Germany, Greece, Iceland, Ireland, Israel, Italy, Luxembourg, Malta, Monaco, The Netherlands, Norway, Portugal, San Marino, Slovenia, Spain, Sweden, Switzerland and the United Kingdom.

\subsubsection{What are high-risk and very-high-risk countries?}

High-risk countries are Bosnia and Herzegovina, Croatia, Czech Republic, Estonia, Hungary, Lithuania, Montenegro, Morocco, Poland, Romania, Serbia, Slovakia, Tunisia and Turkey.

Very-high-risk countries present levels of risk that are more than double that of low-risk countries (i.e. CVD mortality $>450 / 100000$ for men and $>350 / 100000$ for women). Additionally, the male:female ratio is smaller than in low-risk countries, suggesting a major problem for women. The very high-risk countries are Albania, Algeria, Armenia, Azerbaijan, Belarus, Bulgaria, Egypt, Georgia, Kazakhstan, Kyrgyzstan, Latvia, former Yugoslav Republic of Macedonia, Moldova, Russian Federation, Syrian Arab Republic, Tajikistan, Turkmenistan, Ukraine and Uzbekistan.

\subsubsection{How to use the risk estimation charts}

- The SCORE charts are used in apparently healthy people, not for those with established CVD or at very high risk or high risk for other reasons [e.g. DM (see section 3a.8) or chronic kidney disease (CKD; see section 2.4.5.1)], who need intensive risk advice anyway.

- Use of the low-risk chart is recommended for the countries listed above. Use of the high-risk chart is recommended for all other European and Mediterranean countries, taking into account that the high-risk charts may underestimate the risk in very-high-risk countries (see above). Note that several countries have undertaken national recalibrations to allow for time trends 


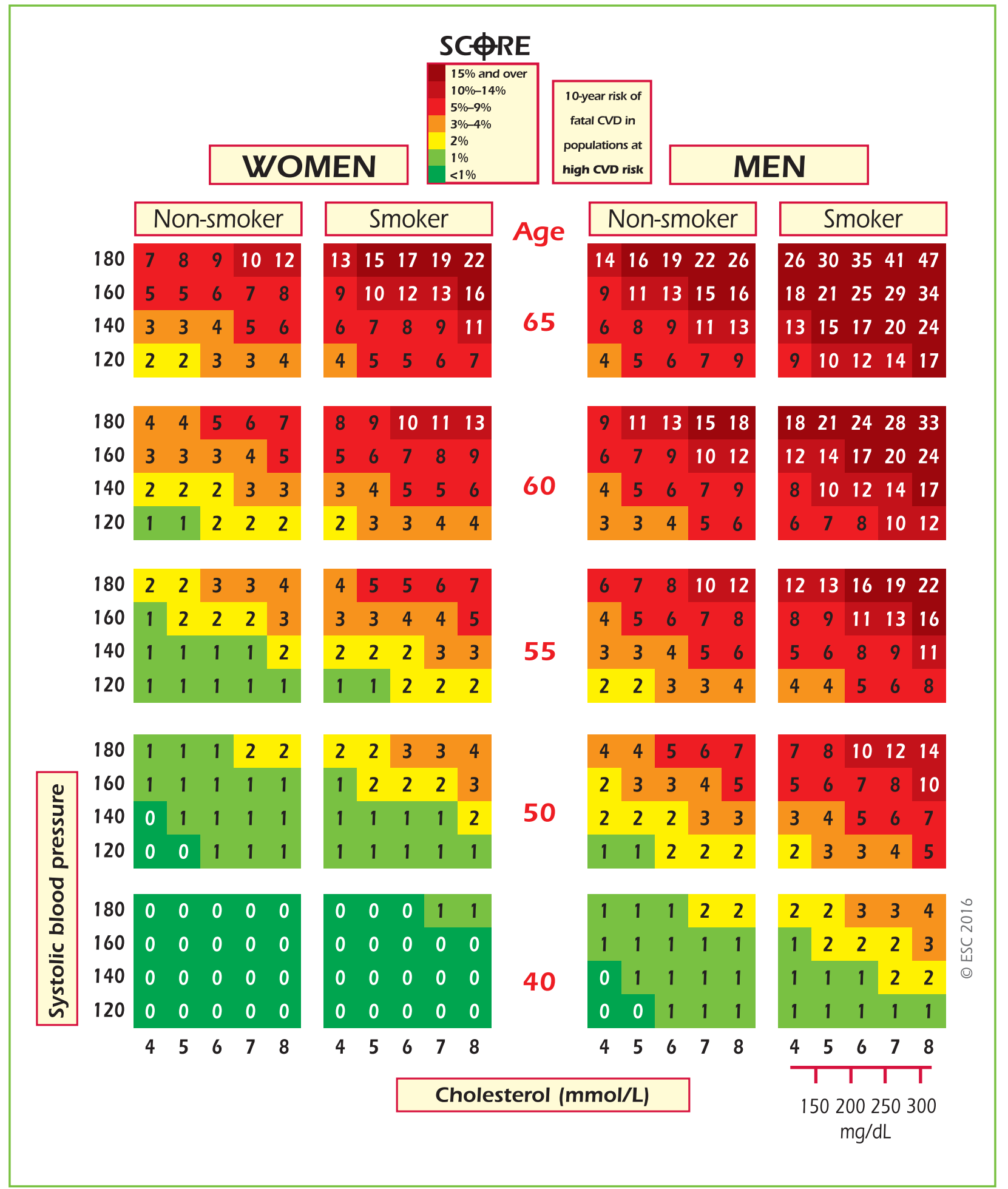

Figure I SCORE chart: 10-year risk of fatal cardiovascular disease in populations of countries at high cardiovascular risk based on the following risk factors: age, sex, smoking, systolic blood pressure, total cholesterol. CVD = cardiovascular disease; SCORE = Systematic Coronary Risk Estimation.

in mortality and risk factor distributions. Such charts are likely to better represent risk levels.

- To estimate a person's 10 year risk of CV death, find the table for their gender, smoking status and (nearest) age. Within the table, find the cell nearest to the person's BP and total cholesterol. Risk estimates will need to be adjusted upwards as the person approaches the next age category.

While no threshold is universally applicable, the intensity of advice should increase with increasing risk. The effect of interventions on the absolute probability of developing a CV event 


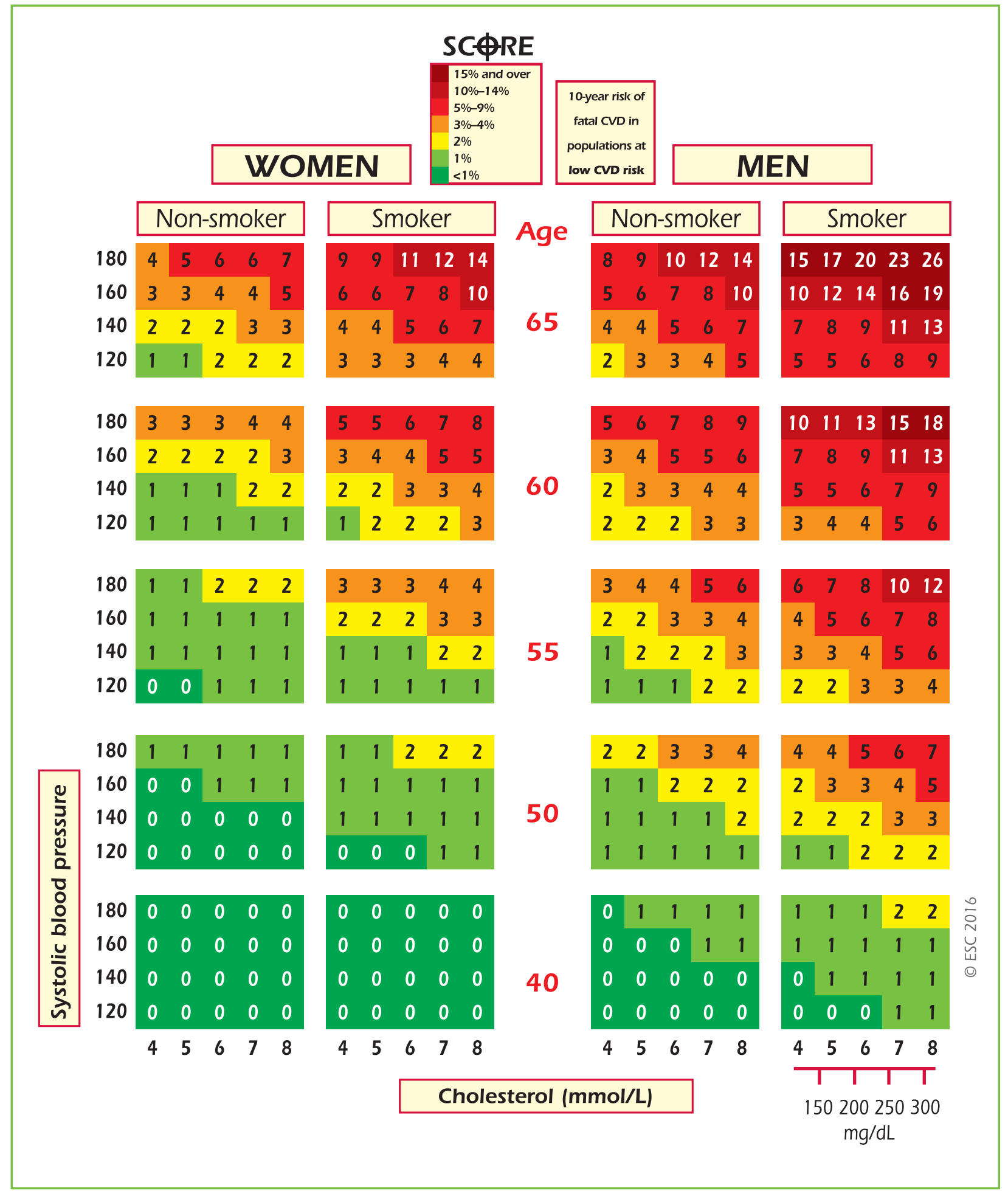

Figure 2 SCORE chart: 10-year risk of fatal cardiovascular disease in populations of countries at low cardiovascular risk based on the following risk factors: age, sex, smoking, systolic blood pressure, total cholesterol. CVD = cardiovascular disease; SCORE = Systematic Coronary Risk Estimation.

increases with an increasing baseline risk; that is, the number of individuals needed to treat (NNT) to prevent one event decreases with increasing risk.
- Low- to moderate-risk persons (calculated SCORE $<\mathbf{5 \%}$ ): should be offered lifestyle advice to maintain their low- to moderate-risk status. 


\begin{tabular}{|c|c|c|c|c|c|c|}
\hline \multirow{6}{*}{ 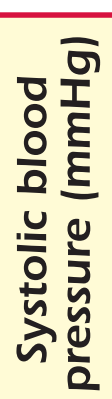 } & \multirow{2}{*}{180} & \multicolumn{5}{|c|}{ Non-smoker } \\
\hline & & 3 & 3 & 4 & 5 & 6 \\
\hline & 160 & 2 & 3 & 3 & 4 & 4 \\
\hline & 140 & 1 & 2 & 2 & 2 & 3 \\
\hline & 120 & 1 & 1 & 1 & 2 & 2 \\
\hline & & 4 & 5 & 6 & 7 & 8 \\
\hline
\end{tabular}

\begin{tabular}{|c|c|c|c|c|}
\hline \multicolumn{5}{|c|}{ Smoker } \\
\hline 6 & 7 & 8 & 10 & 12 \\
\hline 4 & 5 & 6 & 7 & 8 \\
\hline 3 & 3 & 4 & 5 & 6 \\
\hline 2 & 2 & 3 & 3 & 4 \\
\hline 4 & 5 & 6 & 7 & 8 \\
\hline
\end{tabular}

\section{Cholesterol (mmol/L)}

Figure 3 Relative risk chart, derived from SCORE Conversion of cholesterol mmol/L $\rightarrow \mathrm{mg} / \mathrm{dL}: 8=310 ; 7=270 ; 6=230 ; 5=190 ; 4=155$.

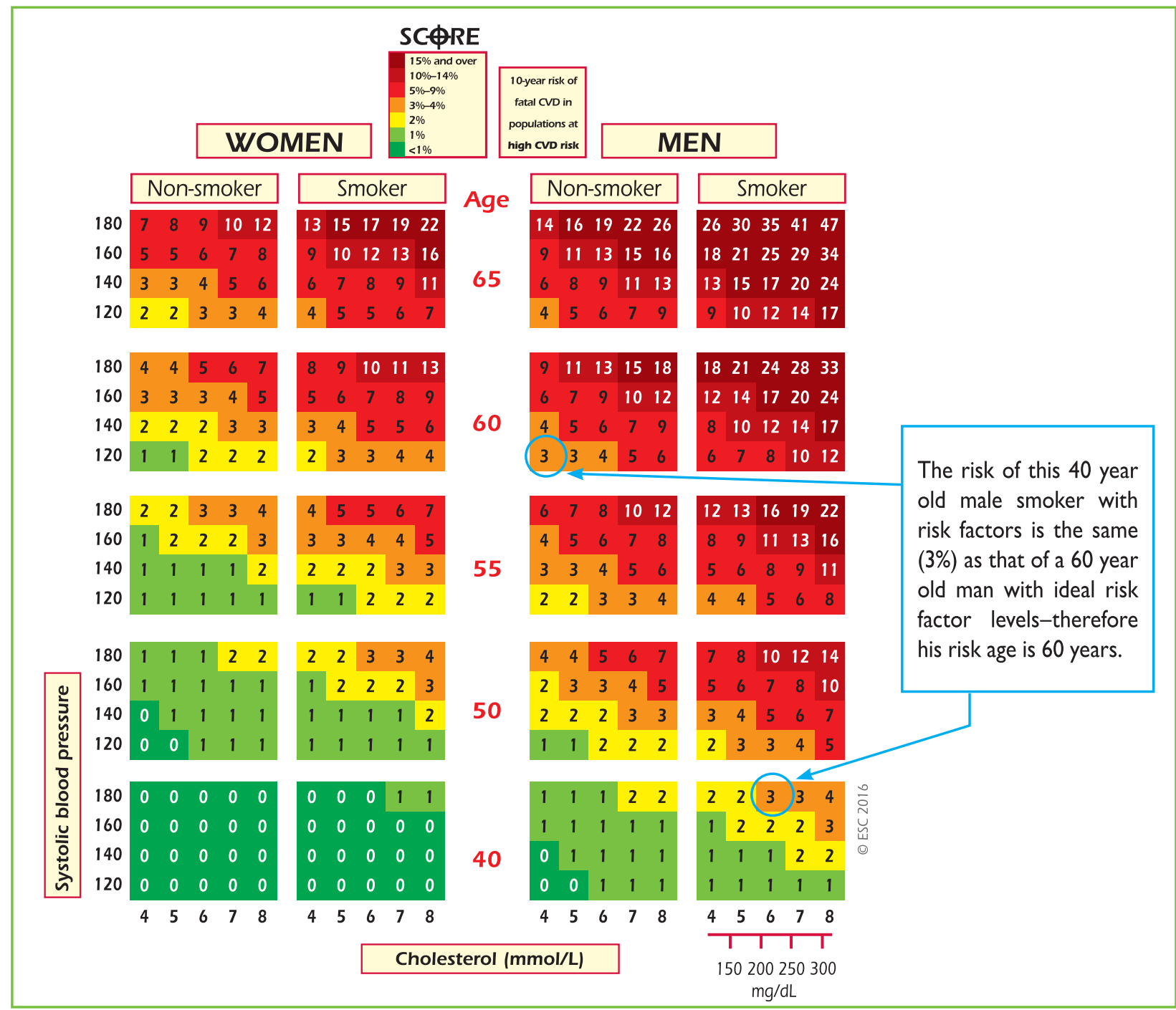

Figure 4 SCORE chart (for use in high-risk European countries) illustrating how the approximate risk age can be read off the chart. SCORE $=$ Systematic Coronary Risk Estimation. 
- High-risk persons (calculated SCORE $\geq \mathbf{5} \%$ and $<\mathbf{1 0 \%}$ ): qualify for intensive lifestyle advice and may be candidates for drug treatment.

- Very-high-risk persons (calculated SCORE $\geq \mathbf{1 0 \%}$ ): drug treatment is more frequently required. In persons $>60$ years of age, these thresholds should be interpreted more leniently, because their age-specific risk is normally around these levels, even when other CV risk factor levels are "normal'. In particular, uncritical initiation of drug treatments of all elderly with risks greater than the $10 \%$ threshold should be discouraged.

Use of the risk charts should be qualified by knowledge of the following aspects:

- The charts assist in risk estimation but must be interpreted in light of the clinician's knowledge and experience and in view of the factors that may modify the calculated risk (see below).

- Relative risks may be high in young persons, even if 10 year absolute risks are low, because events usually occur later in life. The relative risk chart or estimating risk age may be helpful in identifying and counselling such persons.

\section{Table 5 Risk categories}

\begin{tabular}{|c|c|}
\hline Very high-risk & $\begin{array}{l}\text { Subjects with any of the following: } \\
\text { - Documented CVD, clinical or unequivocal on } \\
\text { imaging. Documented clinical CVD includes } \\
\text { previous AMI,ACS, coronary revascularization } \\
\text { and other arterial revascularization procedures, } \\
\text { stroke and TIA, aortic aneurysm and PAD. } \\
\text { Unequivocally documented CVD on imaging } \\
\text { includes significant plaque on coronary } \\
\text { angiography or carotid ultrasound. It does NOT } \\
\text { include some increase in continuous imaging } \\
\text { parameters such as intima-media thickness of } \\
\text { the carotid artery. } \\
\text { - DM with target organ damage such as } \\
\text { proteinuria or with a major risk factor such } \\
\text { as smoking or marked hypercholesterolaemia } \\
\text { or marked hypertension. } \\
\text { - Severe CKD (GFR <30 mL/min/I.73 m2). } \\
\text { - A calculated SCORE } \geq 10 \% \text {. }\end{array}$ \\
\hline High-risk & $\begin{array}{l}\text { Subjects with: } \\
\text { - Markedly elevated single risk factors, in } \\
\text { particular cholesterol }>8 \mathrm{mmol} / \mathrm{L}(>310 \mathrm{mg} / \mathrm{dL} \text { ) } \\
\text { (e.g. in familial hypercholesterolaemia) or } \\
\mathrm{BP} \geq 180 / / 10 \mathrm{mmHg} \text {. } \\
\text { - Most other people with DM (with the } \\
\text { exception of young people with type I DM } \\
\text { and without major risk factors that may be } \\
\text { at low or moderate risk). } \\
\text { - Moderate CKD (GFR } 30-59 \mathrm{~mL} / \mathrm{min} / 1.73 \mathrm{~m}^{2} \text { ). } \\
\text { - A calculated SCORE } \geq 5 \% \text { and }<10 \% \text {. }\end{array}$ \\
\hline Moderate-risk & $\begin{array}{l}\text { SCORE is } \geq 1 \% \text { and }<5 \% \text { at } 10 \text { years. Many middle- } \\
\text { aged subjects belong to this category. }\end{array}$ \\
\hline Low-risk & SCORE < $1 \%$. \\
\hline
\end{tabular}

$\mathrm{ACS}=$ acute coronary syndrome; $\mathrm{AMI}=$ acute myocardial infarction; $\mathrm{BP}=$ blood pressure; $C K D=$ chronic kidney disease; $D M=$ diabetes mellitus; GFR = glomerular filtration rate; $\mathrm{PAD}=$ peripheral artery disease; $\mathrm{SCORE}=$ systematic coronary risk estimation; TIA $=$ transient ischaemic attack.
- The lower risk in women is explained by the fact that risk is deferred by 10 years - the risk of a 60-year-old woman is similar to that of a 50-year-old man. Ultimately, more women than men die of CVD.

- The charts may be used to give some indication of the effects of reducing risk factors, given that there will be a time lag before risk reduces and that the results of RCTs in general give better estimates of the benefits of interventions. Those who stop smoking generally halve their risk.

\subsubsection{Modifiers of calculated total cardiovascular risk}

Apart from the conventional major CV risk factors included in the risk charts, there are other risk factors that could be relevant for assessing total CVD risk. The Task Force recommends additional risk factor assessment if such a risk factor improves risk classification [e.g. by calculation of a net reclassification index (NRI)] and if the assessment is feasible in daily practice. In general, reclassification is of most value when the individual's risk lies close to a decisional threshold, such as a SCORE risk of 5\%. In very-high-risk or very-low-risk situations, the impact of additional risk factors is unlikely to alter management decisions. While the presence of risk modifiers may move an individual's estimated risk upward, absence of these modifiers should lead to lowering an individual's estimated risk.

Table 4 lists examples of factors that fulfil the aforementioned criteria. Several other factors that are frequently discussed in the literature, but may not have the ability to reclassify subjects, are discussed in subsequent paragraphs. Also discussed further in this section are the roles of ethnicity and of specific conditions or diseases that may be associated with a higher than calculated risk, such as CKD, autoimmune diseases, etc. The way modifiers are related to $C V$ risk may be very different. Social deprivation and being overweight, for example, are important as 'causes of the causes' of CVD, in that they may be associated with higher levels of conventional risk factors. Family history may reflect a shared environment, genetic factors or both. Markers such as computed tomography (CT) calcium scoring are indicators of disease rather than risk factors for future disease.

\subsubsection{Risk categories: priorities}

Individuals at highest risk gain most from preventive efforts, and this guides the priorities, which are detailed in Table 5.

\subsubsection{Risk factor targets}

Risk factor goals and target levels for important CV risk factors are presented in Table 6.

\subsubsection{Conclusions}

Estimation of total CV risk remains a crucial part of the present guidelines. The priorities (risk categories) defined in this section are for clinical use and reflect the fact that those at highest risk of a CVD event gain most from preventive measures. This approach should complement public actions to reduce community risk factor levels and promote a healthy lifestyle. The principles of risk estimation and the definition of priorities reflect an attempt to make complex issues simple and accessible. Their very simplicity makes them vulnerable to criticism. Above all, they must be interpreted in light of 
Table 6 Risk factor goals and target levels for important cardiovascular risk factors

\begin{tabular}{|c|c|}
\hline Smoking & No exposure to tobacco in any form. \\
\hline Diet & $\begin{array}{l}\text { Low in saturated fat with a focus on wholegrain } \\
\text { products, vegetables, fruit and fish. }\end{array}$ \\
\hline $\begin{array}{l}\text { Physical } \\
\text { activity }\end{array}$ & $\begin{array}{l}\text { At least } 150 \text { minutes a week of moderate aerobic PA } \\
\text { ( } 30 \text { minutes for } 5 \text { days/week) or } 75 \text { minutes } \\
\text { a week of vigorous aerobic PA (I5 minutes for } \\
5 \text { days/week) or a combination thereof. }\end{array}$ \\
\hline Body weight & $\begin{array}{l}\text { BMI } 20-25 \mathrm{~kg} / \mathrm{m}^{2} \text {. Waist circumference }<94 \mathrm{~cm} \text { (men) } \\
\text { or }<80 \mathrm{~cm} \text { (women). }\end{array}$ \\
\hline $\begin{array}{l}\text { Blood } \\
\text { pressure }\end{array}$ & $<140 / 90 \mathrm{mmHg}^{\mathrm{a}}$ \\
\hline $\begin{array}{l}\text { Lipids }^{b} \\
\mathrm{LDL}^{\mathrm{c}} \text { is the } \\
\text { primary target }\end{array}$ & $\begin{array}{l}\text { Very high-risk: }<1.8 \mathrm{mmol} / \mathrm{L}(<70 \mathrm{mg} / \mathrm{dL}) \text {, or a } \\
\text { reduction of at least } 50 \% \text { if the baseline is between } \\
1.8 \text { and } 3.5 \mathrm{mmol} / \mathrm{L}(70 \text { and } 135 \mathrm{mg} / \mathrm{dL})^{d} \\
\text { High-risk: }<2.6 \mathrm{mmol} / \mathrm{L}(<100 \mathrm{mg} / \mathrm{dL}) \text {, or a } \\
\text { reduction of at least } 50 \% \text { if the baseline is between } \\
2.6 \text { and } 5.1 \mathrm{mmol} / \mathrm{L}(100 \text { and } 200 \mathrm{mg} / \mathrm{dL}) \\
\text { Low to moderate risk: }<3.0 \mathrm{mmol} / \mathrm{L}(<115 \mathrm{mg} / \mathrm{dL}) \text {. }\end{array}$ \\
\hline HDL-C & $\begin{array}{l}\text { No target but }>1.0 \mathrm{mmol} / \mathrm{L}(>40 \mathrm{mg} / \mathrm{dL}) \text { in men and } \\
>1.2 \mathrm{mmol} / \mathrm{L}(>45 \mathrm{mg} / \mathrm{dL}) \text { in women indicate lower risk. }\end{array}$ \\
\hline Triglycerides & $\begin{array}{l}\text { No target but }<1.7 \mathrm{mmol} / \mathrm{L}(<150 \mathrm{mg} / \mathrm{dL}) \text { indicates } \\
\text { lower risk and higher levels indicate a need to look } \\
\text { for other risk factors. }\end{array}$ \\
\hline Diabetes & $\mathrm{HbAlc}<7 \% .(<53 \mathrm{mmol} / \mathrm{mol})$ \\
\hline
\end{tabular}

$\mathrm{BMI}=$ body mass index; $\mathrm{HbA1c}=$ glycated haemoglobin; $\mathrm{HDL}-\mathrm{C}=$ high-density lipoprotein cholesterol; LDL-C = low density lipoprotein cholesterol.

aBlood pressure $<140 / 90 \mathrm{mmHg}$ is the general target. The target can be higher in frail elderly, or lower in most patients with DM (see chapter 3.a.8) and in some (very) high-risk patients without DM who can tolerate multiple blood pressure lowering drugs (see chapter 3.a.9).

${ }^{\mathrm{b}} \mathrm{Non}-\mathrm{HDL}-\mathrm{C}$ is a reasonable and practical alternative target because it does not require fasting. Non HDL-C secondary targets of $<2.6,<3.3$ and $<3.8 \mathrm{mmol} / \mathrm{L}$ $(<100,<130$ and $<145 \mathrm{mg} / \mathrm{dL})$ are recommended for very high, high and low to moderate risk subjects, respectively. See section 3a.7.10 for more details.

${ }^{C} \mathrm{~A}$ view was expressed that primary care physicians might prefer a single general LDL-C goal of $2.6 \mathrm{mmo} / \mathrm{L}(100 \mathrm{mg} / \mathrm{dL})$. While accepting the simplicity of this approach and that it could be useful in some settings, there is better scientific support for the three targets matched to level of risk.

${ }^{\mathrm{d}}$ This is the general recommendation for those at very high-risk. It should be noted that the evidence for patients with CKD is less strong.

the physician's detailed knowledge of his/her patient and in light of local guidance and conditions.

\section{Gaps in evidence}

- There are no recent RCTs of a total risk approach to risk assessment or risk management.

- The young, women, older people and ethnic minorities continue to be underrepresented in clinical trials.

- A systematic comparison of current international guidelines is needed to define areas of agreement and the reasons for discrepancies.

\subsection{Other risk markers}

\subsubsection{Family history/(epi)genetics}

\section{Key messages}

- Family history of premature CVD in first-degree relatives, before 55 years of age in men and 65 years of age in women, increases the risk of CVD.

- Several genetic markers are associated with an increased risk of CVD, but their use in clinical practice is not recommended.

\section{Recommendations for assessment of family historyl (epi)genetics}

\begin{tabular}{|l|c|c|c|}
\hline Recommendations & Class $^{\mathbf{a}}$ & Level $^{\mathbf{b}}$ & Ref $^{\mathbf{c}}$ \\
\hline $\begin{array}{l}\text { Assessment of family history of } \\
\text { premature CVD (defined as a fatal } \\
\text { or non-fatal CVD event or/and } \\
\text { established diagnosis of CVD in } \\
\text { first degree male relatives before 55 } \\
\text { years or female relatives before 65 } \\
\text { years) is recommended as part of } \\
\text { cardiovascular risk assessment. }\end{array}$ & I & C & 7I \\
\hline $\begin{array}{l}\text { The generalized use of DNA-based } \\
\text { tests for CVD risk assessment is not } \\
\text { recommended. }\end{array}$ & III & B & 72,73 \\
\hline
\end{tabular}

CVD $=$ cardiovascular disease

${ }^{\mathrm{a} C l a s s}$ of recommendation.

bevel of evidence.

${ }^{\mathrm{C}}$ Reference(s) supporting recommendations.

\subsubsection{Family history}

Familial history of premature CVD is a crude but simple indicator of the risk of developing CVD, reflecting both the genetic trait and the environment shared among household members. ${ }^{71}$ A positive family history of premature CV death is associated with an increased risk of early and lifetime CVD. ${ }^{74}$ In the few studies that simultaneously assessed and reported the effects of family history and genetic scores, family history remained significantly associated with the incidence of CVD after adjusting for the genetic scores. ${ }^{75,76}$ Limited data exist regarding the ability of family history to improve the prediction of CVD beyond conventional CV risk factors. ${ }^{77-79}$ One possible explanation is the varying definitions of family history applied ${ }^{80}$ and that conventional CV risk factors can partly explain the impact of family history.

A family history of premature CVD is simple, inexpensive information that should be part of the CV risk assessment in all subjects. Family history can be a risk modifier to optimal management after the calculated risk using SCORE lies near a decisional threshold: a positive family history would favour more intensive interventions, while a negative family history would translate into less intensive treatment. $^{77}$

\subsubsection{Genetic markers}

Genetic screening and counselling is effective in some conditions, such as familial hypercholesterolaemia (FH) (see section 3a.7.9). This paragraph will focus on genetic screening for high CV risk in the general population. 
Several recent genome-wide association studies have identified candidate genes associated with CVD. Since the effect of each genetic polymorphism is small, most studies have used genetic scores to summarize the genetic component. There is a lack of consensus regarding which genes and their corresponding single nucleotide polymorphisms (SNPs) should be included in a genetic risk score and which method should be used to calculate the genetic score.

The association of genetic scores with incident CVD has been prospectively studied, adjusting for the main CV risk factors, and most studies have found a significant association, with the relative risks varying between 1.02 and 1.49 per increase in one score unit. $^{77}$ The ability of genetic scores to predict $\mathrm{CV}$ events beyond traditional CV risk factors (i.e. defined by the NRI) was found in about half of the studies. The NRI is a statistical measure quantifying the usefulness of adding new variables to a risk prediction equation. ${ }^{77}$ The biggest improvements in the NRI were observed in participants at intermediate risk, while little or no improvement was observed in participants at high risk. ${ }^{75,81}$ One study estimated that one additional CAD event for every 318 people screened at intermediate risk could be prevented by measuring the CADspecific genetic score in addition to established risk factors. ${ }^{81} \mathrm{Im}$ portantly, since the frequency of polymorphisms might differ, the results may vary between populations. ${ }^{76,82,83}$ Recently, a genetic risk score based on 27 genetic variants enabled the identification of subjects at increased risk of CAD, who would benefit the most from statin therapy, even after adjustment for family history. ${ }^{84}$ Still, it is likely that some reported associations might be due to chance, ${ }^{85}$ and replication studies are needed to confirm positive findings.

Currently, many commercial tests are available, allowing an almost complete assessment of an individual's genome, and strong pressure is being applied to use this information to predict genetic risk and to make genetic testing a routine measure. ${ }^{86}$ Given the lack of agreement regarding which genetic markers should be included, how genetic risk scores should be calculated and uncertainties about improvement in CV risk prediction, the use of genetic markers for the prediction of CVD is not recommended.

\subsubsection{Epigenetics}

Epigenetics studies the chemical changes in DNA that affect gene expression. Methylation of genes related to $\mathrm{CV}$ risk factors is associated with variation in $\mathrm{CV}$ risk factor levels, ${ }^{87,88}$ and lower DNA methylation levels are associated with an increased risk of CAD or stroke. ${ }^{89}$ No information exists, however, regarding the effect of epigenetic markers in improving CVD risk prediction beyond conventional risk factors. Thus, epigenetic screening of CVD is not recommended.

\section{Gaps in evidence}

- The impact of adding family history to the current SCORE risk equation should be assessed.

- Future studies should assess the power of different genetic risk scores to improve CVD risk prediction in several different populations, the number of events prevented and the costeffectiveness of including genetic data in the risk assessment.

\subsubsection{Psychosocial risk factors}

\section{Key messages}

- Low socio-economic status, lack of social support, stress at work and in family life, hostility, depression, anxiety and other mental disorders contribute to the risk of developing CVD and a worse prognosis of CVD, with the absence of these items being associated with a lower risk of developing CVD and a better prognosis of CVD.

- Psychosocial risk factors act as barriers to treatment adherence and efforts to improve lifestyle, as well as to promoting health in patients and populations.

\section{Recommendation for assessment of psychosocial risk factors}

\begin{tabular}{|l|c|c|c|}
\hline Recommendation & Class $^{\mathrm{a}}$ & Level $^{\mathrm{b}}$ & Ref $^{\mathrm{c}}$ \\
\hline $\begin{array}{l}\text { Psychosocial risk factor assessment, } \\
\text { using clinical interview or standardized } \\
\text { questionnaires, should be considered } \\
\text { to identify possible barriers to lifestyle } \\
\text { change or adherence to medication in } \\
\text { individuals at high CVD risk or with } \\
\text { established CVD. }\end{array}$ & Ila & B & $90-92$ \\
\hline
\end{tabular}

${ }^{\mathrm{a} C}$ Class of recommendation.

bLevel of evidence.

${ }^{\mathrm{C}}$ Reference(s) supporting recommendations.

Low socio-economic status, defined as low educational level, low income, holding a low-status job or living in a poor residential area, confer an increased risk of CAD; the relative risk (RR) of CAD mortality risk is $1.3-2.0 .^{93,94}$ Compared with the Framingham risk score, adding social deprivation to $\mathrm{CV}$ risk assessment was able to reduce unattributed risk substantially. ${ }^{45}$

People who are isolated or disconnected from others are at increased risk of developing and dying prematurely from CAD. Similarly, a lack of social support increases CAD risk and worsens the prognosis of CAD. ${ }^{95}$

Acute mental stressors may act as triggers of acute coronary syndrome (ACS). These stressors include exposure to natural catastrophes, as well as personal stressors (e.g. defeat or other serious life events) resulting in acute strong negative emotions (e.g. outbursts of anger or grief). ${ }^{96}$ After the death of a significant person, the incidence rate of acute myocardial infarction (AMI) is elevated 21-fold during the first 24 hours, declining steadily during the subsequent days. ${ }^{97}$

Chronic stress at work (e.g. long working hours, extensive overtime work, high psychological demands, unfairness and job strain) predicts premature incident CAD in men [relative risk (RR) 1.2-1.5]. ${ }^{98}$ In addition, long-term stressful conditions in family life increase CAD risk ( $R R \sim 2.7-4.0) .{ }^{99,100}$

Clinical depression and depressive symptoms predict incident CAD (RR 1.6 and 1.9, respectively) ${ }^{101}$ and worsen its prognosis (RR 1.6 and 2.4, respectively). ${ }^{92,96,101,102}$ Vital exhaustion, most likely representing somatic symptoms of depression, significantly contributed to incident CAD (population attributable risk $21.1 \%$ in women and $27.7 \%$ in men). The NRI improved significantly. ${ }^{103}$ Panic attacks also increase the risk of incident CAD (RR 4.2). ${ }^{104}$ Anxiety is an independent risk factor for 
incident CAD (RR 1.3), ${ }^{92}$ for cardiac mortality following AMI [odds ratio (OR) 1.2 ${ }^{105}$ and cardiac events (OR 1.7). ${ }^{106}$

Meta-analyses reported a 1.5-fold risk of CVD incidence, a 1.2-fold risk of CAD and 1.7-fold risk for stroke in patients with schizophrenia, ${ }^{107}$ and a 1.3-fold risk for incident CAD, even after adjustment for depression, in patients with post-traumatic stress disorder. ${ }^{108}$

Hostility is a personality trait, characterized by extensive experience of mistrust, rage and anger and the tendency to engage in aggressive, maladaptive social relationships. A meta-analysis confirmed that anger and hostility are associated with a small but significant increased risk for CV events in both healthy and CVD populations (RR 1.2). ${ }^{109}$ The type $D$ ('distressed') personality involves an enduring tendency to experience a broad spectrum of negative emotions (negative affectivity) and to inhibit self-expression in relation to others (social inhibition). The type $D$ personality has been shown to predict poor prognosis in patients with CAD (RR 2.2). ${ }^{110}$

In most situations, psychosocial risk factors cluster in individuals and groups. For example, both women and men of lower socio-economic status and/or with chronic stress are more likely to be depressed, hostile and socially isolated. ${ }^{111}$ The INTERHEART study has shown that a cluster of psychosocial risk factors (i.e. social deprivation, stress at work or in family life and depression) is associated with increased risk for myocardial infarction (MI) (RR 3.5 for women and 2.3 for men). The population attributable risk was $40 \%$ in women and $25 \%$ in men. ${ }^{112}$

Mechanisms that link psychosocial factors to increased CV risk include unhealthy lifestyle [more frequent smoking, unhealthy food choices and less physical activity (PA)] and low adherence to behaviour change recommendations or CV medication. ${ }^{93,113}$ In addition, depression and/or chronic stress are associated with alterations in autonomic function, in the hypothalamic-pituitary axis and in other endocrine markers, which affect haemostatic and inflammatory processes, endothelial function and myocardial perfusion. ${ }^{111}$ Enhanced risk in patients with depression may also be due in part to adverse effects of tricyclic antidepressants. ${ }^{91}$

Assessment of psychosocial factors in patients and persons with $\mathrm{CV}$ risk factors should be considered for use as risk modifiers in CV risk prediction, especially in individuals with SCORE risks near decisional thresholds. In addition, psychosocial factors can help identify possible barriers to lifestyle changes and adherence to medication. Standardized methods are available to assess psychosocial factors in many languages and countries. ${ }^{90}$ Alternatively, a preliminary assessment of psychosocial factors can be made within the physicians' clinical interview, as shown in Table 7.

No more than a minimum education according to the requirement of the country and/or a 'yes' for one or more items indicate an increased CV risk and could be applied as a modifier of CV risk (see Chapter 2.3.6). The management of psychosocial risk factors should be addressed according to Chapter 3a.2.

\section{Gap in evidence}

- It remains unknown whether routine screening for psychosocial risk factors contributes to fewer future cardiac events.

\subsubsection{Circulating and urinary biomarkers}

\section{Key messages}

- CV circulating and urinary biomarkers have either no or only limited value when added to CVD risk assessment with the SCORE system.
Table 7 Core questions for the assessment of psychosocial risk factors in clinical practice

\begin{tabular}{|c|c|}
\hline $\begin{array}{l}\text { Low socio- } \\
\text { economic } \\
\text { status }\end{array}$ & $\begin{array}{l}\text { - What is your highest educational degree? } \\
\text { - Are you a manual worker? }\end{array}$ \\
\hline $\begin{array}{l}\text { Work and } \\
\text { family } \\
\text { stress }\end{array}$ & $\begin{array}{l}\text { - Do you lack control over how to meet the demands } \\
\text { at work? } \\
\text { - Is your reward inappropriate for your effort? } \\
\text { - Do you have serious problems with your spouse? }\end{array}$ \\
\hline $\begin{array}{l}\text { Social } \\
\text { isolation }\end{array}$ & $\begin{array}{l}\text { - Are you living alone? } \\
\text { - Do you lack a close confidant? } \\
\text { - Have you lost an important relative or friend over the } \\
\text { last year? }\end{array}$ \\
\hline Depression & $\begin{array}{l}\text { - Do you feel down, depressed and hopeless? } \\
\text { - Have you lost interest and pleasure in life? }\end{array}$ \\
\hline Anxiety & $\begin{array}{l}\text { - Do you suddenly feel fear or panic? } \\
\text { - Are you frequently unable to stop or control } \\
\text { worrying? }\end{array}$ \\
\hline Hostility & $\begin{array}{l}\text { - Do you frequently feel angry over little things? } \\
\text { - Do you often feel annoyed about other people's habits? }\end{array}$ \\
\hline $\begin{array}{l}\text { Type D } \\
\text { personality }\end{array}$ & $\begin{array}{l}\text { - In general, do you often feel anxious, irritable, or } \\
\text { depressed? } \\
\text { - Do you avoid sharing your thoughts and feelings } \\
\text { with other people? }\end{array}$ \\
\hline $\begin{array}{l}\text { Post- } \\
\text { traumatic } \\
\text { stress } \\
\text { disorder }\end{array}$ & $\begin{array}{l}\text { - Have you been exposed to a traumatic event? } \\
\text { - Do you suffer from nightmares or intrusive thoughts? }\end{array}$ \\
\hline $\begin{array}{l}\text { Other } \\
\text { mental } \\
\text { disorders }\end{array}$ & - Do you suffer from any other mental disorder? \\
\hline
\end{tabular}

- There is evidence of publication bias in the field of novel biomarkers of CV risk, leading to inflated estimates of strength of association and potential added value.

\section{Recommendation for assessment of circulating and urinary biomarkers}

\begin{tabular}{|l|c|c|c|}
\hline Recommendation & Class $^{\mathrm{a}}$ & Level $^{\mathrm{b}}$ & Ref $^{\mathrm{c}}$ \\
\hline $\begin{array}{l}\text { Routine assessment of circulating } \\
\text { or urinary biomarkers is not } \\
\text { recommended for refinement of } \\
\text { CVD risk stratification. }\end{array}$ & III & B & III4, III \\
\hline
\end{tabular}

${ }^{\mathrm{a}}$ Class of recommendation.

bLevel of evidence.

${ }^{\mathrm{C}}$ Reference(s) supporting recommendations.

In general, biomarkers can be classified into inflammatory (e.g. high-sensitivity C-reactive protein (hsCRP, fibrinogen), thrombotic (e.g. homocysteine, lipoprotein-associated phospholipase A2), 
glucose- and lipid-related markers (e.g. apolipoproteins) and organspecific markers (e.g. renal, cardiac). However, for the purpose of overall CV risk estimation, these distinctions are generally not relevant. Also, from the perspective of risk stratification (i.e. prediction of future $\mathrm{CV}$ events), the question of whether a biomarker is causally related to CVD or may be a marker of preclinical disease is equally irrelevant.

Among the most extensively studied and discussed biomarkers is hsCRP. This biomarker has shown consistency across large prospective studies as a risk factor integrating multiple metabolic and low-grade inflammatory factors, with RRs approaching those of classical CV risk factors. However, its contribution to the existing methods of $\mathrm{CV}$ risk assessment is probably small. ${ }^{116}$

Meta-analyses and systematic reviews suggest that the vast majority of other circulating and urinary biomarkers have no or limited proven ability to improve risk classification. However, the extent to which they have been tested for their ability to add value to risk stratification varies considerably, ${ }^{114,115}$ with strong evidence of reporting bias. ${ }^{117}$ Organ-specific biomarkers may be useful to guide therapy in specific circumstances (e.g. albuminuria in hypertension or DM may predict kidney dysfunction and warrant renoprotective interventions) (see section $3 a$ ).

If, despite these recommendations, biomarkers are used as risk modifiers, it is important to note that having an unfavourable biomarker profile may be associated with a somewhat higher risk, but also that a favourable profile is associated with a lower risk than calculated. The degree to which the calculated risk is affected by biomarkers is generally unknown, but almost universally smaller than the (adjusted) RRs reported for these biomarkers in the literature. ${ }^{118}$ Hence, in these patients, particularly with a moderate risk profile, only relatively small adjustments in calculated risk are justifiable, and patients who are clearly at high or low risk should not be reclassified based on biomarkers. ${ }^{119}$

\section{Gaps in evidence}

- Not all potentially useful circulatory and urinary biomarkers have undergone state-of-the-art assessment of their added value in CV risk prediction on top of conventional risk factors.

- Biomarkers may be useful in specific subgroups, but this has been addressed in only a limited number of studies.

- The role of metabolomics as risk factors for CVD and to improve $\mathrm{CV}$ risk prediction beyond conventional risk factors should be further assessed.

\subsubsection{Measurement of preclinical vascular damage}

\section{Key messages}

- Routine screening with imaging modalities to predict future CV events is generally not recommended in clinical practice.

- Imaging methods may be considered as risk modifiers in CV risk assessment, i.e. in individuals with calculated $\mathrm{CV}$ risks based on the major conventional risk factors around the decisional thresholds.

\section{Recommendations for imaging methods}

\begin{tabular}{|l|c|c|c|}
\hline Recommendations & Class $^{\mathbf{a}}$ & Level $^{\mathbf{b}}$ & Ref $^{\mathbf{c}}$ \\
\hline $\begin{array}{l}\text { Coronary artery calcium scoring may } \\
\text { be considered as a risk modifier in } \\
\text { CV risk assessment. }\end{array}$ & Ilb & B & I20-I25 \\
\hline $\begin{array}{l}\text { Atherosclerotic plaque detection } \\
\text { by carotid artery scanning may be } \\
\text { considered as a risk modifier in CV } \\
\text { risk assessment. }\end{array}$ & Ilb & B & I26-I28 \\
\hline $\begin{array}{l}\text { ABI may be considered as a risk } \\
\text { modifier in CV risk assessment. }\end{array}$ & Ilb & B & I29-I32 \\
\hline $\begin{array}{l}\text { Carotid ultrasound IMT screening } \\
\text { for CV risk assessment is not } \\
\text { recommended. }\end{array}$ & III & A & I28, I33 \\
\hline
\end{tabular}

$\mathrm{ABI}=$ ankle-brachial index; $\mathrm{CV}=$ cardiovascular; $\mathrm{IMT}=$ intima-media thickness.

${ }^{\mathrm{a} C}$ Class of recommendation.

'Level of evidence.

'Reference(s) supporting recommendations.

Although most CVD can be explained by traditional risk factors, there is substantial variation in the amount of atherosclerosis. Thus interest has continued in the use of non-invasive imaging techniques to improve $\mathrm{CV}$ risk assessment. In individuals with calculated $\mathrm{CV}$ risks based on the major conventional risk factors near the decisional thresholds, some imaging techniques may be considered as risk modifiers to improve risk prediction and decision making.

\subsubsection{Coronary artery calcium}

Coronary artery calcium (CAC) is examined through electron beam or multislice CT. Calcifications indicate late-stage subclinical coronary atherosclerosis. ${ }^{134}$ Atherosclerotic coronary arteries do not necessarily always show calcifications. The extent of the calcification correlates with the extent of total coronary plaque burden. ${ }^{134}$ CAC is not an indicator of the (in)stability of an atherosclerotic plaque. $^{135}$ In patients with $A C S$, the extent of CAC is more pronounced than in those without CAD. ${ }^{136}$

The quantification of CAC scoring is fairly consistent across studies. Most studies use the Agatston score. ${ }^{137}$ The value of the score can be further increased if the age and sex distribution within percentiles are taken into account. A CAC score $\geq 300$ Agatston units or $\geq 75$ th percentile for age, sex and ethnicity is considered to indicate increased $\mathrm{CV}$ risk.

CAC has shown a very high negative predictive value, since an Agatston score of 0 has a negative predictive value of nearly $100 \%$ for ruling out significant coronary narrowing. ${ }^{120}$ However, studies have questioned the negative predictive value of CAC because significant stenosis in the absence of CAC is possible. ${ }^{121}$ Many prospective studies have shown the association of CAC with CAD, and the Agatston score is an independent predictor of CAD. ${ }^{122}$ Importantly, including CAC may improve CV risk prediction in addition to conventional risk factors. ${ }^{123}$ Thus, CAC scoring may be considered in individuals with calculated SCORE risks around the $5 \%$ or $10 \%$ thresholds. ${ }^{124,125}$ 
Although recent studies also showed the presence of CAC in low-risk populations, the added predictive value on CV events remains to be demonstrated. ${ }^{138-140}$

There are concerns regarding costs and radiation exposure. For CAC scoring, the radiation exposure with properly selected techniques is $\pm 1 \mathrm{mSv}$.

\subsubsection{Carotid ultrasound}

Population-based studies have shown correlations between the severity of atherosclerosis in one arterial territory and the involvement of other arteries. ${ }^{126}$ Therefore, early detection of arterial disease in apparently healthy individuals has focused on peripheral arteries, and in particular on the carotid arteries. Risk assessment using carotid ultrasound focuses on the measurement of the intima-media thickness (IMT) and the presence and characteristics of plaques.

The IMT is not only a measure of early atherosclerosis, but also of smooth muscle hypertrophy/hyperplasia. There is a graded increase in CV risk with increasing IMT, ${ }^{126}$ and a value $>0.9 \mathrm{~mm}$ is considered abnormal. The risk of stroke associated with IMT is non-linear, with hazards increasing more rapidly at lower IMTs than at higher IMTs. The IMT-associated risk of cardiac events is also non-linear. ${ }^{127}$ The extent of carotid IMT is an independent predictor of CVD, but seems to be more predictive in women than in men.

The lack of standardization regarding the definition and measurement of IMT, its high variability and low intra-individual reproducibility have raised concerns. A recent meta-analysis failed to demonstrate any added value of IMT compared to the Framingham Risk Score in predicting future CVD, even in the intermediate risk group. ${ }^{128}$ Thus, the systematic use of carotid ultrasound IMT to improve risk assessment is not recommended.

Plaque is usually defined as the presence of a focal wall thickening that it is at least $50 \%$ greater than the surrounding vessel wall or as a focal region with an IMT measurement $\geq 1.5 \mathrm{~mm}$ that protrudes into the lumen. ${ }^{141}$ Plaques may be characterized by their number, size, irregularity and echodensity (echolucent vs. calcified). Plaques are related to both coronary and cerebrovascular events, and echolucent (as opposed to calcified) plaques increase ischaemic cerebrovascular events. ${ }^{127}$ Many studies emphasize the greater value of measures that include plaque area and thickness, rather than IMT alone, in predicting CVD. Therefore, even though formal reclassification analyses have not been undertaken, carotid artery plaque assessment using ultrasonography may be considered to be a risk modifier in $\mathrm{CV}$ risk prediction in some cases.

\subsubsection{Arterial stiffness}

Arterial stiffness is commonly measured using either aortic pulse wave velocity (PWV) or arterial augmentation index. An increase in arterial stiffness is usually related to damage in the arterial wall, as has been shown in hypertensive patients. ${ }^{142}$ Although the relationship between aortic stiffness and CVD is continuous, a PWV threshold of $12 \mathrm{~m} / \mathrm{s}$ has been suggested as a conservative estimate of significant alterations of aortic function in middle-aged hypertensive patients. A meta-analysis showed that arterial stiffness predicts future CVD and improves risk classification. ${ }^{142}$ However, the validity of this conclusion is offset by evidence of substantial publication bias. ${ }^{117}$ The Task Force concludes that arterial stiffness may serve as a useful biomarker to improve CV risk prediction for patients close to decisional thresholds, but its systematic use in the general population to improve risk assessment is not recommended.

\subsubsection{Ankle-brachial index}

The ankle-brachial index $(\mathrm{ABI})$ is an easy-to-perform and reproducible test to detect asymptomatic atherosclerotic disease. An ABI $<0.9$ indicates $\geq 50 \%$ stenosis between the aorta and the distal leg arteries. Because of its acceptable sensitivity (79\%) and specificity $(90 \%),{ }^{131}$ an $\mathrm{ABI}<0.90$ is considered to be a reliable marker of peripheral artery disease (PAD). ${ }^{129}$ An $A B I$ value indicating significant PAD adds value to the medical history, because $50-89 \%$ of patients with an $A B I<0.9$ do not have typical claudication ${ }^{130}$ and it is present in $12-27 \%$ of asymptomatic individuals $>55$ years of age.

The $\mathrm{ABl}$ is inversely related to $\mathrm{CV}$ risk, ${ }^{132}$ but there is controversy regarding its potential to reclassify patients into different risk categories. $^{131,143}$

\subsubsection{Echocardiography}

Echocardiography is more sensitive than electrocardiography in diagnosing left ventricular hypertrophy (LVH) and it precisely quantifies left ventricular (LV) mass and geometric LVH patterns. Cardiac abnormalities detected by echocardiography have an additional predictive power. ${ }^{144,145}$ In view of the lack of convincing evidence that echocardiography improves $\mathrm{CV}$ risk reclassification, and because of the logistical challenges in performing it, this imaging tool is not recommended to improve CV risk prediction.

\section{Gaps in evidence}

- Currently, most imaging techniques have not been rigorously tested as screening tools in CV risk assessment; more evidence on calibration, reclassification and cost-effectiveness is still needed.

- The reduction of CVD risk in patients treated with lipid- or BP-lowering drugs because of reclassification with, for example, $C A C$ or $A B I$ remains to be demonstrated.

\subsubsection{Clinical conditions affecting cardiovascular disease risk}

2.4.5.1 Chronic kidney disease

\section{Key message}

- CKD is associated with an increased risk of CVD, independent of conventional CVD risk factors.

Hypertension, dyslipidaemia and DM are common among patients with CKD. In addition, inflammatory mediators and promoters of calcification cause vascular injury and may explain why CKD is associated with CVD even after adjustment for conventional risk factors. ${ }^{146}$ A decreasing estimated glomerular filtration rate (eGFR) is an important sign of a gradually increasing risk for CVD-related mortality, starting at $<75 \mathrm{~mL} / \mathrm{min} / 1.73 \mathrm{~m}^{2}$ and gradually increasing to an approximate three-fold risk in patients with values of $15 \mathrm{~mL} /$ $\mathrm{min} / 1.73 \mathrm{~m}^{2}$. End-stage renal disease is associated with a very high $\mathrm{CV}$ risk. Independent of eGFR, increased albumin excretion is also associated with $\mathrm{CV}$ mortality risk; the $\mathrm{RR}$ is $\sim 2.5$ in overt proteinuria. ${ }^{147}$ Studies assessing whether the accuracy of $C V$ risk stratification improves with the addition of eGFR levels are emerging, ${ }^{148}$ but there is no consensus on which measure of renal function (i.e. which formula, and creatinine- or cystatine-C-based) best predicts 
CVD. ${ }^{149,150}$ Based on the evidence, the Task Force decided to classify patients with severe CKD (GFR $\left.<30 \mathrm{~mL} / \mathrm{min} / 1.73 \mathrm{~m}^{2}\right)$ as 'very high risk' and those with moderate CKD (GFR 30-59 mL/min/1.73 $\mathrm{m}^{2}$ ) as 'high risk' (see Table 5).

\section{Gap in evidence}

- The contribution of various CKD markers to CVD risk stratification remains unclear.

\subsubsection{Influenza}

\section{Key message}

- There is an association between acute respiratory infections, especially those occurring at times of peak influenza virus circulation, and AMI.

\section{Recommendation for influenza vaccination}

\begin{tabular}{|l|c|c|c|}
\hline Recommendation & Class $^{\mathrm{a}}$ & Level $^{\mathrm{b}}$ & Ref $^{\mathrm{c}}$ \\
\hline $\begin{array}{l}\text { Annual influenza vaccination may } \\
\text { be considered in patients with } \\
\text { established CVD. }\end{array}$ & Ilb & C & $|5|-\mid 54$ \\
\hline
\end{tabular}

${ }^{\mathrm{a}}$ Class of recommendation

bLevel of evidence.

${ }^{c}$ Reference(s) supporting recommendations.

Influenza can trigger a CV event. Studies show an increase in rates of $\mathrm{Ml}$ during the annual influenza season. The risk of $\mathrm{Ml}$ or stroke was more than four times higher after a respiratory tract infection, with the highest risk in the first 3 days. ${ }^{151}$ A recent meta-analysis suggests that preventing influenza, particularly by means of vaccination, can prevent influenza-triggered $\mathrm{AMI},{ }^{154}$ but there is concern that some studies are biased. ${ }^{151-153,155}$

\section{Gap in evidence}

- Large-scale RCTs are needed to assess the efficacy of influenza vaccination in preventing influenza-triggered AMI.

\subsubsection{Periodontitis}

Studies have linked periodontal disease to both atherosclerosis and CVD, ${ }^{156,157}$ and serological studies have linked elevated periodontal bacteria antibody titres to atherosclerotic disease. ${ }^{158} \mathrm{~A}$ longitudinal study has suggested that an improvement in clinical and microbial periodontal status is related to a decreased rate of carotid artery IMT progression during a 3 year follow-up period, ${ }^{159}$ but IMT progression does not seem to be associated with CV events. ${ }^{133}$ Thus, if active treatment or prevention of periodontitis improves, clinical prognosis is still unclear.

\subsubsection{Patients treated for cancer}

\section{Key messages}

- Patients surviving cancer after treatment with chemotherapy or radiotherapy are at increased risk for CVD.

- The increased incidence of CVD is correlated with the (combination of) treatments given and the administered dose.
- The presence of traditional CV risk factors in cancer patients further increases $\mathrm{CV}$ risk.

\section{Recommendations for patients treated for cancer}

\begin{tabular}{|c|c|c|c|}
\hline Recommendations & Class $^{a}$ & Level $^{\mathrm{b}}$ & $\operatorname{Ref}^{c}$ \\
\hline $\begin{array}{l}\text { Cardio-protection in high-risk } \\
\text { patients }{ }^{d} \text { receiving type I } \\
\text { chemotherapy should be considered } \\
\text { for } L V \text { dysfunction prevention }\end{array}$ & Ila & B & 160,161 \\
\hline $\begin{array}{l}\text { Optimization of the CV risk profile } \\
\text { should be considered in cancer } \\
\text { treated patients. }\end{array}$ & Ila & C & \\
\hline
\end{tabular}

$\mathrm{CV}=$ cardiovascular; $\mathrm{LV}=$ left ventricular.

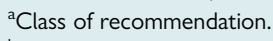

bevel of evidence.

'Reference(s) supporting recommendations.

${ }^{\mathrm{d}}$ High-risk patients are mainly those individuals receiving high cumulative doses of type I chemotherapy and/or combined treatment with other chemotherapic agents and radiotherapy, and/or with CV uncontrolled risk factors.

Survivors of cancer represent an increasingly large population, most of whom have received chemotherapy and/or radiotherapy. Cardiotoxicity due to chemotherapy is related to a direct effect on the cell (anthracycline-like) through the generation of reactive oxygen species (ROS). It can be mediated by topoisomerase $I I \beta$ in cardiomyocytes through the formation of ternary complexes (topoisomerase $\| \beta$-anthracycline-DNA) inducing DNA double-strand breaks and transcriptome changes responsible for defective mitochondrial biogenesis and ROS formation. Some agents (fluorouracil, bevacizumab, sorafenib and sunitinib) can induce a direct ischaemic effect not related to the premature development of atherosclerotic lesions. Moreover, they can increase risk factors such as hypertension and accelerate atherosclerosis, especially in older patients. These effects can be irreversible (type I agents) or partially reversible (type II agents) and can develop many years after treatment exposure. Typically, anthracyclines are the prototype of type I agents and trastuzumab of type II agents. ${ }^{162}$

Cardiotoxicity due to chest radiotherapy can induce micro- and macrovascular injury. It can accelerate atherosclerosis, but this may occur many years after the initial exposure. ${ }^{163-169}$ The latency and severity of radiotherapy cardiotoxicity is related to multiple factors, including the dose (total per fraction), the volume of the heart irradiated, concomitant administration of other cardiotoxic drugs and patient factors (younger age, traditional risk factors, ${ }^{170}$ history of heart disease).

The first step in the identification of higher risk for cardiotoxicity consists of a careful baseline assessment of CV risk factors. Primary care, cardiology and oncology should work together to deliver optimal survivorship care that addresses CVD risk factors as well as prevalent disease. Positive health-promoting behaviour, including lifestyle factors (healthy diet, smoking cessation, regular exercise, weight control) should be strongly advised. In particular, aerobic exercise is considered as a promising nonpharmacological strategy to prevent and/or treat chemotherapyinduced cardiotoxicity. ${ }^{171}$ 
Signs or symptoms of cardiac dysfunction should be monitored before and periodically during treatment for early detection of even asymptomatic abnormalities in patients receiving potentially cardiotoxic chemotherapy, and heart failure (HF) guideline recommendations should be followed if indicated. ${ }^{172}$ Thus, pretreatment evaluation of LV function is required. ${ }^{173} \mathrm{~A}$ targeted approach to treat patients with early LV dysfunction, in combination with global longitudinal strain abnormalities and biomarker (notably troponin) elevation, has been proposed. ${ }^{173,174}$

In the case of a decrease in LV function during or after chemotherapy, the use of cardiotoxic agents should be avoided or delayed, if possible, until after discussion with the oncology team. This calls for adequate communication between oncology and cardiology.

To reduce chemotherapy type I cardiotoxicity, a variety of prophylactic treatments, including $\beta$-blockers, angiotensinconverting enzyme inhibitors (ACE-Is), dexrazozane and statins, has been tested and compiled in a recent meta-analysis. ${ }^{161}$ It has been stressed that early preventive treatment is mandatory to exert a maximum effect. ${ }^{173-176}$

\section{Gaps in evidence}

- Evidence on the effect of early preventive measures to reduce type I cardiotoxicity is inconclusive.

- The most appropriate strategy to improve risk stratification and prevent CVD in patients treated for cancer needs to be tested prospectively.

\subsubsection{Autoimmune disease}

\section{Key messages}

- Rheumatoid arthritis (RA) enhances CV risk independently of traditional risk factors, with an RR of 1.4 and 1.5 in men and women, respectively.

- There is mounting evidence that other immune diseases, such as ankylosing spondylitis or early severe psoriasis, also increase CV risk, with RRs approaching those in RA.

- Post hoc analysis of two statin trials suggests that the relative reduction in CVD incidence in autoimmune diseases is comparable to that seen in the other conditions.

\section{Recommendations for autoimmune disease}

\begin{tabular}{|l|c|c|c|}
\hline Recommendations & Class $^{\mathbf{a}}$ & Level $^{\mathrm{b}}$ & Ref $^{\mathrm{c}}$ \\
\hline $\begin{array}{l}\text { The use of a I.5 factor risk multiplier } \\
\text { for CV risk in rheumatoid arthritis } \\
\text { should be considered, particularly if } \\
\text { disease activity is high. }\end{array}$ & Ila & B & I77 \\
\hline $\begin{array}{l}\text { The use of a I.5 risk multiplier for } \\
\text { CV risk in immune inflammatory } \\
\text { diseases other than rheumatoid } \\
\text { arthritis may be considered on a } \\
\text { patient-by-patient basis, depending } \\
\text { on disease activity/severity. }\end{array}$ & Ilb & C & 177 \\
\hline
\end{tabular}

${ }^{\mathrm{a}}$ Class of recommendation.

bLevel of evidence.

${ }^{c}$ Reference(s) supporting recommendations.
There is now clear evidence implicating high-grade inflammation as a pathway for accelerated vascular disease. ${ }^{178}$ Systemic inflammation appears to enhance $\mathrm{CV}$ risk directly and indirectly via accentuation of existing risk pathways. ${ }^{178}$ While early small studies suggested RA increases CV risk beyond other risk markers, the recent analysis of the national QRESEARCH database in 2.3 million people provides the best available evidence for this. ${ }^{47}$ Such evidence has now been implemented in some national risk scores ${ }^{58}$ and European guidelines. $^{177}$

Evidence in psoriasis is less rigorous, but a recent paper demonstrates broadly comparable CV risks in RA and in early severe psoriasis. ${ }^{179}$ Robust data for independently elevated $\mathrm{CV}$ risks in other autoimmune conditions are generally lacking. Hence, clinical judgment should be applied on a case-by-case basis. There is evidence from post hoc analysis of randomized trials to support a statin-associated reduction in CV risk in autoimmune conditions. ${ }^{180}$ Finally, in all autoimmune diseases, drug interactions of antiinflammatory and immunosuppressive drugs with, for example, statins, antiplatelet agents and antihypertensive agents deserve attention.

\section{Gaps in evidence}

- The association between non-RA immune inflammatory disease and CVD is less clear than for RA.

- The relationship between anti-rheumatic drugs and CV risk is unknown.

\subsubsection{Obstructive sleep apnoea syndrome}

\section{Key message}

- There is evidence of a positive relationship between obstructive sleep apnoea syndrome (OSAS) and hypertension, CAD, atrial fibrillation (AF), stroke, and HF.

OSAS is characterized by recurrent partial or complete collapse of the upper airway during sleep. It affects an estimated $9 \%$ of adult women and $24 \%$ of adult men and has been associated with an RR of 1.7 for CV morbidity and mortality. ${ }^{181}$ Repetitive bursts of sympathetic activity, surges of BP and oxidative stress brought on by pain and episodic hypoxaemia associated with increased levels of mediators of inflammation are thought to promote endothelial dysfunction and atherosclerosis. ${ }^{181}$ Screening for OSAS can be performed using the Berlin Questionnaire and daytime sleepiness can be assessed by the Epworth Sleepiness Scale and overnight oximetry. ${ }^{182}$ Definitive diagnosis often requires polysomnography, usually during a night in a sleep laboratory during which multiple physiological variables are continuously recorded. Treatment options include behavioural changes, such as avoiding alcohol, caffeine or other stimulants of wakefulness before sleep, increased PA, discontinuation of sedating drugs and obesity control. Continuous positive airway pressure is the gold-standard therapy and reduces CV mortality and events. ${ }^{183}$

\section{Gap in evidence}

- More studies are needed to determine whether routine screening reduces (non)fatal CVD. 


\subsubsection{Erectile dysfunction}

\section{Key message}

- Erectile dysfunction (ED) is associated with future CV events in men without and with established CVD.

\section{Recommendation for erectile dysfunction}

\begin{tabular}{|l|c|c|}
\hline Recommendation & Class $^{\mathrm{a}}$ & Level $^{\mathrm{b}}$ \\
\hline $\begin{array}{l}\text { Assessment of CV risk factors and CVD } \\
\text { signs or symptoms in men with ED should be } \\
\text { considered. }\end{array}$ & Ila & C \\
\hline
\end{tabular}

$\mathrm{CV}=$ cardiovascular; $\mathrm{CVD}=$ cardiovascular disease $; \mathrm{ED}=$ erectile dysfunction ${ }^{\mathrm{a} C l a s s}$ of recommendation.

bevel of evidence.

$E D$, defined as the consistent inability to reach and maintain an erection satisfactory for sexual activity, is common, affecting almost $40 \%$ of men $>40$ years of age (with varying degrees of severity), and increases in frequency with age. ED and CVD share common risk factors, including age, hypercholesterolaemia, hypertension, insulin resistance and DM, smoking, obesity, metabolic syndrome, sedentary lifestyle and depression. CVD and ED also share a common pathophysiological basis of aetiology and progression. ${ }^{184}$ Numerous studies have established that ED is associated with asymptomatic CAD. ${ }^{185,186}$ ED precedes CAD, stroke and PAD by a period that usually ranges from 2 to 5 years (average 3 years). A meta-analysis showed that patients with ED compared with subjects without ED have a $44 \%$ higher risk for total CV events, $62 \%$ for AMI, 39\% for stroke and $25 \%$ for all-cause mortality. ${ }^{186}$ The predictive ability of ED is higher in younger ED patients despite the fact that the probability of ED increases with age, and it most likely identifies a group of patients with early and aggressive CVD. Thorough history taking, including CV symptoms and the presence of risk factors and comorbid conditions, assessment of ED severity and physical examination are mandatory first-line elements of investigation. Lifestyle changes are effective in improving sexual function in men: these include physical exercise, improved nutrition, weight control and smoking cessation. ${ }^{184}$

\section{Gap in evidence}

- The benefit of routine screening for ED and the most effective tool to assess it are still unclear.

\subsection{Relevant groups}

\subsubsection{Individuals $<50$ years of age}

\section{Key messages}

- Some people $<50$ years of age have high relative or lifetime CV risk and should be offered lifestyle advice as a minimum.

- Some younger people will have high single CV risk factors that, of themselves, warrant intervention, such as cholesterol levels $>8 \mathrm{mmol} / \mathrm{L}$ or $\mathrm{BP} \geq 180 / 110 \mathrm{mmHg}$.

- The most important group of people $<50$ years of age to identify are those with a family history of premature CVD, who should be tested for $\mathrm{FH}$ and treated accordingly.

\section{Recommendation for individuals $<\mathbf{5 0}$ years of age}

\begin{tabular}{|c|c|c|c|}
\hline Recommendation & Class $^{a}$ & Level $^{b}$ & $\operatorname{Ref}^{c}$ \\
\hline $\begin{array}{l}\text { It is recommended to screen all } \\
\text { individuals under } 50 \text { year of age } \\
\text { with a family history of premature } \\
\text { CVD in a first degree relative (under } \\
55 \text { year of age in males, under } 65 \\
\text { year of age in females) for familial } \\
\text { hypercholesterolaemia using a } \\
\text { validated clinical score. }\end{array}$ & I & B & $187-189$ \\
\hline
\end{tabular}

${ }^{\mathrm{a} C}$ Class of recommendation.

bevel of evidence.

${ }^{\mathrm{C}}$ Reference(s) supporting recommendations.

The most powerful driver of risk in all short-term ( 5 or 10 year) CV risk algorithms is age. As a consequence, all standard CV risk calculators show people $<50$ as low CVD risk, regardless of underlying risk factors. However, some younger individuals are at very high relative risk compared with individuals of a similar age and may have high lifetime risk: they are more likely to develop CVD early and may prematurely suffer fatal or non-fatal CV events. So trying to identify who may be at such risk is an important challenge.

2.5.1.1 Assessing cardiovascular disease risk in people $<50$ years of age Information on CV risk factors should be routinely collected in all adults $<50$ years of age with a first-degree family history (i.e. $<55$ years of age for male and $<65$ years of age for female relatives) of premature CVD. There are no data on the right age to begin collecting such information in the general population, but some guidelines advocate starting at age 40 years. ${ }^{190}$ Repeating such assessments occasionally, such as every 5 years, is recommended, but there are no data to guide this interval.

People $<50$ years of age should be assessed using the standard algorithm in terms of treatment decisions. However, in the absence of a very high individual risk factor level or diagnosis of $\mathrm{FH}$, their 10-year risk will never be high enough to warrant BP- or lipid-lowering therapy. Physicians may want to further differentiate $\mathrm{CV}$ risk in younger people by using a relative risk chart (Figure 3, section 2.3.1); this might be useful in assisting people $<50$ years of age to judge their risk in relation to someone of the same age with low levels of risk factors.

Alternatively, physicians should consider using a risk age calculator (Figure 4, section 2.3.2) or a lifetime risk calculator, such as the JBS3 web-based tool (Figure J in web addenda), ${ }^{58}$ which might act as an educational tool in terms of how changing risk factors might change the lifetime risk score as well as illustrate long-term CVD risk.

People $<50$ years of age with a positive family history of premature CVD should be screened for FH (see section 2.4.1) by clinical criteria (or occasionally genetic testing), such as those defined by the Dutch Lipid Clinic Network. ${ }^{187}$ Alternatives are the Simon Broome Registry criteria ${ }^{188}$ or the US MedPed Program. ${ }^{189}$

\subsubsection{Management of cardiovascular disease risk in people $<50$ years} of age

All people $<50$ years of age with elevated CVD risk factors should be counselled on lifestyle factors (with emphasis on avoiding 
smoking, overweight and sedentary behaviour) and the relationship between risk factors and subsequent disease. There are no data on what are the most effective methods of changing health behaviours in younger people. However, smoking cessation, healthy weight maintenance and regular aerobic activity are all important behaviours on which to provide advice and support.

Younger people with very high BP levels warranting treatment should be managed in the same way as older people with hypertension. In younger people who are judged eligible for a statin on the grounds of either FH or very high lipid levels, the management offered is the same as for older people. Very importantly, for all patients deemed to suffer with $\mathrm{FH}$, the physician making the management decisions should arrange for FH screening for family members (see section 3a.7.9).

\section{Gaps in evidence}

- Age to commence formal CV risk estimation.

- Whether and how to screen populations for FH.

\subsubsection{Elderly}

Age is the dominant driver of cardiovascular risk, and most individuals are already at (very) high risk at the age of 65 years (see section 2.3.1). Especially in the oldest old, cardiovascular risk management is controversial. Opponents argue that risk should not be treated when it is essentially age-driven. Proponents, on the other hand, point out that many preventive treatments are still effective at advanced age in terms of postponing morbidity and mortality.

The Task Force has taken the position that epidemiological evidence of absolute risk reduction in clinical trials is the main driver for recommendations in this guideline. Still, we encourage a discussion with patients regarding quality of life and life potentially gained, as well as regarding the ethical dilemmas of treating risk inherent to ageing, the total burden of drug treatment and the inevitable uncertainties of benefit.

In this guideline, sections on treatment of the main risk factors contain recommendations or considerations specific to the elderly when evidence is available.

\subsubsection{Hypertension}

Most of the elderly-specific evidence is available for BP (section 3a.9). In general, more lenient treatment targets are advocated in the elderly. The hypertension literature also contains increasing evidence that biological rather than calendar age is important. ${ }^{191}$

\subsubsection{Diabetes mellitus}

Evidence supporting more lenient glycaemic control targets in the elderly is also available for DM (section 3a.8). The role of biological age/frailty is less well established than for BP, but nonetheless, a Class Ila recommendation is given to relax glycaemic targets in elderly or frail patients.

\subsubsection{Hyperlipidaemia}

Few areas in CVD prevention are more controversial than the mass use of statins in the elderly. As the section on lipid control points out, there is no evidence of decreasing effectiveness of statins in patients $>75$ years of age (section 3a.7). On the other hand, the costeffectiveness of statins in these patients is offset by even small geriatric-specific adverse effects. ${ }^{192}$ Also, evidence supporting effectiveness in the oldest old (i.e. $>80$ years of age) is very limited. A recent trial suggested no harm of stopping statins in the elderly with a limited life expectancy. ${ }^{193}$ Taken together, the recommendations of cholesterol-lowering treatment in the elderly should be followed with caution and common sense, adverse effects should be monitored closely and treatment should be reconsidered periodically.

\subsubsection{Female-specific conditions}

\section{Key messages}

- Several obstetric complications, in particular pre-eclampsia and pregnancy-related hypertension, are associated with a higher risk of CVD later in life. This higher risk is explained, at least partly, by hypertension and DM.

- Polycystic ovary syndrome (PCOS) confers a significant risk for future development of DM.

\section{Recommendations for female-specific conditions}

\begin{tabular}{|l|c|c|c|}
\hline Recommendations & Class $^{\mathbf{a}}$ & Level $^{\mathrm{b}}$ & Ref $^{\mathbf{c}}$ \\
\hline $\begin{array}{l}\text { In women with a history of pre- } \\
\text { eclampsia and/or pregnancy-induced } \\
\text { hypertension, periodic screening } \\
\text { for hypertension and DM should be } \\
\text { considered. }\end{array}$ & Ila & B & 194-197 \\
\hline $\begin{array}{l}\text { In women with a history of polycystic } \\
\text { ovary syndrome or gestational DM, } \\
\text { periodic screening for DM should be } \\
\text { considered. }\end{array}$ & Ila & B & I98-20I \\
\hline $\begin{array}{l}\text { In women with a history of giving } \\
\text { premature birth, periodic screening } \\
\text { for hypertension and DM may be } \\
\text { considered. }\end{array}$ & Ilb & B & 202, 203 \\
\hline
\end{tabular}

$\mathrm{DM}=$ diabetes mellitus; $\mathrm{PCOS}=$ polycystic ovary syndrome.

${ }^{a}$ Class of recommendation.

bLevel of evidence.

${ }^{c}$ Reference(s) supporting recommendations.

Specific conditions that may occur in females only and may have an impact on CVD risk can be separated into obstetric and nonobstetric conditions.

\subsubsection{Obstetric conditions}

Pre-eclampsia (defined as pregnancy-related hypertension accompanied by proteinuria) occurs in 1-2\% of all pregnancies. Studies suggest that pre-eclampsia is associated with an increase in CV risk by a factor $1.5-2.5,{ }^{194,195}$ while the RR of developing hypertension is $\sim 3^{196}$ and DM $\sim 2 .{ }^{194,197}$ Because most studies did not adjust the elevated risk of future CVD for the development of conventional risk factors, it cannot be established whether the increased CV risk after pre-eclampsia occurs independent of CV risk factors. The rationale for screening these women for the occurrence of hypertension and DM is, however, quite strong.

Pregnancy-related hypertension affects $10-15 \%$ of all pregnancies. The associated risk of later CVD is lower than for preeclampsia, but is still elevated (RR 1.9-2.5). ${ }^{202}$ Also, the risk for 
sustained or future hypertension is elevated (RRs vary widely, from 2.0 to 7.2 or even higher). ${ }^{196,204}$ Again, however, there was incomplete adjustment for conventional risk factors. The risk of developing DM is probably also elevated in these women, but exact estimates are not available.

There are no data to suggest that recurrent pregnancy loss is associated with an increased CV risk. A history of premature birth is possibly associated with an increased risk of CVD in offspring (RR $1.5-2.0),{ }^{202,203}$ which may be partially explained by an increased incidence of hypertension and DM.

Finally, gestational diabetes confers a sharply elevated risk of future DM, with up to $50 \%$ developing DM within 5 years after pregnancy. ${ }^{200}$ Previously, oral glucose tolerance testing was advocated to screen for DM in such patients, but screening by fasting glucose or glycated haemoglobin may be preferable. ${ }^{201}$

\subsubsection{Non-obstetric conditions}

PCOS affects $\sim 5 \%$ of all women in their fertile years. PCOS has been associated with an increased risk for future development of CVD, but larger studies have produced conflicting results. ${ }^{198,205}$ The risk of developing hypertension is probably somewhat increased, but again the data are conflicting. ${ }^{205}$ PCOS does seem to be associated with a higher risk of developing DM (RR 2-4), ${ }^{198,199}$ suggesting that periodic screening for DM is appropriate.

Premature menopause, better defined as primary ovarian insufficiency, occurs in roughly $1 \%$ in women $\leq 40$ years of age. It has been reported to be associated with an increased risk of CVD (RR $\sim 1.5),{ }^{206}$ but studies are sparse. There are insufficient data to draw conclusions on a possible increased risk of hypertension or DM.

\section{Gaps in evidence}

- The degree to which increased CVD risk associated with several of the female-specific conditions occurs independent of conventional CVD risk factors is unknown.

- Information on whether female-specific conditions improve risk classification in women is unknown.

\subsubsection{Ethnic minorities}

\section{Key messages}

- CVD risk varies considerably between immigrant groups. South Asians and sub-Saharan Africans have a higher risk, while Chinese and South Americans have a lower risk.

- South Asians are characterized by a high prevalence and inadequate management of DM.

- Current risk estimation equations do not provide adequate estimations of CVD risk in ethnic minorities.

\section{Recommendation for ethnic minorities}

\begin{tabular}{|l|c|c|c|}
\hline Recommendation & Class $^{\mathbf{a}}$ & Level $^{\mathbf{b}}$ & Ref $^{\mathbf{c}}$ \\
\hline $\begin{array}{l}\text { Ethnicity should be considered in } \\
\text { CVD risk assessment. }\end{array}$ & Ila & A & 207,208 \\
\hline
\end{tabular}

CVD $=$ cardiovascular disease

${ }^{\mathrm{a}}$ Class of recommendation.

bLevel of evidence.

'Reference(s) supporting recommendations.
Europe welcomes a large number of non-EU immigrants per year, mainly from India, China, North Africa and Pakistan. One of 25 Europeans comes from outside Europe, but data regarding CVD risk or CVD risk factors among immigrants are scarce and of differing quality. ${ }^{209}$

First-generation migrants usually display lower CVD mortality rates than natives of the host country, ${ }^{210}$ but with time, migrants tend to approach the CVD risk in their host country. ${ }^{210,211}$ Relative to natives of the host country, CVD mortality risk, as well as the prevalence and management of CVD risk factors among migrants, varies according to country of origin and host country. ${ }^{211-213}$ Given the considerable variability in CVD risk factors between immigrant groups, no single CVD risk score performs adequately in all groups and the use of ethnic-specific scores might be necessary. ${ }^{207}$

Immigrants from South Asia (notably India and Pakistan) present high CVD rates ${ }^{214-216}$ and have a much higher prevalence of DM, ${ }^{217,218}$ while the prevalence of other CV risk factors is slightly lower than or comparable to natives of the host country. ${ }^{217,219}$ Interestingly, the increased prevalence of DM increases the CVD risk in South Asians in some studies ${ }^{214}$ but not in others. Management of DM is also significantly worse, while management of high BP and hypercholesterolaemia is better among South Asians than host country natives. ${ }^{220}$ The higher CVD risk among South Asians makes screening more cost effective than in other immigrant groups, but risk prediction using SCORE might not be optimal. 221

Immigrants from China and Vietnam present lower CVD risk than natives of the host country, ${ }^{214}$ although this finding has been challenged. ${ }^{215}$ This lower risk seems attributable to lower levels of CV risk factors ${ }^{217}$ and higher HDL-C levels. $^{222}$

Immigrants from Turkey have higher estimated CVD risk and higher CVD mortality rates ${ }^{212}$ than host country natives. This seems mainly due to the higher prevalence of smoking, DM, dyslipidaemia, hypertension and obesity rates. ${ }^{222-224}$ Management of CVD risk factors also varies according to the host country; there are no differences in hypertension control compared with natives in The Netherlands, ${ }^{224}$ but there is worse control in Denmark. ${ }^{225}$

Immigrants from Morocco present lower CVD rates than natives from the host country. ${ }^{212}$ Possible explanations include lower BP and cholesterol levels and smoking rates, ${ }^{223,224}$ although a higher prevalence of DM and obesity has also been found. ${ }^{224}$ No differences between Moroccan immigrants and Dutch natives were found regarding hypertension control. ${ }^{223}$

Immigrants from sub-Saharan Africa and the Caribbean present higher CVD rates than natives from the host country in some studies, ${ }^{213,214,226}$ but not all. ${ }^{214}$ African immigrants have higher DM rates $^{218}$ but smoke less ${ }^{219}$ than natives from the host country. Management of CVD risk factors was worse than among natives in one study, ${ }^{220}$ but not in another. ${ }^{227}$

Immigrants from South America have lower CVD mortality rates than natives in Spain, ${ }^{228}$ while no difference was found in Denmark. ${ }^{229}$ South American immigrants in Spain have a lower prevalence of $C V$ risk factors and CVD rates than natives in Spain, but these differences decrease with increasing length of stay. ${ }^{230}$ 
Based on available mortality and prospective data, ${ }^{208}$ the following correction factors could be applied when assessing CVD risk using SCORE among first-generation immigrants only.

- Southern Asia: multiply the risk by 1.4

- Sub-Saharan Africa and the Caribbean: multiply the risk by 1.3

- Western Asia: multiply the risk by 1.2

- Northern Africa: multiply the risk by 0.9

- Eastern Asia or South America: multiply the risk by 0.7

These values reflect the best estimations from available data and should be interpreted with caution, but can be used to guide CV risk management.

\section{Gaps in evidence}

- Studies focusing on CVD risk and the prevalence of CVD risk factors among minorities in Europe are needed.

- Validation of the SCORE risk estimation among ethnic minorities is needed.

- Ethnicity-specific thresholds to define high risk (based on the SCORE evaluation) should be identified. Alternatively, ethnicityspecific CVD risk equations should be developed.

\section{3a. How to intervene at the individual level: risk factor intervention}

\section{3a.1 Behaviour change \\ Key message \\ - Cognitive behavioural methods are effective in supporting persons in adopting a healthy lifestyle.}

\section{Recommendations for facilitating changes in behaviour}

\begin{tabular}{|l|c|c|c|}
\hline Recommendations & Class $^{\mathbf{a}}$ & Level $^{\mathbf{b}}$ & Ref $^{\mathbf{c}}$ \\
\hline $\begin{array}{l}\text { Established cognitive-behavioural } \\
\text { strategies (e.g. motivational } \\
\text { interviewing) to facilitate lifestyle } \\
\text { change are recommended. }\end{array}$ & I & A & 23I \\
\hline $\begin{array}{l}\text { Involvement of multidisciplinary } \\
\text { healthcare professionals } \\
\text { (e.g. nurses, dieticians, psychologists) } \\
\text { is recommended. }\end{array}$ & I & A & 232,233 \\
\hline $\begin{array}{l}\text { In individuals at very high CVD risk, } \\
\text { multimodal interventions integrating } \\
\text { medical resources with education } \\
\text { on healthy lifestyle, physical activity, } \\
\text { stress management and counselling } \\
\text { on psychosocial risk factors, are } \\
\text { recommended. }\end{array}$ & I & A & 233,234 \\
\hline
\end{tabular}

CVD $=$ cardiovascular disease.

${ }^{\mathrm{a}}$ Class of recommendation.

bLevel of evidence.

${ }^{\mathrm{c}}$ Reference(s) supporting recommendations.
'Lifestyle' is usually based on long-standing behavioural patterns that are maintained by social environment. Individual and environmental factors impede the ability to adopt a healthy lifestyle, as does complex or confusing advice from caregivers. Friendly and positive interaction enhances an individual's ability to cope with illness and adhere to recommended lifestyle changes ('empowerment'). It is important to explore each patient's experiences, thoughts, worries, previous knowledge and circumstances of everyday life. Individualized counselling is the basis for motivation and commitment. Decision-making should be shared between the caregiver and patient (including also the individual's spouse and family). ${ }^{232,235}$ Use of the principles of effective communication $^{236}$ (Table 8) will facilitate treatment and prevention of CVD.

In addition, caregivers can build on cognitive behavioural strategies to assess the individual's thoughts, attitudes and beliefs concerning the perceived ability to change behaviour, as well as the environmental context. Behavioural interventions such as 'motivational interviewing' increase motivation and selfefficacy. ${ }^{231}$

Previous unsuccessful attempts often affect self-efficacy for future change. A crucial step is to help set realistic goals combined with self-monitoring of the chosen behaviour. ${ }^{232}$ Moving forward in small, consecutive steps is key to changing long-term behaviour. ${ }^{232}$ Communication training is important for health professionals. The 'ten strategic steps' listed in Table 9 can enhance counselling of behavioural change. 237

Combining the knowledge and skills of caregivers (such as physicians, nurses, psychologists, experts in nutrition, cardiac

\section{Table 8 Principles of effective communication to facilitate behavioural change}

- Spend enough time with the individual to create a therapeutic
relationship - even a few more minutes can make a difference.
- Acknowledge the individual's personal view of his/her disease
and contributing factors.
- Encourage expression of worries and anxieties, concerns and
self-evaluation of motivation for behaviour change and chances
of success.
- Speak to the individual in his/her own language and be supportive of
every improvement in lifestyle.
- Ask questions to check that the individual has understood the
advice and has any support he or she requires to follow it.
- Acknowledge that changing life-long habits can be difficult and that
sustained gradual change is often more permanent than a rapid change.
- Accept that individuals may need support for a long time and that
repeated efforts to encourage and maintain lifestyle change may be
necessary in many individuals.
- Make sure that all health professionals involved provide consistent
information.

- Spend enough time with the individual to create a therapeutic - Acknowledge the individual's personal view of his/her disease and contributing factors. self-evaluation of motivation for behaviour change and chances Speak to the individual in his/her own language and be supportive of

- Ask questions to check that the individual has understood the tollow information. 


\section{Table 9 Ten strategic steps to facilitate behaviour change}

I. Develop a therapeutic alliance.

2. Counsel all individuals at risk of or with manifest cardiovascular disease.

3. Assist individuals to understand the relationship between their behaviour and health.

4. Help individuals assess the barriers to behaviour change.

5. Gain commitments from individuals to own their behaviour change.

6. Involve individuals in identifying and selecting the risk factors to change.

7. Use a combination of strategies including reinforcement of the individual's capacity for change.

8. Design a lifestyle-modification plan.

9. Involve other healthcare staff whenever possible.

10. Monitor progress through follow-up contact.

rehabilitation and sports medicine) into multimodal behavioural interventions can optimize preventive efforts. ${ }^{232-234}$ Multimodal behavioural interventions are especially recommended for individuals at very high risk. ${ }^{232-234}$ These interventions include promoting a healthy lifestyle through behaviour changes, including nutrition, PA, relaxation training, weight management and smoking cessation programmes for resistant smokers. ${ }^{233,234}$ They enhance coping with illness and improve adherence and CV outcome. ${ }^{238,239}$ Psychosocial risk factors (stress, social isolation, and negative emotions) that may act as barriers against behaviour change should be addressed in tailored individual or group counselling sessions. $^{233,234}$

There is evidence that more extensive/longer interventions lead to better long-term results with respect to behaviour change and prognosis. ${ }^{232}$ Individuals of low socio-economic status, older age or female sex may need tailored programmes in order to meet their specific needs regarding information and emotional support. $232,240,241$

\section{Gap in evidence}

- There is limited evidence to determine which interventions are most effective in specific groups (e.g. young-old, male-female, high vs. low socio-economic status).

\section{3a.2 Psychosocial factors}

\section{Key messages}

- Treatment of psychosocial risk factors can counteract psychosocial stress, depression and anxiety, thus facilitating behaviour change and improving quality of life and prognosis.
- The caregiver-patient interaction should follow the principles of patient-centred communication. Age- and sex-specific psychosocial aspects should be considered.

\section{Recommendations for psychosocial factors}

\begin{tabular}{|l|c|c|c|}
\hline Recommendations & Class $^{\mathrm{a}}$ & Level $^{\mathrm{b}}$ & Ref $^{\mathrm{c}}$ \\
\hline $\begin{array}{l}\text { Multimodal behavioural } \\
\text { interventions, integrating health } \\
\text { education, physical exercise } \\
\text { and psychological therapy, for } \\
\text { psychosocial risk factors and coping } \\
\text { with illness are recommended in } \\
\text { patients with established CVD and } \\
\text { psychosocial symptoms in order to } \\
\text { improve psychosocial health. }\end{array}$ & I & A & 242 \\
\hline $\begin{array}{l}\text { Referral for psychotherapy, } \\
\text { medication or collaborative care } \\
\text { should be considered in the case } \\
\text { of clinically significant symptoms of } \\
\text { depression, anxiety or hostility. }\end{array}$ & Ila & A & 243,244 \\
\hline $\begin{array}{l}\text { Treatment of psychosocial risk factors } \\
\text { with the aim of preventing CAD } \\
\text { should be considered when the risk } \\
\text { factor itself is a diagnosable disorder } \\
\text { (e.g. depression) or when the factor } \\
\text { worsens classical risk factors. }\end{array}$ & Ila & B & 245,246 \\
\hline
\end{tabular}

$\mathrm{CAD}=$ coronary artery disease; CVD = cardiovascular disease.

${ }^{a}$ Class of recommendation.

bLevel of evidence.

${ }^{\mathrm{C}}$ Reference(s) supporting recommendations.

Caregivers in clinical practice are in a unique position to directly support their patients regarding psychosocial risk factors in individuals with high CV risk or with established disease. Empathic, patientcentred communication helps to establish and maintain a trustful relationship and is a powerful source of emotional support and professional guidance in coping with psychosocial stressors, depression, anxiety, CV risk factors and CVD. ${ }^{247,248}$ The principles of a supportive caregiver-patient interaction are $^{247,248}$

- Spend enough time with the patient, listen carefully and repeat essential keywords.

- Consider age- and sex-specific psychosocial aspects.

- Encourage expression of emotions, do not trivialize psychosocial burdens and worries.

- Explain essential medical facts in the patient's own language, convey hope and relief from feelings of guilt and reinforce adaptive thoughts and actions.

- In the case of severe mental symptoms, obtain treatment preferences and perform shared decision-making regarding further diagnostic and therapeutic steps.

- Summarize important aspects of the consultation to confirm that the patient has been understood.

- Offer regular follow-up contacts. 
Specialized psychological interventions have additional beneficial effects on distress, depressiveness and anxiousness, even when added to standard rehabilitation. ${ }^{242}$ These interventions include individual or group counselling on psychosocial risk factors and coping with illness, stress management programmes, meditation, autogenic training, biofeedback, breathing, yoga and/or muscular relaxation.

Large and consistent effects on depression have been shown in 'collaborative care', which may involve a systematic assessment of depression, a (non-physician) care manager to perform longitudinal symptom monitoring, treatment interventions and care coordination and specialist-provided stepped care recommendations and treatment. ${ }^{244}$ Collaborative care for depression resulted in a $48 \%$ lower risk for developing first CAD events 8 years after treatment compared with usual care $[\operatorname{RR} 0.52(95 \% \mathrm{Cl} 0.31,0.86)] .{ }^{245}$ Internet-delivered cognitive behavioural therapy in depressed patients with high CVD risk produced small, but robust, improvement of depressive symptoms, adherence and some health behaviours. $^{246}$

In patients with established CAD, mental health treatments for depression (psychotherapy and/or medication) have moderate efficacy for reducing cardiac events (NNT 34), but do not reduce total mortality. ${ }^{243}$ Collaborative care is especially effective on depressive symptoms and partially effective on cardiac prognosis. ${ }^{249,250}$ Furthermore, there is evidence that PA can effectively improve depression in patients with CAD. ${ }^{251}$

In addition to the treatment of mood symptoms, there are several other approaches to psychosocial intervention that have proved useful. Two RCTs $s^{252,253}$ have shown the favourable impact of stress management and social support groups on the prognosis of clinical CAD. Nurse-led interventions reveal beneficial effects on anxiety, depression and general well-being in CAD patients. ${ }^{254,255}$

In hostile CAD patients, a group-based hostility-control intervention may lead not only to decreases in behaviourally assessed hostility levels, but also to decreased levels of depression, resting heart rate $(H R)$ and $C V$ reactivity to mental stress, as well as to increased social support and satisfaction with life. ${ }^{256}$ Work reorganizations aimed at improving autonomy and increasing control at work may result in improved social support and a reduction in physiological stress responses. Hence, a reduction of work stress in managers and supervisors may have beneficial health effects on the target individuals and may also improve perceived social support in their subordinates. $^{257}$

\section{Gap in evidence}

- Evidence that treatment of clinically significant depression and anxiety alone will prevent CVD and improve outcomes is inconclusive.

\section{3a.3 Sedentary behaviour and physical activity \\ Key messages}

- Regular PA is a mainstay of CV prevention; participation decreases all-cause and CV mortality.

- PA increases fitness and improves mental health.
- Sedentary subjects should be encouraged to start light-intensity aerobic PA.

\section{Recommendations for physical activity}

\begin{tabular}{|c|c|c|c|}
\hline Recommendations & Class $^{a}$ & Level $^{\mathrm{b}}$ & $\operatorname{Ref}^{c}$ \\
\hline $\begin{array}{l}\text { It is recommended for healthy } \\
\text { adults of all ages to perform at least } \\
\text { I50 minutes a week of moderate } \\
\text { intensity or } 75 \text { minutes a week of } \\
\text { vigorous intensity aerobic PA or an } \\
\text { equivalent combination thereof. }\end{array}$ & $\mathbf{I}$ & A & $258-261$ \\
\hline $\begin{array}{l}\text { For additional benefits in healthy } \\
\text { adults, a gradual increase in aerobic } \\
\text { PA to } 300 \text { minutes a week of } \\
\text { moderate intensity, or } 150 \text { minutes } \\
\text { a week of vigorous intensity aerobic } \\
\text { PA, or an equivalent combination } \\
\text { thereof is recommended. }\end{array}$ & $\mathbf{I}$ & $\mathbf{A}$ & 259,260 \\
\hline $\begin{array}{l}\text { Regular assessment and counselling } \\
\text { on PA is recommended to promote } \\
\text { the engagement and, if necessary, to } \\
\text { support an increase in PA volume } \\
\text { over time. }\end{array}$ & $\mathbf{I}$ & B & $262-264$ \\
\hline $\begin{array}{l}\text { PA is recommended in low-risk } \\
\text { individuals without further } \\
\text { assessment. }\end{array}$ & $\mathbf{I}$ & c & 265,266 \\
\hline $\begin{array}{l}\text { Multiple sessions of PA should be } \\
\text { considered, each lasting } \\
\geq 10 \text { minutes and evenly spread } \\
\text { throughout the week, i.e. on } \\
4-5 \text { days a week and preferably } \\
\text { every day of the week. }\end{array}$ & Ila & B & 267,268 \\
\hline $\begin{array}{l}\text { Clinical evaluation, including exercise } \\
\text { testing, should be considered for } \\
\text { sedentary people with CV risk } \\
\text { factors who intend to engage in } \\
\text { vigorous PAs or sports. }\end{array}$ & Ila & C & 265 \\
\hline
\end{tabular}

$\mathrm{CV}=$ cardiovascular; $\mathrm{PA}=$ physical activity

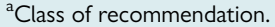

bevel of evidence.

'Reference(s) supporting recommendations.

dVolume is the total weekly dose of PA.

\section{3a.3.1 Introduction}

Regular PA reduces the risk of many adverse health outcomes over a wide age range: all-cause and CVD mortality are reduced in healthy individuals by $20-30 \%$ in a dose-response fashion, ${ }^{258-260,267,269}$ in subjects with coronary risk factors ${ }^{269}$ and in cardiac patients. ${ }^{270} \mathrm{PA}$ has a positive effect on many risk factors, including hypertension, low-density lipoprotein cholesterol (LDL-C) and non-HDL-C, body weight and type $2 \mathrm{DM}^{267}$ This applies to both men and women and across a broad range of ages from childhood to the very elderly. A sedentary lifestyle is one of the major risk factors for CVD independent of participation in PA. ${ }^{271}$ 


\section{3a.3.2 Physical activity prescription}

Health providers should assess the PA level in any subject (how many days and minutes per day are spent on average doing PA at moderate or vigorous intensity). They should warn against inactivity and help add PA to daily life. Subjects should be advised on appropriate types of activities and ways of progressing and should be helped to set personal goals to achieve and maintain the benefits. To this end, individuals should be encouraged to find some activity they either enjoy and/or that they can include in their daily routines, as such activities are more likely to be sustainable. For a more effective behaviour change, clinicians should explore practical ways to overcome barriers to exercise. For this reason, the link between primary care and local community-based structures for activity, recreation and sport is crucial. ${ }^{262}$ The amount of time spent being sedentary should be minimized by active travelling (cycling or walking), taking breaks from extended periods of sitting and reducing screen time. ${ }^{272}$ Brief exercises are more cost effective than supervised gym-based exercise classes or instructor-led walking programmes. ${ }^{264}$

\section{3a.3.2.1 Aerobic physical activity}

Aerobic PA, the most studied and recommended modality, with a beneficial dose-response effect on prognosis, ${ }^{259,260,268}$ consists of movements of large muscle mass in a rhythmic manner for a sustained period. It includes everyday activity, including active travel (cycling or walking), heavy household work, gardening, occupational activity and leisure time activity or exercise such as brisk walking, Nordic walking, hiking, jogging or running, cycling, cross-country skiing, aerobic dancing, skating, rowing or swimming.

Similar to all other interventions, its prescription can be adjusted in terms of frequency, duration and intensity. However, practising PA below the lowest recommended levels should be encouraged in individuals unable to meet the minimum or in those sedentary individuals who have just started, with a gradual increase in activity level.

Moderate or vigorous aerobic exercise should be recommended. This can be expressed either in absolute or relative terms.

Absolute intensity is the amount of energy expended per minute of activity, assessed by oxygen uptake per unit of time $(\mathrm{mL} / \mathrm{min}$ or $\mathrm{L} / \mathrm{min})$ or by metabolic equivalent (MET), which is estimated as the rate of energy expenditure while sitting at rest. By convention this corresponds to $3.5 \mathrm{~mL} \mathrm{O} / \mathrm{kg} / \mathrm{min}) .{ }^{273} \mathrm{~A}$ list of PA intensities in MET values is available. ${ }^{274}$ An absolute measure does not take into account individual factors such as body weight, sex, and fitness level: older persons exercising at a vigorous intensity of 6 METs may be exercising at their maximum intensity, while a younger person working at the same absolute intensity may be exercising moderately.

Relative intensity is the level of effort required to perform an activity. Less fit individuals generally require a higher level of effort than fitter people to perform the same activity. It is determined relative to an individual's level of cardiorespiratory fitness $\left(\mathrm{V}\right.$ ? $\mathrm{O}_{2}$ max $)$ or as a percentage of a person's measured or estimated maximum HR (\%HRmax), which is 220 - age. It also can be expressed as an index of individual rate of effort (how hard the person feels he/she is exercising), that is, the rating of perceived exertion (RPE) or by frequency of breathing (the so-called Talk Test). For individuals on medication, it is important to consider possible modification of $\mathrm{HR}$ response and to refer to other relative intensity parameters. Especially for older and deconditioned individuals, a relative measure of intensity is more appropriate. Classification for both absolute and relative intensity and examples are presented in Table 10.

PA should occur at a frequency of at least three to five sessions per week, but preferably every day.

It is recommended that individuals accumulate at least $30 \mathrm{~min} /$ day, 5 days/week of moderate intensity PA (i.e. $150 \mathrm{~min} /$ week) or $15 \mathrm{~min} /$ day, 5 days/week of vigorous intensity PA ( $75 \mathrm{~min} /$ week), or a combination of both, performed in sessions with a duration of at least 10 min. Shorter exercise sessions (i.e. $<10 \mathrm{~min}$ ) may also be appropriate, especially in very deconditioned individuals. ${ }^{267,276,277}$ For lipid control or body weight management, longer durations of exercise, 40 and 60-90 min/day, respectively, have been proposed. ${ }^{278}$

Aerobic interval training and high-intensity interval training cannot yet be broadly recommended until further data on safety and efficacy are available. ${ }^{266}$

\section{3a.3.2.2 Muscle strength/resistance physical activity}

Isotonic PA stimulates bone formation and reduces bone loss; it preserves and enhances muscle mass, strength, power and functional

Table 10 Classification of physical activity intensity and examples of absolute and relative intensity levels

\begin{tabular}{|c|c|c|c|c|c|}
\hline \multicolumn{3}{|c|}{ Absolute intensity } & \multicolumn{3}{|c|}{ Relative intensity } \\
\hline Intensity & MET & Examples & \%HRmax & RPE (Borg scale score) & Talk Test \\
\hline Light & $1.1-2.9$ & Walking $<4.7 \mathrm{~km} / \mathrm{h}$, light household work. & $50-63$ & $10-11$ & \\
\hline Moderate & $3-5.9$ & $\begin{array}{l}\text { Walking briskly ( } 4.8-6.5 \mathrm{~km} / \mathrm{h} \text { ), slow cycling (I5 } \\
\mathrm{km} / \mathrm{h} \text { ), painting/decorating, vacuuming, gardening } \\
\text { (mowing lawn), golf (pulling clubs in trolley), tennis } \\
\text { (doubles), ballroom dancing, water aerobics. }\end{array}$ & $64-76$ & $12-13$ & $\begin{array}{l}\text { Breathing is faster but compatible } \\
\text { with speaking full sentences. }\end{array}$ \\
\hline Vigorous & $\geq 6$ & $\begin{array}{l}\text { Race-walking, jogging or running, bicycling }>15 \\
\mathrm{~km} / \mathrm{h} \text {, heavy gardening (continuous digging or } \\
\text { hoeing), swimming laps, tennis (single). }\end{array}$ & $77-93$ & $14-16$ & $\begin{array}{l}\text { Breathing very hard, incompatible } \\
\text { with carrying on a conversation } \\
\text { comfortably. }\end{array}$ \\
\hline
\end{tabular}

MET (metabolic equivalent) is estimated as the energy cost of a given activity divided by resting energy expenditure: $1 \mathrm{MET}=3.5 \mathrm{~mL} \mathrm{O}_{2} \mathrm{~kg}-1 \mathrm{~min}-1$ oxygen consumption $\left(\mathrm{VO} \mathrm{O}_{2}\right.$ ) RPE, rating of perceived exertion (20 value Borg score).

$\%$ HRmax, percentage of measured or estimated maximum heart rate (220-age).

Modified from Howley. ${ }^{275}$ 
ability, with some evidence of benefit in lipid and BP control and insulin sensitivity, especially in combination with aerobic exercise. ${ }^{267,279}$ It should target the major muscle groups (agonist and antagonist) and include multijoint or compound movements through the full range of motion of the joints, such as working with resistance bands, calisthenics using body weight for resistance, carrying heavy loads and heavy gardening. For each exercise session, the suggested prescription is two to three sets of $8-12$ repetitions at the intensity of $60-80 \%$ of the individual's 1 repetition maximum (1 RM, the maximum load that can be lifted one time) at a frequency of least 2 days a week. For older adults or very deconditioned individuals, it is suggested to start with one set of $10-15$ repetitions at $60-70 \%$ of 1 RM. $^{280}$

\section{3a.3.2.3 Neuromotor physical activity}

For older adults at risk of falls, neuromotor exercise helps to maintain and improve balance and motor skills (balance, agility, coordination and gait). This includes multifaceted activities such as tai chi and yoga, and recreational activities using paddles or sport balls to challenge hand-eye coordination. The optimal volume is not known. ${ }^{276}$

\section{3a.3.2.4 Phases and progression of physical activity}

PA sessions should include the following phases: warm-up, conditioning (aerobic, muscle strength/resistance and neuromotor exercise), cool-down and stretching/flexibility. Progressive warm-up before and cool-down after exercise may prevent injuries and adverse cardiac events. Inactive adults should start gradually, at light or moderate intensity for short periods of time (even $<10 \mathrm{~min}$ ), with sessions spread throughout the week. With the improvement in exercise tolerance, each subject progresses in the level of PA, but increases in any components (i.e. frequency, duration and intensity) should be gradual, to minimize risks of muscle soreness, injury, fatigue and the long-term risk of overtraining. ${ }^{276}$ Following any adjustments, the individual should check for adverse effects (e.g. excessive shortness of breath) and if there are any such effects, downward adjustments should be made. ${ }^{276}$

\section{3a.3.3 Risk assessment}

The risk of an adverse $\mathrm{CV}$ response during PA is extremely low for apparently healthy adults (5-17 sudden deaths/million population/year). ${ }^{281}$ The risk of participation is outweighed by the substantial health benefits conferred by PA. ${ }^{267}$ Risk during lightor moderate-intensity exercise is lower than during vigorous activity, ${ }^{267}$ thus in healthy individuals who wish to undertake moderate PA, such as a walking programme, a preliminary medical evaluation is not needed. 266

Before starting more intensive leisure time activities (i.e. structured or competitive activity, amateur sports, exercise and fitness training), a risk assessment should be tailored to the individual's clinical (i.e. metabolic, musculoskeletal condition/disease) and cardiac risk profile, the current level of habitual PA and the intended level of PA. ${ }^{265}$ Individuals who exercise only occasionally seem to have an increased risk of acute coronary events and sudden cardiac death during or after exercise. ${ }^{282}$ Sedentary subjects and those with CV risk factors should start aerobic PA at low-intensity activity and progress gradually. Clinical evaluation, including exercise testing, may be considered for sedentary people with CV risk factors who intend to engage in vigorous PA and sports. The information gathered from exercise tests may be useful in establishing a safe and effective exercise prescription. Validated self-assessment questionnaires have been proposed for sedentary individuals entering low-intensity leisure time sports activity or starting moderate-intensity activities ${ }^{265}$ (see Table $B$ in web addenda).

\section{Gaps in evidence}

- The lower and upper limit of aerobic PA intensity, duration and frequency to exert a beneficial effect is unknown.

- The effectiveness of PA monitoring vs. simple counselling to optimize the motivation of patients to adhere to active lifestyle is unknown.

- The role and sustainability of modern technology (such as wearable technology, 'exergaming' and smartphone apps) for motivating people to undertake more PA has not been established.

\section{3a.4 Smoking intervention}

\section{Key messages}

- Stopping smoking is the most cost-effective strategy for CVD prevention.

- There is a strong evidence base for brief interventions with advice to stop smoking, all types of nicotine replacement therapy (NRT), bupropion, varenicline and greater effectiveness of drugs in combination, except for NRT plus varenicline. The most effective are brief interventions plus assistance with stopping using drug therapy and follow-up support.

- Electronic cigarettes (e-cigarettes) may help in smoking cessation but should be covered by the same marketing restrictions as cigarettes.

- Passive secondary smoking carries significant risk, with the need to protect non-smokers.

\section{Recommendations for smoking intervention strategies}

\begin{tabular}{|l|c|c|c|}
\hline Recommendations & Class $^{\mathrm{a}}$ & Level $^{\mathrm{b}}$ & Ref $^{\mathrm{c}}$ \\
\hline $\begin{array}{l}\text { It is recommended to identify } \\
\text { smokers and provide repeated advice } \\
\text { on stopping with offers to help, by } \\
\text { the use of follow up support, nicotine } \\
\text { replacement therapies, varenicline, } \\
\text { and bupropion individually or in } \\
\text { combination. }\end{array}$ & I & A & 283-286 \\
\hline $\begin{array}{l}\text { It is recommended to stop all } \\
\text { smoking of tobacco or herbal } \\
\text { products, as this is strongly and } \\
\text { independently causal of CVD. }\end{array}$ & I & B & 287-29I \\
\hline $\begin{array}{l}\text { It is recommended to avoid passive } \\
\text { smoking. }\end{array}$ & I & B & 292,293 \\
\hline
\end{tabular}

$\mathrm{CVD}=$ cardiovascular disease

${ }^{a}$ Class of recommendation.

bLevel of evidence.

'Reference(s) supporting recommendations.

\section{3a.4.1 Introduction}

Smoking is a lethal addictive disorder. A lifetime smoker has a $50 \%$ probability of dying due to smoking, and on average will lose 10 
years of life, ${ }^{287}$ contrasting with $<3$ years with severe hypertension and $<1$ year with mild hypertension. ${ }^{288}$ Smoking is an established cause of a plethora of diseases and is responsible for $50 \%$ of all avoidable deaths in smokers, half of these due to CVD. The 10 -year fatal CVD risk is approximately doubled in smokers. The $\mathrm{RR}$ in smokers $<50$ years of age is five-fold higher than in non-smokers. ${ }^{289}$

Slightly less than half of lifetime smokers will continue smoking until death. Approximately $70 \%$ of UK smokers want to stop smoking at some time in the future, ${ }^{290}$ with $\sim 43 \%$ trying to stop in the past year; however, only $2-3 \%$ of the population succeed in stopping. ${ }^{291}$ Even modest and low levels of smoking confer vascular risk. ${ }^{294}$

Although the rate of smoking is declining in Europe, it remains very common and is increasing in women, adolescents and the socially disadvantaged. ${ }^{295}$ Widening education-related inequalities in smoking cessation rates have been observed in many European countries. In the EUROASPIRE IV survey among CAD patients, $16 \%$ smoked after a mean follow-up time of 16 months, and nearly half of the participants who smoked at the time of their coronary event were persistent smokers. The survey also found that evidence-based treatment for smoking cessation was underused. ${ }^{6}$

\section{3a.4.2 Dosage and type}

The risks associated with smoking show a dose-response relationship with no lower limit for deleterious effects. ${ }^{296}$ Duration also plays a role, and while cigarette smoking is the most common, all types of smoked tobacco, including low-tar ('mild' or 'light') cigarettes, filtered cigarettes, cigars and pipes, are harmful. ${ }^{292}$ Smoking is deleterious regardless of how it is done, including by water pipe. Tobacco smoke is more harmful when inhaled, but smokers who claim not to inhale the smoke (e.g. pipe smokers) are also at increased risk of CVD. Smokeless tobacco is also associated with a small but statistically significant increased risk of $\mathrm{Ml}$ and stroke.

\section{3a.4.3 Passive smoking}

Passive smoking increases the risk of CAD. ${ }^{293,297}$ A smoking spouse or workplace exposure increases CVD risk by an estimated $30 \%$. Major health benefits result from reduced environmental tobacco smoke, with public smoking bans in various different geographical locations leading to significant decreases in Ml rates (see section 3c.4).

\section{3a.4.4 Mechanisms by which tobacco smoking increases risk}

Smoking enhances the development of both atherosclerosis and superimposed thrombotic phenomena. Smoking affects endothelial function, oxidative processes, platelet function, fibrinolysis, inflammation, lipid oxidation and vasomotor function. In experimental studies, several of these effects are fully or partly reversible within a very short time. Plaque formation is not thought to be fully reversible and thus smokers would never be expected to reach the risk level of never smokers concerning CVD. Nicotine replacement shows no adverse effect on outcomes in patients with cardiac disease. ${ }^{298,299}$

\section{3a.4.5 Smoking cessation}

The benefits of smoking cessation have a large evidence base. Some advantages are almost immediate; others take more time. CVD risk in former smokers is in between that of current and never smokers.
Stopping smoking after an $\mathrm{Ml}$ is potentially the most effective of all preventive measures: a systematic review and meta-analysis showed reductions in Mls and in the composite endpoints of death/MI (RR 0.57 and 0.74 , respectively) compared with continued smoking. ${ }^{300}$ The benefit is consistent over gender, duration of follow-up, study site and time period. Significant morbidity reductions occur within the first 6 months. ${ }^{301}$ Randomized trials also support smoking cessation, with the risk of CVD approaching (but never equalling) the risk of never smokers within 10-15 years.

Smoking reduction has not been shown to increase the probability of future smoking cessation, but some advocate nicotine-assisted smoking reduction in smokers unable or unwilling to quit. Quitting must be encouraged in all smokers (Table 11). There is no age limit to the benefits of smoking cessation. Passive smoking should also be avoided.

Professional support can increase the odds of stopping [RR 1.66 $(95 \% \mathrm{Cl} 1.42,1.94)]{ }^{302}$ An impetus for smoking cessation occurs at the time of diagnosing or (invasive) treatment of CVD. Prompting a person to try to quit, brief reiteration of $\mathrm{CV}$ and other health hazards and agreeing on a specific plan with a follow-up arrangement are evidence-based interventions (see Figure $K$ in web addenda).

Smoking cessation programmes initiated during hospital admission should continue for a prolonged period after discharge. A smoking history including daily tobacco consumption and degree of addiction (most commonly assessed by the Fagerström test ${ }^{302}$ ) may guide the degree of support and pharmacological aids. Smokers should be advised about expected weight gain of, on average, $5 \mathrm{~kg}$ and that the health benefits of tobacco cessation far outweigh the risks from weight gain.

\section{3a.4.6 Evidence-based drug interventions}

Following the failure of advice, encouragement and motivational interventions, or in addition to them, NRT, varenicline or bupropion should be offered to assist cessation. ${ }^{285}$ All forms of NRT (chewing gum, transdermal nicotine patches, nasal spray, inhaler, sublingual tablets) are effective: in a systematic review, the RR for abstinence with NRT vs. control was 1.60; NRTs increase the rate of quitting by $50-70 \%$, regardless of setting. ${ }^{303}$

The antidepressant bupropion aids long-term smoking cessation with a similar efficacy to NRT. ${ }^{286}$ A meta-analysis of 44 trials

Table I I The "Five As" for a smoking cessation strategy for routine practice

\begin{tabular}{|l|l|}
\hline A-ASK: & $\begin{array}{l}\text { Systematically inquire about smoking status at } \\
\text { every opportunity. }\end{array}$ \\
\hline A-ADVISE: & Unequivocally urge all smokers to quit. \\
\hline A-ASSESS: & $\begin{array}{l}\text { Determine the person's degree of addiction and } \\
\text { readiness to quit }\end{array}$ \\
\hline A-ASSIST: & $\begin{array}{l}\text { Agree on a smoking cessation strategy, including } \\
\text { setting a quit date, behavioural counselling, and } \\
\text { pharmacological support. }\end{array}$ \\
\hline A-ARRANGE: & Arrange a schedule of follow-up. \\
\hline
\end{tabular}


comparing long-term cessation rates using bupropion vs. control yielded a relative success rate of 1.62. ${ }^{283}$ Bupropion carries a known risk of seizures (reported as $\sim 1 / 1000$ users), ${ }^{286}$ without increased risks of neuropsychiatric or heart and circulatory problems. Overall, NRT and bupropion help $\sim 80 \%$ more people to quit than placebo; this means that for every 10 people who quit with placebo, $\sim 18$ could be expected to quit with NRT or with bupropion. ${ }^{285}$

The partial nicotine receptor agonist varenicline at the standard dose increases the chances of quitting more than two-fold compared with placebo (14 trials, 6166 people). ${ }^{283}$ The number of people stopping smoking with varenicline is higher than with bupropion (three trials, 1622 people). Varenicline more than doubles the chances of quitting compared with placebo, so that for every 10 who quit with placebo, $\sim 28$ could be expected to quit with varenicline. Varenicline helps $\sim 50 \%$ more people to quit than nicotine patch and 'other' NRTs (tablets, sprays, lozenges and inhalers) and $\sim 70 \%$ more people than nicotine gum. So for every 10 people who quit with an NRT patch or with 'other' NRTs, $\sim 15$ would be expected to quit with varenicline, and for every 10 who quit with NRT gum, $\sim 17$ would be expected to quit with varenicline. ${ }^{285}$

Low-dose varenicline (four trials, 1272 people) roughly doubles the chances of quitting and reduces the number and severity of side effects. The main side effect of varenicline is nausea, but this is mostly mild or moderate and usually subsides over time. ${ }^{285}$ Although concerns have been raised, retrospective cohort studies and an $\mathrm{RCT}^{304}$ indicate no severe adverse events with varenicline in the setting of ACS patients, with the large EVITA trial in ACS ongoing.

Clonidine has helped people to quit, but causes side effects and is therefore a second-line agent. It is not clear whether mecamylamine used with NRT helps people to quit. Other treatments did not seem to help. So far, nicotine vaccines are not licensed for use anywhere in the world. 285

Combining two types of NRT is as effective as using varenicline, and helps more people to quit than a single type of NRT. ${ }^{285}$

\section{3a.4.7 Electronic cigarettes}

Electronic cigarettes (e-cigarettes) are battery-operated devices that simulate combustible cigarettes by heating nicotine and other chemicals into a vapour that is inhaled. Electronic cigarettes deliver the addictive nicotine without the vast majority of tobacco chemicals, and are probably less harmful than tobacco. ${ }^{305}$

Evidence on the effectiveness of e-cigarettes is limited due to the small number of trials, low event rates and wide confidence intervals. ${ }^{306}$ Data from some observational studies and a randomized trial suggest that the efficacy of first-generation e-cigarettes is similar to that of transdermal NRT patches ${ }^{307}$ or NRT inhalers. ${ }^{308}$ The benefit may come from low nicotine delivery or just the non-nicotine behavioural components of e-cigarette use. About $6 \%$ of former smokers who used e-cigarettes daily relapsed to smoking after 1 month and $6 \%$ after 1 year, and nearly half of dual users of both tobacco and e-cigarettes stopped smoking after 1 year, indicating that e-cigarette use might be effective in relapse prevention and smoking cessation. ${ }^{309}$ These studies and real-world data indicate that e-cigarettes are moderately effective as smoking cessation and harm reduction aids, but that a significant component of that effect is due to changes in behaviour rather than in nicotine delivery. Recent evidence indicates that e-cigarettes, as currently being used, are associated with significantly less quitting among smokers. ${ }^{310}$ Although no safety issues have been observed in the short term (2 years), determining the long-term health effects of e-cigarettes (and in particular dual use with cigarettes) will require more research. ${ }^{305}$

\section{3a.4.8 Other smoking cessation interventions}

Both individual and group behavioural interventions are effective in helping smokers quit. Support from the individual's partner and family is important. There are no reliable data that acupuncture, acupressure, laser therapy, hypnotherapy or electrostimulation are effective for smoking cessation.

\section{Gap in evidence}

- More efficient, safe and cost-effective smoking cessation aids are required.

\section{3a.5 Nutrition}

\section{Key messages}

- Dietary habits influence the risk of CVD and other chronic diseases such as cancer.

- Energy intake should be limited to the amount of energy needed to maintain (or obtain) a healthy weight, that is, a BMI $>20.0$ but $<25.0 \mathrm{~kg} / \mathrm{m}^{2}$.

- In general, when following the rules for a healthy diet, no dietary supplements are needed.

\section{Recommendation on nutrition}

\begin{tabular}{|l|c|c|c|}
\hline Recommendation & Class $^{\text {a }}$ & Level $^{\text {b }}$ & Ref $^{\mathbf{c}}$ \\
\hline $\begin{array}{l}\text { A healthy diet is recommended as a } \\
\text { cornerstone of CVD prevention in all } \\
\text { individuals. }\end{array}$ & $\mathbf{I}$ & $\mathbf{B}$ & $31 \mathrm{I}$ \\
\hline
\end{tabular}

CVD $=$ cardiovascular disease

${ }^{\mathrm{a} C}$ Class of recommendation.

'Level of evidence.

${ }^{\mathrm{C}}$ Reference(s) supporting recommendations.

\section{3a.5.1 Introduction}

Dietary habits influence $\mathrm{CV}$ risk, either through an effect on risk factors such as cholesterol, BP, body weight and DM, or through other effects. ${ }^{311}$ Table 12 summarizes the characteristics of a healthy diet.

Most evidence on the relation between nutrition and CVD is based on observational studies; randomized clinical trials estimating the impact of diet on endpoints are scarce. The impact of diet is studied on three levels: specific nutrients, specific foods/food groups and specific dietary patterns, of which the Mediterranean diet is the most studied.

The nutrients of interest with respect to CVD are fatty acids (which mainly affect lipoprotein levels), minerals (which mainly affect BP), vitamins and fibre.

\section{3a.5.2 Fatty acids}

For prevention of CVD, the types of fatty acids consumed are more important than the total fat content. 


\section{Table I 2 Healthy diet characteristics}

\begin{tabular}{|c|}
\hline $\begin{array}{l}\text { - Saturated fatty acids to account for }<10 \% \text { of total energy intake, } \\
\text { through replacement by polyunsaturated fatty acids. }\end{array}$ \\
\hline $\begin{array}{l}\text { - Trans unsaturated fatty acids: as little as possible, preferably no intake } \\
\text { from processed food, and }<1 \% \text { of total energy intake from natural origin. }\end{array}$ \\
\hline - $<5 \mathrm{~g}$ of salt per day. \\
\hline - $30-45 \mathrm{~g}$ of fibre per day, preferably from wholegrain products. \\
\hline - $\geq 200$ g of fruit per day (2-3 servings). \\
\hline - $\geq 200 \mathrm{~g}$ of vegetables per day ( $2-3$ servings). \\
\hline - Fish I-2 times per week, one of which to be oily fish. \\
\hline - 30 grams unsalted nuts per day. \\
\hline $\begin{array}{l}\text { - Consumption of alcoholic beverages should be limited to } 2 \text { glasses per } \\
\text { day ( } 20 \mathrm{~g} / \mathrm{d} \text { of alcohol) for men and I glass per day ( } 10 \mathrm{~g} / \mathrm{d} \text { of alcohol) } \\
\text { for women. }\end{array}$ \\
\hline $\begin{array}{l}\text { - Sugar-sweetened soft drinks and alcoholic beverages consumption } \\
\text { must be discouraged. }\end{array}$ \\
\hline
\end{tabular}

The risk of CAD is reduced by $2-3 \%$ when $1 \%$ of energy intake from saturated fatty acids is replaced by polyunsaturated fatty acids. The same has not been clearly shown for replacement with carbohydrates and monounsaturated fatty acids (MUFAs). Saturated fatty acid intake should be reduced to a maximum of $10 \%$ of energy intake by replacing it with polyunsaturated fatty acids. ${ }^{312}$

MUFAs have a favourable effect on HDL-C levels when they replace saturated fatty acids or carbohydrates, ${ }^{313}$ but there is little evidence that MUFAs lower CAD risk.

Polyunsaturated fatty acids lower LDL-C levels, and to a lesser extent HDL-C levels, when they replace saturated fatty acids. The polyunsaturated fatty acids can be divided into two subgroups: omega- 6 fatty acids, mainly from plant foods, and omega- 3 fatty acids, mainly from fish oils and fats. Within the subclass of omega- 3 fatty acids, eicosapentaenoic acid and docosahexaenoic acid (EPA/ DHA) are especially important. They do not change serum cholesterol levels and, with currently available cardioprotective therapies, it is debatable whether they exert a favourable effect on all-cause, CAD, and stroke mortality. ${ }^{314,315}$

The trans fatty acids, a subclass of unsaturated fatty acids, have been shown to be especially harmful due to their unfavourable impact on both total cholesterol (increase) and HDL-C (decrease). These fatty acids are formed during industrial processing (hardening) of fats and are present in, for example, margarine and bakery products. A meta-analysis of prospective cohort studies has shown that, on average, a $2 \%$ increase in energy intake from trans fatty acids increases CAD risk by $23 \% .{ }^{316}$ It is recommended to derive $<1 \%$ of total energy intake from trans fatty acids - the less the better.

The impact of dietary cholesterol on serum cholesterol levels is weak compared with that of the fatty acid composition of the diet. When guidelines are followed to lower saturated fat intake, this usually also leads to a reduction in dietary cholesterol intake. Therefore, some guidelines (including this one) on healthy diet do not give specific guidelines on the intake of dietary cholesterol; others recommend a limited intake of $<300 \mathrm{mg} /$ day.

\section{3a.5.3 Minerals}

A meta-analysis estimated that even a modest reduction in sodium intake of $1 \mathrm{~g} /$ day reduces SBP by $3.1 \mathrm{mmHg}$ in hypertensive patients and $1.6 \mathrm{mmHg}$ in normotensive patients. ${ }^{317}$ The Dietary Approaches to Stop Hypertension (DASH) trial showed a dose-response relation between sodium reduction and $\mathrm{BP}$ reduction. ${ }^{318}$ In most western countries, salt intake is high ( $\sim 9-10 \mathrm{~g} /$ day), whereas the recommended maximum intake is $5 \mathrm{~g} /$ day. Optimal intake levels might be as low as $\sim 3 \mathrm{~g} /$ day. Although the relation between salt intake and BP remains controversial, the totality of evidence warrants salt reduction as an important way to prevent CAD and stroke. On average, $80 \%$ of salt intake comes from processed foods, while only $20 \%$ is added later on. Salt reduction can be achieved by making different dietary choices (fewer processed foods, more basic foods) and the reformulation of foods (lowering salt content) (see Chapter 3c.2).

Potassium has favourable effects on BP. The main sources of potassium are fruits and vegetables. An inverse statistically significant association exists between potassium intake and the risk of incident stroke $[R R 0.76(95 \% \mathrm{Cl} 0.66,0.89)] .{ }^{319}$ Apart from reducing sodium intake, increasing potassium intake contributes to the lowering of BP.

\section{3a.5.4 Vitamins}

Many case-control and prospective observational studies have observed inverse associations between levels of vitamin $A$ and $E$ and the risk of CVD. However, intervention trials have failed to confirm these observational studies. Also, for the B vitamins (B6, folic acid and B12) and vitamin C, trials have shown no beneficial effects.

In the bottom tertile of serum levels of vitamin D, CV and total mortality is $35 \%$ higher [RR $1.35(95 \% \mathrm{Cl} 1.13,1.61)]$ than in the highest tertile. ${ }^{320}$ A $41 \%$ higher risk of CV mortality [RR 1.41 $(95 \% \mathrm{Cl} 1.18,1.68)]$ and $57 \%$ higher risk of all-cause mortality [RR $1.57(95 \% \mathrm{Cl} 1.36,1.81)]$ has been reported in the lowest vs. highest quintile. ${ }^{321}$ A much smaller effect was observed in RCTs: an 11\% risk reduction in all-cause mortality was observed for vitamin D3 supplementation [RR 0.89 (95\% Cl 0.80, 0.99)], but not for vitamin D2 supplementation. ${ }^{320}$ Due to a lack of power, it was not possible to look at CV mortality specifically. Therefore, conclusions about vitamin D supplementation [type of supplement (D2 or D3), dosage and duration] for $\mathrm{CV}$ prevention cannot yet be drawn.

\section{3a.5.5. Fibre}

Recent meta-analyses of prospective cohort studies show that a $7 \mathrm{~g} /$ day higher intake of total fibre is associated with a $9 \%$ lower risk of CAD [RR $0.91(95 \% \mathrm{Cl} 0.87,0.94)]^{322}$ and a $10 \mathrm{~g} /$ day higher fibre intake is associated with a $16 \%$ lower risk of stroke [RR $0.84(95 \%$ $\mathrm{Cl} 0.75,0.94)]^{323}$ and a $6 \%$ lower risk of type $2 \mathrm{DM}[\mathrm{RR} 0.94(95 \% \mathrm{Cl}$ $0.91,0.97)]^{324}$ There is no evidence yet for a similar association with fibre from fruits and vegetables. Although the mechanism has not been elucidated completely, it is known that a high fibre intake reduces postprandial glucose responses after carbohydrate-rich meals and lowers total cholesterol and LDL-C levels. 


\section{3a.5.6 Foods and food groups}

3a.5.6.1 Fruits and vegetables

Prospective cohort studies have shown a protective effect of the consumption of fruits and vegetables on CVD, but RCTs are scarce. A meta-analysis reported a decrease of $4 \%$ [RR $0.96(95 \% \mathrm{Cl} 0.92$, 0.99)] in CV mortality for each additional serving of fruits (equivalent to $77 \mathrm{~g}$ ) and vegetables (equivalent to $80 \mathrm{~g}$ ) per day, while all-cause mortality did not reduce further with intakes of more than five servings. ${ }^{325} \mathrm{~A}$ meta-analysis reported a risk reduction for stroke of $11 \%$ [RR 0.89 (95\% $\mathrm{Cl} 0.83,0.97)]$ for three to five daily servings of fruits and vegetables and of $26 \%$ [RR $0.74(95 \% \mathrm{Cl} 0.69,0.79)$ ] for more than five servings compared with less than three servings. ${ }^{326}$ A meta-analysis on CAD reported a 4\% decrease in CAD risk [RR $0.96(95 \% \mathrm{Cl} 0.93$, 0.99)] for each additional serving of fruits and vegetables per day. ${ }^{327}$

\section{3a.5.6.2 Nuts}

A meta-analysis of prospective cohort studies has shown that daily consumption of $30 \mathrm{~g}$ of nuts reduces the risk of CVD by $\sim 30 \%$ [RR $0.71(95 \% \mathrm{Cl} 0.59,0.85)]{ }^{328}$ It must be noted that the energy density of nuts is high.

\section{3a.5.6.3 Fish}

The protective effect of fish on CVD is attributed to the n-3 fatty acid content. Pooled risk estimates from prospective cohort studies show that eating fish at least once a week results in a $16 \%$ reduction in the risk of CAD [RR $0.85(95 \% \mathrm{Cl} 0.75,0.95)]$ compared with eating less fish. ${ }^{329}$ A recent meta-analysis showed that eating fish two to four times a week reduces the risk of stroke by $6 \%$ [RR $0.94(95 \% \mathrm{Cl}$ $0.90,0.98)$ ] compared with eating fish less than once a week. ${ }^{330}$ The relation between fish intake and CV risk is not linear. Especially in the range of no or very low intake, risk is increased. The public health impact of a small increase in fish consumption in the general population is therefore potentially large.

For fish oil, three randomized controlled prevention trials have been published. All three trials, in post-AMI or CAD patients who received an extra amount of 400-1000 g EPA/DHA daily, did not observe a reduction in $\mathrm{CV}$ events in the intervention group. A recent meta-analysis of 20 trials, mostly prevention of recurrent CV events and mostly using fish oil supplements, showed no benefit of fish oil supplementation on CV outcomes. ${ }^{315}$

\section{3a.5.6.4 Alcoholic beverages}

Drinking three or more alcoholic beverages per day is associated with elevated CVD risk. Results from epidemiological studies suggest a lower risk of CVD occurring with moderate (one to two units per day) alcohol consumption compared with non-drinkers. This association appears not to be explained by special characteristics of abstainers, ${ }^{331}$ although the potential for residual confounding and reverse causality cannot be fully excluded. Moreover, a recent Mendelian randomization study including analyses from 59 epidemiological studies has shed doubt on any beneficial effect of moderate alcohol consumption, ${ }^{332}$ suggesting that the lowest risks for CV outcomes were in abstainers and that any amount of alcohol is associated with elevated BP and BMI.

\section{3a.5.6.5 Soft drinks and sugar}

Sugar-sweetened soft drinks are the largest single food source of calories in the US diet and are important in Europe. In children and adolescents, beverages may now even account for $10-15 \%$ of the calories consumed. Regular consumption of soft drinks has been associated with overweight, metabolic syndrome and type 2 DM. Substitution of sugar-sweetened soft drinks with artificially sweetened drinks resulted in less weight gain in children over an 18-month period. ${ }^{333}$ Sugar-sweetened beverages also cause weight gain in adults. Regular consumption of sugar-sweetened beverages (i.e. two servings per day compared with one serving per month) was associated with a $35 \%$ higher risk of CAD in women, even after other unhealthy lifestyle and dietary factors were accounted for, whereas artificially sweetened beverages were not associated with CAD. The $\mathrm{WHO}$ guideline recommends a maximum intake of $10 \%$ of energy from sugar (mono- and disaccharides), which includes added sugars as well as sugars present in fruits and fruit juices. ${ }^{334}$

\section{3a.5.7 Functional foods}

Functional foods containing phytosterols (plant sterols and stanols) are effective in lowering LDL-C levels by an average of $10 \%$ when consumed in amounts of $2 \mathrm{~g} /$ day. The cholesterol-lowering effect is in addition to that obtained with a low-fat diet or use of statins. Further cholesterol reduction can be obtained with higher doses of phytosterols. ${ }^{335}$ No studies with clinical endpoints have been performed yet.

\section{3a.5.8 Dietary patterns}

Studying the impact of a total dietary pattern theoretically shows the full preventive potential of diet since it yields a combined estimate of the impact of several favourable dietary habits. The Mediterranean diet comprises many of the nutrients and foods that have been discussed previously: high intake of fruits, vegetables, legumes, wholegrain products, fish and unsaturated fatty acids (especially olive oil); moderate consumption of alcohol (mostly wine, preferably consumed with meals) and low consumption of (red) meat, dairy products and saturated fatty acids. A meta-analysis of prospective cohort studies has demonstrated that greater adherence to a Mediterranean diet is associated with a $10 \%$ reduction in CV incidence or mortality [pooled RR 0.90 (95\% Cl 0.87 , $0.93)$ ] and an $8 \%$ reduction in all-cause mortality [pooled $R R$ $0.92(95 \% \mathrm{Cl} 0.90,0.94)] .{ }^{336} \mathrm{An} \mathrm{RCT}$ in high-risk individuals suggested that following a Mediterranean diet over a 5 year period, compared with a control diet, was related to a $29 \%$ lower risk of CVD [RR $0.71(95 \% \mathrm{Cl} 0.56,0.90)]^{337}$

\section{Gaps in evidence}

- The biggest challenge in dietary prevention of CVD is to develop more effective strategies to make people change their diet (both quantitatively and qualitatively) and to maintain that healthy diet and a normal weight.

- Research into the substances in foods that underlie the protective effects is ongoing.

\section{3a.6 Body weight}

\section{Key messages}

- Both overweight and obesity are associated with an increased risk of CVD death and all-cause mortality. All-cause mortality is lowest with a BMI of $20-25 \mathrm{~kg} / \mathrm{m}^{2}$ (in those $<60$ years of age); further weight reduction cannot be considered protective against CVD. 
- Healthy weight in the elderly is higher than in the young and middle-aged.

- Achieving and maintaining a healthy weight has a favourable effect on metabolic risk factors (BP, blood lipids, glucose tolerance) and lower CV risk.

\section{Recommendation for body weight}

\begin{tabular}{|l|c|c|c|}
\hline Recommendation & Class $^{\mathrm{a}}$ & Level $^{\mathrm{b}}$ & Ref $^{\mathrm{c}}$ \\
\hline $\begin{array}{l}\text { It is recommended that subjects } \\
\text { with healthy weight } \\
\text { their weight. It is recommended } \\
\text { that overweight and obese people } \\
\text { achieve a healthy weight (or aim for } \\
\text { a reduction in weight) in order to } \\
\text { reduce BP, dyslipidaemia and risk } \\
\text { of developing type 2 DM, and thus } \\
\text { improve the CV risk profile. }\end{array}$ & & & \\
\end{tabular}

$\mathrm{BP}=$ blood pressure; $\mathrm{CVD}=$ cardiovascular disease; $\mathrm{DM}=$ diabetes mellitus

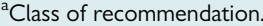

bLevel of evidence.

'Reference(s) supporting recommendations.

${ }^{d} \mathrm{BMI} 20-25 \mathrm{~kg} / \mathrm{m}^{2}$. There is evidence that optimal weight in elderly is higher than in the young and middle-aged. ${ }^{339}$

\section{3a.6.1 Introduction}

In many countries, favourable trends in major risk factors such as blood cholesterol, BP and smoking prevalence have been observed, translating into reduced CV mortality. However, BMI has greatly increased in all countries over recent decades, resulting in a concomitant increase in the prevalence of type $2 \mathrm{DM}$. In the USA, it has been projected that if obesity trends from 2005 to 2020 continue, obesity will increasingly offset the positive effects of declining smoking rates. ${ }^{340}$ The main clinical complications of increasing body weight are increases in BP, dyslipidaemia, insulin resistance, systemic inflammation and prothrombotic state and albuminuria and the development of DM and $C V$ events (HF, CAD, AF, stroke).

\section{3a.6.2 Which index of obesity is the best predictor of cardiovascular risk?}

BMI [weight $(\mathrm{kg}) /$ height $\left(\mathrm{m}^{2}\right)$ ] can be measured easily and is used extensively to define categories of body weight (see Table $C$ in the web addenda). ${ }^{341}$ In addition to the amount of body fat, its distribution is important. Body fat stored in the abdomen (intra-abdominal fat) carries a higher risk than subcutaneous fat.

Several measures of body fatness are available (see Table $D$ in the web addenda). Most data are available for BMI, waist:hip circumference ratio and simple waist circumference. The optimal level for measurement of waist circumference is midway from the lower rib margin to the anterior superior iliac crest, in the standing position. The WHO thresholds for waist circumference are the most widely accepted in Europe. Based on these thresholds, two action levels are recommended:

(i) waist circumference $\geq 94 \mathrm{~cm}$ in men and $\geq 80 \mathrm{~cm}$ in women represents the threshold at which no further weight should be gained and (ii) waist circumference $\geq 102 \mathrm{~cm}$ in men and $\geq 88 \mathrm{~cm}$ in women represents the threshold at which weight reduction should be advised.

These thresholds have been calculated based on Caucasians, and it is apparent that different cut-offs for anthropometric measurements are required in different races and ethnicities. A meta-analysis concluded that both $\mathrm{BMI}$ and waist circumference are similarly strong and continuously associated with CVD and type 2 DM. ${ }^{342}$ Therefore, BMI generally suffices in routine practice.

\section{3a.6.3 Does 'metabolically healthy obesity' exist?}

The phenotype of 'metabolically healthy obesity' ( $\mathrm{MHO}$ ), defined by the presence of obesity in the absence of metabolic risk factors, has gained a lot of interest. Some studies argue that a specific subgroup of obese individuals is resistant to metabolic complications such as arterial hypertension and insulin resistance. However, $\mathrm{MHO}$ individuals present a higher all-cause mortality compared with normal weight metabolically healthy individuals. ${ }^{343,344}$ Long-term results from the Whitehall study support the notion that $\mathrm{MHO}$ is a transient phase ${ }^{345}$ moving towards glucometabolic abnormalities rather than a specific 'state'.

\section{3a.6.4 The obesity paradox in established heart disease} At the population level, obesity is associated with CVD risk. However, among those with established CAD, the evidence is contradictory. Systematic reviews of patients with CAD or undergoing percutaneous coronary intervention have suggested an 'obesity paradox' whereby obesity appears protective. ${ }^{338,346}$ This is also the case for HF patients. However, this evidence should not be misinterpreted to recommend higher target BMls for those with established CVD since reverse causality may be operating. Cardiorespiratory fitness might influence relationships between adiposity and clinical prognosis in the obesity paradox. Normal weight unfit individuals have a higher risk of mortality than fit individuals, regardless of their BMI. Overweight and obese fit individuals have mortality risks similar to normal weight fit individuals. ${ }^{347}$ Furthermore, the results of the EPIC study suggest that the influence of physical inactivity on mortality appears to be greater than that of high BMI. ${ }^{348}$

\section{3a.6.5 Treatment goals and modalities}

CVD risk has a continuous positive relationship with $\mathrm{BMI}$ and other measures of body fat. Because all-cause mortality appears to increase at BMI levels $<20,{ }^{339}$ we do not recommend such low BMI levels as treatment goals.

Although diet, exercise and behaviour modifications are the mainstay therapies for overweight and obesity, they are often unsuccessful for long-term treatment. Medical therapy with orlistat and/or bariatric surgery are additional options. A recent meta-analysis indicates that patients undergoing bariatric surgery have a reduced risk of MI, stroke, $\mathrm{CV}$ events and mortality compared with non-surgical controls. ${ }^{349}$

\section{Gaps in evidence}

- Knowledge and implementation of effective strategies to achieve weight loss and maintain a long-term healthy weight.

- Identification of the relative roles of diet, exercise and behaviour modification in the management of overweight and obese people.

- The optimal level of BMI over the life course (at older ages and after a CV event). 


\section{3a.7 Lipid control}

\section{Key messages}

- Elevated levels of plasma LDL-C are causal to atherosclerosis.

- Reduction of LDL-C decreases CV events.

- Low HDL-C is associated with increased CV risk, but manoeuvres to increase HDL-C have not been associated with a decreased CV risk.

- Lifestyle and dietary changes are recommended for all.

- Total CV risk should guide the intensity of the intervention.

- Total cholesterol and HDL-C are adequately measured on nonfasting samples, thus allowing non-HDL-C to be derived.

\section{Recommendations for lipid control}

\begin{tabular}{|c|c|c|c|}
\hline Recommendations $^{\text {de }}$ & Class $^{a}$ & Level $^{b}$ & $\operatorname{Ref}^{c}$ \\
\hline $\begin{array}{l}\text { In patients at VERY HIGH CV risk, } \\
\text { an } \mathrm{LDL}-\mathrm{C} \text { goal }<1.8 \mathrm{mmol} / \mathrm{L} \\
(<70 \mathrm{mg} / \mathrm{dL}) \text {, or a reduction of at } \\
\text { least } 50 \% \text { if the baseline is between } \\
1.8 \text { and } 3.5 \mathrm{mmol} / \mathrm{L}(70 \text { and } 135 \mathrm{mg} / \\
\mathrm{dL} \text { ) is recommended. }\end{array}$ & I & B & $350-353$ \\
\hline $\begin{array}{l}\text { In patients at HIGH CV risk, an } \\
\mathrm{LDL}-\mathrm{C} \text { goal }<2.6 \mathrm{mmol} / \mathrm{L} \\
(<100 \mathrm{mg} / \mathrm{dL}) \text {, or a reduction of at } \\
\text { least } 50 \% \text { if the baseline is between } \\
2.6 \text { and } 5.1 \mathrm{mmol} / \mathrm{L} \text { ( } 100 \text { and } \\
200 \mathrm{mg} / \mathrm{dL} \text { ) is recommended. }\end{array}$ & I & B & $350-353$ \\
\hline $\begin{array}{l}\text { In the remaining patients on LDL-C } \\
\text { lowering treatment, an LDL-C goal } \\
<3.0 \mathrm{mmol} / \mathrm{L}(<115 \mathrm{mg} / \mathrm{dL}) \text { should be } \\
\text { considered. }\end{array}$ & Ila & C & $350-353$ \\
\hline
\end{tabular}

$\mathrm{CV}=$ cardiovascular; $\mathrm{HDL}-\mathrm{C}=$ high-density lipoprotein cholesterol;

LDL-C = low-density lipoprotein cholesterol.

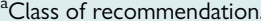

bevel of evidence.

'Reference(s) supporting recommendations.

${ }^{\mathrm{d}}$ Non-HDL-C is a reasonable and practical alternative target because it does not require fasting. Non HDL-C secondary targets of $<2.6,<3.3$ and $<3.8 \mathrm{mmol} / \mathrm{L}$ $(<100,<130$ and $<145 \mathrm{mg} / \mathrm{dL})$ are recommended for very high, high and low to moderate risk subjects, respectively See section 3a.7.10 for more details.

${ }^{\mathrm{e}} \mathrm{A}$ view was expressed that primary care physicians might prefer a single LDL-C goal of $2.6 \mathrm{mmol} / \mathrm{L}(100 \mathrm{mg} / \mathrm{dL})$. While accepting the simplicity of this approach and that it could be useful in some settings, there is better scientific support for the three targets matched to level of risk.

'This is the general recommendation for those at very high-risk. It should be noted that the evidence for patients with CKD is less strong.

\section{3a.7.1 Introduction}

The crucial role of dyslipidaemia, especially hypercholesterolaemia, in the development of CVD is documented beyond any doubt by genetic, pathology, observational and intervention studies.

In blood plasma, lipids such as cholesterol and triglycerides circulate as lipoproteins in association with various proteins (apolipoproteins). The main carrier of cholesterol in plasma (LDL-C) is atherogenic. The role of triglyceride-rich lipoproteins is currently under active investigation: chylomicrons and large very-low-density lipoproteins (VLDLs) appear not to be atherogenic, but very high concentrations of these triglyceride-rich lipoproteins can cause pancreatitis. Remnant lipoproteins [total cholesterol - (LDL-C +
HDL-C)] have recently been identified in Mendelian randomization studies as pro-atherogenic lipoproteins.

\section{3a.7.2 Total and low-density lipoprotein cholesterol}

Most cholesterol is normally carried in LDL-C. Over a wide range of plasma cholesterol concentrations, there is a strong and graded positive association between total as well as LDL-C and risk of CVD. ${ }^{354}$ This association applies to men and women, and to those without CVD as well as with established CVD.

The evidence that reducing plasma LDL-C reduces CVD risk is unequivocal; the results of epidemiological studies and trials with and without statins using angiographic or clinical endpoints confirm that the reduction of LDL-C is of prime concern in the prevention of CVD. ${ }^{38}$

Meta-analyses of many statin trials show a dose-dependent relative reduction in CVD with LDL-C lowering. Every $1.0 \mathrm{mmol} / \mathrm{L}$ reduction in LDL-C is associated with a corresponding 20-25\% reduction in CVD mortality and non-fatal MI. $^{350}$

\section{3a.7.3 Apolipoprotein B}

Apolipoprotein B (apoB; the main apoprotein of atherogenic lipoproteins) levels have also been measured in outcome studies in parallel with LDL-C. ${ }^{355}$ Based on the available evidence, it appears that apoB is a similar risk marker to LDL-C. ${ }^{356}$ Also, there appears to be less laboratory error in the determination of apoB than LDL-C, particularly in patients with marked hypertriglyceridaemia [ $>3.4 \mathrm{mmol} / \mathrm{L}(>300 \mathrm{mg} / \mathrm{dL})]$, but there is no evidence that apoB is a better predictor of CVD than LDL-C. ${ }^{357}$

\section{3a.7.4 Triglycerides}

Hypertriglyceridaemia is a significant independent CVD risk factor, but the association is far weaker than for hypercholesterolaemia. ${ }^{358}$ The risk is associated more strongly with moderate than with very severe hypertriglyceridaemia [ $>10 \mathrm{mmol} / \mathrm{L}(>\sim 900 \mathrm{mg} / \mathrm{dL})]$, which is a risk factor for pancreatitis. There are, however, no randomized trials to provide sufficient evidence to derive target levels for triglycerides. Meta-analyses suggest that targeting triglycerides may reduce CVD in specific subgroups with high triglycerides and low HDL-C. At present, fasting triglycerides $>1.7 \mathrm{mmol} / \mathrm{L}$ ( $>$ $\sim 150 \mathrm{mg} / \mathrm{dL}$ ) continue to be considered a marker of increased risk, but concentrations $\leq 1.7 \mathrm{mmol} / \mathrm{L}$ are not evidence-based target levels for therapy.

\section{3a.7.5 High-density lipoprotein cholesterol}

Low HDL-C is independently associated with higher CVD risk. ${ }^{359}$ Low HDL-C may even rival hypercholesterolaemia (due to high concentrations of LDL-C) as a risk factor for CAD. ${ }^{360}$ The combination of moderately elevated triglycerides and low concentrations of HDL-C is very common in patients with type $2 \mathrm{DM}$, abdominal obesity and insulin resistance and in those who are physically inactive. This lipid pattern is also characterized by the presence of small, dense, atherogenic LDL particles. An HDL-C level $<1.0 \mathrm{mmol} / \mathrm{L}(<40 \mathrm{mg} / \mathrm{dL})$ in men and $<1.2 \mathrm{mmol} / \mathrm{L}(<45 \mathrm{mg}$ ) $\mathrm{dL}$ ) in women may be regarded as a marker of increased risk. Recent Mendelian randomization studies, however, cast doubt on the causal role of HDL-C in CVD. ${ }^{361}$ Physical activity and other lifestyle factors, rather than drug treatment, remain important means of increasing HDL-C levels. 


\section{3a.7.6 Lipoprotein(a)}

Lipoprotein(a) $[L p(a)]$ is a low-density lipoprotein to which an additional protein called apolipoprotein(a) is attached. High concentrations of $L P(a)$ are associated with increased risk of CAD and ischaemic stroke and Mendelian randomization studies support a causal role in CVD for $L p(a)$. There is no randomized intervention study showing that reducing Lp(a) decreases CVD risk. ${ }^{362}$ At present there is no justification for screening the general population for $\operatorname{Lp}(\mathrm{a})$, but it may be considered in patients at moderate risk to refine risk evaluation or in subjects with a family history of early CVD.

\section{3a.7.7 Apolipoprotein B/apolipoprotein A1 ratio}

Apolipoprotein A1 (apoA1) is the major apoprotein of high-density lipoprotein. It is beyond doubt that the apoB:apoA1 ratio is one of the strongest risk markers. ${ }^{112,355}$ However, there is insufficient evidence to support this variable as a treatment goal. Since the measurement of apolipoproteins is not available to all physicians in Europe, is more costly than currently used lipid variables and only adds moderately to the information derived from currently applied lipid parameters, its use is not recommended.

\section{3a.7.8 Calculated lipoprotein variables}

3a.7.8.1 Low-density lipoprotein cholesterol

LDL-C can be measured directly, but in most studies and in many laboratories LDL-C is calculated using the Friedewald formula: ${ }^{363}$

- In mmol/L: LDL-C = total cholesterol - HDL-C - $(0.45 \times$ triglycerides)

- In mg/dL: LDL-C = total cholesterol - HDL-C - $(0.2 \times$ triglycerides)

The calculation is valid only when the concentration of triglycerides is $<4.5 \mathrm{mmol} / \mathrm{L}$ ( $<\sim 400 \mathrm{mg} / \mathrm{dL}$ ). Similar problems may be faced when $\mathrm{LDL}-\mathrm{C}$ is low $[<\sim 1.3 \mathrm{mmol} / \mathrm{L}(<50 \mathrm{mg} / \mathrm{dL})]$. Direct methods may be less sensitive to plasma triglyceride levels. However, recent data show that the direct methods may also be biased when triglyceride levels are high. Also, the values obtained with the different direct methods are not necessarily identical, especially for low and high LDL-C values.

\section{3a.7.8.2 Non-high-density lipoprotein cholesterol}

(accurate in non-fasting samples)

Non-HDL-C comprises the cholesterol in low-density lipoprotein, intermediate-density lipoprotein, remnant and VLDL, thus capturing all the information regarding pro-atherogenic lipoproteins. Non-HDL-C predicts CVD risk even better than LDL-C. ${ }^{351}$ LDL-C limits may be transferred to non-HDL-C limits by adding $0.8 \mathrm{mmol} / \mathrm{L}(30 \mathrm{mg} / \mathrm{dL})$. Calculated by simply subtracting HDL-C from total cholesterol, non-HDL-C, unlike LDL-C, does not require the triglyceride concentration to be $<4.5 \mathrm{mmol} / \mathrm{L}(<400 \mathrm{mg} / \mathrm{dL})$. Therefore, it is certainly a better measure than calculated LDL-C for patients with increased plasma triglyceride concentrations, but also has an additional advantage of not requiring patients to fast before blood sampling. There is evidence for a role of non-HDL-C as a treatment target. ${ }^{364}$ Since non-HDL-C is capturing the information regarding all the atherogenic apoB-containing lipoproteins, we suggest that it is a reasonable alternative treatment goal while acknowledging that it has not been an endpoint in therapeutic trials.

\section{3a.7.8.3 Remnant cholesterol}

Recently the remnant cholesterol [total cholesterol - (HDL-C + LDL-C)] has been shown to be causally related to atherosclerosis in Mendelian randomization studies. This parameter, however, is not suggested as a predictor or main target for therapy and further population data and clinical studies are awaited.

\section{3a.7.9 Exclusion of secondary and familial dyslipidaemia}

The presence of dyslipidaemias secondary to other conditions must be excluded before beginning treatment, as treatment of underlying disease improves hyperlipidaemia without requiring antilipidaemic therapy. This is particularly true for hypothyroidism. Secondary dyslipidaemias can also be caused by alcohol abuse, DM, Cushing's syndrome, diseases of the liver and kidneys and several drugs (e.g. corticosteroids). Patients who could have genetic dyslipidaemias, such as $\mathrm{FH}$, can be identified by extreme lipid abnormalities and/ or family history. If possible, these patients should be referred for specialist evaluation. The treatment recommendations in this guideline may not apply to these specific patients, who are dealt with in detail in the ESC/European Atherosclerosis Society guidelines on dyslipidaemias. ${ }^{38,352}$ An LDL-C $>5.1 \mathrm{mmol} / \mathrm{L}(>200 \mathrm{mg} / \mathrm{dL})$ in therapy-naive patients requires careful evaluation for possible $\mathrm{FH}$. However, in the presence of premature CVD or family history, possible $\mathrm{FH}$ should be considered at lower LDL-C levels.

\section{3a.7.10 Who should be treated and what are the goals?} In general, RCTs are the ideal evidence base for decisional thresholds and treatment goals. For treatment goals, this requires RCTs randomly allocating subjects to different lipid goal levels. However, most evidence in terms of treatment goals is derived from observational studies and from post hoc analyses of RCTs (and meta-regression analyses thereof) randomly allocating different treatment strategies (and not treatment goals). Hence, recommendations reflect consensus based on large-scale epidemiological data and RCTs comparing treatment regimens, not on RCTs comparing different lipid goal levels.

In the past, an LDL-C of $2.6 \mathrm{mmol} / \mathrm{L}(100 \mathrm{mg} / \mathrm{dL})$ has been considered a treatment threshold and goal. This goal remains reasonable for most patients who have an indication for LDL-C-lowering therapy based on calculation of the CV risk (see section 2).

Evidence from trials has suggested that lowering LDL-C to $\leq 1.8 \mathrm{mmol} / \mathrm{L}(<70 \mathrm{mg} / \mathrm{dL})$ is associated with a lower risk of recurrent CVD events. ${ }^{365}$ Therefore, an LDL-C level of $1.8 \mathrm{mmol} / \mathrm{L}$ (70 mg/dL) appears to be a reasonable goal for prevention of recurrent $C V$ events and in other very-high-risk subjects. A treatment goal of an LDL-C reduction of at least $50 \%$ is also recommended if the baseline LDL-C level is $1.8-3.5 \mathrm{mmol} / \mathrm{L}(70-135 \mathrm{mg} / \mathrm{dL})$.

Non-HDL-C target values may be an alternate target if nonfasting samples are obtained, and goals should be $<2.6,<3.3$ and $<3.8 \mathrm{mmol} / \mathrm{L}(<100,<130$ and $<145 \mathrm{mg} / \mathrm{dL})$ with very high, high and low to moderate CV risk, respectively. In addition, this is a secondary goal in people with elevated triglycerides. In the same subjects, although not generally recommended, apoB levels at $<80$ and $<100 \mathrm{mg} / \mathrm{dL}$ can be reasonable goals for subjects with very high and high $\mathrm{CV}$ risk, respectively.

The benefit of cholesterol-lowering therapy depends on initial levels of risk: the higher the risk, the greater the benefit in absolute risk reduction (Table 13). There are no differences in the relative reduction between men and women and between younger and older age or between those with and without DM. ${ }^{366}$ 
Table I 3 Possible intervention strategies as a function of total cardiovascular risk and low-density lipoprotein cholesterol level

\begin{tabular}{|c|c|c|c|c|c|}
\hline \multirow{2}{*}{$\begin{array}{c}\text { Total CV risk } \\
\text { (SCORE) } \\
\%\end{array}$} & \multicolumn{5}{|c|}{ LDL-C levels } \\
\hline & $\begin{array}{c}<70 \mathrm{mg} / \mathrm{dL} \\
<1.8 \mathrm{mmol} / \mathrm{L}\end{array}$ & $\begin{array}{l}70 \text { to }<100 \mathrm{mg} / \mathrm{dL} \\
1.8 \text { to }<2.6 \mathrm{mmol} / \mathrm{L}\end{array}$ & $\begin{array}{l}100 \text { to }<155 \mathrm{mg} / \mathrm{dL} \\
2.6 \text { to }<4.0 \mathrm{mmol} / \mathrm{L}\end{array}$ & $\begin{array}{l}155 \text { to }<190 \mathrm{mg} / \mathrm{dL} \\
4.0 \text { to }<4.9 \mathrm{mmol} / \mathrm{L}\end{array}$ & $\begin{array}{l}\geq 190 \mathrm{mg} / \mathrm{dL} \\
\geq 4.9 \mathrm{mmol} / \mathrm{L}\end{array}$ \\
\hline$<1$ & Lifestyle advice & Lifestyle advice & Lifestyle advice & Lifestyle advice & $\begin{array}{l}\text { Lifestyle advice, } \\
\text { consider drug if } \\
\text { uncontrolled }\end{array}$ \\
\hline Class $^{\mathrm{a}} /$ Level $^{\mathrm{b}}$ & I/C & I/C & I/C & I/C & $\mathrm{lla} / \mathrm{A}$ \\
\hline$\geq \mid$ to $<5$ & Lifestyle advice & Lifestyle advice & $\begin{array}{l}\text { Lifestyle advice, } \\
\text { consider drug if } \\
\text { uncontrolled }\end{array}$ & $\begin{array}{l}\text { Lifestyle advice, } \\
\text { consider drug if } \\
\text { uncontrolled }\end{array}$ & $\begin{array}{l}\text { Lifestyle advice, } \\
\text { consider drug if } \\
\text { uncontrolled }\end{array}$ \\
\hline Class $^{\mathrm{a}} /$ Level $^{\mathrm{b}}$ & I/C & I/C & $\mathrm{Ila} / \mathrm{A}$ & $\mathrm{Ila} / \mathrm{A}$ & I/A \\
\hline $\begin{array}{l}\geq 5 \text { to }<10, \\
\text { or high-risk }\end{array}$ & Lifestyle advice & $\begin{array}{l}\text { Lifestyle advice, } \\
\text { consider drug if } \\
\text { uncontrolled }\end{array}$ & $\begin{array}{l}\text { Lifestyle advice } \\
\text { and drug treatment } \\
\text { for most }\end{array}$ & $\begin{array}{l}\text { Lifestyle advice } \\
\text { and drug treatment }\end{array}$ & $\begin{array}{l}\text { Lifestyle advice } \\
\text { and drug treatment }\end{array}$ \\
\hline Class $^{\mathrm{a}} /$ Level $^{\mathrm{b}}$ & $\mathrm{Ila} / \mathrm{A}$ & $\mathrm{lla} / \mathrm{A}$ & $\mathrm{Ila} / \mathrm{A}$ & I/A & $\mathrm{I} / \mathrm{A}$ \\
\hline $\begin{array}{l}\geq 10 \text { or } \\
\text { very high-risk }\end{array}$ & $\begin{array}{l}\text { Lifestyle advice, } \\
\text { consider drug }\end{array}$ & $\begin{array}{l}\text { Lifestyle advice } \\
\text { and concomitant } \\
\text { drug treatment }\end{array}$ & $\begin{array}{l}\text { Lifestyle advice } \\
\text { and concomitant } \\
\text { drug treatment }\end{array}$ & $\begin{array}{l}\text { Lifestyle advice } \\
\text { and concomitant } \\
\text { drug treatment }\end{array}$ & $\begin{array}{l}\text { Lifestyle advice } \\
\text { and concomitant } \\
\text { drug treatment }\end{array}$ \\
\hline Class $^{\mathrm{a}} /$ Level $^{\mathrm{b}}$ & $\mathrm{lla} / \mathrm{A}$ & $\mathrm{lla} / \mathrm{A}$ & I/A & $\mathrm{I} / \mathrm{A}$ & $\mathrm{I} / \mathrm{A}$ \\
\hline
\end{tabular}

$\mathrm{CV}=$ cardiovascular; $\mathrm{LDL}-\mathrm{C}=$ low-density lipoprotein cholesterol; SCORE = Systematic Coronary Risk Estimation.

${ }^{\mathrm{a}}$ Class of recommendation.

bLevel of evidence.

Guidance on the use of drug treatment must be interpreted in the light of the physician's judgement and knowledge with regards to his or her individual patient. Note that risk stratification is not applicable in familial hypercholesterolaemia, where drug treatment is recommended, and that, in this table, drug treatment may be considered at risks lower than the generic treatment thresholds indicated in paragraph 2.3.5. Thus treatment may occasionally be considered in moderate risk (1-5\%) individuals, provided that patients are wellinformed of the limited absolute risk reduction, and high numbers needed to treat. In higher risk (5-10\%), drug therapy is associated with somewhat larger absolute benefits, and should at least be considered. Drug therapy is strongly advised in those at very high risk ( $\geq 10 \%)$. If baseline LDL-C in this category is already below the target level of $1.8 \mathrm{mmol} / \mathrm{L}$, benefit of statin therapy initiation is less certain, but may still be present.

\section{3a.7.11 Patients with kidney disease}

CKD can be characterized by mixed dyslipidaemia (high triglycerides, high LDL-C and low HDL-C). ${ }^{367}$ Statin therapy has a beneficial effect on CVD outcomes in CKD ${ }^{368}$ and in some studies slows the rate of kidney function loss. ${ }^{369,370}$ Similar data have been observed for combination therapy of a statin with ezetimibe, but not for ezetimibe alone. ${ }^{368}$ For patients with end-stage renal disease, we recommend that hypolipidaemic therapy should not be initiated. If patients with CKD already on a hypolipidaemic therapy enter endstage renal disease, the therapy may be maintained. ${ }^{368}$

\section{3a.7.12 Drugs}

The currently available lipid-lowering drugs include inhibitors of 3-hydroxy-3-methylglutaryl-coenzyme A reductase (statins), fibrates, bile acid sequestrants (anion exchange resins), niacin (nicotinic acid), selective cholesterol absorption inhibitors (e.g. ezetimibe) and, more recently, proprotein convertase subtilisin/kexin type 9 (PCSK9) inhibitors. Response to all therapy varies widely among individuals and therefore monitoring the effect on LDL-C levels is recommended.

Statins, by decreasing LDL-C, reduce CV morbidity and mortality as well as the need for coronary artery interventions. ${ }^{371,372}$
Statins at doses that effectively reduce LDL-C by at least $50 \%$ also seem to halt progression or even contribute to regression of coronary atherosclerosis. ${ }^{373}$ Statins also lower triglycerides, and meta-analysis evidence shows statins may also lower pancreatitis risk. ${ }^{374}$ Therefore, they should be used as the drugs of first choice in patients with hypercholesterolaemia or combined hyperlipidaemia.

Data indicate that combination therapy with ezetimibe also brings a benefit that is in line with the Cholesterol Treatment Trialists' (CTT) Collaboration meta-analysis supporting the notion that LDL-C reduction is key to the achieved benefit independent of the approach used. ${ }^{353,375}$

Increased levels of liver enzymes in plasma occur occasionally during statin therapy, and in most cases are reversible. Routine monitoring of liver enzyme values is not indicated. In addition, 5-10\% of patients receiving statins complain of myalgia, but rhabdomyolysis is extremely rare. The risk of myopathy (severe muscular symptoms) can be minimized by identifying vulnerable patients and/or by avoiding statin interactions with specific drugs ${ }^{376}$ (see Table $E$ in web addenda). Because statins are prescribed on a long-term basis, possible interactions with other drugs deserve particular and continuous attention, as many patients will receive pharmacological therapy for concomitant 
conditions. ${ }^{377}$ In practice, management of a patient with myalgia but without a major creatinine kinase increase is based on trial and error and usually involves a trial of a different statin or the use of a very low dosage several days a week with a gradual increase. ${ }^{376}$

In general, the safety profile of statins is acceptable, and earlier observations that lipid-lowering treatment may contribute to an increase in non-CV mortality (e.g. cancers, suicides, depression) or mental disorders were not confirmed in a large meta-analysis. ${ }^{378}$ Increased blood sugar and glycated haemoglobin (HbA1c) levels (i.e. increased risk of type 2 DM) occur after statin treatment and are dose dependent, in part linked to very slight weight gain, but the benefits of statins outweigh the risks for the vast majority of patients. ${ }^{377-379}$ Patients should be reminded that adhering to lifestyle changes when prescribed a statin should lessen any modest DM risk. $^{379-382}$

For non-statin treatments, selective cholesterol absorption inhibitors (e.g. ezetimibe) are not usually used as monotherapy to decrease LDL-C concentrations, unless patients are intolerant to statins. They are recommended as combination therapy with statins in selected patients when a specific goal is not reached with the maximal tolerated dose of a statin.

Bile acid sequestrants also decrease total cholesterol and LDL-C but are poorly tolerated and tend to increase plasma triglyceride concentrations. They are therefore not recommended for routine use in CVD prevention.

Fibrates and niacin are used primarily for triglyceride lowering and increasing HDL-C, while fish oils (n-3 fatty acids) in doses of $2-4 \mathrm{~g} /$ day are used for triglyceride lowering. ${ }^{360}$ Evidence supporting the use of these drugs for CVD event reduction is limited and, given the strong evidence favouring statins, routine use of these drugs in CVD prevention is not recommended. In order to prevent pancreatitis, when triglycerides are $>10 \mathrm{mmol} / \mathrm{L}(>900 \mathrm{mg} / \mathrm{dL})$ they must be reduced not only by drugs but also by restriction of alcohol, treatment of DM, withdrawal of oestrogen therapy, etc. In those rare patients with severe primary hypertriglyceridaemia, specialist referral must be considered.

Regarding new therapies, recent data from phase I-III trials show that PCSK9 inhibitors sharply decrease LDL-C by up to $60 \%$, either as monotherapy or in addition to the maximal statin dose. Whether this approach results in the predicted reduction in CV events is being addressed in large outcome trials; preliminary evidence suggests that this is the case. ${ }^{383-385}$

\section{3a.7.13 Drug combinations}

Patients with dyslipidaemia, particularly those with established CVD, DM or asymptomatic high-risk individuals, may not always reach treatment goals, even with the highest tolerated statin dose. Therefore, combination treatment may be needed. It must be stressed, however, that the only combination that has evidence of clinical benefit (one large RCT) is that of a statin combined with ezetimibe. ${ }^{353}$ Based on the relatively limited body of evidence, clinicians may restrict the use of this combination to patients at high or very-high risk of CVD.

Combinations of niacin and a statin increase HDL-C and decrease triglycerides better than either of these drugs alone, but flushing is the main adverse effect of niacin, which may affect compliance. Furthermore, there is no evidence of clinical benefit for this combination. ${ }^{386}$
Fibrates, particularly fenofibrate, may be useful, not only for decreasing high triglyceride concentrations and increasing low HDL-C, but for lowering LDL-C further when used with a statin. There is limited evidence for this combination in terms of a reduction in CVD events. In selected cases, however, this approach may be considered, such as when, during statin treatment, triglycerides remain high and/or HDL-C is very low. Other drugs metabolized through cytochrome P450 should be avoided when this combination is prescribed. Fibrates should preferably be taken in the morning and statins in the evening to minimize peak dose concentrations and decrease the risk of myopathy. Patients have to be instructed about warning symptoms (myalgia), even though such adverse effects are very rare. Gemfibrozil should not be added to a statin treatment, because of the high potential for interactions.

If target levels cannot be reached even on maximal doses of lipid-lowering therapy or drug combinations, patients will still benefit from treatment to the extent that the dyslipidaemia has been improved. In these patients, increased attention to other risk factors may help to reduce total risk.

\section{Gaps in evidence}

- Triglyceride or HDL-C values as a target for therapy.

- Whether Lp(a) lowering against background statin therapy can reduce the risk of CVD.

- How to increase adoption of non-HDL-C and non-fasting samples in clinical practice.

- Whether functional foods and food supplements with a lipid-lowering effect can safely reduce the risk of CVD.

\section{3a.8 Diabetes mellitus (type 2 and type 1) Key messages}

- The multifactorial approach is very important in patients with type 2 DM.

- Lifestyle management to aid weight control by sustainable dietary changes and increased PA levels should be central in the management of patients with type 2 DM.

- Intensive management of hyperglycaemia reduces the risk of microvascular complications and, to a lesser extent, the risk of CVD. However, targets should be relaxed in the elderly, frail, those with long-duration DM and those with existing CVD.

- Intensive treatment of BP in DM, with a target of $140 \mathrm{mmHg}$ systolic for the majority, reduces the risk of macrovascular and microvascular outcomes. A lower SBP target of $130 \mathrm{mmHg}$ further lessens the risks for stroke, retinopathy and albuminuria and should be applied to selected patients.

- Lipid lowering is a key mechanism to lower CVD risk in both type 2 and type $1 \mathrm{DM}$. All patients $>40$ years of age and selected younger patients at elevated risk are recommended for statin therapy.

- In DM patients with existing CVD, the use of a sodium-glucose co-transporter-2 (SGLT2) inhibitor substantially lessened CVD and total mortality and HF hospitalisation without major adverse effects. SGLT2 inhibitors should be considered early in the course of DM management in such patients.

- Recent evidence points to sizeable reductions in CVD mortality in DM patients via improvements in risk factor management, although the increasing worldwide DM prevalence will create major challenges. More should be done to prevent DM. 


\section{Recommendations for management of diabetes}

\begin{tabular}{|c|c|c|c|}
\hline Recommendations & Class $^{\mathrm{a}}$ & Level $^{\mathrm{b}}$ & $\operatorname{Ref}^{c}$ \\
\hline $\begin{array}{l}\text { Lifestyle changes including smoking cessation, low fat diet, high fibre diet, aerobic physical activity, and strength training are } \\
\text { recommended. }\end{array}$ & $\mathbf{I}$ & A & 387 \\
\hline Reduction in energy intake is recommended to patients to help achieve lower weight or prevent weight gain. & I & B & 387 \\
\hline $\begin{array}{l}\text { A target } \mathrm{HbAlc} \text { for the reduction in risk of CVD and microvascular complications in DM of }<7.0 \% \text { ( }<53 \mathrm{mmol} / \mathrm{mol} \text { ) is } \\
\text { recommended for the majority of non-pregnant adults with either type I or type } 2 \mathrm{DM} \text {. }\end{array}$ & $\mathbf{I}$ & A & 388,389 \\
\hline $\begin{array}{l}\text { For patients with a long duration of DM, the elderly, frail, or those with existing CVD, a relaxing of the HbAlc targets (i.e. less } \\
\text { stringent) should be considered. }\end{array}$ & Ila & B & 389 \\
\hline $\begin{array}{l}\text { A target } \mathrm{HbAlc} \text { of } \leq 6.5 \% \text { ( } \leq 48 \mathrm{mmol} / \mathrm{mol} \text { ) should be considered at diagnosis or early in the course of type } 2 \mathrm{DM} \text { in patients, who } \\
\text { are not frail and do not have CVD. }\end{array}$ & Ila & B & 389 \\
\hline $\begin{array}{l}\text { When screening for DM in individuals with or without CVD, assessment of HbAlc (which can be done non-fasting) or fasting } \\
\text { blood glucose should be considered. An oral glucose tolerance test can be offered when there is still doubt. }\end{array}$ & Ila & A & 390 \\
\hline Metformin is recommended as first-line therapy, if tolerated and not contra-indicated, following evaluation of renal function. & I & B & 391 \\
\hline $\begin{array}{l}\text { Avoidance of hypoglycaemia and excessive weight gain should be considered and individual approaches (with respect to both } \\
\text { treatment targets and drug choices) should be considered in patients with advanced disease. }\end{array}$ & Ila & B & $\begin{array}{l}389,392, \\
393\end{array}$ \\
\hline $\begin{array}{l}\text { In patients with type } 2 \mathrm{DM} \text { and CVD, the use of an SGLT2 inhibitor should be considered early in the course of the disease to } \\
\text { reduce } \mathrm{CV} \text { and total mortality. }\end{array}$ & Ila & B & 394 \\
\hline $\begin{array}{l}\text { Lipid lowering agents (principally statins) are recommended to reduce CV risk in all patients with type } 2 \text { or type I DM above the } \\
\text { age of } 40 \text { years. }\end{array}$ & I & A & 371,372 \\
\hline $\begin{array}{l}\text { Lipid lowering agents (principally statins) may be considered also in individuals below } 40 \text { years of age if at significantly elevated } \\
\text { risk, based on the presence of micro-vascular complications or of multiple } \mathrm{CV} \text { risk factors. }\end{array}$ & Ilb & $\mathbf{A}$ & 371,372 \\
\hline $\begin{array}{l}\text { In DM patients at very high-risk (see table 5), a LDL-C target }<1.8 \mathrm{mmol} / \mathrm{L}(<70 \mathrm{mg} / \mathrm{dL} \text { ), or a reduction of at least } 50 \% \text { if the } \\
\text { baseline } \mathrm{LDL}-\mathrm{C} \text { is between } 1.8 \text { and } 3.5 \mathrm{mmol} / \mathrm{L}(70 \text { and } 135 \mathrm{mg} / \mathrm{dL} \text { ), is recommended. } \\
\text { In DM patients with high-risk (see table } 5), \mathrm{LDL}-\mathrm{C} \text { target }<2.6 \mathrm{mmol} / \mathrm{L}(<100 \mathrm{mg} / \mathrm{dL} \text { ) or a reduction of at least } 50 \% \text { if the baseline } \\
\mathrm{LDL}-\mathrm{C} \text { is between } 2.6 \text { and } 5.1 \mathrm{mmol} / \mathrm{L}(100 \text { and } 200 \mathrm{mg} / \mathrm{dL} \text { ) is recommended. }\end{array}$ & $\mathbf{I}$ & B & 395 \\
\hline $\begin{array}{l}\text { BP targets in type } 2 \mathrm{DM} \text { are generally recommended to be }<140 / 85 \mathrm{mmHg} \text {, but a lower target of }<130 / 80 \mathrm{mmHg} \text { is recommended } \\
\text { in selected patients (e.g.younger patients at elevated risk for specific complications) for additional gains on stroke, retinopathy and } \\
\text { albuminuria risk. Renin-angiotensin-aldosterone system blocker is recommended in the treatment of hypertension in DM, particularly } \\
\text { in the presence of proteinuria or micro- albuminuria. Recommended BP target in patients with type I DM is }<130 / 80 \mathrm{mmHg} \text {. }\end{array}$ & $\mathbf{I}$ & B & 396,397 \\
\hline The use of drugs that increase HDL-C to prevent CVD in type $2 \mathrm{DM}$ is not recommended. & III & $\mathbf{A}$ & 386 \\
\hline Antiplatelet therapy (e.g. with aspirin) is not recommended for people with DM who do not have CVD. & III & $\mathbf{A}$ & 398 \\
\hline
\end{tabular}

$\mathrm{BP}=$ blood pressure; $\mathrm{CV}=$ cardiovascular; $\mathrm{DM}=$ diabetes mellitus; $\mathrm{HbA1c}=$ glycated haemoglobin; $\mathrm{HDL}-\mathrm{C}=$ high-density lipoprotein cholesterol; LDL-C = low-density lipoprotein cholesterol; SGLT2 = Sodium-glucose co-transporter-2.

${ }^{\mathrm{a} C}$ Class of recommendation.

bLevel of evidence.

'Reference(s) supporting recommendations.

${ }^{\mathrm{d}} \mathrm{Non}-\mathrm{HDL}-\mathrm{C}$ is a reasonable and practical alternative target because it does not require fasting. Non $\mathrm{HDL}-\mathrm{C}$ secondary targets of $<2.6$ and $<3.3 \mathrm{mmo} / \mathrm{L}(<100 \mathrm{and}<130 \mathrm{mg} / \mathrm{dL})$ are recommended for very high, and high-risk subjects, respectively See section 3a.7.10 for more details.

People with DM are on average at double the risk of CVD. ${ }^{399} \mathrm{~A}$ simple DM risk questionnaire can guide which patients without CVD should be tested for DM. ${ }^{400}$

Keeping close to the recommended targets for BP, lipid control, glycaemia and $\mathrm{HbA} 1 \mathrm{c}$ is important for the prevention of CVD. Clear reductions have occurred in CVD death rates in DM consistent with better management of risk factors, although the increasing prevalence of DM continues to create pressures on all health care systems.

The targets, especially the glycaemic and in some cases lipids, should be less stringently implemented in older people with DM, those with a longer duration of DM, those with evidence of CVD and the frail. 401
There is mounting evidence for a very high relative risk in younger individuals with type 2 DM (age $<40$ years), ${ }^{402}$ and additional guidance on care is needed.

Except for glucose management, prevention of CVD follows the same general principles as for people without DM. Achieving low BP levels and low LDL-C and total cholesterol concentrations is particularly important. Many treatment targets are more stringent for patients with DM. Typically, patients with type 2 DM have multiple CVD risk factors, each requiring treatment according to existing guidelines.

\section{3a.8.1 Lifestyle intervention}

The ESC and European Association for the Study of Diabetes scientific statements advocate lifestyle management as a first 
measure for the prevention and management of DM. ${ }^{387}$ Most patients with DM are obese, so weight control is a central component. Several dietary patterns can be adopted where the predominance of fruits, vegetables, wholegrain cereals and low-fat protein sources is more important than the precise proportions of total energy provided by the major macronutrients. Salt intake should be restricted. Specific dietary recommendations include limiting saturated and trans fats and alcohol intake, monitoring carbohydrate consumption and increasing dietary fibre. A Mediterranean-type diet is acceptable, where fat sources are derived primarily from monounsaturated oils.

A combination of aerobic and resistance exercise training is effective in the prevention of the progression of DM and for the control of glycaemia. Little is known about how to promote and sustain PA; however, reinforcement by health care providers to patients to find sustainable ways to increase PA is crucial. Smoking increases the risk of DM, CVD and premature death and should be strongly discouraged (see section 3a.4.5). ${ }^{387,403}$ Lifestyle intervention can also prevent DM development in those at elevated risk and, in turn, lowers future microvascular and macrovascular risks. ${ }^{404}$

\section{3a.8.2 Cardiovascular risk}

At diagnosis or in those with a short duration of disease, DM is not a CAD risk equivalent state. ${ }^{405,406}$ In general, risk levels approach CAD risk equivalence after about a decade or in those with proteinuria or low eGFR. ${ }^{406-408}$ Emerging data suggest that patients who develop DM at a younger age have a high complication burden. ${ }^{402}$ People with DM with existing CAD have a vascular risk well in excess of those with CAD but without DM and a substantially lower life expectancy. ${ }^{409}$

Statins are recommended for all those newly diagnosed with type 2 DM beyond a certain age ( $>40$ years is currently recommended). This recommendation reflects greater lifetime vascular risk trajectories in these individuals. However, a proportion of DM patients at $40-50$ years of age may have a low 10 year risk of CVD due to normal BP and lipid levels and being non-smokers, and in such cases there remains a role for physician judgement. Equally, in some patients $<40$ years of age with type 2 DM with evidence of end-organ damage or significant risk factors, statins may be indicated.

\section{3a.8.3 Glucose control}

The UK Prospective Diabetes Study (UKPDS) established the importance of intensive glucose lowering with respect to CVD risk reduction in newly diagnosed patients with DM but not treated with modern BP- or lipid-lowering therapies, with the best evidence to support metformin, leading to its position as first-line therapy. Three trials were conducted to see if $\mathrm{CV}$ events could be reduced further with more intensive glycaemia treatment and lower target HbA1c levels. ${ }^{389,393,410}$ However, the results were surprising, with unexpected increases in total and CVD deaths in the Action to Control Cardiovascular Risk in Diabetes (ACCORD) trial and a trend towards an increase in CVD death in the Veterans Affairs Diabetes Trial (VADT). The results prompted concerns about the safety of intensive glucose lowering and the appropriateness of pursuing tight glucose control, particularly in older people with DM and in those with existing CVD. Subsequent meta-analyses of intensive glucose control, including data from UKPDS, Prospective Pioglitazone Clinical Trial in Macrovascular Events (PROactive), ACCORD, Action in Diabetes and Vascular disease: PreterAx and Diamicron MR Controlled Evaluation (ADVANCE) and VADT, ${ }^{411}$ showed significant reductions in non-fatal AMI and CAD events, but no effect on stroke or total mortality. ${ }^{412,413}$ The additional analyses of these trials suggested that CVD benefits for an average $\mathrm{HbA} 1 \mathrm{c}$ reduction of $\sim 0.9 \%$ over 5 years were far less than via usual reductions in cholesterol and $\mathrm{BP}$ seen with statins and available BP-lowering agents. Four recent trials of newer DM therapies (DPP-4 and GLP-1) ${ }^{414-417}$ in patients with DM and existing CVD or at high risk demonstrated noninferiority (i.e. safety) but not superiority with respect to CVD risk. There was, however, an increase in the rate of hospitalization for HF with saxagliptin in the Saxagliptin Assessment of Vascular Outcomes Recorded in Patients with Diabetes Mellitus - Trombolysis in Myocardial Infarction (SAVOR-TIMI 53) trial.416

Very recently, the SGLT2 inhibitor empagliflozin demonstrated substantial reductions in CVD death (by 38\%) and all-cause mortality (by $32 \%$ ), as well as in hospitalisation for HF (by $35 \%$ ), as compared with standard care, suggesting use of an SLGT2 inhibitor should come very early in the course of management of patients with DM and CVD. ${ }^{394}$ The pattern of trial results whereby non-fatal $\mathrm{MI}$ and stroke were not reduced by active treatment, as well as the rapid separation of mortality curves, suggest that the mechanism of benefit was likely to relate more to cardio-renal haemodynamic effects than to atherothrombotic actions or effects of glucose lowering per se. More research on understanding the trial results is needed.

\section{3a.8.4 Blood pressure}

In people with type $2 \mathrm{DM}$, apart from lifestyle interventions, the reduction of BP (along with cholesterol) should be targeted as strictly as targeting glucose/HbA1c levels. BP targets should be considered regardless of overall CV risk score in patients with type $2 \mathrm{DM}$.

Hypertension is more common in patients with type 2 DM compared with the general population. A recent systematic review and meta-analysis of randomized trials of BP-lowering agents in $>100$ 000 patients with type $2 \mathrm{DM}$ confirmed that lowering $\mathrm{BP}$ reduces the risk of all-cause mortality, $\mathrm{CV}$ events, $\mathrm{CAD}$ events, stroke, $\mathrm{HF}$, retinopathy, new or worsening albuminuria and renal failure. ${ }^{418}$ The results were similar when trials with low risk of bias were selected. Furthermore, a systolic target $<140 \mathrm{mmHg}$ lessens the risk of total mortality and most separate outcomes. Further reductions in the risk for albuminuria, retinopathy and stroke, but not in overall survival or aggregate clinical endpoints, were achieved with a systolic target $<130 \mathrm{mmHg}$. In people $>80$ years of age, targets should be set higher, aiming for $<150 / 90 \mathrm{mmHg}$, unless renal impairment is present.

Combination treatment is commonly needed to lower BP effectively in DM. An ACE-I or an angiotensin receptor blocker (ARB), where tolerated, should always be included as first-line therapy because of the evidence of superior protective effects against initiation or progression of nephropathy.

\section{3a.8.5 Lipid-lowering therapy}

The Heart Protection Study (HPS) demonstrated that treatment with simvastatin $40 \mathrm{mg}$ reduced the risk of CAD and stroke in people with DM and individuals without DM who had no prior AMI or angina pectoris. ${ }^{372}$ Further robust support for statin benefit came from the Collaborative Atorvastatin Diabetes Study (CARDS), which compared $10 \mathrm{mg}$ atorvastatin with placebo, ${ }^{371}$ and from the 
CTT meta-analysis in DM patients. ${ }^{419}$ There is also trial evidence to show greater CVD risk reduction with more intense statin therapy in DM patients. ${ }^{395}$ More recent trial evidence shows a clear CVD benefit of lowering LDL-C with ezetimibe on top of a statin in patients with type 2 DM. $^{353}$ Emerging evidence also shows that PCSK9 inhibitors are equally efficacious in lowering LDL-C in type 2 DM patients, although results of CV outcome trials are awaited. Lower treatment targets should be pursued in patients with type 2 DM who have overt CVD or CKD.

While the most common lipid abnormality in type 2 DM is elevated triglyceride and low HDL-C, trials examining possible CVD benefits of lipid (mainly triglyceride) lowering with fibrates in DM have not been positive. The US Food and Drug Administration (FDA) states that the current evidence base is insufficient to support fibrates for CVD protection and that more trial evidence is needed. $^{420}$

Prescribing of lipid-lowering agents in older people with DM (>85 years) requires special consideration because exposure to higher doses (or higher potency) may not increase life expectancy, but may increase the risk of adverse effects.

\section{3a.8.6 Antithrombotic therapy}

Patients with type 1 or type 2 DM have an increased tendency to develop thrombotic phenomena. The Antiplatelet Trialists' Collaboration meta-analysis demonstrated the benefits of antithrombotic therapy (mainly aspirin) in patients with DM with clinically established CAD, cerebrovascular disease or other forms of thrombotic disease, with a $25 \%$ reduction in risk of CV events. ${ }^{421}$

The role of aspirin in patients without CVD remains unproven. $A$ meta-analysis of six RCTs found no statistically significant reduction in the risk of major CV events or all-cause mortality when aspirin was compared with placebo or no aspirin in people with DM and no pre-existing CVD. ${ }^{398}$ Further trials are ongoing.

\section{3a.8.7 Microalbuminuria}

Microalbuminuria (urinary albumin excretion from 30 to $300 \mathrm{mg} /$ $24 \mathrm{~h}$ ) predicts the development of overt nephropathy in patients with type 1 or type 2 DM, while the presence of overt proteinuria (300 mg/24 h) generally indicates established renal parenchymal damage. In patients with DM and hypertension, microalbuminuria - even below the current threshold values-predicts CV events, and a continuous relationship between $\mathrm{CV}$ as well as non- $\mathrm{CV}$ mortality and urinary protein:creatinine ratios has been reported. Microalbuminuria can be measured from spot urine samples (due to inaccuracy in sampling, $24 \mathrm{~h}$ or night-time urine collection is discouraged) by indexing the urinary albumin concentration to the urinary creatinine concentration $(2.5 / 3.5-25 / 35 \mathrm{mg} / \mathrm{mmol})$. Patients with $D M$ and microalbuminuria or proteinuria should be treated with an $A C E-I$ or $A R B$ regardless of baseline $B P$.

\section{Gaps in evidence}

- There is a need to examine whether a type 2 DM CV risk score based on either 10 year or lifetime risk helps to improve targeting of preventative therapies and leads to a reduction in CV risk or a gain in lifetime years free from disease.

- Further trial data are needed to establish if the empagliflozin outcome findings hold for other classes of SGLT2 inhibitors and to better understand the mechanisms of benefit. It would also be useful to know if SGLT2 inhibitors lessen CV mortality and HF risks in patients with DM but without CVD.

- More research on the benefits of glucagon-like peptide 1 (GLP-1) receptor agonists on CVD risk is needed and trials are due to be reported in subsequent years. Early evidence suggests no CVD benefit with short-term use of dipeptidyl peptidase 4 (DPP-4) inhibitors in people at high risk for CVD, as reviewed. $^{422}$

\section{3a.8.8 Type 1 diabetes}

\section{Key messages}

- CVD and mortality risks have decreased in type $1 \mathrm{DM}$ patients but remain unacceptably elevated in those with very poor glycaemic control or any evidence of kidney disease.

- Intensive management of hyperglycaemia in DM reduces the risk of macrovascular complications and premature mortality; a target of $6.5-7.5 \%(48-58 \mathrm{mmol} / \mathrm{mol}) \mathrm{HbA} 1 \mathrm{c}$ is recommended.

- The recommended $\mathrm{BP}$ target in the majority of patients with type $1 \mathrm{DM}$ is $130 / 80 \mathrm{mmHg}$.

- Lipid-lowering agents targeting LDL-C reduction should be recommended to the majority of patients $>40$ years of age and to those younger than this with evidence of nephropathy or with multiple risk factors.

Type 1 DM is the result of a lack of insulin production in the pancreas, confirmed by absent or virtually absent C-peptide levels. The average age of onset is $\sim 14$ years, although persons of any age can develop type 1 DM. Type 1 DM should be suspected in any patient who progresses to insulin within the first year of diagnosis. A large contemporary study in Scotland observed a relative risk for CVD events of 2.3 in men and 3 in women with type 1 DM compared with the general population, ${ }^{423}$ suggesting CVD risks may have declined over time, commensurate with improvements in life expectancy. ${ }^{424}$ Another report from Sweden demonstrated CVD mortality rates in type $1 \mathrm{DM}$ to be twice the rates of the general population in those with $\mathrm{HbA} 1 \mathrm{c}$ levels $<6.9 \%$ (52 $\mathrm{mmol} / \mathrm{mol}$ ), whereas risk was especially high $(\sim 10$-fold) in those with very poor control $[\geq 9.7 \%(\geq 83 \mathrm{mmol} / \mathrm{mol})] .{ }^{425}$ In the majority of studies, the risk of CVD events or mortality was highest among those with diabetic nephropathy, macroalbuminuria or CKD. The presence of proliferative retinopathy and autonomic neuropathy also signalled an elevated CVD risk.

The Diabetes Control and Complications Trial (DCCT) established the importance of tight glucose control to lessen the risks of both microvascular and macrovascular disease. A 27 year followup of this trial showed that 6.5 years of initial intensive DM therapy in type 1 DM was associated with a modestly lower all-cause mortality rate when compared with conventional therapy. ${ }^{426}$ A glycaemic target for $\mathrm{HbA} 1 \mathrm{c}$ of $6.5-7.5 \%$ (48-58 mmol/mol) appears to be a balanced approach for long-term care of patients with type 1 DM. The use of insulin analogues, insulin pumps and continuous glucose monitoring to improve glycaemic control while minimizing hypoglycaemia is the subject of intense research, as is the use of agents (e.g. metformin, GLP-1 agonists) commonly used in type 2 DM.

The CTT suggested lipid lowering with statins is as equally effective in type 1 patients as in type $2{ }^{427}$ All patients $>40$ years of age 
with type $1 \mathrm{DM}$ should be recommended for statins unless they have a short duration of DM and no other risk factors. Younger patients with multiple risk factors or evidence of end organ damage (albuminuria, low eGFR, proliferative retinopathy or neuropathy) should be considered for statin therapy.

A target BP of $130 / 80 \mathrm{mmHg}$ is accepted practice in type $1 \mathrm{DM}$, with evidence of specific benefits of ACE-Is or ARBs on the early development and later progression of microvascular disease in younger type 1 DM patients. A lower target BP of 120/75-80 $\mathrm{mmHg}$ may be helpful in younger type $1 \mathrm{DM}$ patients $(<40$ years of age) with persistent microalbuminuria. Studies supporting improved CVD outcome in type $1 \mathrm{DM}$ through $\mathrm{BP}$ reduction are lacking. As more patients with type $1 \mathrm{DM}$ are living to older age, SBP targets may need to be relaxed $(140 \mathrm{mmHg})$ in some to avoid side effects.

Current evidence suggests many patients with type $1 \mathrm{DM}>40$ years of age continue to smoke, are still not receiving statins and, perhaps most importantly, have very poor glucose control. ${ }^{423}$ Further efforts to target these established risk factors are needed.

\section{Gaps in evidence}

- Further studies are needed on metformin and GLP-1 receptor agonists in (subgroups of) patients with type $1 \mathrm{DM}$ to determine whether they improve glycaemic control, aid in weight reduction and improve clinical outcomes.

- There is a need for a CVD risk score in type $1 \mathrm{DM}$ to better guide initiation of preventative therapies in younger patients.

\section{3a.9 Hypertension \\ Key messages}

- Elevated BP is a major risk factor for CAD, HF, cerebrovascular disease, PAD, CKD and AF.

- The decision to start BP-lowering treatment depends on the BP level and total CV risk.

- Benefits of treatment are mainly driven by BP reduction per se, not by drug type.

- Combination treatment is needed to control BP in most patients.

\section{Recommendations for management of hypertension}

\begin{tabular}{|c|c|c|c|}
\hline Recommendations & Class $^{\mathrm{a}}$ & Level $^{\mathrm{b}}$ & $\operatorname{Ref}^{c}$ \\
\hline $\begin{array}{l}\text { Lifestyle measures (weight control, increased physical activity, alcohol moderation, sodium restriction, and increased consumption of } \\
\text { fruits, vegetables, and low-fat dairy products) are recommended in all patients with hypertension and in individuals with high normal BP. }\end{array}$ & $\mathbf{I}$ & $\mathbf{A}$ & $\begin{array}{c}337, \\
428-430\end{array}$ \\
\hline $\begin{array}{l}\text { All major BP lowering drug classes (i.e. diuretics, ACE-I, calcium antagonists, ARBs, and B-blockers) do not differ significantly in } \\
\text { their BP-lowering efficacy and thus are recommended as BP lowering treatment. }\end{array}$ & $\mathbf{I}$ & $\mathbf{A}$ & 431,432 \\
\hline $\begin{array}{l}\text { In asymptomatic subjects with hypertension but free of CVD, CKD, and DM, total CV risk stratification using the SCORE } \\
\text { model is recommended. }\end{array}$ & $\mathbf{I}$ & B & 30 \\
\hline $\begin{array}{l}\text { Drug treatment is recommended in patients with grade } 3 \text { hypertension irrespective of } \mathrm{CV} \text { risk, as well as in patients with grade } \\
\text { I or } 2 \text { hypertension who are at very high CV risk. }\end{array}$ & $\mathbf{I}$ & B & 433 \\
\hline Drug treatment should be considered in patients with grade I or 2 hypertension who are at high CV risk. & Ila & B & 433 \\
\hline In patients at low to moderate total CV risk and with grade I or 2 hypertension, lifestyle measures are recommended. & I & B & 433 \\
\hline $\begin{array}{l}\text { In patients at low to moderate total CV risk and with grade I or } 2 \text { hypertension, if lifestyle measures fail to reduce BP, drug } \\
\text { treatment may be considered. }\end{array}$ & Ilb & B & 433 \\
\hline $\mathrm{SBP}<140 \mathrm{mmHg}$ and $\mathrm{DBP}<90 \mathrm{mmHg}$ are recommended in all treated hypertensive patients $<60$ years old. & $\mathbf{I}$ & B & 433 \\
\hline In patients $>60$ years old with $S B P \geq 160 \mathrm{mmHg}$, it is recommended to reduce $S B P$ to between 150 and $140 \mathrm{mmHg}$. & $\mathbf{I}$ & B & 434 \\
\hline $\begin{array}{l}\text { In fit patients }<80 \text { years old, a target } \mathrm{SBP}<140 \mathrm{mmHg} \text { may be considered if treatment is well tolerated. In some of these } \\
\text { patients a target SBP }<120 \mathrm{mmHg} \text { may be considered if at (very) high-risk and tolerate multiple BP lowering drugs. }\end{array}$ & Ilb & B & 434,435 \\
\hline $\begin{array}{l}\text { In individuals }>80 \text { years and with initial } S B P \geq 160 \mathrm{mmHg} \text {, it is recommended to reduce } S B P \text { to between } 150 \text { and } \\
140 \mathrm{mmHg} \text {, provided they are in good physical and mental conditions. }\end{array}$ & $\mathbf{I}$ & B & 434 \\
\hline $\begin{array}{l}\text { In frail elderly patients, a careful treatment intensity (e.g. number of BP lowering drugs) and BP targets should be considered, } \\
\text { and clinical effects of treatment should be carefully monitored. }\end{array}$ & Ila & B & 436 \\
\hline $\begin{array}{l}\text { Initiation of BP lowering therapy with a two-drug combination may be considered in patients with markedly elevated baseline BP } \\
\text { or at high CV risk. Combination of two drugs at fixed doses in a single pill may be considered because of improved adherence. }\end{array}$ & Illb & C & 437 \\
\hline $\begin{array}{l}\text { B-blockers and thiazide diuretics are not recommended in hypertensive patients with multiple metabolic risk factors, }{ }^{d} \text { due to } \\
\text { the increased risk of DM. }\end{array}$ & III & B & 438 \\
\hline
\end{tabular}

$\mathrm{ACE}-\mathrm{I}=$ angiotensin-converting enzyme inhibitor; $\mathrm{ARBs}=$ angiotensin receptor blockers; $\mathrm{BP}=$ blood pressure; $\mathrm{CKD}=$ chronic kidney disease; $\mathrm{CV}=$ cardiovascular; $\mathrm{CVD}=$ cardiovascular disease; DBP = diastolic blood pressure; SBP = systolic blood pressure; SCORE = Systematic Coronary Risk Estimation

${ }^{a}$ Class of recommendation.

bevel of evidence.

'Reference(s) supporting recommendations.

${ }^{d}$ Overweight, obesity, dyslipidaemia, impaired glucose tolerance. 


\section{3a.9.1. Introduction}

High BP is a leading risk factor for disease burden globally, accounting for 9.4 million deaths and $7.0 \%$ of global disability-adjusted lifeyears (DALYs) in $2010 .{ }^{439}$ Compared with 1990, the impact of high BP has increased by $\sim 2.1$ million deaths. ${ }^{439}$ Overall, the prevalence of hypertension is $\sim 30-45 \%$ in adult persons $\geq 18$ years of age, with a steep increase with ageing.

Elevated $\mathrm{BP}$ is a risk factor for CAD, HF, cerebrovascular disease, $P A D, C K D$ and AF. The risk of death from either CAD or stroke increases progressively and linearly from BP levels as low as 115 $\mathrm{mmHg}$ systolic and $75 \mathrm{mmHg}$ diastolic upwards, ${ }^{440}$ although for absolute risk the curves flatten in the lower BP ranges.

\section{3a.9.2 Definition and classifications of hypertension}

The definition and classifications of hypertension are shown in Table $14 .^{11}$

\section{3a.9.3 Blood pressure measurement}

Office BP is recommended for screening and diagnosis of hypertension, which should be based on at least two BP measurements per visit and on at least two visits. If the BP is only slightly elevated, repeated measurements should be made over a period of several months to achieve an acceptable definition of the individual's 'usual' $\mathrm{BP}$ and to decide about initiating drug treatment. If BP is more markedly elevated or accompanied by target organ damage, other CV factors or established CV or renal disease, repeated BP measurements are required within a shorter period in order to make treatment decisions.

\section{3a.9.4 Office or clinic blood pressure measurement}

Auscultatory or oscillometric semi-automatic sphygmomanometers should be validated and checked periodically. ${ }^{441}$ Measurement of BP at the upper arm is preferred, and cuff and bladder dimensions should be adapted to the arm circumference. If feasible, automated recording of multiple BP readings in the office, with the patient seated in an isolated room, might be

\section{Table I4 Definition and classification of blood pressure levels $^{\mathrm{a}}$}

\begin{tabular}{|l|l|l|l|}
\hline Category & $\begin{array}{l}\text { Systolic BP } \\
(\mathbf{m m H g})\end{array}$ & $\begin{array}{l}\text { Diastolic BP } \\
(\mathbf{m m H g})\end{array}$ \\
\hline Optimal & $<120$ & and & $<80$ \\
\hline Normal & $120-129$ & and/or & $80-84$ \\
\hline High-normal & $130-139$ & and/or & $85-89$ \\
\hline Grade I hypertension & $140-159$ & and/or & $90-99$ \\
\hline Grade 2 hypertension & $160-179$ & and/or & $100-109$ \\
\hline Grade 3 hypertension & $\geq 180$ & and/or & $\geq 110$ \\
\hline $\begin{array}{l}\text { Isolated systolic } \\
\text { hypertension }\end{array}$ & $\geq 140$ & and & $<90$ \\
\hline
\end{tabular}

$\mathrm{BP}=$ blood pressure.

${ }^{\mathrm{a} B P}$ levels in untreated individuals. considered as a means of improving reproducibility and matching office BP values closer to those provided by daytime ambulatory BP monitoring (ABPM) or home BP measurements (HBPMs). ${ }^{44}$ Note that automated devices are not validated for BP measurement in patients with AF.

\section{3a.9.5 Out-of-office blood pressure monitoring}

Out-of-office BP is commonly assessed by ABPM or HBPM, usually by self-measurement; it is usually lower than the office BP and the difference increases as office BP increases (Table 15). ${ }^{443}$

The following general principles and remarks should be taken into account: (i) the procedure should be adequately explained to the patient, with verbal and written instructions; (ii) interpretation of the results should take into account that the reproducibility of out-of-office BP measurements is reasonably good for $24 \mathrm{~h}$, day and night BP averages, but less so for shorter periods; (iii) ABPM and HBPM provide somewhat different information on the subject's BP status and risk, and the two methods should thus be regarded as complementary rather than competitive; (iv) devices should be validated and regularly calibrated, at least every 6 months.

Both ABPM and HBPM values are closely related to prognosis. ${ }^{444}$ Night-time BP seems to be a stronger predictor than daytime BP. Out-of-office measurement may be useful not only in untreated subjects, but also in treated patients, with the aim of monitoring the effects of treatment and increasing compliance with drug therapy (Table 16).

\section{3a.9.6 Diagnostic evaluation in hypertensive patients}

Laboratory tests should include haemoglobin, fasting plasma glucose ( $\mathrm{HbA} 1 \mathrm{c}$ if not fasting) and serum tests for total cholesterol, HDL-C, triglycerides, potassium, uric acid, creatinine (and calculated renal function) and thyrotropin (in postmenopausal women). Urinalysis should include albumin:creatinine ratio, dipstick test, sediment and quantitative proteinuria if the dipstick test is positive. Echocardiography and fundoscopy can be considered. The routine measurement of additional biomarkers and/or the use of vascular imaging methods is not recommended.

Table I 5 Blood pressure thresholds for definition of hypertension with different types of BP measurement

\begin{tabular}{|l|l|l|}
\hline & SBP $(\mathbf{m m H g})$ & DBP $(\mathbf{m m H g})$ \\
\hline Office or clinic & 140 & 90 \\
\hline 24-hour & $125-130$ & 80 \\
\hline Day & $130-135$ & 85 \\
\hline Night & 120 & 70 \\
\hline Home & $130-135$ & 85 \\
\hline
\end{tabular}

$\mathrm{DPB}=$ diastolic blood pressure; $\mathrm{SBP}=$ systolic blood pressure 
Table I 6 Clinical indications for the use of out-of-office blood pressure measurements (home blood pressure measurement, ambulatory blood pressure measurement)

Suspicion of white-coat or masked hypertension

- High office BP in individuals without organ damage and at low total CV risk.

- Normal office BP in individuals with organ damage or at high total CV risk.

- Considerable variability of office BP over the same or different visits.

- Autonomic, postural, post-prandial, siesta- and drug-induced hypotension.

- Elevated office BP or suspected pre-eclampsia in pregnant women. - Identification of true and false resistant hypertension.

Specific indications for ABPM

- Marked discordance between office BP and home BP.

- Assessment of dipping status.

- Suspicion of nocturnal hypertension or absence of dipping, such as in patients with sleep apnoea, CKD, or DM.

- Assessment of BP variability.

$\mathrm{ABPM}=$ ambulatory blood pressure monitoring; $\mathrm{BP}=$ blood pressure; $\mathrm{CKD}=$ chronic kidney disease; $\mathrm{CV}=$ cardiovascular.

\section{3a.9.7 Risk stratification in hypertension}

The decision to start pharmacological treatment depends not only on the BP level but also on total CV risk, outlined in section 2. However, even subclinical hypertensive organ damage predicts $C V$ death independently of SCORE, and the combination may improve risk prediction, especially in subjects at moderate risk (SCORE 14\%). ${ }^{445,446}$ Echocardiography is more sensitive than ECG in diagnosing $\mathrm{LVH}$ and in predicting $\mathrm{CV}$ risk, and may help in more precise stratification of the overall risk and in directing therapy. ${ }^{447}$ An albumin:creatine ratio $>30 \mathrm{mg} / \mathrm{g}$ in urine is also a marker of subclinical damage in hypertensive patients.

\section{3a.9.8 Who to treat, and when to initiate antihypertensive treatment}

The decision to start antihypertensive treatment depends on the BP level and total CV risk. Lifestyle changes are recommended in all patients with suboptimal BP, including masked hypertension. Prompt initiation of drug treatment is recommended in individuals with grade 3 hypertension with any level of CV risk. ${ }^{431}$ Lowering BP with drugs is more frequently required when the total $C V$ risk is very high and should also be considered when the risk is high (section 2.3.5). ${ }^{431}$ Initiation of BP-lowering drug treatment may also be considered in grade 1 or 2 hypertensive patients at low to moderate risk when $\mathrm{BP}$ is within this range at several repeated visits or elevated by ambulatory BP criteria and remains within this range despite a reasonable period of time with lifestyle changes. ${ }^{447}$ However, the NNT in this patient category is very high, and patients should be informed and their preference must be considered.

Lifestyle changes only with close BP monitoring should be the recommendation in young individuals with isolated moderate elevation of brachial SBP ${ }^{448}$ and in individuals with high-normal BP who are at low or moderate risk. ${ }^{447}$ Also, in white coat hypertensive patients without additional risk factors, therapeutic intervention should be limited to lifestyle changes, accompanied by close followup. Drug treatment may also be considered in white coat hypertensive patients with a higher CV risk because of metabolic derangements or in the presence of organ damage.

\section{3a.9.9 How to treat}

3a.9.9.1 Lifestyle changes

Lifestyle interventions, weight control and regular PA alone may be sufficient for patients with high-normal and grade 1 hypertension, and should always be advised for patients receiving BP-lowering drugs, as these may reduce the dosage of BP-lowering drugs needed to achieve BP control. The lifestyle intervention specific to hypertension is salt restriction. At the individual level, effective salt reduction is by no means easy to achieve. As a minimum, advice should be given to avoid added salt and high-salt food. As the BP-lowering effect of increased potassium has been well documented in the DASH diet (rich in fruits, vegetables and low-fat dairy products with a reduced content of dietary cholesterol as well as saturated and total fat), patients with hypertension should generally be advised to eat more fruits and vegetables and to reduce their intake of saturated fat and cholesterol. ${ }^{447}$

\section{3a.9.9.2 Blood pressure-lowering drugs}

The large number of randomized trials of BP-lowering therapy, both those comparing active treatment vs. placebo and those comparing different compounds, confirm that (i) the main benefits of BP-lowering treatment are due to lowering of BP per se, and are largely independent of the drugs employed; and (ii) thiazide and thiazide-like diuretics (chlorthalidone and indapamide), $\beta$-blockers, calcium antagonists, ACE-Is and ARBs can adequately lower BP and reduce the risk of $C V$ death and morbidity. ${ }^{431,432}$ Thus these drugs are all recommended for initiation and maintenance of BP control, either as monotherapy or in combination. Some aspects should be considered for each of the BP-lowering drug groups.

The position of $\beta$-blockers as first-choice BP-lowering drugs has been questioned. A meta-analysis of 147 randomized trials ${ }^{431}$ reports only a slight inferiority of $\beta$-blockers in preventing stroke (17\% reduction rather than $29 \%$ reduction with other agents), but a similar effect in preventing CAD and HF, and higher efficacy in patients with a recent coronary event. However, since $\beta$-blockers induce weight gain, have adverse effects on lipid metabolism and increase (compared with other drugs) the incidence of DM, they are not preferred in hypertensive patients with multiple metabolic risk factors and conditions that increase the risk of newonset DM (such as obesity, impaired fasting glucose). However, this may not apply to vasodilating $\beta$-blockers such as carvedilol and nebivolol, which have less or no dysmetabolic action, as well as a reduced incidence of new-onset DM compared with conventional $\beta$-blockers.

Thiazide diuretics also have dyslipidaemic and diabetogenic effects, particularly when used in high doses. Thiazides have often been administered together with $\beta$-blockers in trials showing a relative excess of new-onset DM.

ACE-Is and ARBs are particularly effective in reducing $\mathrm{LVH}$, reducing microalbuminuria and proteinuria, preserving renal function and delaying end-stage renal disease. 
Evidence concerning the benefits of other classes of agents is much more limited. The $\alpha_{1}$ blockers, centrally acting agents $\left(\alpha_{2}\right.$ adrenoreceptor agonists and imidazoline-receptor agonists), antialdosterone drugs and the renin inhibitor aliskiren effectively lower $\mathrm{BP}$ in hypertension, but there are no data documenting their ability to improve CV outcome. All of these agents have frequently been used as added drugs in trials documenting CV protection and can thus be used for combination treatment in addition to the recommended combinations (see below).

Drugs with $24 \mathrm{~h}$ efficacy are preferred. Simplification of treatment improves adherence to therapy, and effective $24 \mathrm{~h} \mathrm{BP}$ control is prognostically important in addition to office BP control. Longacting drugs also minimize BP variability, which may offer protection against progression of organ damage and the risk of $C V$ events.

Any all-purpose ranking of drugs for general BP lowering is infeasible and no evidence is available that different choices should be made based on age or sex (except for caution in using ACE-Is and ARBs in women of childbearing age because of possible teratogenic effects). ${ }^{449}$ Some agents should be considered as the preferred choice in specific conditions because they have been used in trials that included patients with those conditions or because of greater effectiveness in specific types of organ damage (Table 17). ${ }^{447}$

\section{3a.9.9.3 Combination treatment}

Combination treatment is needed to control BP in most patients. The addition of a drug from another class should thus be regarded as a recommended treatment strategy unless the initial drug needs to be withdrawn because of side effects or the absence of any BP-lowering effects. The extra BP reduction from combining drugs from two different classes is approximately five times greater than doubling the dose of one drug ${ }^{450}$ and may reduce the side effects associated with either drug. The combination of two drugs may also offer advantages for treatment initiation, particularly in patients at (very) high risk in whom early BP control may be desirable. Trial evidence of outcome reduction has been obtained, particularly for the combination of a diuretic with an ACE-I, an ARB or a calcium antagonist. ${ }^{451}$

Despite the trial evidence of outcome reduction, the $\beta$-blocker/ diuretic combination favours the development of DM and should thus be avoided unless required for other reasons. The combination of ACE-I and ARB is not recommended. ${ }^{452}$ Specific benefits of such a combination in nephropathic patients with proteinuria (because of a superior anti-proteinuric effect) await confirmation in event-based trials, and if used, should be monitored closely.

In $15-20 \%$ of hypertensive patients, a combination of three drugs is needed to achieve BP control, thus a combination of three BP-lowering drugs at fixed doses in a single tablet may be favoured, because reducing the number of daily pills improves adherence, which is low in patients with hypertension. The most rational combinations appear to be a blocker of the renin-angiotensin system, a calcium antagonist and a diuretic at effective doses.

\section{3a.9.10 Blood pressure goals}

There are only a few randomized clinical trials comparing different treatment targets. Hence any recommendation on target levels largely derives from observational studies and post hoc analyses of RCTs, which have mostly compared different treatment regimens and reported achieved BP levels.

\section{Table 17 Drugs to be preferred in specific conditions}

\begin{tabular}{|c|c|}
\hline Condition & Drug \\
\hline \multicolumn{2}{|c|}{ Asymptomatic organ damage } \\
\hline LVH & ACE-I, calcium antagonist, ARB \\
\hline $\begin{array}{l}\text { Asymptomatic } \\
\text { atherosclerosis }\end{array}$ & Calcium antagonist,ACE-I \\
\hline Microalbuminuria & ACE-I,ARB \\
\hline Renal dysfunction & ACE-I,ARB \\
\hline \multicolumn{2}{|l|}{ Clinical CV event } \\
\hline Previous stroke & Any agent effectively lowering BP \\
\hline Previous MI & B-blockers,ACE-I,ARB \\
\hline Angina pectoris & B-blockers, calcium antagonist \\
\hline Heart failure & $\begin{array}{l}\text { Diuretic, B-blockers,ACE-I,ARB, } \\
\text { mineralocorticoid receptor antagonist }\end{array}$ \\
\hline Aortic aneurysm & B-blockers \\
\hline $\begin{array}{l}\text { Atrial fibrillation: } \\
\text { prevention }\end{array}$ & $\begin{array}{l}\text { Consider ARB,ACE-I, B-blockers or } \\
\text { mineralocorticoid receptor antagonist }\end{array}$ \\
\hline $\begin{array}{l}\text { Atrial fibrillation: } \\
\text { rate control }\end{array}$ & $\begin{array}{l}\text { B-blockers, non-dihydropyridine calcium } \\
\text { antagonist }\end{array}$ \\
\hline ESRD/proteinuria & ACE-I,ARB \\
\hline Peripheral artery disease & ACE-I, calcium antagonist \\
\hline \multicolumn{2}{|l|}{ Other } \\
\hline ISH (elderly) & Diuretic, calcium antagonist \\
\hline Diabetes mellitus & ACE-I,ARB \\
\hline Pregnancy & Methyldopa, B-blockers, calcium antagonist \\
\hline Black people & Diuretic, calcium antagonist \\
\hline
\end{tabular}

ACE-I = angiotensin-converting enzyme inhibitor; $A R B=$ angiotensin receptor blocker; $\mathrm{BP}=$ blood pressure; $\mathrm{CV}=$ cardiovascular; Diuretic $=$ thiazide or thiazide-like; ESRD = end-stage renal disease;

$\mathrm{ISH}=$ isolated systolic hypertension; $\mathrm{LVH}=$ left ventricular hypertrophy; $\mathrm{MI}=$ myocardial infarction.

There is sufficient evidence to recommend that SBP be lowered to $<140 \mathrm{mmHg}$ and DBP to $<90 \mathrm{mmHg}$ in all non-elderly hypertensive patients. Evidence is missing in the elderly hypertensive patient, in whom the benefit of lowering SBP to $<140 \mathrm{mmHg}$ has not been tested in randomized trials.

A DBP target $<90 \mathrm{mmHg}$ is always recommended, except in patients with DM, in whom values $<85 \mathrm{mmHg}$ are recommended. Nevertheless, it should be considered that DBP values between 80 and $85 \mathrm{mmHg}$ are generally safe and well tolerated. ${ }^{396,397}$

Post hoc analyses of large-scale trials (e.g. ONTARGET, INVEST and VALUE), although suffering from the limitation posed by comparisons of non-randomized groups, suggest that, at least in highrisk hypertensive patients, there may be no advantage in lowering $\mathrm{SBP}$ to $<130 \mathrm{mmHg}$, except perhaps for risk of stroke. A J-curve phenomenon for achieved SBP $<130 \mathrm{mmHg}$ cannot be excluded, ${ }^{447}$ mainly in patients with advanced atherosclerotic diseases and/or frailty. 
The publication of the primary results of the Systolic Blood Pressure Intervention Trial (SPRINT), which compared the benefit of treatment of SBP to a target of $<120 \mathrm{mmHg}$ with treatment to a target of $<140 \mathrm{mmHg}$, challenged the above goal recommendations in high-risk patients without DM. ${ }^{435}$ Frail elderly were underrepresented in this trial. Targeting an SBP $<120 \mathrm{mmHg}$ compared with $<140 \mathrm{mmHg}$ (average values $121 \mathrm{mmHg}$ and $136 \mathrm{mmHg}$, respectively, at the first year) resulted in lower rates of a combined outcome of fatal and non-fatal major $\mathrm{CV}$ events and death from any cause. However, significantly higher rates of serious adverse events, hypotension, syncope, electrolyte abnormalities and acute kidney injury or failure, but not injurious falls, were observed in the intensive-treatment group. The fact that the study was open label in a strategy close to usual care with frequent visits may have helped to adjust the antihypertensive treatment if serious side effects occurred and thus minimized the risk of events. Generalizability of the findings of SPRINT to patients with DM and to frail elderly is problematic.

Based on current data, it may still be prudent to recommend lowering SBP/DBP to values within the range $130-139 / 80-85 \mathrm{mmHg}$, and possibly close to the lower values in this range, in all hypertensive patients.

\section{3a.9.11 Hypertension in special groups}

3a.9.11.1 Diabetes mellitus

See section 3a.8.4.

\section{3a.9.11.2 Elderly}

Large meta-analyses confirm that treatment is highly beneficial in the elderly hypertensive patient. The proportional benefit in patients $>60$ years of age is no less than that for younger patients.

In patients $>60$ years of age with SBP $\geq 160 \mathrm{mmHg}$, there is solid evidence to recommend reducing SBP to $140-150 \mathrm{mmHg}$. However, in fit patients $<80$ years of age, BP-lowering treatment may be considered at SBP values $\geq 140 \mathrm{mmHg}$, with a target SBP $<140 \mathrm{mmHg}$ if treatment is well tolerated.

Evidence is now available from an outcome trial that BP-lowering treatment also has benefits in patients $\geq 80$ years of age. Because patients in the Hypertension in the Very Elderly Trial (HYVET) were generally in good condition, the extent to which HYVET data can be extrapolated to more frail octogenarians is uncertain. In individuals $>80$ years of age with an initial SBP $\geq 160 \mathrm{mmHg}$, it is recommended to reduce SBP to $140-150 \mathrm{mmHg}$, provided the individual is in good physical and mental condition. ${ }^{436}$ The decision to treat should be made on an individual basis, and patients should always be carefully monitored during treatment, with $\mathrm{BP}$ also measured in the standing position. In frail elderly patients, it is recommended to be careful and reach a decision based on monitoring of the clinical effects of treatment.

\section{3a.9.12 Resistant hypertension}

The definition of hypertension resistant to treatment is when a therapeutic strategy that includes appropriate lifestyle measures plus a diuretic and two other BP-lowering drugs belonging to different classes at adequate doses (but not necessarily including a mineralocorticoid receptor antagonist) fails to lower SBP and DBP values to $<140 \mathrm{mmHg}$ and $<90 \mathrm{mmHg}$, respectively. Depending on the population examined and the level of medical screening, the prevalence of resistant hypertension has been reported to range from 5 to $30 \%$ of the overall hypertensive population, with figures $<10 \%$ probably representing the true prevalence. Resistant hypertension is associated with a high risk of $\mathrm{CV}$ and renal events. ${ }^{453} \mathrm{Be}$ fore a patient is considered treatment resistant, consideration should be given to a lack of treatment adherence, white coat syndrome or high salt or alcohol intake, as well as drug intake with a potential pressor effect, the use of recreational drugs or secondary hypertension. In these patients, physicians should check whether the drugs included in the existing multiple drug regimen have any BP-lowering effect and withdraw them if their effect is absent or minimal. Anti-aldosterone drugs, amiloride or the $\alpha_{1}$ blocker doxazosin should be considered as the fourth or fifth drug, if no contraindication exists (eGFR $<45 \mathrm{~mL} / \mathrm{min} / \mathrm{m}^{2}$ and/or serum potassium $>4.5 \mathrm{mmol} / \mathrm{L}$ for mineralocorticoid receptor antagonists).

In the case of drug treatment ineffectiveness (i.e. resistant hypertension), specialist referral should be considered. Any invasive approach in these patients should be considered only for truly resistant hypertensive patients, with clinic values $\geq 160 \mathrm{mmHg}$ SBP or $\geq 110 \mathrm{mmHg}$ DBP and with BP elevation confirmed by ABPM.

\section{3a.9.13 Duration of treatment and follow-up}

Generally, BP-lowering therapy should be maintained indefinitely. Cessation of therapy in hypertensive patients is mostly followed by the return of BP to pretreatment levels. In some patients, in whom treatment is accompanied by effective BP control for an extended period, it may be possible to reduce the number and/or dosage of drugs. This may be particularly the case if BP control is accompanied by healthy lifestyle changes. A reduction of medications should be made gradually and the patient should be checked frequently because of the risk of reappearance of hypertension.

Patient follow-up should be carried out by the health care team, which should include physicians, nurses and pharmacists in a concerted activity, although wide variations exist in the organization of health care systems across Europe. In some countries, the task relies more on physicians, while in others, specially educated and trained nurses play a more prominent role. Once the target is reached, a visit interval of a few months is reasonable; there is no difference in BP control between 3 and 6 month intervals. The regression of asymptomatic organ damage occurring during treatment reflects the treatment-induced reduction of morbid and fatal CV events; ${ }^{454}$ however, a cost-effectiveness analysis in which signs of organ damage should best be assessed in the follow-up has never been done. $^{447}$

\section{Gaps in evidence}

- Drug treatment in white coat hypertension.

- If and when drug treatment should be started in the high-normal BP range.

- The optimal office BP values (i.e. the most protective and safe) for patients to achieve by treatment in different demographic and clinical conditions. 
- The optimal out-of-office (home and ambulatory) BP targets and whether the treatment strategies based on control of out-of-office BP provide an advantage over strategies based on conventional (office) BP control.

\section{3a.10 Antiplatelet therapy}

\section{Key messages}

- Antiplatelet therapy is not recommended in individuals free from CVD, due to the increased risk of major bleeding.

\section{Recommendations for antiplatelet therapy}

\begin{tabular}{|c|c|c|c|}
\hline Recommendations & Class $^{\mathrm{a}}$ & Level $^{\mathrm{b}}$ & $\operatorname{Ref}^{c}$ \\
\hline $\begin{array}{l}\text { In acute coronary syndromes, a } \\
\mathrm{P}^{2} \mathrm{Y}_{12} \text { inhibitor for } 12 \text { months is } \\
\text { recommended in addition to aspirin, } \\
\text { unless there are contra-indications } \\
\text { such as excessive risk of bleeding. }\end{array}$ & I & $\mathbf{A}$ & $455-457$ \\
\hline $\begin{array}{l}\mathrm{P} 2 \mathrm{Y}_{12} \text { inhibitor administration for a } \\
\text { shorter duration of } 3-6 \text { months after } \\
\text { DES implantation may be considered } \\
\text { in patients deemed at high bleeding } \\
\text { risk. }\end{array}$ & Ilb & $\mathbf{A}$ & $458-461$ \\
\hline $\begin{array}{l}\mathrm{P} 2 \mathrm{Y}_{12} \text { inhibitor administration in } \\
\text { addition to aspirin beyond I year } \\
\text { may be considered after careful } \\
\text { assessment of ischaemic and bleeding } \\
\text { risks of the patient. }\end{array}$ & Ilb & $\mathbf{A}$ & 462,463 \\
\hline $\begin{array}{l}\text { In the chronic phase (>12 months) } \\
\text { after MI, aspirin is recommended. }\end{array}$ & $\mathbf{I}$ & $\mathbf{A}$ & 464 \\
\hline $\begin{array}{l}\text { In patients with non-cardioembolic } \\
\text { ischaemic stroke or TIA, prevention } \\
\text { with aspirin only, or dipyridamole } \\
\text { plus aspirin or clopidogrel alone is } \\
\text { recommended. }\end{array}$ & I & $\mathbf{A}$ & $465-467$ \\
\hline $\begin{array}{l}\text { Prasugrel is not recommended in } \\
\text { patients with stable CAD. Ticagrelor } \\
\text { is not recommended in patients with } \\
\text { stable CAD without a previous ACS. }\end{array}$ & III & C & 463 \\
\hline $\begin{array}{l}\text { In patients with non-cardioembolic } \\
\text { cerebral ischaemic events, } \\
\text { anticoagulation is not recommended. }\end{array}$ & III & B & 468,469 \\
\hline $\begin{array}{l}\text { Antiplatelet therapy is not } \\
\text { recommended in individuals without } \\
\text { CVD due to the increased risk of } \\
\text { major bleeding. }\end{array}$ & III & B & 464 \\
\hline
\end{tabular}

$\mathrm{ACS}=$ acute coronary syndrome; $\mathrm{CAD}=$ coronary artery disease; $\mathrm{DES}=$ drugeluting stent; $\mathrm{MI}=$ myocardial infarction; $\mathrm{TIA}=$ transient ischaemic attack.

${ }^{a}$ Class of recommendation.

Level of evidence.

${ }^{\mathrm{C}}$ Reference(s) supporting recommendations.

\section{3a.10.1 Antiplatelet therapy in individuals without cardiovascular disease}

Prevention in individuals without overt CV or cerebrovascular disease was investigated using long-term aspirin vs. control in a systematic review of six trials including 95000 individuals. A risk reduction from $0.57 \%$ to $0.51 \%$ /year of serious vascular events was found by the Antithrombotic Trialists' Collaboration. ${ }^{464}$ Major gastrointestinal and extracranial bleeds increased by $0.03 \%$ /year. The risk of vascular mortality was not changed by treatment with aspirin. In a recent Japanese study, ${ }^{470}$ patients $60-$ 85 years of age presenting with hypertension, dyslipidaemia or DM were randomized to treatment with $100 \mathrm{mg}$ aspirin or placebo. The 5 year cumulative primary outcome event rate (death from CV causes) was not significantly different between the groups, but treatment with aspirin significantly increased the risk of extracranial haemorrhage requiring transfusion or hospitalization $(P=0.004)$. In individuals with multiple risk factors, clopidogrel in combination with aspirin vs. aspirin alone was tested in the Clopidogrel for High Atherothrombotic Risk and Ischemic Stabilisation, Management, and Avoidance (CHARISMA) trial and was not of significant benefit. ${ }^{471}$ The results of the four major ongoing primary prevention trials-two in DM patients, ${ }^{472,473}$ one in individuals of advanced age ${ }^{474}$ and one in individuals with moderate $\mathrm{CV}$ risk ${ }^{475}$-are expected to become available over the next 5 years.

\section{3a.10.2 Antiplatelet therapy in individuals with cardiovascular or cerebrovascular disease}

In the acute state of cerebral ischaemia, aspirin reduced the risk of new vascular events within 2-4 weeks by preventing four recurrent strokes and five vascular deaths per 1000 patients treated. $^{476}$

Following an episode of ACS, dual antiplatelet therapy given for a period of 12 months is a standard treatment based on results from the CURE, ${ }^{455}$ TRITON $^{456}$ and PLATO ${ }^{457}$ studies, whereas no clinical studies support the use of prasugrel and ticagrelor in patients with stable CAD.

In long-term prevention after $\mathrm{Ml}$, stroke or PAD, aspirin is the most studied drug. In a meta-analysis of 16 trials comprising 17 000 individuals, the Antithrombotic Trialists' Collaboration, ${ }^{464}$ aspirin treatment was associated with serious vascular events in $6.7 \%$ of patients/year vs. $8.2 \%$ of controls. The risk of total stroke was $2.08 \% /$ year vs. $2.59 \%(P=0.002)$ and coronary events was $4.3 \% / y e a r$ vs. $5.3 \%(P=0.0001)$. Aspirin was associated with a $10 \%$ reduction in total mortality, with a significant excess of major bleeds; nevertheless, the benefits of aspirin exceeded the bleeding hazards.

In patients with prior MI, stroke or PAD, clopidogrel showed a slight superiority with respect to aspirin; the rate of serious vascular events was $5.32 \% /$ year with clopidogrel vs. $5.83 \%$ 
with aspirin $(P=0.043)$. There were slightly more bleeds with aspirin. ${ }^{477}$

Adding aspirin to clopidogrel in high-risk patients with recent ischaemic stroke or transient ischaemic attack (TIA) was associated with a non-significant difference in reducing major vascular events. However, the risk of life-threatening or major bleeding was significantly increased by the addition of aspirin. ${ }^{478}$

On the other hand, the Clopidogrel in High-risk patients with Acute Non-disabling Cerebrovascular Events (CHANCE) trial showed that the combined treatment of clopidogrel and aspirin decreased the 90 day risk of stroke without increasing haemorrhage compared with aspirin alone in 5170 Chinese patients randomized within $24 \mathrm{~h}$ after symptom onset of minor stroke or TIA to clopidogrel-aspirin or to aspirin alone. $^{479}$

In patients with prior non-cardioembolic ischaemic stroke, dual antiplatelet therapy with dipyridamole plus aspirin showed superiority over aspirin. ${ }^{465}$ In such patients, oral vitamin $\mathrm{K}$ antagonists are not superior to aspirin and are associated with a higher bleeding risk. $^{468,469}$

In patients with ischaemic stroke, a direct comparison of dipyridamole plus aspirin vs. clopidogrel alone ${ }^{466}$ showed similar rates of recurrent stroke, including haemorrhagic stroke. There was a higher frequency of major haemorrhagic events with dipyridamole plus aspirin $(4.1 \%$ vs. $3.6 \%)$.

Vorapaxar is a novel antiplatelet agent that selectively inhibits the cellular actions of thrombin through antagonism of PAR-1. In 26449 patients who had a history of $\mathrm{MI}$, ischaemic stroke or $\mathrm{PAD}$, the primary composite endpoint-CV death, $\mathrm{MI}$ or stroke - was significantly reduced with vorapaxar in addition to standard antiplatelet therapy, but with increased risk of moderate or severe bleeding. ${ }^{480}$ Vorapaxar cannot be recommended systematically in patients with stable atherosclerotic disease.

\section{Gap in evidence}

- Experience with the new antiplatelet drugs in patients with stable CAD is still limited and so is their use in combination with anticoagulant treatment.

\section{3a.11 Adherence to medication \\ Key messages}

- Adherence to medication in individuals at high risk and in patients with CVD is low.

- Several types of interventions are effective in improving medication adherence.

- The polypill may increase adherence to treatment and improve CV risk factor control.

\section{Recommendations for achieving medication adherence}

\begin{tabular}{|l|l|l|l|}
\hline Recommendations & Class $^{\mathbf{a}}$ & Level $^{\mathbf{b}}$ & Ref $^{\mathrm{c}}$ \\
\hline $\begin{array}{l}\text { Simplifying the treatment regimen } \\
\text { to the lowest acceptable level is } \\
\text { recommended, with repetitive } \\
\text { monitoring and feedback. In case of } \\
\text { persistent non-adherence, multi- } \\
\text { session or combined behavioural } \\
\text { interventions are recommended. }\end{array}$ & I & A & 48I \\
\hline $\begin{array}{l}\text { It is recommended that physicians } \\
\text { assess medication adherence, and } \\
\text { identify reasons for non-adherence in } \\
\text { order to tailor further interventions. }\end{array}$ & I & C & $482-484$ \\
\hline $\begin{array}{l}\text { The use of the polypill and } \\
\text { combination therapy to increase } \\
\text { adherence to drug therapy may be } \\
\text { considered. }\end{array}$ & Ilb & B & 485,486 \\
\hline
\end{tabular}

${ }^{\mathrm{a} C}$ Class of recommendation.

'Level of evidence.

'Reference(s) supporting recommendations.

Adherence to medication in individuals at high risk and in patients with CVD is low, resulting in worse outcomes and higher health care costs. ${ }^{487}$ One month after AMI, $25-30 \%$ of patients stop at least one drug, with a progressive decline in adherence over time. After 1 year, only $50 \%$ of patients report persistent use of statins, $\beta$-blockers or BP-lowering therapy. ${ }^{483,484}$ The reasons for poor adherence are multifactorial (Table $F$ in web addenda). ${ }^{483}$

Cost-related non-adherence is a relevant problem in many health care systems. For example, in American veterans, adherence to lipid-lowering medication decreased as co-payments increased. ${ }^{488}$ Depression also independently doubles the risk for nonadherence. ${ }^{489}$ Reasons for non-adherence tend to cluster; for example, complex medication regimens may be important in individuals with chronic disease or multiple risk factors. This places high demands on caregivers to provide clear advice and continuous care. ${ }^{484}$ Physicians often fail to communicate critical elements of medication use (e.g. possible adverse effects, how long to take the medication and the frequency or timing of dosing). ${ }^{490}$ Thus there is a need to train physicians to identify risk factors for non-adherence and promote adherence to medication.

Several interventions are effective in improving adherence in chronic conditions. ${ }^{481}$ Solely reducing dosage demands resulted in strong effects, but other interventions such as repetitive monitoring and feedback, multisession information and combined behavioural interventions have shown effects ranging from minor to strong. ${ }^{481}$ Collaboration with pharmacists or pharmacist-directed care was 
superior to standard care with respect to BP, total cholesterol and LDL-C levels. ${ }^{491}$ Knowledge of one's CAC score may increase risk perception and adherence to medication. ${ }^{492}$

In clinical practice, physicians should assess adherence to medication, identify reasons for possible non-adherence and promote adherence according to the following established principles:

- Provide clear advice regarding the benefits and possible adverse effects of the medication and the duration and timing of dosing.

- Consider patients' habits and preferences (shared decisionmaking).

- Simplify the treatment regimen to the lowest feasible level.

- Ask patients in a non-judgmental way how the medication works for them and discuss possible reasons for non-adherence (e.g. side effects, worries).

- Implement repetitive monitoring and feedback.

- Introduce physician assistants and/or trained nurses or pharmacists whenever it is necessary and feasible.

- In case of persistent non-adherence, offer multisession or combined behavioural interventions [e.g. for patients after myocardial revascularization in a cardiac rehabilitation (CR) setting].

\section{3a.11.1 Polypill}

More than a decade ago, Wald and Law quantified the efficacy and adverse effects of a fixed dose combination (FDC) from published trials and proposed that an FDC consisting of a statin, BP-lowering agents, aspirin and folate could potentially reduce CVD by $80 \%$ in individuals $>55$ years of age. ${ }^{493}$

A recent systematic review and meta-analysis ${ }^{485}$ summarizes nine randomized trials $(n=7047)$ on FDCs, largely conducted in higher-risk populations and primarily designed to evaluate changes in CV risk factors and adherence. However, FDCs included in the analysis were single pills of diverse composition and doses (although all contained a statin and at least one BP-lowering agent) and had a range of comparators (placebo, single-drug active component or 'usual care'). No convincing evidence of either benefit or risk for FDCs in terms of all-cause mortality or CV events was found. FDC therapy improved adherence (only one trial) compared with a multidrug strategy by $33 \%(95 \% \mathrm{Cl} 26 \%, 41 \%)$ compared with usual care.

In another international study, not included in the previous meta-analysis, 695 CAD patients were randomized to test the effect of an FDC polypill containing aspirin, simvastatin and ramipril, or the three drugs separately. The study showed that FDC improved adherence compared with separate medications after 9 months of follow-up (adherence 63\% vs. 52\%; $P=0.006$ ). ${ }^{486}$

The polypill should not be considered in isolation, but as an integral part of a comprehensive CVD prevention strategy that includes efforts to reduce tobacco use, increase PA and increase consumption of a heart-healthy diet. ${ }^{494}$ However, potential adverse effects of a single drug component of the FDC cannot be specifically corrected and therefore may also affect treatment adherence to the other components. Until we have the results of ongoing trials with major CVD as the endpoint, the polypill cannot be recommended for prevention of CVD and cannot be prescribed to all individuals.

\section{Gaps in evidence}

- There is limited evidence about which interventions for improving adherence to medication are the most effective and in whom (e.g. young-old, male-female, high vs. low socio-economic status).

- The effect of the polypill as a global strategy to reduce CVD remains uncertain.

\section{3b. How to intervene at the individual level: disease-specific intervention-atrial fibrillation, coronary artery disease, chronic heart failure, cerebrovascular disease, peripheral artery disease (web addenda)}

\section{3c. How to intervene at the population level}

\section{3c.1 Introduction (healthy lifestyle promotion)}

The population level approach follows the Geoffrey Rose paradigm: small shifts in the risk of disease (or risk factor) across a whole population consistently lead to greater reductions in disease burden than a large shift in high-risk individuals only. This population-wide approach has further advantages: it addresses $\mathrm{CV}$ health over the entire life course and reduces health inequalities.

Individual behaviour is enacted in an environment with hierarchical levels, which encompass individual choice, family influence, cultural and ethnic grouping, workplace, health care and policy at the state and global levels (e.g. EU policies and international trade agreements). The aim of this section is to provide stakeholders with evidence-based suggestions for the most effective interventions to improve CVD risk that can be implemented at a group, community, regional, national or global level. Health care professionals play an important role in advocating evidence-based population-level interventions.

Strategies such as 'nudging' (to push mildly) and 'default' have been proposed as tools. By changing the context to make healthy decisions the default, the individual is nudged in the healthy direction. The task for both national and local authorities is to create social environments that provide healthier defaults.

The evidence presented here builds on recent comprehensive reviews ${ }^{311,495-497}$ and individual studies and summarizes the 'totality of evidence'. It is rarely feasible to use an RCT to evaluate population-level interventions (in contrast to individual-level interventions). The guidelines committee has chosen to follow the definition of 'level of evidence' for populationlevel approaches. Thus consistent findings from several highquality studies were considered sufficient to merit strong recommendations. 


\section{3c.2 Population-based approaches to diet Key messages}

- Structural measures such as product reformulation, limitations on marketing and taxes on unhealthy foods, subsidizing the costs of healthier foods and consumer-friendly nutrition labelling will improve healthy food choices.

- Healthy environments in the community, at schools and in workplaces will stimulate a healthy lifestyle.
Many EU countries recognize the health benefits of reducing the energy density and salt and sugar content as well as replacement of trans and saturated fat by unsaturated fat in foods and drinks. ${ }^{311,495,498}$ These have led to successful reductions in trans fats ${ }^{499}$ and salt, ${ }^{495,499-501}$ the latter likely leading to decreases in BP. ${ }^{501}$ Mandatory upper limits harmonized across the EU will ensure that all EU consumers are equally protected. $^{498}$

\section{Recommendations for population-based approaches to diet}

\begin{tabular}{|c|c|c|c|c|}
\hline & Recommendations & Class $^{\mathrm{a}}$ & Level $^{\mathbf{b}}$ & $\operatorname{Ref}^{c}$ \\
\hline \multirow{4}{*}{$\begin{array}{l}\text { Governmental } \\
\text { restrictions and } \\
\text { mandates }\end{array}$} & $\begin{array}{l}\text { Legislation on composition of foods to reduce energy density, salt and saturated fat, and (added) sugar } \\
\text { content of foods and beverages, and to limit portion sizes is recommended. }\end{array}$ & I & B & $\begin{array}{l}311,495 \\
\quad 496 \\
498-501\end{array}$ \\
\hline & Elimination of industrially produced transfats is recommended & I & $\mathbf{A}$ & 316 \\
\hline & $\begin{array}{l}\text { Facilitating an integrated and coherent policy and activities of the (local) governments, non-governmental } \\
\text { organizations, food industry, retail, catering, schools, workplaces and other stakeholders to promote a } \\
\text { healthy diet and to prevent overweight is recommended. }\end{array}$ & I & C & 498,502 \\
\hline & $\begin{array}{l}\text { Legislation restricting marketing aimed at children of foods that are high in fats, sugar and/or salt, less } \\
\text { healthy options, junk foods, drinks with alcohol and non-alcoholic beverages rich in sugar (e.g. on TV, } \\
\text { internet, social media and on food packages) is recommended. }\end{array}$ & I & C & $\begin{array}{l}311,495 \\
503,504\end{array}$ \\
\hline $\begin{array}{l}\text { Media and } \\
\text { education }\end{array}$ & $\begin{array}{l}\text { Reformulation of foods accompanied by educational information campaigns should be considered to } \\
\text { create awareness on the nutrition quality of foods among consumers. }\end{array}$ & Ila & C & 505,506 \\
\hline \multirow{3}{*}{$\begin{array}{l}\text { Labelling and } \\
\text { information }\end{array}$} & Mandatory and harmonized simplified front-of-pack nutrition labelling is recommended. & I & C & $\begin{array}{l}311,496 \\
506\end{array}$ \\
\hline & $\begin{array}{l}\text { Independently and coherently formulated criteria for nutrient profiles should be considered in support of } \\
\text { health and nutrition claims and front-of-pack logos (e.g. traffic lights, healthy choices, key-holes). }\end{array}$ & Illa & C & 311 \\
\hline & $\begin{array}{l}\text { Mandatory nutrition labelling for non-pre-packaged foods, including in restaurants hospitals and } \\
\text { workplaces, should be considered. }\end{array}$ & Ila & C & 311,506 \\
\hline \multirow{2}{*}{$\begin{array}{l}\text { Economic } \\
\text { incentives }\end{array}$} & Pricing and subsidy strategies are recommended to promote healthier food and beverage choices. & $\mathbf{I}$ & B & $\begin{array}{l}311,495 \\
507,508\end{array}$ \\
\hline & Taxes on foods and beverages rich in sugar and saturated fat, and on alcoholic drinks are recommended. & $\mathbf{I}$ & B & $\begin{array}{l}311,495 \\
507,508\end{array}$ \\
\hline \multirow{2}{*}{ Schools } & $\begin{array}{l}\text { At all schools, pre-schools and daycare centres a multi-component, comprehensive and coherent policy is } \\
\text { recommended to promote a healthy diet. }\end{array}$ & I & B & $\begin{array}{l}311,495 \\
502,504\end{array}$ \\
\hline & Availability of fresh drinking water and healthy foods in schools, and in vending machines is recommended. & $\mathbf{I}$ & B & $\begin{array}{l}311,495 \\
504\end{array}$ \\
\hline \multirow{2}{*}{ Workplaces } & $\begin{array}{l}\text { At all companies a coherent and comprehensive health policy and nutritional education are } \\
\text { recommended to stimulate the health awareness of employees. }\end{array}$ & I & B & $\begin{array}{l}311,495 \\
496,509\end{array}$ \\
\hline & $\begin{array}{l}\text { Increased availability of fresh drinking water and improved nutritional quality of food served and/or sold } \\
\text { in the workplace, and in vending machines should be considered. }\end{array}$ & Ila & C & 311,496 \\
\hline $\begin{array}{l}\text { Community } \\
\text { setting }\end{array}$ & $\begin{array}{l}\text { Regulation of location and density of fast food and alcohol purchasing outlets and other catering } \\
\text { establishments should be considered. }\end{array}$ & Ila & C & $495-497$ \\
\hline
\end{tabular}

${ }^{\text {a }}$ Class of recommendation.

bLevel of evidence.

${ }^{\mathrm{c}}$ Reference(s) supporting recommendations.

Diet is a powerful determinant of obesity, hypertension, dyslipidaemia, DM and CV health. Rapid reductions in CV events can be seen after changes in diet at the population level. ${ }^{497,510}$ Stakeholders, including health care professionals, have a shared responsibility for population-based approaches and can help to promote healthy diets and environments ${ }^{495,498}$ (Figure $L$ in web addenda ${ }^{504}$ ).
Governments can facilitate nationwide cooperation between (local) governments, non-governmental organizations (NGOs), the food industry, retail, catering, schools, workplaces and other stakeholders. The French Ensemble Prévenons l'Obésité des Enfants (EPODE) project is an example of a multistakeholder cooperation that can help decrease childhood obesity. ${ }^{502}$ Similar 
projects are in place in Belgium, Spain, The Netherlands, Greece and Australia.

Educational tools and intervention in the media may lead to a reduction in childhood obesity (e.g. limiting children's exposure to advertising of unhealthy foods). ${ }^{311,495,497,502,503} \ln 2013$, the European Heart Network (EHN) published a report summarizing recent developments in relation to the marketing of unhealthy foods to children. ${ }^{504}$ Accompanying consumer awareness campaigns on healthy foods ${ }^{505}$ and nutrition labelling can be effective. Consumers understand different systems of labelling and their use has a positive impact on sales. ${ }^{506}$ The EHN is calling for a simplified, colour-coded, front-of-pack scheme indicating high, medium and low levels of nutrients. ${ }^{311,495,497}$ This scheme can be applied to all foods and could be expanded to certain restaurants. ${ }^{311}$ Labelling also stimulates the reformulation of foods, ${ }^{504}$ and thus it has the potential to improve dietary intake and reduce diet-related chronic diseases.

Pricing strategies can lead to a decline in the sales of unhealthy foods and an increase in the sales of fruits and vegetables. Modelling studies have demonstrated that food taxes could improve energy and nutrient intake, BMl and health. ${ }^{495,507,508}$ An increasing number of countries have introduced taxes on unhealthy foods and drinks [e.g. the fat tax in Denmark (caused a 10-15\% decrease in consumption; now repealed) and the junk food tax in Hungary (sales declined by $27 \%)]^{504}$

Consideration should be given to balanced economic incentives: subsidies and taxes to counteract any unbalanced effect on the socially disadvantaged.

To tackle obesity, every school and workplace should have a policy to promote a healthy environment and provide healthy foods and meals. ${ }^{495,504}$ Ideally, health education should be part of the school curriculum. Workplace dietary modification interventions alone and in combination with nutrition education or environmental changes have shown improvements in the consumption of fruits and vegetables and/or fats. ${ }^{509}$

In the community, planning the location and density of fast food outlets and good access to supermarkets is needed, especially in deprived areas. ${ }^{495-497}$

\section{Gaps in evidence}

- Scientific evidence of the impact of food and nutrition policy instruments on outcome measures such as food intake and CV health is largely lacking.

- Cost-effectiveness studies of the impact of different policy options are also limited.

\section{3c.3 Population-based approaches to physical activity \\ Key messages}

- A sedentary lifestyle and physical inactivity affects more than half of the population worldwide.

- Regular PA is recommended for all men and women as a lifelong part of lifestyle, with at least $150 \mathrm{~min} /$ week of moderate activity or at least $75 \mathrm{~min} /$ week of vigorous activity or an equivalent combination thereof. Any activity is better than none and more activity is better than some.

- Population-based interventions are effective in promoting PA.

- Early childhood education in PA and movement should start at preschool/kindergarten.

- Daily PA at school should be at least 30 minutes, and preferably 60 minutes.

- Good neighbourhoods and a safe environment enhances and encourages PA in everyday life.

\section{Recommendations for population-based approaches to physical activity}

\begin{tabular}{|c|c|c|c|c|}
\hline & Recommendations & Class $^{\mathbf{a}}$ & Level $^{\mathrm{b}}$ & $\operatorname{Ref}^{c}$ \\
\hline $\begin{array}{l}\text { Governmental } \\
\text { restrictions and } \\
\text { mandates }\end{array}$ & Consideration of PA when planning new landscaping/buildings or towns is recommended. & I & C & $\begin{array}{c}3 \mid I \\
5|1-5| 3\end{array}$ \\
\hline \multirow{2}{*}{$\begin{array}{l}\text { Media and } \\
\text { education } \\
\text { See also section } \\
3 \mathrm{c.} 2 \text { for multi- } \\
\text { component } \\
\text { interventions }\end{array}$} & $\begin{array}{l}\text { Sustained, focused, media and educational campaigns, using multiple media modes (e.g. apps, posters, flyers } \\
\text { and signage) may be considered to promote PA. }\end{array}$ & Illb & C & 496 \\
\hline & $\begin{array}{l}\text { Short term community-based educational programmes and wearable devices promoting healthy } \\
\text { behaviours, such as walking should be considered. }\end{array}$ & Ila & C & $5 \mid 4-516$ \\
\hline \multirow{2}{*}{$\begin{array}{l}\text { Labelling and } \\
\text { information }\end{array}$} & Point-of-decision prompts should be considered to encourage use of stairs. & Ila & B & 516,517 \\
\hline & $\begin{array}{l}\text { Exercise prescription for health promotion by physicians, especially GPs, similar to drug prescription } \\
\text { should be considered. }\end{array}$ & Ila & C & 517,518 \\
\hline \multirow{4}{*}{$\begin{array}{l}\text { Economic } \\
\text { incentives }\end{array}$} & Increased fuel (gasoline) taxes should be considered to increase active transport/commuting. & Ila & C & 512,518 \\
\hline & $\begin{array}{l}\text { Tax reduction incentives for individuals to purchase exercise equipment or health club/fitness } \\
\text { memberships may be considered. }\end{array}$ & Illb & C & 512,518 \\
\hline & Sustained individual financial incentives may be considered for increased activity/fitness or weight loss. & Illb & C & $\begin{array}{l}512,513 \\
518\end{array}$ \\
\hline & $\begin{array}{l}\text { Tax reduction incentives to employers to offer comprehensive worksite wellness programmes } \\
\text { with nutrition, } \mathrm{PA} \text {, and tobacco cessation/prevention components may be considered. }\end{array}$ & Illb & C & 512,518 \\
\hline
\end{tabular}




\section{Recommendations for population-based approaches to physical activity (continued)}

\begin{tabular}{|c|c|c|c|c|}
\hline & Recommendations & Class $^{\mathrm{a}}$ & Level $^{\mathrm{b}}$ & $\operatorname{Ref}^{c}$ \\
\hline \multirow{4}{*}{$\begin{array}{l}\text { Schools } \\
\text { See also section } \\
3 c .2 \text { for multi- } \\
\text { component } \\
\text { interventions }\end{array}$} & $\begin{array}{l}\text { Increased availability and types of school playground spaces and equipment for exercise activity and } \\
\text { sports are recommended. }\end{array}$ & $\mathbf{I}$ & C & 512,519 \\
\hline & Regular classroom PA breaks during academic lessons should be considered. & Ila & B & 511 \\
\hline & $\begin{array}{l}\text { Increasing active commuting to school should be considered e.g. a walking school bus programme with } \\
\text { supervised walking routes to and from school for safety. }\end{array}$ & Ila & C & 512,514 \\
\hline & $\begin{array}{l}\text { Increased number and duration of PA classes, with revised PA curricula to implement at least moderate } \\
\text { activity and trained teachers in exercise and sports may be considered. }\end{array}$ & IIlb & B & 511,513 \\
\hline \multirow{3}{*}{$\begin{array}{l}\text { Workplaces } \\
\text { See also section } \\
3 c .2 \text { for multi- } \\
\text { component } \\
\text { interventions }\end{array}$} & Comprehensive worksite wellness programmes should be considered with nutrition and PA components. & Ila & B & \\
\hline & $\begin{array}{l}\text { Structured worksite programmes that encourage PA and provide a set time for PA during work hours } \\
\text { should be considered. Improving stairway access and appeal, potentially in combination with "skip-stop" } \\
\text { elevators that skip some floors should be considered. }\end{array}$ & Ila & C & $\begin{array}{c}512 \\
520-522\end{array}$ \\
\hline & Promoting worksite fitness centres should be considered. & Ila & C & 517 \\
\hline \multirow{3}{*}{$\begin{array}{l}\text { Community } \\
\text { setting }\end{array}$} & $\begin{array}{l}\text { Health care providers should consider inquiring about PA in every medical encounter and adding it to the } \\
\text { record. In addition, they should consider to motivate the individual and promote PA. }\end{array}$ & Ila & C & 512,520 \\
\hline & $\begin{array}{l}\text { Improved accessibility of recreation and PA spaces and facilities (e.g. building of parks and playgrounds, } \\
\text { increasing operating hours, use of school facilities during non-school hours), improved walkability should } \\
\text { be considered. }\end{array}$ & Ila & C & 512,520 \\
\hline & Improved neighbourhood aesthetics (to increase activity in adults) should be considered. & Ila & C & 512,520 \\
\hline
\end{tabular}

GPs = general practitioners; $\mathrm{PA}=$ physical activity

${ }^{a}$ Class of recommendation.

bevel of evidence.

${ }^{\mathrm{C}}$ Reference(s) supporting recommendations.

In most countries, the majority of adults and children do not achieve the minimum activity levels recommended by health organizations: every person should engage in moderate exercise for at least $150 \mathrm{~min} /$ week and/or vigorous activity for at least $75 \mathrm{~min} /$ week or an equivalent thereof. ${ }^{258,520}$ For population-based prevention, the statement of 'seven best investments',512 gives the universal and comprehensive advice to promote PA. ${ }^{512}$

Specific national guidelines developed for PA include frequency, intensity, time (duration) and type of activity (FITT), which can influence legislative initiatives, such as 'active cities' with bicycle lanes and walking paths and reallocation of road space.

Focused media and educational campaigns can initiate physical activities. ${ }^{519}$ Recent campaigns from sports medicine societies have endorsed PA prescriptions from GPs (http://www.efsma.net). The PA should be assessed at every medical encounter.

A simple strategy for increasing daily exercise is to encourage the use of stairs rather than the elevator or escalator, along with signage directing people to the stairs and health promotion materials endorsing the positive effects of stair climbing. ${ }^{516}$

Interestingly, an increase in fuel prices may reduce car driving and increase active commuting for those who live within reasonable walking or biking distances, with the exception of diseased or disabled persons. ${ }^{496}$
PA education should be started in preschool/kindergarten and continue for all levels of primary and secondary education. For school education, a multicomponent intervention should focus on improving lifelong PA by trained teachers. At least $3 \mathrm{~h} /$ week, and preferably $60 \mathrm{~min} /$ day, of sports or PA should be performed during school time. ${ }^{511}$ Regular activity also improves cognitive competence for learning. ${ }^{513,521}$ This activity can be supplemented with active commuting to school and supervised walking routes to and from school, with less reliance on buses. ${ }^{514}$

Workplaces can offer different opportunities for PA promotion. Some larger companies offer a fitness centre on company grounds without fees for employees. Workplace-based interventions may increase regular physical exercise for employees, but results demonstrate that a high proportion of workers do not participate. $^{522}$ Therefore, supervisors and managers should endorse workplace interventions by encouraging employees to undertake PA.

Improved accessibility to recreation and exercise facilities with increased operating hours and utilizing community resources such as school playgrounds may increase regular PA in all age groups and reduce socio-economic inequality of access. ${ }^{517}$

\section{Gap in evidence}

- Sustainability and long-term outcomes of population-based actions to promote PA. 


\section{3c.4 Population-based approaches to smoking and other tobacco use}

\section{Key messages}

- Adolescence is the most vulnerable period for uptake of smoking, with lifelong consequences.

- High taxes on all tobacco products is the most effective policy measure to reduce smoking uptake by the young.

- Restrictions on smokeless tobacco due to strong evidence of harm.
- Restrictions on e-cigarettes due to uncertainty regarding safety and effect.

- Plain packaging is effective in reducing tobacco consumption.

- Restrictions on advertising, promotion and sponsorship by the tobacco industry.

- A goal would be to make a common European decision to achieve a smoking-free Europe by 2030.

\section{Recommendations for population-based approaches to smoking and other tobacco use}

\begin{tabular}{|c|c|c|c|c|}
\hline & Recommendations & Class $^{a}$ & Level $^{\mathrm{b}}$ & $\operatorname{Ref}^{c}$ \\
\hline \multirow{9}{*}{$\begin{array}{l}\text { Governmental } \\
\text { restrictions and } \\
\text { mandates }\end{array}$} & Banning smoking in public places is recommended to prevent smoking and to promote smoking cessation. & $\mathbf{I}$ & $\mathbf{A}$ & 495 \\
\hline & $\begin{array}{l}\text { Banning smoking in public places, outside public entrances, workplaces, in restaurants and bars is } \\
\text { recommended to protect people from passive smoking. }\end{array}$ & $\mathbf{I}$ & $\mathbf{A}$ & 496,523 \\
\hline & Prohibit sales of tobacco products to adolescents are recommended. & $\mathbf{I}$ & $\mathbf{A}$ & 495 \\
\hline & Banning of tobacco vending machines is recommended. & $\mathbf{I}$ & A & 495 \\
\hline & Restrictions on advertising, marketing and sale of smokeless tobacco are recommended. & $\mathbf{I}$ & $\mathbf{A}$ & $524-527$ \\
\hline & Complete ban on advertising and promotion of tobacco products are recommended. & $\mathbf{I}$ & B & 496 \\
\hline & Reduced density of retail tobacco outlets in residential areas, schools and hospitals is recommended. & $\mathbf{I}$ & B & 496 \\
\hline & Harmonization of border sales and tax free sales of all tobacco products is recommended. & $\mathbf{I}$ & B & 495 \\
\hline & Restrictions on advertising, marketing and sale of electronic cigarettes should be considered. & Ila & $\mathbf{A}$ & 305,528 \\
\hline \multirow{3}{*}{$\begin{array}{l}\text { Media and } \\
\text { education }\end{array}$} & Telephone and internet based lines for cessation counselling and support services are recommended. & $\mathbf{I}$ & $\mathbf{A}$ & 496 \\
\hline & $\begin{array}{l}\text { Media and educational campaigns as part of multicomponent strategies to reduce smoking and increase } \\
\text { quit rates, reduce passive smoking and use of smokeless tobacco are recommended. }\end{array}$ & $\mathbf{I}$ & $\mathbf{A}$ & 496 \\
\hline & $\begin{array}{l}\text { Media and educational campaigns concentrating solely on reducing smoking, increasing quit rates, reducing } \\
\text { passive smoking and the use of smokeless tobacco should be considered. }\end{array}$ & Ila & B & 495,496 \\
\hline \multirow{2}{*}{$\begin{array}{l}\text { Labelling and } \\
\text { information }\end{array}$} & Cigarette package pictorial and text warnings are recommended. & $\mathbf{I}$ & B & 495,496 \\
\hline & Plain packaging is recommended. & $\mathbf{I}$ & B & 495,496 \\
\hline $\begin{array}{l}\text { Economic } \\
\text { incentives }\end{array}$ & Higher taxes and prices on all tobacco products are recommended. & $\mathbf{I}$ & $\mathbf{A}$ & 495,496 \\
\hline \multirow{2}{*}{ Schools } & Banning smoking in schools, pre-schools and child care to protect from passive smoking is recommended. & $\mathbf{I}$ & $\mathbf{A}$ & 495 \\
\hline & Promotion and teaching of a healthy lifestyle including tobacco-free life should be considered in all schools. & Ila & B & 496 \\
\hline \multirow{2}{*}{ Workplaces } & Workplace specific bans on smoking to reduce passive smoking and increase quit rates are recommended. & $\mathbf{I}$ & $\mathbf{A}$ & 495,496 \\
\hline & Workplace policy on healthy choices including tobacco cessation/prevention is recommended. & $\mathbf{I}$ & $\mathbf{A}$ & 496 \\
\hline \multirow{5}{*}{$\begin{array}{l}\text { Community } \\
\text { setting }\end{array}$} & $\begin{array}{l}\text { It is recommended that health personnel, caregivers and school personnel set an example by not smoking } \\
\text { or using tobacco products at work. }\end{array}$ & $\mathbf{I}$ & $\mathbf{A}$ & 495,496 \\
\hline & It is recommended to advise pregnant women to be tobacco-free during pregnancy. & $\mathbf{I}$ & A & 524 \\
\hline & It is recommended to advise parents to be tobacco-free when children are present. & $\mathbf{I}$ & $\mathbf{A}$ & 495,496 \\
\hline & It is recommended to advise parents to never smoke in cars and private homes. & $\mathbf{I}$ & $\mathbf{A}$ & 495,496 \\
\hline & Residence-specific restrictions on smoking should be considered. & Ila & B & 496 \\
\hline
\end{tabular}

${ }^{a}$ Class of recommendation.

bevel of evidence.

'Reference(s) supporting recommendations. 
The WHO Framework Convention on Tobacco Control recommends smoke-free laws: protecting people from tobacco smoke and banning smoke in public places, warning about the dangers of tobacco, raising taxes on tobacco and enforcing advertising bans. ${ }^{523}$ Children and low socio-economic groups are sensitive to population-based tobacco intervention. Passive smoking increases CVD risk, ${ }^{495,496}$ more so in women than in men. ${ }^{529}$ All smoking, including smoking a water pipe, is deleterious. Smokeless tobacco (in Europe usually snus, a moist powder tobacco placed under the upper lip) increases the risk of fatal CVD events, ${ }^{525-527}$ and the use of snus during pregnancy increases the risk of stillbirth. ${ }^{530}$ There is no evidence that snus increases smoking cessation more than nicotine replacement products or medication. Many smokers use e-cigarettes to quit. There are many unanswered questions about their safety, efficacy for harm reduction and cessation and impact on public health. International legislation should be harmonized to prevent a new tobacco epidemic. ${ }^{495}$

Multicomponent strategies are best. Advertising bans reduce tobacco consumption, and mass media campaigns reduce smoking uptake by teenagers and increase adult quitting. ${ }^{495}$ Media and educational campaigns in schools reduce smoking and promote smoking cessation. Editors should increase the coverage of tobacco and health in the media. ${ }^{531}$ Telephone or Internet-based cessation support reduces tobacco use. ${ }^{496}$

Packs with pictorial and text warnings raise awareness of tobacco dangers. ${ }^{495}$ Plain and standardized packaging without brand labels enhances the effectiveness.
Higher taxes reduce tobacco consumption and encourage quitting, particularly among young and lower socio-economic groups. ${ }^{495,496}$

School-based smoking bans should be implemented. ${ }^{496}$ Smoking bans at workplaces reduce exposure to passive smoking, decrease smoking and increase quitting rates. ${ }^{495}$ Tobacco outlet density near homes, hospitals and schools should be reduced. Pregnant women should avoid tobacco, and parents should be tobacco free when children are present. Health personnel, caregivers and teachers must set an example by not using tobacco products at work.

\section{Gaps in evidence}

- Effect of school-based smoking restrictions.

- Health harm of e-cigarettes.

- More evidence on environmental smoking is needed, as smoke particles may remain in rooms for many years.

\section{3c.5 Alcohol abuse protection}

\section{Key messages}

- Excessive alcohol intake is associated with increased CV mortality, and alcohol ranks as the second-leading cause of DALYs lost in high-income countries.

- The interventions for addressing the harmful use of alcohol are cost effective, with good return (i.e. increasing alcoholic beverage excise taxes, restricting access to alcoholic beverages and implementing comprehensive restrictions and bans on advertising and promotion of alcoholic beverages).

\section{Recommendations for protecting against alcohol abuse}

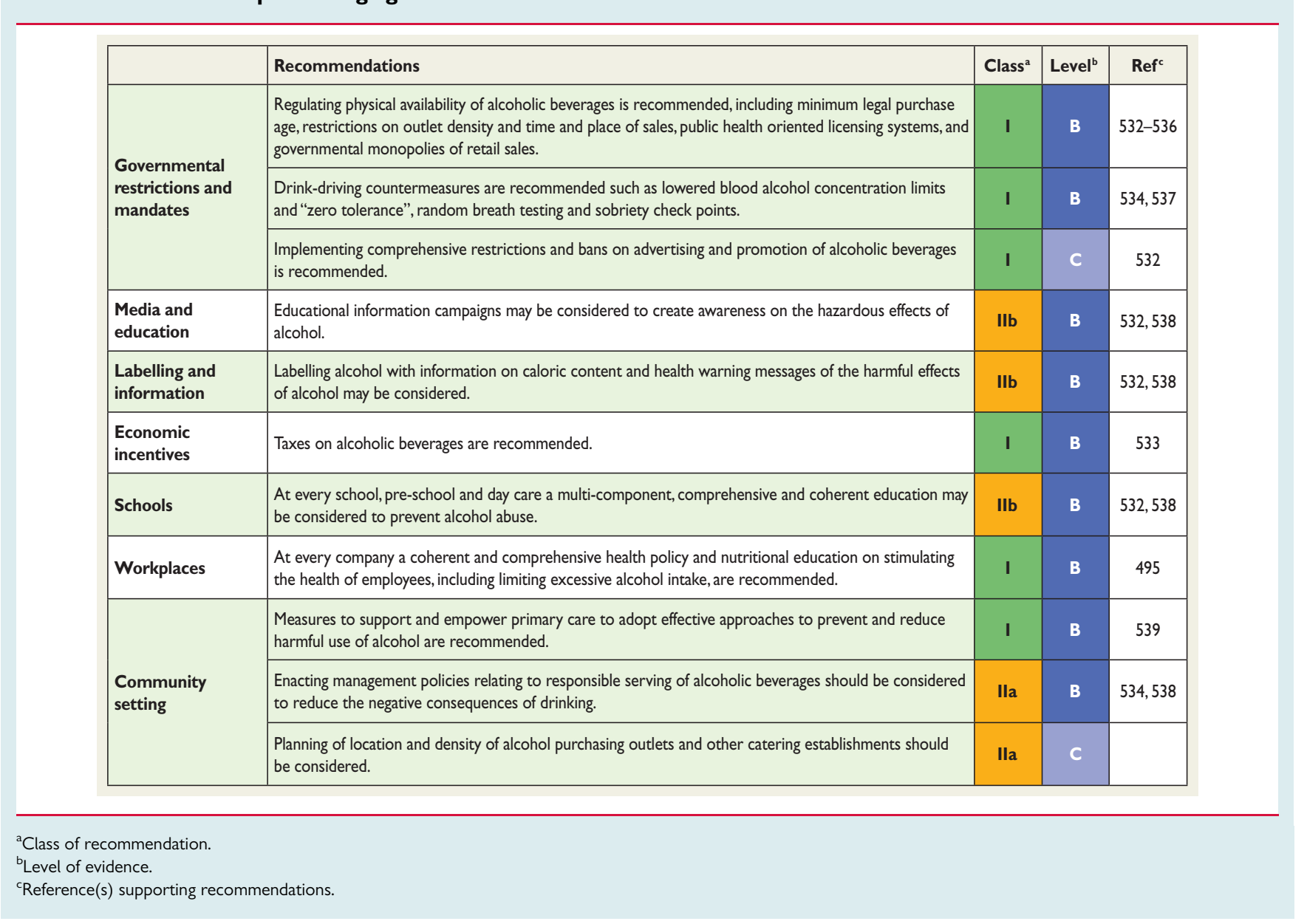


At the population level, alcohol consumption is associated with multiple health risks that clearly outweigh any potential benefits. In 2012, 3.3 million deaths (5.9\% of all global deaths) and 139 million DALYs (5.1\% of the global burden of disease and injury) were attributable to alcohol consumption. The highest numbers of deaths are from CVDs, with $33.3 \%$ of the alcohol-attributable deaths due to CVDs. ${ }^{534}$ Ischaemic heart disease mortality is $65 \%$ higher in male heavy drinkers and more than double in female heavy drinkers. ${ }^{540}$

The relationship between alcohol consumption and CAD and cerebrovascular diseases is complex. It depends on both the level and pattern of alcohol consumption. Low alcohol consumption, ranging from one to three alcohol units per day (a unit equates to about $80 \mathrm{~mL}$ of wine, $250 \mathrm{~mL}$ of normal strength beer or $30-50 \mathrm{~mL}$ of spirits) in some segments of the population is associated with the lowest all-cause mortality, largely due to lower coronary mortality. ${ }^{541}$

SBP and DBP levels increase as alcohol consumption increases to $>3$ units/day, as does the risk of cardiac arrhythmias, cardiomyopathy, sudden death and haemorrhagic stroke. ${ }^{542}$ The pattern of alcohol use has an effect on CVD risk; binge drinking is associated with a higher risk of sudden death and stroke. ${ }^{543}$

The following strategies and interventions have the highest level of effectiveness to prevent the harmful use of alcohol: age limits for sale and serving; ${ }^{535}$ drink-driving strategies; ${ }^{.37}$ government retail monopolies on the sale of alcohol and reducing the hours of sale; ${ }^{536}$ banning alcohol advertising, promotion and sponsorship of events ${ }^{532}$ and an increase in retail prices. ${ }^{533,538}$

In the absence of other population-level measures, such as taxation and advertising restrictions, labelling alcohol with information on caloric content and health warning messages of the harmful effects of alcohol has been shown to have a limited effect. ${ }^{538}$

Alcohol regulations in the policies of workplaces, educational centres and schools are effective. ${ }^{532}$

Brief intervention in primary care to prevent alcohol abuse has been shown to be effective. ${ }^{539}$

In the community, excessive alcohol intake can be limited by restrictions in the number and opening hours of outlets and by increasing the minimum age for sales and servings. ${ }^{495}$

\section{Gap in evidence}

- Better quality evidence is needed with regard to potential confounding in studies on the effects of alcohol consumption.

\section{3c.6 Healthy environment}

Air pollution contributes to the risk of respiratory and CV diseases. ${ }^{544}$ Important sources of fine particles in the EU are motorized road traffic, power plants and industrial and residential heating using oil, coal or wood. Up to a third of Europeans living in urban areas are exposed to levels exceeding EU air quality standards. In particular, young and old individuals and subjects with a high risk of CVD are more prone to the detrimental effects of air pollution on the circulation and the heart.

The EU Commission released a policy package to be implemented by the year 2030 with measures to reduce harmful emissions from traffic, energy plants and agriculture. Further efforts to reduce air pollution should be encouraged and taken up by national governments (e.g. through appropriate and effective legislation). Patient organizations and health professionals have an important role to play in supporting education and policy initiatives and provide a strong voice in the call for action at the governmental level. ${ }^{544}$

The media can inform the population on air quality (e.g. by apps) and by providing smog alerts. Information on patients' behaviour during smog is needed. Economic incentives such as reduced taxes on electric and hybrid cars can contribute to the improvement of air quality. New houses and schools can be built in areas remote from highways and polluting industries.

\section{4a. Where to intervene at the individual level}

The question of 'where' prevention should take place requires only a simple answer: everywhere! Prevention of CVD should be valued and implemented at all levels of society and in all health care settings. This should include increased spending on prevention in health care and on actions that make communities healthier. All clinicians should consider prevention and promotion of healthy lifestyles a professional responsibility with individual patients and should support policies that promote healthier lifestyles. Patients should also be empowered and have the knowledge and support to make informed decisions and to demand robust prevention efforts from health care groups and society.

\section{4a.1 Clinical settings and stakeholders 4a.1.1 Cardiovascular disease prevention in primary care Key messages}

- The prevention of CVD should be delivered in all health care settings, including primary care.

- Where appropriate, all health professionals should assess CV risk factors to determine the individual's total CV risk score.

- GPs and nurses should work together as a team to provide the most effective multidisciplinary care.

\section{Recommendation for cardiovascular disease prevention} in primary care

\begin{tabular}{|l|c|c|}
\hline Recommendation & Class $^{\mathbf{a}}$ & Level $^{\mathbf{b}}$ \\
\hline $\begin{array}{l}\text { It is recommended that GPs, nurses and allied } \\
\text { health professionals within primary care deliver }\end{array}$ & I & C \\
CVD prevention for high-risk patients. & & \\
\hline
\end{tabular}

${ }^{\mathrm{a}}$ Class of recommendation.

bevel of evidence.

The physician in general practice is the key person to initiate, coordinate and provide long-term follow-up for CVD prevention. In most countries, GPs deliver $>90 \%$ of consultations and provide most public health medicine, including preventive care and chronic disease monitoring. In the case of CVD prevention, they have a unique role in identifying individuals at risk of CVD and assessing their eligibility for intervention based on their risk profile. How to maximize attendance rates and adherence, particularly in those who are at highest risk, remains an issue.

As mentioned in section 2.2, a systematic approach is recommended to risk assessment, giving priority to persons with a priori higher risk (such as family history of premature CVD, presence of hypertension, etc.); opportunistic screening of persons $<40$ years of age without $\mathrm{CV}$ risk factors is not recommended.

Intensive and structured intervention in general practice contributes to the prevention of recurrent $\mathrm{CV}$ events and reduces hospital admissions in CAD patients. ${ }^{545}$ 
The successful implementation of CVD prevention guidelines relies heavily on GPs providing risk factor evaluation, intervention and patient education. However, CV targets in general practice are often not achieved. The EUROASPIRE III survey (primary prevention arm) showed that the lifestyle of people being treated as high CV riskdefined as patients treated with BP- and lipid-lowering drugs as well as anti-diabetes drugs — showed much persistent smoking and a high prevalence of both obesity and central obesity. BP, lipid and glucose control is poor, with most patients not achieving the targets defined in the prevention guidelines. ${ }^{5}$

Surveys done among GPs and physicians in several European regions found that most were aware of the European guidelines on CVD prevention, but that only $36-57 \%$ were using the guidelines in practice, and less than half performed comprehensive risk assessments. The main barrier was time, but GPs also cited that there were too many guidelines, unrealistic targets for risk factor control, a preference for using their own experience and a lack of knowledge regarding comprehensive risk assessment. ${ }^{54-549}$ Online resources, mobile apps, pocket guidelines and summary cards may contribute as a means to overcome the implementation challenge.

Evidence for an effective role for nurses in primary care exists. A study of nurse-coordinated preventive cardiology programmes for primary prevention of CVD compared with routine practice conducted in a matched, paired-cluster RCT in six pairs of general practices in six European countries showed more high-risk patients achieved the lifestyle and risk factor targets in the nursecoordinated arm compared with usual care. ${ }^{550}$

In 2009, a randomized trial in The Netherlands on CVD risk management and preventive care found that practice nurses achieved results equal to GPs after 1 year of follow-up. ${ }^{551}$ A clinical trial $(n=525)$ in the USA also showed that advanced practice nurses working with community health workers can achieve significant improvements in $\mathrm{CV}$ risk factors (BP, cholesterol, DM control) in underserved inner-city populations compared with enhanced usual care, and it was cost-effective. ${ }^{552}$

\section{Gap in evidence}

- Further research is needed in order to explore what is the best strategy to improve implementation of CVD prevention guidelines in general practice, taking into account the heterogeneity among countries in terms of health systems and local resources.

\section{4a.1.2 Acute hospital admission setting}

\section{Recommendation for CVD prevention strategies in the acute hospital admission setting}

\begin{tabular}{|c|c|c|c|}
\hline Recommendation & Class $^{a}$ & Level $^{b}$ & $\operatorname{Ref}^{c}$ \\
\hline $\begin{array}{l}\text { It is recommended to implement } \\
\text { strategies for prevention in } \\
\text { CVD patients, including lifestyle } \\
\text { changes, risk factor management } \\
\text { and pharmacological optimization, } \\
\text { after an acute event before hospital } \\
\text { discharge to lower risk of mortality } \\
\text { and morbidity. }\end{array}$ & I & $\mathbf{A}$ & 300,553 \\
\hline
\end{tabular}

${ }^{a}$ Class of recommendation.

bLevel of evidence.

'Reference(s) supporting recommendations.
The importance of starting appropriate prevention before hospital discharge cannot be overemphasized, as prevention treatment tends to decrease rather than increase post-hospitalization, with proportions of patients on appropriate therapy declining over time and patients not reaching risk factor targets. ${ }^{295,554}$

The acute care team should emphasize the importance of the preventive measures directly to the patient, because failure to do so may suggest that these measure are valueless; and they interact with other health professionals (e.g. physicians, nurses) to ensure that prevention strategies initiated during hospitalization are sustained and supported in other settings.

Thus patients, while in acute care, should receive appropriate interventions to optimize prevention strategies. These include full clinical assessment to guide optimization of medical therapy, individualized behavioural education for risk factor modification and referral to exercise-based CR.

Education should be person-centred with full participation of patients and caregivers, providing explanations for each intervention, while early mobilization and physical conditioning programmes should vary according to the individual's clinical status.

\section{4a.1.3 Specialized prevention programmes}

\section{Recommendations for specialized prevention programmes}

\begin{tabular}{|l|c|c|c|}
\hline Recommendations & Class $^{\mathbf{a}}$ & Level $^{\mathrm{b}}$ & Ref $^{\mathrm{c}}$ \\
\hline $\begin{array}{l}\text { Participation in a CR programme } \\
\text { for patients hospitalized for an acute } \\
\text { coronary event or revascularization, } \\
\text { and for patients with HF, is } \\
\text { recommended to improve patient } \\
\text { outcomes. }\end{array}$ & I & A & 555,556 \\
\hline $\begin{array}{l}\text { Preventive programmes for therapy } \\
\text { optimisation, adherence and risk } \\
\text { factor management are recommended } \\
\text { for stable patients with CVD to } \\
\text { reduce disease recurrence. }\end{array}$ & I & B & $557-560$ \\
\hline $\begin{array}{l}\text { Methods to increase referral to and } \\
\text { uptake of CR should be considered } \\
\text { such as electronic prompts or } \\
\text { automatic referrals, referral and } \\
\text { liaison visits, structured follow-up } \\
\text { by physicians, nurses or therapists, } \\
\text { and early starts to programmes after } \\
\text { discharge. }\end{array}$ & Ila & B & 557,558 \\
\hline $\begin{array}{l}\text { Nurses and allied health professional } \\
\text { led programmes should be considered } \\
\text { to deliver CVD prevention across } \\
\text { healthcare settings. }\end{array}$ & Ila & B & $550-552$, \\
\hline
\end{tabular}

$\mathrm{CR}=$ cardiac rehabilitation; $\mathrm{CVD}=$ cardiovascular disease; $\mathrm{HF}=$ heart failure

${ }^{\mathrm{a} C}$ Class of recommendation.

'Level of evidence.

${ }^{\mathrm{C}}$ Reference(s) supporting recommendations.

Specialized prevention programmes are delivered as CR or other prevention programmes for all patients with CVD or at high risk for CVD. The core components and goals of CR have been standardized, ${ }^{562}$ but the structure, length and type of programme offered 
differs widely by country, affected by national guidelines and standards, legislation and payment factors. ${ }^{563}$

$\mathrm{CR}$ is a comprehensive programme involving exercise training, risk factor modification, education and psychological support. An overview of six Cochrane systematic reviews of CR (148 RCTs with 98093 subjects) concluded that for low- to moderaterisk patients with HF, or who are post-MI or revascularization, exercise-based CR decreased hospital admissions and improved health-related quality of life (HRQoL) compared with usual care, and may reduce mortality longer term. ${ }^{555}$ A limitation of current reviews is the inclusion of trials prior to modern treatment, differing patients groups and heterogeneous programmes of CR. Thus more research is needed to determine the optimal intervention. A number of recent controlled cohort studies have found a survival benefit for patients receiving CR compared with no CR. An ongoing meta-analysis of $C R$ in the modern era may provide more definitive results regarding patient programmes and outcomes. At present, the benefit of CR appears to be through direct physiological effects of exercise training and through CR's effects on risk factors, behaviour and mood. ${ }^{555} \mathrm{CR}$ also provides an opportunity for social support and to screen patients for psychosocial risk factors.

Referral and participation in CR varies widely across countries: many CR programmes do not include unstable patients or patients with HF, devices or PAD, and referral and retention of women and older, higher-risk patients remains suboptimal. ${ }^{563,564}$ Referrals to CR can be increased through electronic prompts or automatic referrals, while patient uptake may be improved with structured follow-up by nurses or therapists and early starts to programmes after discharge. ${ }^{557,558,565}$

Nurse-led programmes can also deliver effective preventive programmes in patients with CVD. The EUROACTION trial used a 16 week family-centred approach that led to healthier lifestyle changes in activity and diet and more effective control of risk factors in patients and their partners compared with usual care. ${ }^{550}$ The Randomised Evaluation of Secondary Prevention by Outpatient Nurse Specialists (RESPONSE) trial randomized patients after ACS to usual care or to nurse-coordinated prevention intervention of outpatient visits over 6 months: at 1 year, patients in the intervention group had better control of risk factors, fewer readmissions and emergency department visits and a predicted RR of mortality (using SCORE) $17 \%$ lower than the control group. ${ }^{561}$

\section{4a.1.4 Alternative rehabilitation models Key message}

- Home-based rehabilitation with and without telemonitoring holds promise for increasing participation and supporting behavioural change.

CR has predominantly been implemented in hospitals or in community centres with trained staff. Home-based rehabilitation programmes have the potential to increase patient participation by offering greater flexibility and options for activities. A systematic review of 12 trials (with 1978 patients) of home- vs. centre-based rehabilitation found no difference in outcomes, adherence or cost between the two in the short term and up to 24 months. ${ }^{566}$ The majority of studies recruited low-risk, predominantly male patients, and activities were self-regulated with intermittent support, usually by telephone. Home-based rehabilitation thus offers an alternative for some patients, although relatively few programmes in Europe offer it. ${ }^{563}$

\section{4a.1.4.1 Telerehabilitation}

Telerehabilitation, i.e. the use of electronic communication and information technologies to provide and support remote clinical care after an acute event, has been found to be more effective than usual care in achieving behavioural change, and equally effective as a CR programme. ${ }^{557,567}$ Simple telemonitoring, including ECG transmission by telephone in patients with CVD, has been found to be safe and acceptable to patients and results in improvements in physical capacity. ${ }^{568}$ Recent studies are also using smartphone applications for monitoring and delivery of content and support, with improvements in uptake, adherence and completion of rehabilitation in younger patients. ${ }^{569}$

Thus telerehabilitation could further widen participation to more patients and provide monitoring and greater individualized behavioural support, but large-scale randomized trials are needed.

\section{4a.1.5 Maintaining lifestyle changes}

Maintaining healthy behaviours after a specialized prevention programme is problematic for many patients.

Specialized prevention programmes and patient consultations should use a patient-centred approach that focuses on the patient's priorities and goals and incorporates lifestyle changes within the context of the patient's life. Behavioural change of personal value to the individual is more likely to be maintained (see section 3a.1).

Longer-term support for behaviour change may be needed and community maintenance programmes may be useful. In the Global Secondary Prevention Strategies to Limit Event Recurrence After MI (GOSPEL) trial, 3241 patients were randomized post-CR programme to an intensive multifactorial intervention over 3 years or usual care. Patients in the intervention group received monthly exercise and counselling sessions for 6 months, then every 6 months for 3 years. Compared with usual care, the intervention group had improved PA, diet and total cholesterol maintained throughout the study. The intervention significantly decreased several combined endpoints, such as CV mortality plus non-fatal $\mathrm{MI}$ and stroke by $33 \%$, cardiac death plus non-fatal MI by $36 \%$ and non-fatal MI by $48 \%$ compared with usual care. ${ }^{570}$

\section{Gaps in evidence}

- The optimal CR programme in the era of modern cardiology and the incremental benefits of various components of CR programmes, especially for underserved patient groups.

- Alternative and cost-effective models of CR are needed to ensure participation globally, including low- and middle-income countries.

\section{4a.2 How to monitor preventive activities Key message}

- Standards of performance in CVD prevention may serve as vehicles to accelerate appropriate translation of scientific evidence into clinical practice. 


\section{Recommendation for monitoring preventive strategies}

\begin{tabular}{|l|c|c|}
\hline Recommendation & Class $^{\mathbf{a}}$ & Level $^{\mathbf{b}}$ \\
\hline $\begin{array}{l}\text { Systematically monitoring the process of delivery } \\
\text { of cardiovascular disease prevention activities as } \\
\text { well as outcomes may be considered. }\end{array}$ & Ilb & C \\
\hline
\end{tabular}

${ }^{\mathrm{a}}$ Class of recommendation.

bLevel of evidence.

Candidates for measures of performance are some of those processes of care that are recommended by the guideline either as class I, which identifies recommended procedures/treatments, or class III, which identifies procedures/treatments that are not recommended.

The development of standards of performance involves identification of a set of measures that target a specific patient population observed over a particular time period. Thus these performance measures are aimed at any clinician or health care professional who sees adult subjects ( $\geq 18$ years of age) at risk for CVD. Table 18 provides examples of performance measurements of CVD prevention. Detailed specifications for each performance measure, including the numerator, denominator, period of assessment, method of reporting and sources of data, should be developed at the local level. An optimal target of $100 \%$ is recommended for all standards. If this is not achievable, an interim local target could be set.

\section{4b. Where to intervene at the population level}

\section{Key message}

- Governmental and non-governmental organizations (NGOs) such as heart foundations and other health-promoting organizations can be a powerful force in promoting a healthy lifestyle and healthy environments in CVD prevention.

\section{4b.1 Government and public health}

Recommendations for population-based interventions to promote $\mathrm{CV}$ health are described in section 3c. These preventive strategies to address unhealthy diets, smoking and physical inactivity must take place at different levels. At each level, different clusters of stakeholders are concerned and responsible for the interventions: ${ }^{495}$

- International level- WHO, World Trade Organization, EU

- National level-government departments, health authorities, health-promoting agencies, consumer organizations, health NGOs, industries

- Regional and local level-local governmental departments, communities, schools, workplaces, health professionals, catering sector, retailers, NGOs.

At the EU level as well as at the level of national governments, legislation should be developed regarding, for example, the nutritional composition of foods; nutrition labelling; smoke-free policies and environments; restrictions on marketing of unhealthy foods, alcohol and tobacco products and promoting environments that encourage PA in everyday life. ${ }^{311}$ Also, policy measures to reduce air pollution should be developed. Both levels may use economic instruments
Table I 8 Examples of performance measurements of CVD prevention

- Subjects identified as tobacco users who received cessation intervention.

- Subjects for whom sedentary habits have been recorded and are counselled to increase PA.

- Subjects for whom unhealthy diet/nutritional habits have been recorded and are counselled to improve diet.

- Subjects for whom weight and BMI and/or waist circumference is documented above normal limits and are counselled on weight management.

- Subjects $>40$ years old with at least one lipid profile performed within the past 5 years.

- Patients $<60$ years old and with hypertension (not DM) who had a recorded $\mathrm{BP}$ reading at their most recent visit of $<140 / 90 \mathrm{mmHg}$.

- Patients with DM who had a recorded $\mathrm{HbAlc}<7.0 \%(<53 \mathrm{mmol} / \mathrm{mol})$ at the most recent visit.

- Patients with a qualifying event/diagnosis who have been referred to an in-patient CR or out-patient CR programme before hospital discharge.

$\mathrm{BMI}=$ body mass index; $\mathrm{BP}=$ blood pressure; $\mathrm{CR}=$ cardiac rehabilitation; $\mathrm{HbA1c}=$ glycated haemoglobin; $\mathrm{PA}=$ physical activity.

such as taxes and subsidies to support strategies on food and nutrition, tobacco and alcohol. It is not necessarily exclusively the responsibility of governments to ensure the availability of and accessibility to PA opportunities and healthy foods; this should be a joint effort by government, industry and businesses. Health authorities should monitor improvements, and if voluntary efforts by industry prove inadequate, governments must intervene.

\section{4b.2 Non-governmental organizations}

NGOs are important stakeholders in advocating the development and maintenance of public health policies and are important partners with health care workers in promoting $\mathrm{CV}$ prevention.

Several Brussels-based NGOs aim at improving the CV health of the public and patients, including EHN, health and medical professionals [ESC, European Chronic Disease Alliance (ECDA)] and consumer organizations [Bureau Européen des Unions de Consommateurs (BEUC)].

$\mathrm{CV}$ patients' organizations provide their patient members with the opportunity to obtain support from their peers. They produce patient information in the form of booklets and web-based materials and promote CR.

Stakeholders such as NGOs and health professionals (e.g. cardiologists, internists and GPs) have a responsibility in agenda setting and monitoring interventions, and can initiate mass media campaigns to improve health.

In creating healthy and active environments, especially in schools, workplaces and the community, stakeholders such as teachers and parent organizations, the catering sector, employer organizations, trade unions, sport clubs and fitness centres and organizations promoting cycling, walking, public transport or involved in urban planning and mobility can play a role. An example is the French EPODE project, aimed at reducing overweight in children. ${ }^{502}$ 


\section{To do and not to do messages from the Guidelines}

Recommendations for cardiovascular risk assessment

Systematic CV risk assessment is recommended in individuals at increased $\mathrm{CV}$ risk, i.e. with family history of premature CVD, familial hyperlipidaemia, major CV risk factors (such as smoking, high BP, DM or raised lipid levels) or comorbidities increasing CV risk.

It is recommended to repeat $\mathrm{CV}$ risk assessment every 5 years, and more often for individuals with risks close to thresholds mandating treatment.

Systematic $\mathrm{CV}$ risk assessment in men $<40$ of age and women $<50$ years of age with no known $\mathrm{CV}$ risk factors is not recommended. Recommendations for how to estimate cardiovascular risk

Total CV risk estimation, using a risk estimation system such as SCORE, is recommended for adults $>40$ years of age, unless they are automatically categorised as being at high risk or very high risk based on documented CVD, DM (>40 years of age), kidney disease or a highly elevated single risk factor.

Routine assessment of circulating or urinary biomarkers is not recommended for refinement of CVD risk stratification. Carotid ultrasound IMT screening for CV risk assessment is not recommended.

\section{Recommendations for how to intervene}

It is recommended for healthy adults of all ages to perform at least 150 minutes a week of moderate intensity or 75 minutes a week of vigorous intensity aerobic PA or an equivalent combination thereof.

$\mathrm{PA}$ is recommended in low risk individuals without further assessment.

It is recommended to identify smokers and provide repeated advice on stopping with offers to help, by the use of follow up support, nicotine replacement therapies, varenicline, and bupropion individually or in combination.

A healthy diet is recommended as a cornerstone of CVD prevention in all individuals.

It is recommended that subjects with healthy weight maintain their weight. It is recommended that overweight and obese people achieve a healthy weight (or aim for a reduction in weight).

In patients at VERY HIGH CV risk, an LDL-C goal $<1.8 \mathrm{mmol} / \mathrm{L}(<70 \mathrm{mg} / \mathrm{dL})$, or a reduction of at least $50 \%$ if the baseline is between

1.8 and $3.5 \mathrm{mmol} / \mathrm{L}(70$ and $135 \mathrm{mg} / \mathrm{dL})$ is recommended.

In patients at HIGH CV risk, an LDL-C goal $<2.6 \mathrm{mmol} / \mathrm{L}(<100 \mathrm{mg} / \mathrm{dL})$, or a reduction of at least $50 \%$ if the baseline is between 2.6 and

$5.1 \mathrm{mmol} / \mathrm{L}(100$ and $200 \mathrm{mg} / \mathrm{dL})$ is recommended.

In treated hypertensive patients $<60$ years old, $\mathrm{SBP}<140 \mathrm{mmHg}$ and $\mathrm{DBP}<90 \mathrm{mmHg}$ are recommended

In patients $>60$ years old with $S B P \geq 160 \mathrm{mmHg}$, it is recommended to reduce SBP to between I50 and I40 mm Hg.

In individuals $>80$ years and with initial $S B P \geq 160 \mathrm{mmHg}$, it is recommended to reduce SBP to between 150 and $140 \mathrm{mmHg}$, provided they are in good physical and mental conditions.

BP targets in type $2 \mathrm{DM}$ are $<140 / 85 \mathrm{mmHg}$, but a lower target of $<130 / 80 \mathrm{mmHg}$ is recommended in selected patients (e.g. younger patients at elevated risk for specific complications) for additional gains on stroke, retinopathy and albuminuria risk.

BP targets in patients with type I DM are $<130 / 80 \mathrm{mmHg}$.

Drug treatment is recommended in patients with grade 3 hypertension irrespective of $\mathrm{CV}$ risk, as well as in patients with grade I or 2 hypertension who are at very high CV risk.

All major BP lowering drug classes (i.e. diuretics, ACE-I, calcium antagonists, ARBs, and B-blockers) do not differ significantly in their BP-lowering efficacy and thus are recommended as BP lowering treatment.

Renin-angiotensin-aldosterone system blocker is recommended in the treatment of hypertension in DM, particularly in the presence of proteinuria or micro-albuminuria.

B-blockers and thiazide diuretics are not recommended in hypertensive patients with multiple metabolic risk factors due to the increased risk of DM.

A target $\mathrm{HbAlc}$ for the reduction in risk of CVD and microvascular complications in $\mathrm{DM}$ of $<7.0 \%(<53 \mathrm{mmol} / \mathrm{mol})$ is recommended for the majority of non-pregnant adults with either type I or type 2 DM.

In DM, metformin is recommended as first-line therapy, if tolerated and not contra-indicated, following evaluation of renal function.

Lipid lowering agents (principally statins) are recommended to reduce CV risk in all patients with type 2 or type I DM above the age of 40 years.

Antiplatelet therapy is not recommended in individuals without CVD due to the increased risk of major bleeding.

Recommendations for achieving medication and healthy lifestyle adherence

Simplifying the treatment regimen to the lowest acceptable level is recommended, with repetitive monitoring and feedback. In the case of persistent non-adherence, multi-session or combined behavioural interventions are recommended.

It is recommended that health personnel, caregivers set an example by following healthy lifestyle, such as not smoking or using tobacco products at work.

\begin{tabular}{|c|c|}
\hline Class $^{a}$ & Level $^{\mathrm{b}}$ \\
\hline I & C \\
\hline I & C \\
\hline III & c \\
\hline Class $^{\mathrm{a}}$ & Level $^{b}$ \\
\hline I & C \\
\hline III & B \\
\hline III & A \\
\hline Class $^{a}$ & Level $^{\mathrm{b}}$ \\
\hline I & A \\
\hline I & c \\
\hline I & A \\
\hline I & B \\
\hline I & $\mathbf{A}$ \\
\hline I & B \\
\hline I & B \\
\hline I & B \\
\hline I & B \\
\hline I & B \\
\hline I & A \\
\hline I & B \\
\hline III & B \\
\hline I & $\mathbf{A}$ \\
\hline I & B \\
\hline I & $\mathbf{A}$ \\
\hline III & B \\
\hline Class $^{\mathrm{a}}$ & Level $^{\mathrm{b}}$ \\
\hline I & $\mathbf{A}$ \\
\hline I & A \\
\hline
\end{tabular}


To do and not to do messages from the Guidelines (continued)

\begin{tabular}{|l|l|l|}
\hline Recommendation for CVD prevention implementation $^{\text {In }}$ & Class $^{\mathbf{a}}$ & Level $^{\mathbf{b}}$ \\
\hline $\begin{array}{l}\text { In primary care, it is recommended that GPs, nurses and allied health professionals within primary care deliver CVD prevention for high- } \\
\text { risk patients. }\end{array}$ & I & C \\
\hline $\begin{array}{l}\text { In acute hospital setting, it is recommended to implement strategies for prevention in CVD patients, including lifestyle changes, risk factor } \\
\text { management and pharmacological optimization, after an acute event before hospital discharge to lower risk of mortality and morbidity. }\end{array}$ & I \\
\hline $\begin{array}{l}\text { Participation in a cardiac rehabilitation programme for patients hospitalized for an acute coronary event or revascularization, and for } \\
\text { patients with HF, is recommended. }\end{array}$ & A I \\
\hline
\end{tabular}

$\mathrm{ACE}-\mathrm{I}=$ angiotensin-converting enzyme inhibitor; $\mathrm{ACS}=$ acute coronary syndrome; $\mathrm{ARBs}=$ angiotensin receptor blockers; $\mathrm{BP}=$ blood pressure; $\mathrm{CAD}=$ coronary artery disease; $\mathrm{CKD}=$ chronic kidney disease; $\mathrm{CV}=$ cardiovascular; $\mathrm{CVD}=$ cardiovascular disease; $\mathrm{DBP}=$ diastolic blood pressure; $\mathrm{DM}=$ diabetes mellitus; $\mathrm{GPs}=$ general practitioners; HbA1c $=$ glycated haemoglobin; HDL-C = high-density lipoprotein cholesterol; HF = heart failure; IMT = intima-media thickness; LDL-C = low-density lipoprotein cholesterol; PA = physical activity; SBP = systolic blood pressure; SCORE = Systematic Coronary Risk Estimation; TIA = transient ischaemic attack.

${ }^{\mathrm{a}}$ Class of recommendation.

bLevel of evidence.

\section{Appendix}

ESC Committee for Practice Guidelines (CPG): Jose Luis Zamorano (Chairperson) (Spain), Victor Aboyans (France), Stephan Achenbach (Germany), Stefan Agewall (Norway), Lina Badimon (Spain), Gonzalo Barón-Esquivias (Spain), Helmut Baumgartner (Germany), Jeroen J. Bax (The Netherlands), Héctor Bueno (Spain), Scipione Carerj (Italy), Veronica Dean (France), Çetin Erol (Turkey), Donna Fitzsimons (UK), Oliver Gaemperli (Switzerland), Paulus Kirchhof (UK/Germany), Philippe Kolh (Belgium), Patrizio Lancellotti (Belgium), Gregory Y.H. Lip (UK), Petros Nihoyannopoulos (UK), Massimo F. Piepoli (Italy), Piotr Ponikowski (Poland), Marco Roffi (Switzerland), Adam Torbicki (Poland), António Vaz Carneiro (Portugal), Stephan Windecker (Switzerland).

ESC National Cardiac Societies actively involved in the review process of the 2016 European Guidelines on cardiovascular disease prevention in clinical practice:

Austria: Austrian Society of Cardiology, Bernhard Metzler; Azerbaijan: Azerbaijan Society of Cardiology, Ruslan Najafov; Belarus: Belorussian Scientific Society of Cardiologists, Valeriy Stelmashok; Belgium: Belgian Society of Cardiology, Catherine De Maeyer; Bosnia and Herzegovina: Association of Cardiologists of Bosnia and Herzegovina, Mirza Dilić; Bulgaria: Bulgarian Society of Cardiology, Ivan Gruev; Croatia: Croatian Cardiac Society, Davor Miličić; Czech Republic: Czech Society of Cardiology, Helena Vaverkova; Denmark: Danish Society of Cardiology, Ida Gustafsson; Egypt: Egyptian Society of Cardiology, Ihab Attia; Estonia: Estonian Society of Cardiology, Davit Duishvili; Former Yugoslav Republic of Macedonia: Macedonian FYR Society of Cardiology, Nela Kostova; France: French Society of Cardiology, Jean Ferrières; Georgia: Georgian Society of Cardiology, Zurab
Klimiashvili; Germany: German Cardiac Society, Rainer Hambrecht; Greece: Hellenic Cardiological Society, Konstantinos Tsioufis; Hungary: Hungarian Society of Cardiology, Eszter Szabados; Iceland: Icelandic Society of Cardiology, Karl Andersen; Ireland: Irish Cardiac Society, Carl Vaughan; Israel: Israel Heart Society, Barak Zafrir; Italy: Italian Federation of Cardiology, Salvatore Novo; Kazakhstan: Association of Cardiologists of Kazakhstan, Kairat Davletov; Kosovo: Kosovo Society of Cardiology, Fisnik Jashari; Kyrgyzstan: Kyrgyz Society of Cardiology, Alina Kerimkulova, Latvia: Latvian Society of Cardiology, Iveta Mintale; Lebanon: Lebanese Society of Cardiology, Georges Saade; Lithuania: Lithuanian Society of Cardiology, Zaneta Petrulioniene; Luxembourg: Luxembourg Society of Cardiology, Charles Delagardelle; Malta: Maltese Cardiac Society, Caroline J. Magri; Moldova: Moldavian Society of Cardiology, Victor Rudi; Morocco: Moroccan Society of Cardiology, Latifa Oukerraj; The Netherlands: Netherlands Society of Cardiology, B. Ersen Çölkesen; Norway: Norwegian Society of Cardiology, Henrik Schirmer; Poland: Polish Cardiac Society, Piotr Jankowski; Portugal: Portuguese Society of Cardiology, Roberto Palma dos Reis; Romania: Romanian Society of Cardiology, Daniel Gherasim; Russian Federation: Russian Society of Cardiology, Sergey Nedogoda; San Marino: San Marino Society of Cardiology, Marco Zavatta; Serbia: Cardiology Society of Serbia, Vojislav Giga; Slovakia: Slovak Society of Cardiology, Slavomira Filipova; Spain: Spanish Society of Cardiology, Luis Rodríguez Padial; Sweden: Swedish Society of Cardiology, Anna Kiessling; Switzerland: Swiss Society of Cardiology, François Mach; Tunisia: Tunisian Society of Cardiology and Cardio-Vascular Surgery, Abdallah Mahdhaoui; Turkey: Turkish Society of Cardiology, Dilek Ural; Ukraine: Ukrainian Association of Cardiology, Elena Nesukay; United Kingdom: British Cardiovascular Society, Chris Gale. 


\section{References}

1. A Dictionary of Epidemiology. 4th ed. New York: Oxford University Press.

2. Moran AE, Forouzanfar MH, Roth GA, Mensah GA, Ezzati M, Murray CJ, Naghavi M. Temporal trends in ischemic heart disease mortality in 21 world regions, 1980 to 2010: the Global Burden of Disease 2010 study. Circulation 2014; 129:1483-1492

3. Finucane MM, Stevens GA, Cowan MJ, Danaei G, Lin JK, Paciorek CJ, Singh GM, Gutierrez HR, Lu Y, Bahalim AN, Farzadfar F, Riley LM, Ezzati M. National, regional, and global trends in body-mass index since 1980: systematic analysis of health examination surveys and epidemiological studies with 960 country-years and 9.1 million participants. Lancet 2011;377:557-567.

4. Danaei G, Finucane MM, Lu Y, Singh GM, Cowan MJ, Paciorek CJ, Lin JK, Farzadfar F, Khang YH, Stevens GA, Rao M, Ali MK, Riley LM, Robinson CA, Ezzati M. National, regional, and global trends in fasting plasma glucose and diabetes prevalence since 1980: systematic analysis of health examination surveys and epidemiological studies with 370 country-years and 2.7 million participants. Lancet 2011;378:31-40.

5. Kotseva K, Wood D, De Backer G, De Bacquer D, Pyorala K, Reiner Z, Keil U, EUROASPIRE III. Management of cardiovascular risk factors in asymptomatic high-risk patients in general practice: cross-sectional survey in 12 European countries. Eur J Cardiovasc Prev Rehabil 2010;17:530-540.

6. Kotseva K, Wood D, De Bacquer D, De Backer G, Ryden L, Jennings C, Gyberg V, Amouyel P, Bruthans J, Castro Conde A, Cifkova R, Deckers JW, De Sutter J, Dilic M, Dolzhenko M, Erglis A, Fras Z, Gaita D, Gotcheva N, Goudevenos J, Heuschmann P, Laucevicius A, Lehto S, Lovic D, Milicic D, Moore D, Nicolaides E, Oganov R, Pajak A, Pogosova N, Reiner Z, Stagmo M, Stork S, Tokgozoglu L, Vulic D. EUROASPIRE IV: a European Society of Cardiology survey on the lifestyle, risk factor and therapeutic management of coronary patients from 24 European countries. Eur J Prev Cardiol 2016;23:636-648.

7. Cooney MT, Dudina A, Whincup P, Capewell S, Menotti A, Jousilahti P, Njolstad I, Oganov R, Thomsen T, Tverdal A, Wedel H, Wilhelmsen L, Graham I. Reevaluating the Rose approach: comparative benefits of the population and highrisk preventive strategies. Eur J Cardiovasc Prev Rehabil 2009;16:541-549.

8. Liu K, Daviglus ML, Loria CM, Colangelo LA, Spring B, Moller AC, Lloyd-Jones DM. Healthy lifestyle through young adulthood and the presence of low cardiovascular disease risk profile in middle age: the Coronary Artery Risk Development in (Young) Adults (CARDIA) study. Circulation 2012;125: 996-1004

9. NICE Public Health Guidance 25. Prevention of Cardiovascular Disease. http://www. nice.org.uk/guidance/PH25.

10. World Health Organization. Global status report on non-communicable diseases 2010. http://apps.who.int/iris/bitstream/10665/44579/1/9789240686458_eng. pdf.

11. Perk J, De Backer G, Gohlke H, Graham I, Reiner Z, Verschuren M, Albus C, Benlian P, Boysen G, Cifkova R, Deaton C, Ebrahim S, Fisher M, Germano G, Hobbs R, Hoes A, Karadeniz S, Mezzani A, Prescott E, Ryden L, Scherer M, Syvanne M, Scholte op Reimer WJ, Vrints C, Wood D, Zamorano JL, Zannad F. European Guidelines on cardiovascular disease prevention in clinical practice (version 2012): the Fifth Joint Task Force of the European Society of Cardiology and Other Societies on Cardiovascular Disease Prevention in Clinical Practice (constituted by representatives of nine societies and by invited experts). Eur Heart J 2012;33:1635-701.

12. Cobiac LJ, Magnus A, Lim S, Barendregt J], Carter R, Vos T. Which interventions offer best value for money in primary prevention of cardiovascular disease? PLoS One 2012; 7:e41842.

13. Collins M, Mason H, O'Flaherty M, Guzman-Castillo M, CritchleyJ, Capewell S. An economic evaluation of salt reduction policies to reduce coronary heart disease in England: a policy modeling study. Value Health 2014;17:517-524.

14. Nichols M TN, Scarborough P, Rayner P. European Cardiovascular Disease Statistics, 2012 edition. http://www.escardio.org/static_file/Escardio/Press-media/pressreleases/2013/EU-cardiovascular-disease-statistics-2012.pdf.

15. McConnachie A, Walker A, Robertson M, Marchbank L, Peacock J, Packard C], Cobbe SM, Ford I. Long-term impact on healthcare resource utilization of statin treatment, and its cost effectiveness in the primary prevention of cardiovascular disease: a record linkage study. Eur Heart J 2014;35:290-298.

16. Mistry H, Morris S, Dyer M, Kotseva K, Wood D, Buxton M. Cost-effectiveness of a European preventive cardiology programme in primary care: a Markov modelling approach. BMJ Open 2012;2:e001029.

17. Plans-Rubio $P$. The cost effectiveness of statin therapies in Spain in 2010, after the introduction of generics and reference prices. Am J Cardiovasc Drugs 2010;10: $369-382$.

18. World Health Organization. Scaling up action agains noncommunicable diseases: how much will it cost? Geneva: World Health Organization, 2011.
19. Mason H, Shoaibi A, Ghandour R, O'Flaherty M, Capewell S, Khatib R, Jabr S, Unal B, Sozmen K, Arfa C, Aissi W, Ben Romdhane H, Fouad F, Al-Ali R, Husseini A, MedCHAMPS project team. A cost effectiveness analysis of salt reduction policies to reduce coronary heart disease in four Eastern Mediterranean countries. PLoS One 2014;9:e84445.

20. O'Keeffe C, Kabir Z, O'Flaherty M, Walton J, Capewell S, Perry IJ. Modelling the impact of specific food policy options on coronary heart disease and stroke deaths in Ireland. BMJ Open 2013;3:e002837.

21. Roth GA, Forouzanfar MH, Moran AE, Barber R, Nguyen G, Feigin VL, Naghavi M, Mensah GA, Murray CJ. Demographic and epidemiologic drivers of global cardiovascular mortality. N Engl J Med 2015;372:1333-1341.

22. Pereira M, Azevedo A, Lunet N, Carreira H, O’Flaherty M, Capewell S, Bennett K. Explaining the decline in coronary heart disease mortality in Portugal between 1995 and 2008. Circ Cardiovasc Qual Outcomes 2013;6:634-642.

23. Banegas JR, Lopez-Garcia E, Dallongeville J, Guallar E, Halcox JP, Borghi C Masso-Gonzalez EL, Jimenez FJ, Perk J, Steg PG, De Backer G, Rodriguez-Artalejo F. Achievement of treatment goals for primary prevention of cardiovascular disease in clinical practice across Europe: the EURIKA study. Eur Heart J 2011;32:2143-2152.

24. De Smedt D, Kotseva K, De Bacquer D, Wood D, De Backer G, Dallongeville J, Seppo L, Pajak A, Reiner Z, Vanuzzo D, Georgiev B, Gotcheva N, Annemans L. Cost-effectiveness of optimizing prevention in patients with coronary heart disease: the EUROASPIRE III health economics project. Eur Heart J 2012;33: 2865-2872.

25. Blood Pressure Lowering Treatment Trialists' Collaboration, Sundstrom J, Arima H, Woodward M, Jackson R, Karmali K, Lloyd-Jones D, Baigent C, Emberson J, Rahimi K, MacMahon S, Patel A, Perkovic V, Turnbull F, Neal B. Blood pressure-lowering treatment based on cardiovascular risk: a meta-analysis of individual patient data. Lancet 2014;384:591-598.

26. Thomopoulos C, Parati G, Zanchetti A. Effects of blood pressure lowering on outcome incidence in hypertension: 3 . Effects in patients at different levels of cardiovascular risk-overview and meta-analyses of randomized trials. J Hypertens 2014;32:2305-2314.

27. Thomopoulos C, Parati G, Zanchetti A. Effects of blood pressure lowering on outcome incidence in hypertension: 2 . Effects at different baseline and achieved blood pressure levels-overview and meta-analyses of randomized trials. J Hypertens 2014;32:2296-2304.

28. Anderson KM, Odell PM, Wilson PW, Kannel WB. Cardiovascular disease risk profiles. Am Heart J 1991;121(1 Pt 2):293-298.

29. Graham I, Atar D, Borch-Johnsen K, Boysen G, Burell G, Cifkova R, Dallongeville J, De Backer G, Ebrahim S, Gjelsvik B, Herrmann-Lingen C, Hoes A, Humphries S, Knapton M, Perk J, Priori SG, Pyorala K, Reiner Z, Ruilope L, Sans-Menendez S, Op Reimer WS, Weissberg P, Wood D, Yarnell J, Zamorano JL, Walma E, Fitzgerald T, Cooney MT, Dudina A, Vahanian A, Camm J, De Caterina R, Dean V, Dickstein K, Funck-Brentano C, Filippatos G, Hellemans I, Kristensen SD, McGregor K, Sechtem U, Silber S, Tendera M, Widimsky P, Zamorano JL, Altiner A, Bonora E, Durrington PN, Fagard R, Giampaoli S, Hemingway H, Hakansson J, Kjeldsen SE, Larsen ML, Mancia G, Manolis AJ, Orth-Gomer K, Pedersen T, Rayner M, Ryden L, Sammut M, Schneiderman N, Stalenhoef AF, Tokgozoglu L, Wiklund $O$, Zampelas A. European guidelines on cardiovascular disease prevention in clinical practice: full text. Fourth Joint Task Force of the European Society of Cardiology and other societies on cardiovascular disease prevention in clinical practice (constituted by representatives of nine societies and by invited experts). Eur J Cardiovasc Prev Rehabil 2007;14(Suppl 2):S1-S113.

30. Conroy RM, Pyorala K, Fitzgerald AP, Sans S, Menotti A, De Backer G, De Bacquer D, Ducimetiere P, Jousilahti P, Keil U, Njolstad I, Oganov RG, Thomsen T, Tunstall-Pedoe H, Tverdal A, Wedel H, Whincup P, Wilhelmsen L, Graham IM. Estimation of ten-year risk of fatal cardiovascular disease in Europe: the SCORE project. Eur HJ 2003;24:987-1003.

31. Si S, Moss JR, Sullivan TR, Newton SS, Stocks NP. Effectiveness of general practicebased health checks: a systematic review and meta-analysis. Br J Gen Pract 2014;64 e47-e53.

32. Jorgensen T, Jacobsen RK, Toft U, Aadahl M, Glumer C, Pisinger C. Effect of screening and lifestyle counselling on incidence of ischaemic heart disease in general population: Inter99 randomised trial. BMJ 2014;348:g3617.

33. Ebrahim S, Taylor F, Ward K, Beswick A, Burke M, Davey Smith G. Multiple risk factor interventions for primary prevention of coronary heart disease. Cochrane Database Syst Rev 2011;1:CD001561.

34. Krogsboll LT, Jorgensen KJ, Gronhoj Larsen C, Gotzsche PC. General health checks in adults for reducing morbidity and mortality from disease. Cochrane Database Syst Rev 2012;10:CD009009.

35. National Institute for Health and Care Excellence. Lipid Modification: Cardiovascular Risk Assessment and the Modification of Blood Lipids for the Primary and Secondary Prevention of Cardiovascular Disease. London: National Institute for Health and Care Excellence, 2014. 
36. American Heart Association. Heart-Health Screenings. http://www.heart.org/ HEARTORG/Conditions/Heart-HealthScreenings_UCM_428687_Article.jsp\#.VtxbjseZaPU.

37. Scottish Intercollegiate Guidelines Network. Risk estimation and the prevention of cardiovascular disease. A national clinical guideline. Edinburgh: Scottish Intercollegiate Guidelines Network, 2007.

38. European Association for Cardiovascular Prevention \& Rehabilitation, Reiner Z, Catapano AL, De Backer G, Graham I, Taskinen MR, Wiklund O, Agewall S, Alegria E, Chapman MJ, Durrington P, Erdine S, Halcox J, Hobbs R, Kjekshus J, Filardi PP, Riccardi G, Storey RF, Wood D. ESC/EAS Guidelines for the management of dyslipidaemias: the Task Force for the management of dyslipidaemias of the European Society of Cardiology (ESC) the European Atherosclerosis Society (EAS). Eur Heart J 2011;32:1769-1818.

39. Chamnan P, Simmons RK, Khaw KT, Wareham NJ, Griffin SJ. Estimating the population impact of screening strategies for identifying and treating people at high risk of cardiovascular disease: modelling study. BMJ 2010;340:c1693.

40. Nielsen AD, Videbech P, Gerke O, Petersen H, Jensen JM, Sand NP, Egstrup K, Larsen ML, Mickley H, Diederichsen AC. Population screening for coronary artery calcification does not increase mental distress and the use of psychoactive medication. J Thorac Imaging 2012;27:202-206.

41. Christensen B, Engberg M, Lauritzen T. No long-term psychological reaction to information about increased risk of coronary heart disease in general practice. Eur J Cardiovasc Prev Rehabil 2004;11:239-243.

42. Lokkegaard T, Andersen JS, Jacobsen RK, Badsberg JH, Jorgensen T, Pisinger C. Psychological consequences of screening for cardiovascular risk factors in an unselected general population: results from the Inter 99 randomised intervention study. Scand J Public Health 2015;43:102-110.

43. Jorgensen T, Ladelund S, Borch-Johnsen K, Pisinger C, Schrader AM, Thomsen T, Glumer C, Ibsen H, Mortensen EL. Screening for risk of cardiovascular disease is not associated with mental distress: the Inter99 study. Prev Med 2009;48: $242-246$.

44. D’Agostino RB Sr, Vasan RS, Pencina MJ, Wolf PA, Cobain M, Massaro JM, Kannel WB. General cardiovascular risk profile for use in primary care: the Framingham Heart Study. Circulation 2008;117:743-753.

45. Woodward M, Brindle P, Tunstall-Pedoe H. Adding social deprivation and family history to cardiovascular risk assessment: the ASSIGN score from the Scottish Heart Health Extended Cohort (SHHEC). Heart 2007;93:172-176.

46. Hippisley-Cox J, Coupland C, Vinogradova Y, Robson J, May M, Brindle P. Derivation and validation of QRISK, a new cardiovascular disease risk score for the United Kingdom: prospective open cohort study. BMJ 2007;335:136.

47. Hippisley-Cox J, Coupland C, Vinogradova Y, Robson J, Minhas R, Sheikh A, Brindle P. Predicting cardiovascular risk in England and Wales: prospective derivation and validation of QRISK2. BMJ 2008;336:1475-1482.

48. Assmann G, Cullen P, Schulte H. Simple scoring scheme for calculating the risk of acute coronary events based on the 10-year follow-up of the prospective cardiovascular Munster (PROCAM) study. Circulation 2002;105:310-315.

49. Giampaoli S. CUORE: a sustainable cardiovascular disease prevention strategy. Eur J Cardiovasc Prev Rehabil 2007;14:161-162.

50. Goff DC Jr, Lloyd-Jones DM, Bennett G, Coady S, D'Agostino RB Sr, Gibbons R, Greenland P, Lackland DT, Levy D, O'Donnell CJ, Robinson JG, Schwartz JS, Shero ST, Smith SC Jr, Sorlie P, Stone NJ, Wilson PW. 2013 ACC/AHA guideline on the assessment of cardiovascular risk: a report of the American College of Cardiology/American Heart Association Task Force on Practice Guidelines. J Am Coll Cardiol 2014;63(25 Pt B):2935-2959.

51. Krones T, Keller H, Sonnichsen A, Sadowski EM, Baum E, Wegscheider K, Rochon J, Donner-Banzhoff N. Absolute cardiovascular disease risk and shared decision making in primary care: a randomized controlled trial. Ann Fam Med 2008;6:218-227.

52. Hajifathalian K, Ueda P, Lu Y, Woodward M, Ahmadvand A, Aguilar-Salinas CA, Azizi F, Cifkova R, Di Cesare M, Eriksen L, Farzadfar F, Ikeda N, Khalili D, Khang YH, Lanska V, Leon-Munoz L, Magliano D, Msyamboza KP, Oh K, Rodriguez-Artalejo F, Rojas-Martinez R, Shaw JE, Stevens GA, Tolstrup J, Zhou B, Salomon JA, Ezzati M, Danaei G. A novel risk score to predict cardiovascular disease risk in national populations (Globorisk): a pooled analysis of prospective cohorts and health examination surveys. Lancet Diabetes Endocrinol 2015;3:339-355.

53. Aktas MK, Ozduran V, Pothier CE, Lang R, Lauer MS. Global risk scores and exercise testing for predicting all-cause mortality in a preventive medicine program. JAMA 2004;292:1462-1468

54. Grundy SM, Cleeman JI, Merz CN, Brewer HB Jr, Clark LT, Hunninghake DB, Pasternak RC, Smith SC Jr, Stone NJ. Implications of recent clinical trials for the National Cholesterol Education Program Adult Treatment Panel III guidelines. Arterioscler Thromb Vasc Biol 2004;24:e149-e161.

55. Genest J, McPherson R, Frohlich J, Anderson T, Campbell N, Carpentier A, Couture P, Dufour R, Fodor G, Francis GA, Grover S, Gupta M, Hegele RA,
Lau DC, Leiter L, Lewis GF, Lonn E, Mancini GB, Ng D, Pearson G], Sniderman A, Stone JA, Ur E. 2009 Canadian Cardiovascular Society/Canadian guidelines for the diagnosis and treatment of dyslipidemia and prevention of cardiovascular disease in the adult - 2009 recommendations. Can J Cardiol 2009;25 $567-579$.

56. Williams M. Risk assessment and management of cardiovascular disease in New Zealand. N Z Med J 2003;116:U661

57. Rabar S, Harker M, O’Flynn N, Wierzbicki AS, Guideline Development G. Lipid modification and cardiovascular risk assessment for the primary and secondary prevention of cardiovascular disease: summary of updated NICE guidance. BM 2014;349:g4356.

58. Board JBS. Joint British Societies' consensus recommendations for the prevention of cardiovascular disease (JBS3). Heart 2014;100(Suppl 2):ii1-ii67.

59. Cooney MT, Dudina A, D'Agostino R, Graham IM. Cardiovascular risk-estimation systems in primary prevention: do they differ? Do they make a difference? Can we see the future? Circulation 2010;122:300-310.

60. Cooney MT, Dudina AL, Graham IM. Value and limitations of existing scores for the assessment of cardiovascular risk: a review for clinicians. J Am Coll Cardiol 2009. 54:1209-1227.

61. van Dis I, Geleijnse JM, Boer JM, Kromhout D, Boshuizen H, Grobbee DE, van der Schouw YT, Verschuren WM. Effect of including nonfatal events in cardiovascular risk estimation, illustrated with data from The Netherlands. Eur J Prev Cardiol 2014; 21:377-383.

62. Pyorala K, De Backer G, Graham I, Poole-Wilson P, Wood D. Prevention of coronary heart disease in clinical practice. Recommendations of the Task Force of the European Society of Cardiology, European Atherosclerosis Society and European Society of Hypertension. Eur Heart J 1994;15:1300-1331.

63. Cooney MT, Dudina A, De Bacquer D, Fitzgerald A, Conroy R, Sans S, Menotti A De Backer G, Jousilahti P, Keil U, Thomsen T, Whincup P, Graham I. How much does HDL cholesterol add to risk estimation? A report from the SCORE Investigators. Eur J Cardiovasc Prev Rehabil 2009;16:304-314.

64. Cooney MT, Dudina A, De Bacquer D, Wilhelmsen L, Sans S, Menotti A, De Backer G, Jousilahti P, Keil U, Thomsen T, Whincup P, Graham IM. HDL cholesterol protects against cardiovascular disease in both genders, at all ages and at all levels of risk. Atherosclerosis 2009;206:611-616.

65. Mortensen MB, Afzal S, Nordestgaard BG, Falk E. The high-density lipoprotein-adjusted SCORE model worsens SCORE-based risk classification in a contemporary population of 30,824 Europeans: the Copenhagen General Population Study. Eur Heart J 2015;36:2446-2453.

66. Emerging Risk Factors Collaboration, Di Angelantonio E, Sarwar N, Perry P. Kaptoge S, Ray KK, Thompson A, Wood AM, Lewington S, Sattar N, Packard CJ, Collins R, Thompson SG, Danesh J. Major ipids, apolipoproteins,and risk of vascular disease. JAMA 2009;302:1993-2000.

67. Wilson PW, Pencina M, Jacques P, Selhub J, D'Agostino R Sr, O'Donnell CJ. C-reactive protein and reclassification of cardiovascular risk in the Framingham Heart Study. Circ Cardiovasc Qual Outcomes 2008;1:92-97.

68. Cooney MT, Vartiainen E, Laatikainen T, De Bacquer D, McGorrian C, Dudina A Graham I. Cardiovascular risk age: concepts and practicalities. Heart 2012;98: 941-946.

69. Cuende Jl, Cuende N, Calaveras-Lagartos J. How to calculate vascular age with the SCORE project scales: a new method of cardiovascular risk evaluation. Eur Heart 2010;31:2351-2358.

70. World Health Organisation. WHO Global Health Repository. Cardiovascular diseases, deaths per 100000 . Data by country. http://apps.who.int/gho/data/ node.main.A865CARDIOVASCULAR?lang=en.

71. Banerjee A. A review of family history of cardiovascular disease: risk factor and research tool. Int J Clin Pract 2012;66:536-543.

72. Di Angelantonio E, Butterworth AS. Clinical utility of genetic variants for cardiovascular risk prediction: a futile exercise or insufficient data? Circ Cardiovasc Genet 2012;5:387-390.

73. loannidis JP. Prediction of cardiovascular disease outcomes and established cardiovascular risk factors by genome-wide association markers. Circ Cardiovasc Genet 2009;2:7-15.

74. Bachmann JM, Willis BL, Ayers CR, Khera A, Berry JD. Association between family history and coronary heart disease death across long-term follow-up in men: the Cooper Center Longitudinal Study. Circulation 2012;125:3092-3098.

75. Tikkanen E, Havulinna AS, Palotie A, Salomaa V, Ripatti S. Genetic risk prediction and a 2-stage risk screening strategy for coronary heart disease. Arterioscler Thromb Vasc Biol 2013;33:2261-2266.

76. Ripatti S, Tikkanen E, Orho-Melander M, Havulinna AS, Silander K, Sharma A, Guiducci C, Perola M, Jula A, Sinisalo J, Lokki ML, Nieminen MS, Melander O, Salomaa $\mathrm{V}$, Peltonen L, Kathiresan S. A multilocus genetic risk score for coronary heart disease: case-control and prospective cohort analyses. Lancet 2010;376 $1393-1400$. 
77. Sivapalaratnam S, Boekholdt SM, Trip MD, Sandhu MS, Luben R, Kastelein JJ, Wareham NJ, Khaw KT. Family history of premature coronary heart disease and risk prediction in the EPIC-Norfolk prospective population study. Heart 2010;96:1985-1989.

78. Veronesi G, Gianfagna F, Giampaoli S, Chambless LE, Mancia G, Cesana G, Ferrario MM. Improving long-term prediction of first cardiovascular event: the contribution of family history of coronary heart disease and social status. Prev Med 2014;64:75-80.

79. Yeboah J, McClelland RL, Polonsky TS, Burke GL, Sibley CT, O'Leary D, Carr JJ, Goff DC, Greenland P, Herrington DM. Comparison of novel risk markers for improvement in cardiovascular risk assessment in intermediate-risk individuals. JAMA 2012;308:788-795.

80. Hughes MF, Saarela O, Stritzke J, Kee F, Silander K, Klopp N, Kontto J, Karvanen J, Willenborg C, Salomaa V, Virtamo J, Amouyel P, Arveiler D, Ferrieres J, Wiklund PG, Baumert J, Thorand B, Diemert P, Tregouet DA, Hengstenberg C, Peters A, Evans A, Koenig W, Erdmann J, Samani NJ, Kuulasmaa K, Schunkert $\mathrm{H}$. Genetic markers enhance coronary risk prediction in men: the MORGAM prospective cohorts. PLoS One 2012;7:e40922.

81. Ganna A, Magnusson PK, Pedersen NL, de Faire U, Reilly M, Arnlov J, Sundstrom J, Hamsten A, Ingelsson E. Multilocus genetic risk scores for coronary heart disease prediction. Arteriosd Thromb Vasc Biol 2013;33:2267-2272.

82. Brautbar A, Pompeii LA, Dehghan A, Ngwa JS, Nambi V, Virani SS, Rivadeneira F, Uitterlinden AG, Hofman A, Witteman JC, Pencina MJ, Folsom AR, Cupples LA, Ballantyne CM, Boerwinkle E. A genetic risk score based on direct associations with coronary heart disease improves coronary heart disease risk prediction in the Atherosclerosis Risk in Communities (ARIC), but not in the Rotterdam and Framingham Offspring, Studies. Atherosclerosis 2012;223:421-426.

83. Bressler J, Folsom AR, Couper DJ, Volcik KA, Boerwinkle E. Genetic variants identified in a European genome-wide association study that were found to predict incident coronary heart disease in the atherosclerosis risk in communities study. Am J Epidemiol 2010;171:14-23.

84. Mega JL, Stitziel NO, Smith JG, Chasman DI, Caulfield MJ, Devlin JJ, Nordio F, Hyde CL, Cannon CP, Sacks FM, Poulter NR, Sever PS, Ridker PM, Braunwald E, Melander O, Kathiresan S, Sabatine MS. Genetic risk, coronary heart disease events, and the clinical benefit of statin therapy: an analysis of primary and secondary prevention trials. Lancet 2015;385:2264-2271.

85. Floyd CN, Mustafa A, Ferro A. The PIA1/A2 polymorphism of glycoprotein Illa as a risk factor for myocardial infarction: a meta-analysis. PLoS One 2014;9:e101518.

86. Singleton A, Erby LH, Foisie KV, Kaphingst KA. Informed choice in direct-to-consumer genetic testing (DTCGT) websites: a content analysis of benefits, risks, and limitations. J Genet Couns 2012;21:433-439.

87. Guay SP, Brisson D, Lamarche B, Marceau P, Vohl MC, Gaudet D, Bouchard L. DNA methylation variations at CETP and LPL gene promoter loci: new molecular biomarkers associated with blood lipid profile variability. Atherosclerosis 2013;228: 413-420.

88. Wang X, Falkner B, Zhu H, Shi H, Su S, Xu X, Sharma AK, Dong Y, Treiber F, Gutin B, Harshfield G, Snieder H. A genome-wide methylation study on essential hypertension in young African American males. PLoS One 2013;8:e53938.

89. Baccarelli A, Wright R, Bollati V, Litonjua A, Zanobetti A, Tarantini L, Sparrow D, Vokonas P, Schwartz J. Ischemic heart disease and stroke in relation to blood DNA methylation. Epidemiology 2010;21:819-828.

90. Albus C, Jordan J, Herrmann-Lingen C. Screening for psychosocial risk factors in patients with coronary heart disease-recommendations for clinical practice. Eur J Cardiovasc Prev Rehabil 2004;11:75-79.

91. Lichtman $J H$, Froelicher ES, Blumenthal JA, Carney RM, Doering LV, Frasure-Smith N, Freedland KE, Jaffe AS, Leifheit-Limson EC, Sheps DS, Vaccarino $\mathrm{V}$, Wulsin L. Depression as a risk factor for poor prognosis among patients with acute coronary syndrome: systematic review and recommendations: a scientific statement from the American Heart Association. Circulation 2014;129. 1350-1369.

92. Pogosova N, Saner H, Pedersen SS, Cupples ME, McGee H, Hofer S, Doyle F, Schmid JP, von Kanel R. Psychosocial aspects in cardiac rehabilitation: from theory to practice. A position paper from the Cardiac Rehabilitation Section of the European Association of Cardiovascular Prevention and Rehabilitation of the European Society of Cardiology. Eur J Prev Cardiol 2015;22:1290-1306.

93. Albert MA, Glynn RJ, Buring J, Ridker PM. Impact of traditional and novel risk factors on the relationship between socioeconomic status and incident cardiovascular events. Circulation 2006;114:2619-2626.

94. Alter DA, Franklin B, Ko DT, Austin PC, Lee DS, Oh PI, Stukel TA, Tu JV. Socioeconomic status, functional recovery, and long-term mortality among patients surviving acute myocardial infarction. PLoS One 2014;8:e65130.

95. Barth J, Schneider S, von Kanel R. Lack of social support in the etiology and the prognosis of coronary heart disease: a systematic review and meta-analysis. Psychosom Med 2010;72:229-238.
96. Nawrot TS, Perez L, Kunzli N, Munters E, Nemery B. Public health importance of triggers of myocardial infarction: a comparative risk assessment. Lancet 2011;377: 732-740.

97. Mostofsky E, Penner EA, Mittleman MA. Outbursts of anger as a trigger of acute cardiovascular events: a systematic review and meta-analysis. Eur Heart J 2014;35 1404-1410.

98. Kivimaki M, Nyberg ST, Batty GD, Fransson El, Heikkila K, Alfredsson L, Bjorner JB, Borritz M, Burr H, Casini A, Clays E, De Bacquer D, Dragano N, Ferrie JE, Geuskens GA, Goldberg M, Hamer M, Hooftman WE, Houtman IL, Joensuu M, Jokela M, Kittel F, Knutsson A, Koskenvuo M, Koskinen A, Kouvonen A, Kumari M, Madsen IE, Marmot MG, Nielsen ML, Nordin M, Oksanen T, Pentti J, Rugulies R, Salo P, Siegrist J, Singh-Manoux A, Suominen SB, Vaananen A, Vahtera J, Virtanen M, Westerholm PJ, Westerlund H, Zins M, Steptoe A, Theorell T. Job strain as a risk factor for coronary heart disease: a collaborative meta-analysis of individual participant data. Lancet 2012;380:1491-1497.

99. Eaker ED, Sullivan LM, Kelly-Hayes M, D’Agostino RB Sr, Benjamin EJ. Marital status, marital strain, and risk of coronary heart disease or total mortality: the Framingham Offspring Study. Psychosom Med 2007;69:509-513.

100. Kivimaki M, Jokela M, Nyberg ST, Singh-Manoux A, Fransson El, Alfredsson L, Bjorner JB, Borritz M, Burr H, Casini A, Clays E, De Bacquer D, Dragano N Erbel R, Geuskens GA, Hamer M, Hooftman WE, Houtman IL, Jockel KH, Kittel F, Knutsson A, Koskenvuo M, Lunau T, Madsen IE, Nielsen ML, Nordin M, Oksanen T, Pejtersen JH, Pentti J, Rugulies R, Salo P, Shipley MJ, Siegrist J, Steptoe A, Suominen SB, Theorell T, Vahtera J, Westerholm PJ, Westerlund H, O'Reilly D, Kumari M, Batty GD, Ferrie JE, Virtanen M. Long working hours and risk of coronary heart disease and stroke: a systematic review and meta-analysis of published and unpublished data for 603838 individuals. Lancet 2015;386:1739-1746.

101. Spindler H, Pedersen SS. Posttraumatic stress disorder in the wake of heart disease: prevalence, risk factors, and future research directions. Psychosom Med 2005; 67:715-723.

102. Orth-Gomer K, Wamala SP, Horsten M, Schenck-Gustafsson K, Schneiderman N, Mittleman MA. Marital stress worsens prognosis in women with coronary heart disease: the Stockholm Female Coronary Risk Study. JAMA 2000;284:3008-3014.

103. Schnohr P, Marott JL, Kristensen TS, Gyntelberg F, Gronbaek M, Lange P, Jensen MT, Jensen GB, Prescott E. Ranking of psychosocial and traditional risk factors by importance for coronary heart disease: the Copenhagen City Heart Study. Eur Heart J 2015;36:1385-1393.

104. Smoller JW, Pollack MH, Wassertheil-Smoller S, Jackson RD, Oberman A, Wong ND, Sheps D. Panic attacks and risk of incident cardiovascular events among postmenopausal women in the Women's Health Initiative Observational Study. Arch Gen Psychiatry 2007;64:1153-1160.

105. Roest AM, Martens EJ, de Jonge P, Denollet J. Anxiety and risk of incident coronary heart disease: a meta-analysis. J Am Coll Cardiol 2010;56:38-46.

106. Roest AM, Martens EJ, Denollet J, de Jonge P. Prognostic association of anxiety post myocardial infarction with mortality and new cardiac events: a meta-analysis. Psychosom Med 2010;72:563-569.

107. Fan Z, Wu Y, Shen J, Ji T, Zhan R. Schizophrenia and the risk of cardiovascular diseases: a meta-analysis of thirteen cohort studies. J Psychiatr Res 2013;47: 1549-1556.

108. Edmondson D, Kronish IM, Shaffer JA, Falzon L, Burg MM. Posttraumatic stress disorder and risk for coronary heart disease: a meta-analytic review. Am Heart J 2013;166:806-814.

109. Chida Y, Steptoe A. The association of anger and hostility with future coronary heart disease: a meta-analytic review of prospective evidence. J Am Coll Cardiol 2009;53:936-946.

110. Grande G, Romppel M, Barth J. Association between type D personality and prognosis in patients with cardiovascular diseases: a systematic review and meta-analysis. Ann Behav Med 2012;43:299-310.

111. Chandola T, Britton A, Brunner E, Hemingway H, Malik M, Kumari M, Badrick E, Kivimaki M, Marmot M. Work stress and coronary heart disease: what are the mechanisms? Eur Heart J 2008;29:640-648.

112. Yusuf S, Hawken S, Ounpuu S, Dans T, Avezum A, Lanas F, McQueen M, Budaj A, Pais $\mathrm{P}$, Varigos J, Lisheng L. Effect of potentially modifiable risk factors associated with myocardial infarction in 52 countries (the INTERHEART study): case-control study. Lancet 2004;364:937-952.

113. Stringhini S, Sabia S, Shipley M, Brunner E, Nabi H, Kivimaki M, Singh-Manoux A Association of socioeconomic position with health behaviors and mortality. JAMA 2010;303:1159-1166.

114. Gilstrap LG, Wang TJ. Biomarkers and cardiovascular risk assessment for primary prevention: an update. Clin Chem 2012;58:72-82.

115. loannidis JP, Tzoulaki I. Minimal and null predictive effects for the most popular blood biomarkers of cardiovascular disease. Circ Res 2012;110:658-662. 
116. Emerging Risk Factors Collaboration, Kaptoge S, Di Angelantonio E, Pennells L, Wood AM, White IR, Gao P, Walker M, Thompson A, Sarwar N, Caslake M, Butterworth AS, Amouyel P, Assmann G, Bakker SJ, Barr EL, Barrett-Connor E, Benjamin EJ, Bjorkelund C, Brenner H, Brunner E, Clarke R, Cooper JA, Cremer P, Cushman M, Dagenais GR, D'Agostino RB Sr, Dankner R, Davey-Smith G, Deeg D, Dekker JM, Engstrom G, Folsom AR, Fowkes FG, Gallacher J, Gaziano JM, Giampaoli S, Gillum RF, Hofman A, Howard BV, Ingelsson E, Iso H, Jorgensen T, Kiechl S, Kitamura A, Kiyohara Y, Koenig W, Kromhout D, Kuller LH, Lawlor DA, Meade TW, Nissinen A, Nordestgaard BG, Onat A, Panagiotakos DB, Psaty BM, Rodriguez B, Rosengren A, Salomaa V, Kauhanen J, Salonen JT, Shaffer JA, Shea S, Ford I, Stehouwer CD, Strandberg TE, Tipping RW, Tosetto A, Wassertheil-Smoller S, Wennberg P, Westendorp RG, Whincup PH, Wilhelmsen L, Woodward M, Lowe GD, Wareham NJ, Khaw KT, Sattar N, Packard CJ, Gudnason V, Ridker PM, Pepys MB, Thompson SG, Danesh J. C-reactive protein, fibrinogen, and cardiovascular disease prediction. N Engl J Med 2012;367:1310-1320.

117. Tzoulaki I, Siontis KC, Evangelou E, loannidis JP. Bias in associations of emerging biomarkers with cardiovascular disease. JAMA Intern Med 2013;173:664-671.

118. Kooter AJ, Kostense PJ, Groenewold J, Thijs A, Sattar N, Smulders YM. Integrating information from novel risk factors with calculated risks: the critical impact of risk factor prevalence. Circulation 2011;124:741-745.

119. Wurtz P, Havulinna AS, Soininen P, Tynkkynen T, Prieto-Merino D, Tillin T, Ghorbani A, Artati A, Wang Q, Tiainen M, Kangas AJ, Kettunen J, Kaikkonen J, Mikkila V, Jula A, Kahonen M, Lehtimaki T, Lawlor DA, Gaunt TR, Hughes AD, Sattar N, Illig T, Adamski J, Wang TJ, Perola M, Ripatti S, Vasan RS, Raitakari OT, Gerszten RE, Casas JP, Chaturvedi N, Ala-Korpela M, Salomaa V. Metabolite profiling and cardiovascular event risk: a prospective study of 3 population-based cohorts. Circulation 2015;131:774-85.

120. Haberl R, Becker A, Leber A, Knez A, Becker C, Lang C, Bruning R, Reiser M, Steinbeck $G$. Correlation of coronary calcification and angiographically documented stenoses in patients with suspected coronary artery disease: results of 1,764 patients. J Am Coll Cardiol 2001;37:451-457.

121. Marwan M, Ropers D, Pflederer T, Daniel WG, Achenbach S. Clinical characteristics of patients with obstructive coronary lesions in the absence of coronary calcification: an evaluation by coronary CT angiography. Heart 2009;95:1056-1060.

122. Hecht HS, Superko HR. Electron beam tomography and National Cholesterol Education Program guidelines in asymptomatic women. J Am Coll Cardiol 2001; 37:1506-1511.

123. Hadamitzky M, Freissmuth B, Meyer T, Hein F, Kastrati A, Martinoff S, Schomig A, Hausleiter J. Prognostic value of coronary computed tomographic angiography for prediction of cardiac events in patients with suspected coronary artery disease. JACC Cardiovasc Imaging 2009;2:404-411.

124. van Werkhoven JM, Gaemperli O, Schuijf JD, Jukema JW, Kroft LJ, Leschka S, Alkadhi H, Valenta I, Pundziute G, de Roos A, van der Wall EE, Kaufmann PA, Bax JJ. Multislice computed tomography coronary angiography for risk stratification in patients with an intermediate pretest likelihood. Heart 2009;95: 1607-1611.

125. Peters SA, den Ruijter HM, Bots ML, Moons KG. Improvements in risk stratification for the occurrence of cardiovascular disease by imaging subclinical atherosclerosis: a systematic review. Heart 2012;98:177-184.

126. O'Leary DH, Polak JF, Kronmal RA, Manolio TA, Burke GL, Wolfson SK Jr. Carotid-artery intima and media thickness as a risk factor for myocardial infarction and stroke in older adults. Cardiovascular Health Study Collaborative Research Group. N Engl J Med 1999;340:14-22.

127. Chambless LE, Heiss G, Folsom AR, Rosamond W, Szklo M, Sharrett AR, Clegg LX. Association of coronary heart disease incidence with carotid arterial wall thickness and major risk factors: the Atherosclerosis Risk in Communities (ARIC) Study, 1987-1993. Am J Epidemiol 1997;146:483-494.

128. Den Ruijter HM, Peters SA, Anderson TJ, Britton AR, Dekker JM, Eijkemans MJ, Engstrom G, Evans GW, de Graaf J, Grobbee DE, Hedblad B, Hofman A, Holewijn S, Ikeda A, Kavousi M, Kitagawa K, Kitamura A, Koffijberg $H$, Lonn EM, Lorenz MW, Mathiesen EB, Nijpels G, Okazaki S, O'Leary DH, Polak JF, Price JF, Robertson C, Rembold CM, Rosvall M, Rundek T, Salonen JT, Sitzer M, Stehouwer CD, Witteman JC, Moons KG, Bots ML. Common carotid intima-media thickness measurements in cardiovascular risk prediction: a meta-analysis. JAMA 2012;308:796-803.

129. Hiatt WR. Medical treatment of peripheral arterial disease and claudication. $N$ Engl J Med 2001;344:1608-21.

130. McDermott MM, Greenland P, Liu K, Guralnik JM, Celic L, Criqui MH, Chan C, Martin GJ, Schneider J, Pearce WH, Taylor LM, Clark E. The ankle brachial index is associated with leg function and physical activity: the Walking and Leg Circulation Study. Ann Intern Med 2002;136:873-883.

131. Fowkes FG, Murray GD, Newman AB, Lee RJ. Ankle brachial index combined with Framingham Risk Score to predict cardiovascular events and mortality: a meta-analysis. JAMA 2008;300:197-208.
132. Fowkes FG, Price JF, Stewart MC, Butcher I, Leng GC, Pell AC, Sandercock PA, Fox KA, Lowe GD, Murray GD. Aspirin for prevention of cardiovascular events in a general population screened for a low ankle brachial index: a randomized controlled trial. JAMA 2010;303:841-848.

133. Lorenz MW, Polak JF, Kavousi M, Mathiesen EB, Volzke H, Tuomainen TP, Sander D, Plichart M, Catapano AL, Robertson CM, Kiechl S, Rundek T, Desvarieux M, Lind L, Schmid C, DasMahapatra P, Gao L, Ziegelbauer K, Bots ML, Thompson SG. Carotid intima-media thickness progression to predict cardiovascular events in the general population (the PROG-IMT collaborative project): a meta-analysis of individual participant data. Lancet 2012;379: 2053-2062.

134. Tinana A, Mintz GS, Weissman NJ. Volumetric intravascular ultrasound quantification of the amount of atherosclerosis and calcium in nonstenotic arterial segments. Am J Cardiol 2002;89:757-760.

135. Burke AP, Kolodgie FD, Farb A, Weber D, Virmani R. Morphological predictors of arterial remodeling in coronary atherosclerosis. Circulation 2002;105:297-303.

136. Schmermund A, Schwartz RS, Adamzik M, Sangiorgi G, Pfeifer EA, Rumberger JA, Burke AP, Farb A, Virmani R. Coronary atherosclerosis in unheralded sudden coronary death under age 50: histo-pathologic comparison with 'healthy' subjects dying out of hospital. Atherosclerosis 2001;155:499-508.

137. Silber S. Comparison of spiral and electron beam tomography in the evaluation of coronary calcification in asymptomatic persons. Int J Cardiol 2002;82:297-298; author reply 299.

138. Gibson AO, Blaha MJ, Arnan MK, Sacco RL, Szklo M, Herrington DM, Yeboah J. Coronary artery calcium and incident cerebrovascular events in an asymptomatic cohort. The MESA Study. JACC Cardiovasc Imaging 2014;7:1108-1115.

139. Fernandez-Friera L, Penalvo JL, Fernandez-Ortiz A, Ibanez B, Lopez-Melgar B, Laclaustra M, Oliva B, Mocoroa A, Mendiguren J, Martinez de Vega V, Garcia L, Molina J, Sanchez-Gonzalez J, Guzman G, Alonso-Farto JC, Guallar E, Civeira F, Sillesen H, Pocock S, Ordovas JM, Sanz G, Jimenez-Borreguero LJ, Fuster V. Prevalence, vascular distribution, and multiterritorial extent of subclinical atherosclerosis in a middle-aged cohort: the PESA (Progression of Early Subclinical Atherosclerosis) study. Circulation 2015;131:2104-2113.

140. Nasir K, Bittencourt MS, Blaha MJ, Blankstein R, Agatson AS, Rivera J], Miemdema MD, Sibley CT, Shaw LJ, Blumenthal RS, Budoff MJ, Krumholz HM. Implications of coronary artery calcium testing among statin candidates according to American College of Cardiology/American Heart Association cholesterol management guidelines: MESA (Multi-Ethnic Study of Atherosclerosis). J Am Coll Cardiol 2015; 66:1657-1668.

141. Stein JH, Korcarz CE, Hurst RT, Lonn E, Kendall CB, Mohler ER, Najjar SS, Rembold CM, Post WS. Use of carotid ultrasound to identify subclinical vascular disease and evaluate cardiovascular disease risk: a consensus statement from the American Society of Echocardiography Carotid Intima-Media Thickness Task Force. Endorsed by the Society for Vascular Medicine. J Am Soc Echocardiogr 2008:21:93-111; quiz 189-190

142. Vlachopoulos C, Aznaouridis K, Stefanadis C. Prediction of cardiovascular events and all-cause mortality with arterial stiffness: a systematic review and meta-analysis. J Am Coll Cardiol 2010;55:1318-1327.

143. U.S. Preventive Services Task Force. Using nontraditional risk factors in coronary heart disease risk assessment: U.S. Preventive Services Task Force recommendation statement. Ann Intern Med 2009;151:474-482.

144. Taylor HA, Penman AD, Han H, Dele-Michael A, Skelton TN, Fox ER, Benjamin EJ, Arnett DK, Mosley TH Jr. Left ventricular architecture and survival in African-Americans free of coronary heart disease (from the Atherosclerosis Risk in Communities [ARIC] study). Am J Cardiol 2007;99:1413-1420.

145. Muiesan ML, Salvetti M, Monteduro C, Bonzi B, Paini A, Viola S, Poisa P, Rizzoni D, Castellano M, Agabiti-Rosei E. Left ventricular concentric geometry during treatment adversely affects cardiovascular prognosis in hypertensive patients. Hypertension 2004:43:731-738.

146. Schiffrin EL, Lipman ML, Mann JF. Chronic kidney disease: effects on the cardiovascular system. Circulation 2007;116:85-97.

147. Chronic Kidney Disease Prognosis Consortium, Matsushita K, van der Velde M, Astor BC, Woodward M, Levey AS, de Jong PE, Coresh J, Gansevoort RT. Association of estimated glomerular filtration rate albuminuria with all-cause cardiovascular mortality in general population cohorts: a collaborative meta-analysis. Lancet 2010;375:2073-2081.

148. Matsushita K, Coresh J, Sang Y, Chalmers J, Fox C, Guallar E, Jafar T, Jassal SK, Landman GW, Muntner P, Roderick P, Sairenchi T, Schottker B, Shankar A, Shlipak M, Tonelli M, Townend J, van Zuilen A, Yamagishi K, Yamashita K, Gansevoort R, Sarnak M, Warnock DG, Woodward M, Arnlov J, Consortium CKDP. Estimated glomerular filtration rate and albuminuria for prediction of cardiovascular outcomes: a collaborative meta-analysis of individual participant data. Lancet Diabetes Endocrinol 2015;3:514-525.

149. Shlipak MG, Matsushita K, Arnlov J, Inker LA, Katz R, Polkinghorne KR, Rothenbacher D, Sarnak MJ, Astor BC, Coresh J, Levey AS, Gansevoort RT. 
Cystatin C versus creatinine in determining risk based on kidney function. N EnglJ Med 2013;369:932-943.

150. Matsushita K, Mahmoodi BK, Woodward M, Emberson JR, Jafar TH, Jee SH, Polkinghorne KR, Shankar A, Smith DH, Tonelli M, Warnock DG, Wen CP, Coresh J, Gansevoort RT, Hemmelgarn BR, Levey AS. Comparison of risk prediction using the CKD-EPI equation and the MDRD study equation for estimated glomerular filtration rate. JAMA 2012;307:1941-51.

151. Smeeth L, Thomas SL, Hall AJ, Hubbard R, Farrington P, Vallance P. Risk of myocardial infarction and stroke after acute infection or vaccination. N Engl J Med 2004:351:2611-2618

152. Siriwardena AN, Gwini SM, Coupland CA. Influenza vaccination, pneumococcal vaccination and risk of acute myocardial infarction: matched case-control study. CMAJ 2010;182:1617-1623.

153. Gwini SM, Coupland CA, Siriwardena AN. The effect of influenza vaccination on risk of acute myocardial infarction: self-controlled case-series study. Vaccine 2011; 29:1145-1149.

154. Udell JA, Zawi R, Bhatt DL, Keshtkar-Jahromi M, Gaughran F, Phrommintikul A, Ciszewski A, Vakili H, Hoffman EB, Farkouh ME, Cannon CP. Association between influenza vaccination and cardiovascular outcomes in high-risk patients: a meta-analysis. JAMA 2013;310:1711-1720.

155. Warren-Gash C, Hayward AC, Hemingway H, Denaxas S, Thomas SL, Timmis AD, Whitaker H, Smeeth L. Influenza infection and risk of acute myocardial infarction in England and Wales: a CALIBER self-controlled case series study. J Infect Dis 2012;206:1652-1659.

156. Jimenez M, Krall EA, Garcia RI, Vokonas PS, Dietrich T. Periodontitis and incidence of cerebrovascular disease in men. Ann Neurol 2009;66:505-512.

157. Dietrich T, Jimenez M, Krall Kaye EA, Vokonas PS, Garcia RI. Age-dependent associations between chronic periodontitis/edentulism and risk of coronary heart disease. Circulation 2008;117:1668-1674.

158. Beck JD, Eke P, Lin D, Madianos P, Couper D, Moss K, Elter J, Heiss G, Offenbacher $S$. Associations between $\lg G$ antibody to oral organisms and carotid intima-medial thickness in community-dwelling adults. Atherosclerosis 2005;183 342-348.

159. Desvarieux M, Demmer RT, Jacobs DR, Papapanou PN, Sacco RL, Rundek T. Changes in clinical and microbiological periodontal profiles relate to progression of carotid intima-media thickness: the Oral Infections and Vascular Disease Epidemiology study. J Am Heart Assoc 2013;2:e000254.

160. Bosch X, Rovira M, Sitges M, Domenech A, Ortiz-Perez JT, de Caralt TM, Morales-Ruiz M, Perea RJ, Monzo M, Esteve J. Enalapril and carvedilol for preventing chemotherapy-induced left ventricular systolic dysfunction in patients with malignant hemopathies: the OVERCOME trial (preventiOn of left Ventricular dysfunction with Enalapril and caRvedilol in patients submitted to intensive ChemOtherapy for the treatment of Malignant hEmopathies). J Am Coll Cardiol 2013;61:2355-2362.

161. Kalam K, Marwick TH. Role of cardioprotective therapy for prevention of cardiotoxicity with chemotherapy: a systematic review and meta-analysis. Eur J Cancer 2013:49:2900-2909.

162. Chen J, Long JB, Hurria A, Owusu C, Steingart RM, Gross CP. Incidence of heart failure or cardiomyopathy after adjuvant trastuzumab therapy for breast cancer. J Am Coll Cardiol 2012;60:2504-2512.

163. Darby S, McGale P, Peto R, Granath F, Hall P, Ekbom A. Mortality from cardiovascular disease more than 10 years after radiotherapy for breast cancer: nationwide cohort study of 90000 Swedish women. BMJ 2003;326:256-257.

164. Smith GL, Smith BD, Buchholz TA, Giordano SH, Garden AS, Woodward WA, Krumholz HM, Weber RS, Ang KK, Rosenthal DI. Cerebrovascular disease risk in older head and neck cancer patients after radiotherapy. J Clin Oncol 2008;26: 5119-5125.

165. Fajardo LF. Is the pathology of radiation injury different in small vs large blood vessels? Cardiovasc Radiat Med 1999;1:108-110.

166. van der Pal HJ, van Dalen EC, van Delden E, van Dijk IW, Kok WE, Geskus RB, Sieswerda E, Oldenburger F, Koning CC, van Leeuwen FE, Caron HN, Kremer LC. High risk of symptomatic cardiac events in childhood cancer survivors. J Clin Oncol 2012;30:1429-1437.

167. Hooning MJ, Botma A, Aleman BM, Baaijens MH, Bartelink H, Klijn JG, Taylor CW, van Leeuwen FE. Long-term risk of cardiovascular disease in 10-year survivors of breast cancer. J Natl Cancer Instit 2007;99:365-375.

168. Yeh JM, Nohria A, Diller L. Routine echocardiography screening for asymptomatic left ventricular dysfunction in childhood cancer survivors: a model-based estimation of the clinical and economic effects. Ann Intern Med 2014;160:661-671.

169. Jensen BV, Skovsgaard T, Nielsen SL. Functional monitoring of anthracycline cardiotoxicity: a prospective, blinded, long-term observational study of outcome in 120 patients. Ann Oncology 2002;13:699-709.

170. Darby SC, Ewertz M, McGale P, Bennet AM, Blom-Goldman U, Bronnum D, Correa C, Cutter D, Gagliardi G, Gigante B, Jensen MB, Nisbet A, Peto R,
Rahimi K, Taylor C, Hall P. Risk of ischemic heart disease in women after radiotherapy for breast cancer. N Engl J Med 2013;368:987-998.

171. Mishra SI, Scherer RW, Snyder C, Geigle PM, Berlanstein DR, Topaloglu O. Exercise interventions on health-related quality of life for people with cancer during active treatment. Cochrane Database Syst Rev 2012;8:CD008465.

172. McMurray IJ, Adamopoulos S, Anker SD, Auricchio A, Bohm M, Dickstein K, Falk V, Filippatos G, Fonseca C, Gomez-Sanchez MA, Jaarsma T, Kober L, Lip GY, Maggioni AP, Parkhomenko A, Pieske BM, Popescu BA, Ronnevik PK, Rutten FH, Schwitter J, Seferovic P, Stepinska J, Trindade PT, Voors AA, Zannad F, Zeiher A. ESC Guidelines for the diagnosis and treatment of acute and chronic heart failure 2012: the Task Force for the Diagnosis and Treatment of Acute and Chronic Heart Failure 2012 of the European Society of Cardiology. Developed in collaboration with the Heart Failure Association (HFA) of the ESC. Eur Heart J 2012;33:1787-1847.

173. Plana JC, Galderisi M, Barac A, Ewer MS, Ky B, Scherrer-Crosbie M, Ganame J, Sebag IA, Agler DA, Badano LP, Banchs J, Cardinale D, Carver J, Cerqueira M, DeCara JM, Edvardsen T, Flamm SD, Force T, Griffin BP, Jerusalem G, Liu JE, Magalhaes A, Marwick T, Sanchez LY, Sicari R, Villarraga HR, Lancellotti P. Expert consensus for multimodality imaging evaluation of adult patients during and after cancer therapy: a report from the American Society of Echocardiography and the European Association of Cardiovascular Imaging. Eur Heart J Cardiovasc Imaging 2014;15:1063-1093.

174. Curigliano G, Cardinale D, Suter T, Plataniotis G, de Azambuja E, Sandri MT, Criscitiello C, Goldhirsch A, Cipolla C, Roila F. Cardiovascular toxicity induced by chemotherapy, targeted agents and radiotherapy: ESMO Clinical Practice Guidelines. Ann Oncology 2012;23(Suppl 7):vii155-vii166.

175. Cardinale D, Colombo A, Lamantia G, Colombo N, Civelli M, De Giacomi G, Rubino M, Veglia F, Fiorentini C, Cipolla CM. Anthracycline-induced cardiomyopathy: clinical relevance and response to pharmacologic therapy. J Am Coll Cardiol 2010;55:213-220.

176. Felker GM, Thompson RE, Hare JM, Hruban RH, Clemetson DE, Howard DL, Baughman KL, Kasper EK. Underlying causes and long-term survival in patients with initially unexplained cardiomyopathy. N Engl J Med 2000;342:1077-1084.

177. Peters MJ, Symmons DP, McCarey D, Dijkmans BA, Nicola P, Kvien TK Mclnnes IB, Haentzschel H, Gonzalez-Gay MA, Provan S, Semb A, Sidiropoulos P, Kitas G, Smulders YM, Soubrier M, Szekanecz Z, Sattar N, Nurmohamed MT. EULAR evidence-based recommendations for cardiovascular risk management in patients with rheumatoid arthritis and other forms of inflammatory arthritis. Ann Rheum Dis 2010;69:325-331.

178. Sattar N, McCarey DW, Capell H, Mclnnes IB. Explaining how "high-grade" systemic inflammation accelerates vascular risk in rheumatoid arthritis. Circulation 2003;108:2957-63.

179. Ogdie A, Yu Y, Haynes K, Love TJ, Maliha S, Jiang Y, Troxel AB, Hennessy S, Kimmel SE, Margolis DJ, Choi H, Mehta NN, Gelfand JM. Risk of major cardiovascular events in patients with psoriatic arthritis, psoriasis and rheumatoid arthritis: a population-based cohort study. Ann Rheum Dis 2015;74:326-332.

180. Semb AG, Kvien TK, DeMicco DA, Fayyad R, Wun CC, LaRosa JC, Betteridge J, Pedersen TR, Holme I. Effect of intensive lipid-lowering therapy on cardiovascular outcome in patients with and those without inflammatory joint disease. Arthritis Rheum 2012;64:2836-2846.

181. Gonzaga C, Bertolami A, Bertolami M, Amodeo C, Calhoun D. Obstructive sleep apnea, hypertension and cardiovascular diseases. J Hum Hypertens 2015;29: 705-712.

182. Johns MW. A new method for measuring daytime sleepiness: the Epworth sleepiness scale. Sleep 1991;14:540-545.

183. Somers VK, White DP, Amin R, Abraham WT, Costa F, Culebras A, Daniels S, Floras JS, Hunt CE, Olson LJ, Pickering TG, Russell R, Woo M, Young T. Sleep apnea and cardiovascular disease: an American Heart Association/American College of Cardiology Foundation Scientific Statement from the American Heart Association Council for High Blood Pressure Research Professional Education Committee, Council on Clinical Cardiology, Stroke Council, and Council on Cardiovascular Nursing. In collaboration with the National Heart, Lung, and Blood Institute National Center on Sleep Disorders Research (National Institutes of Health). Circulation 2008;1 18:1080-1111.

184. Vlachopoulos C, Jackson G, Stefanadis C, Montorsi P. Erectile dysfunction in the cardiovascular patient. Eur Heart J 2013:34:2034-2046.

185. Montorsi P, Ravagnani PM, Galli S, Salonia A, Briganti A, Werba JP, Montorsi F. Association between erectile dysfunction and coronary artery disease: matching the right target with the right test in the right patient. Eur Urol 2006;50:721-731.

186. Vlachopoulos CV, Terentes-Printzios DG, loakeimidis NK, Aznaouridis KA, Stefanadis $\mathrm{Cl}$. Prediction of cardiovascular events and all-cause mortality with erectile dysfunction: a systematic review and meta-analysis of cohort studies. Circ Cardiovasc Qual Outcomes 2013;6:99-109.

187. World Health Organization. Familial hypercholesterolemia - report of a second WHO consultation. Geneva: World Health Organization, 1999. 
188. Scientific Steering Committee on behalf of the Simon Broome Register Group. Risk of fatal coronary heart disease in familial hypercholesterolaemia. BMJ 1991; 303:893-896.

189. Williams RR, Hunt SC, Schumacher MC, Hegele RA, Leppert MF, Ludwig EH, Hopkins PN. Diagnosing heterozygous familial hypercholesterolemia using new practical criteria validated by molecular genetics. Am J Cardiol 1993;72:171-176.

190. Stone NJ, Robinson JG, Lichtenstein AH, Bairey Merz CN, Blum CB, Eckel RH, Goldberg AC, Gordon D, Levy D, Lloyd-Jones DM, McBride P, Schwartz JS, Shero ST, Smith SC Jr, Watson K, Wilson PW. 2013 ACC/AHA guideline on the treatment of blood cholesterol to reduce atherosclerotic cardiovascular risk in adults: a report of the American College of Cardiology/American Heart Association Task Force on Practice Guidelines. J Am Coll Cardiol 2014;63(25 Pt B): 2889-2934.

191. Muller M, Smulders YM, de Leeuw PW, Stehouwer CD. Treatment of hypertension in the oldest old: a critical role for frailty? Hypertension 2014;63:433-441.

192. Odden MC, Pletcher MJ, Coxson PG, Thekkethala D, Guzman D, Heller D, Goldman L, Bibbins-Domingo K. Cost-effectiveness and population impact of statins for primary prevention in adults aged 75 years or older in the United States. Ann Intern Med 2015;162:533-541.

193. Kutner JS, Blatchford PJ, Taylor DH Jr, Ritchie CS, Bull JH, Fairclough DL, Hanson LC, LeBlanc TW, Samsa GP, Wolf S, Aziz NM, Currow DC, Ferrell B, Wagner-Johnston N, Zafar SY, Cleary JF, Dev S, Goode PS, Kamal AH, Kassner C, Kvale EA, McCallum JG, Ogunseitan AB, Pantilat SZ, Portenoy RK, Prince-Paul M, Sloan JA, Swetz KM, Von Gunten CF, Abernethy AP. Safety and benefit of discontinuing statin therapy in the setting of advanced, life-limiting illness: a randomized clinical trial. JAMA Intern Med 2015;175:691-700.

194. Lykke JA, Langhoff-Roos J, Sibai BM, Funai EF, Triche EW, Paidas MJ. Hypertensive pregnancy disorders and subsequent cardiovascular morbidity and type 2 diabetes mellitus in the mother. Hypertension 2009;53:944-51.

195. Skjaerven R, Wilcox AJ, Klungsoyr K, Irgens LM, Vikse BE, Vatten LJ, Lie RT. Cardiovascular mortality after pre-eclampsia in one child mothers: prospective, population based cohort study. BMJ 2012;345:e7677.

196. Wilson BJ, Watson MS, Prescott GJ, Sunderland S, Campbell DM, Hannaford P, Smith WC. Hypertensive diseases of pregnancy and risk of hypertension and stroke in later life: results from cohort study. BMJ 2003;326:845.

197. Engeland A, Bjorge T, Daltveit AK, Skurtveit S, Vangen S, Vollset SE, Furu K. Risk of diabetes after gestational diabetes and preeclampsia. A registry-based study of 230,000 women in Norway. Eur J Epidemiol 2011;26:157-163.

198. Morgan CL, Jenkins-Jones S, Currie CJ, Rees DA. Evaluation of adverse outcome in young women with polycystic ovary syndrome versus matched, reference controls: a retrospective, observational study. J Clin Endocrinol Metab 2012;97: $3251-3260$.

199. Moran LJ, Misso ML, Wild RA, Norman RJ. Impaired glucose tolerance, type 2 diabetes and metabolic syndrome in polycystic ovary syndrome: a systematic review and meta-analysis. Hum Reprod Update 2010;16:347-363.

200. Bellamy L, Casas JP, Hingorani AD, Williams D. Type 2 diabetes mellitus after gestational diabetes: a systematic review and meta-analysis. Lancet 2009;373: 1773-1779.

201. Venkataraman H, Sattar N, Saravanan P. Postnatal testing following gestational diabetes: time to replace the oral glucose tolerance test? Lancet Diabetes Endocrinol 2015;3:754-756

202. Lykke JA, Paidas MJ, Damm P, Triche EW, Kuczynski E, Langhoff-Roos J. Preterm delivery and risk of subsequent cardiovascular morbidity and type-II diabetes in the mother. BJOG 2010;117:274-281.

203. Bonamy AK, Parikh NI, Cnattingius S, Ludvigsson JF, Ingelsson E. Birth characteristics and subsequent risks of maternal cardiovascular disease: effects of gestational age and fetal growth. Circulation 2011;124:2839-2846.

204. Marin R, Gorostidi M, Portal CG, Sanchez M, Sanchez E, Alvarez J. Long-term prognosis of hypertension in pregnancy. Hypertens Pregnancy 2000;19:199-209.

205. Shaw LJ, Bairey Merz CN, Azziz R, Stanczyk FZ, Sopko G, Braunstein GD, Kelsey SF, Kip KE, Cooper-Dehoff RM, Johnson BD, Vaccarino V, Reis SE, Bittner V, Hodgson TK, Rogers W, Pepine CJ. Postmenopausal women with a history of irregular menses and elevated androgen measurements at high risk for worsening cardiovascular event-free survival: results from the National Institutes of Health-National Heart, Lung, and Blood Institute sponsored Women's Ischemia Syndrome Evaluation. J Clin Endocrinol Metab 2008;93:1276-1284.

206. Hong JS, Yi SW, Kang HC, Jee SH, Kang HG, Bayasgalan G, Ohrr H. Age at menopause and cause-specific mortality in South Korean women: Kangwha Cohort Study. Maturitas 2007;56:411-419.

207. Tillin T, Hughes AD, Whincup P, Mayet J, Sattar N, McKeigue PM, Chaturvedi N. Ethnicity and prediction of cardiovascular disease: performance of QRISK2 and Framingham scores in a U.K. tri-ethnic prospective cohort study (SABRE-Southall And Brent REvisited). Heart 2014;100:60-67.

208. Cappuccio FP, Oakeshott P, Strazzullo P, Kerry SM. Application of Framingham risk estimates to ethnic minorities in United Kingdom and implications for primary prevention of heart disease in general practice: cross sectional population based study. BMJ 2002;325:1271.

209. Gadd M, Johansson SE, Sundquist J, Wandell P. Are there differences in all-cause and coronary heart disease mortality between immigrants in Sweden and in their country of birth? A follow-up study of total populations. BMC Public Health 2006;6: 102.

210. Patel JV, Vyas A, Cruickshank JK, Prabhakaran D, Hughes E, Reddy KS, Mackness MI, Bhatnagar D, Durrington PN. Impact of migration on coronary heart disease risk factors: comparison of Gujaratis in Britain and their contemporaries in villages of origin in India. Atherosclerosis 2006;185:297-306.

211. Rafnsson SB, Bhopal RS, Agyemang C, Fagot-Campagna A, Harding S, Hammar N, Hedlund E, Juel K, Primatesta P, Rosato M, Rey G, Wild SH, Mackenbach JP, Stirbu I, Kunst AE. Sizable variations in circulatory disease mortality by region and country of birth in six European countries. Eur J Public Health 2013;23 594-605.

212. van Oeffelen AA, Vaartjes I, Stronks K, Bots ML, Agyemang C. Incidence of acute myocardial infarction in first and second generation minority groups: does the second generation converge towards the majority population? Int J Cardiol 2013;168 5422-5429.

213. Harding S, Rosato M, Teyhan A. Trends for coronary heart disease and stroke mortality among migrants in England and Wales, 1979-2003: slow declines notable for some groups. Heart 2008;94:463-470.

214. Bhopal RS, Bansal N, Fischbacher CM, Brown H, Capewell S, Scottish H. Ethnic variations in the incidence and mortality of stroke in the Scottish Health and Ethnicity Linkage Study of 4.65 million people. Eur J Prev Cardiol 2012;19:1503-1508.

215. Tran AT, Straand J, Diep LM, Meyer HE, Birkeland KI, Jenum AK. Cardiovascular disease by diabetes status in five ethnic minority groups compared to ethnic Norwegians. BMC Public Health 2011;11:554

216. Bansal N, Fischbacher CM, Bhopal RS, Brown H, Steiner MF, Capewell S. Myocardial infarction incidence and survival by ethnic group: Scottish Health and Ethnicity Linkage retrospective cohort study. BMJ Open 2013;3:e003415.

217. Bhopal RS, Humphry RW, Fischbacher CM. Changes in cardiovascular risk factors in relation to increasing ethnic inequalities in cardiovascular mortality: comparison of cross-sectional data in the Health Surveys for England 1999 and 2004. BMJ Open 2013;3:e003485.

218. Agyemang C, Kunst AE, Bhopal R, Anujuo K, Zaninotto P, Nazroo J, Nicolaou M, Unwin N, van Valkengoed I, Redekop WK, Stronks K. Diabetes prevalence in populations of South Asian Indian and African origins: a comparison of England and the Netherlands. Epidemiology 2011;22:563-567.

219. Agyemang C, Stronks K, Tromp N, Bhopal R, Zaninotto P, Unwin N, Nazroo J, Kunst AE. A cross-national comparative study of smoking prevalence and cessation between English and Dutch South Asian and African origin populations: the role of national context. Nicotine Tob Res 2010;12:557-566.

220. Mathur R, Hull SA, Badrick E, Robson J. Cardiovascular multimorbidity: the effect of ethnicity on prevalence and risk factor management. Br J Gen Pract 2011;61 e262-e270.

221. Bhopal R, Fischbacher C, Vartiainen E, Unwin N, White M, Alberti G. Predicted and observed cardiovascular disease in South Asians: application of FINRISK, Framingham and SCORE models to Newcastle Heart Project data. J Public Health 2005;27:93-100.

222. Glenday K, Kumar BN, Tverdal A, Meyer HE. Cardiovascular disease risk factors among five major ethnic groups in Oslo, Norway: the Oslo Immigrant Health Study. Eur J Cardiovasc Prev Rehabil 2006;13:348-355.

223. Agyemang C, Ujcic-Voortman J, Uitenbroek D, Foets M, Droomers M. Prevalence and management of hypertension among Turkish, Moroccan and native Dutch ethnic groups in Amsterdam, the Netherlands: the Amsterdam Health Monitor Survey. J Hypertens 2006;24:2169-2176.

224. El Fakiri F, Bruijnzeels MA, Foets MM, Hoes AW. Different distribution of cardiovascular risk factors according to ethnicity: a study in a high risk population. J Immigrant Minority Health 2008;10:559-65.

225. Hempler NF, Diderichsen F, Larsen FB, Ladelund S, Jorgensen T. Do immigrants from Turkey, Pakistan and Yugoslavia receive adequate medical treatment with beta-blockers and statins after acute myocardial infarction compared with Danishborn residents? A register-based follow-up study. Eur J Clin Pharmacol 2010;66: 735-742.

226. Regidor E, de La Fuente L, Martinez D, Calle ME, Dominguez V. Heterogeneity in cause-specific mortality according to birthplace in immigrant men residing in Madrid, Spain. Ann Epidemiol 2008;18:605-13.

227. Schofield $P$, Saka $O$, Ashworth $M$. Ethnic differences in blood pressure monitoring and control in south east London. Br J Gen Pract 2011;61:190-196.

228. Regidor E, Ronda E, Pascual C, Martinez D, Elisa Calle M, Dominguez V. [Mortality from cardiovascular diseases in immigrants residing in Madrid]. Med Clin 2009;132: $621-624$.

229. Bo A, Zinckernagel L, Krasnik A, Petersen JH, Norredam M. Coronary heart disease incidence among non-Western immigrants compared to Danish-born 
people: effect of country of birth, migrant status, and income. Eur J Prev Cardiol 2015;22:1281-1289.

230. Lozano Sanchez ML, Leal Hernandez M, Abellan Huerta J, Gomez Jara P, Ortin Ortin EJ, Abellan Aleman J. [Cardiovascular risk of immigrants living in Spain according to origin years of stay]. Aten Primaria 2013;45:92-100.

231. Rubak S, Sandbaek A, Lauritzen T, Christensen B. Motivational interviewing: a systematic review and meta-analysis. Br J Gen Pract 2005;55:305-312.

232. Artinian NT, Fletcher GF, Mozaffarian D, Kris-Etherton P, Van Horn L, Lichtenstein AH, Kumanyika S, Kraus WE, Fleg JL, Redeker NS, Meininger JC, Banks J, Stuart-Shor EM, Fletcher BJ, Miller TD, Hughes S, Braun LT, Kopin LA, Berra K, Hayman LL, Ewing LJ, Ades PA, Durstine JL, Houston-Miller N, Burke LE. Interventions to promote physical activity and dietary lifestyle changes for cardiovascular risk factor reduction in adults: a scientific statement from the American Heart Association. Circulation 2010;122:406-441.

233. Balady GJ, Williams MA, Ades PA, Bittner V, Comoss P, Foody JM, Franklin B, Sanderson B, Southard D, American Heart Association Exercise CR. Core components of cardiac rehabilitation/secondary prevention programs: 2007 update: a scientific statement from the American Heart Association Exercise, Cardiac Rehabilitation, and Prevention Committee, the Council on Clinical Cardiology; the Councils on Cardiovascular Nursing, Epidemiology and Prevention, and Nutrition, Physical Activity, and Metabolism; and the American Association of Cardiovascular and Pulmonary Rehabilitation. Circulation 2007;115:2675-2682.

234. Piepoli MF, Corra U, Benzer W, Bjarnason-Wehrens B, Dendale P, Gaita D, McGee H, Mendes M, Niebauer J, Zwisler AD, Schmid JP. Secondary prevention through cardiac rehabilitation: from knowledge to implementation. A position paper from the Cardiac Rehabilitation Section of the European Association of Cardiovascular Prevention and Rehabilitation. Eur J Cardiovasc Prev Rehabil 2010;17: $1-17$.

235. General Medical Council. Consent: patients and doctors making decisions together. Manchester, UK: General Medical Council, 2008.

236. Martin LR, DiMatteo MR, eds. The Oxford Handbook of Health Communication, Behaviour Change, and Treatment Adherence. New York: Oxford University Press, 2014.

237. U.S. Preventive Services Task Force. Guide to Clinical Preventive Services. 2nd ed. Baltimore: Williams \& Wilkins, 1996.

238. Auer R, Gaume J, Rodondi N, Cornuz J, Ghali WA. Efficacy of in-hospital multidimensional interventions of secondary prevention after acute coronary syndrome: a systematic review and meta-analysis. Circulation 2008;117:3109-3117.

239. Janssen V, De Gucht V, Dusseldorp E, Maes S. Lifestyle modification programmes for patients with coronary heart disease: a systematic review and meta-analysis of randomized controlled trials. Eur J Prev Cardiol 2013;20:620-640.

240. Hazelton G, Williams JW, Wakefield J, Perlman A, Kraus WE, Wolever RQ. Psychosocial benefits of cardiac rehabilitation among women compared with men. J Cardiopulm Rehab Prev 2014;34:21-28.

241. Burell G, Granlund B. Women's hearts need special treatment. Int J Bbehav Med 2002;9:228-242.

242. Whalley B, Thompson DR, Taylor RS. Psychological interventions for coronary heart disease: cochrane systematic review and meta-analysis. Int J Behav Med 2014;21:109-121.

243. Rutledge T, Redwine LS, Linke SE, Mills PJ. A meta-analysis of mental health treatments and cardiac rehabilitation for improving clinical outcomes and depression among patients with coronary heart disease. Psychosom Med 2013;75:335-349.

244. Huffman JC, Mastromauro CA, Beach SR, Celano CM, DuBois CM, Healy BC, Suarez L, Rollman BL, Januzzi JL. Collaborative care for depression and anxiety disorders in patients with recent cardiac events: the Management of Sadness and Anxiety in Cardiology (MOSAIC) randomized clinical trial. JAMA Intern Med 2014;174:927-935.

245. Stewart JC, Perkins AJ, Callahan CM. Effect of collaborative care for depression on risk of cardiovascular events: data from the IMPACT randomized controlled trial. Psychosom Med 2014;76:29-37.

246. Glozier N, Christensen H, Naismith S, Cockayne N, Donkin L, Neal B, Mackinnon A, Hickie I. Internet-delivered cognitive behavioural therapy for adults with mild to moderate depression and high cardiovascular disease risks: a randomised attention-controlled trial. PLoS One 2013;8:e59139.

247. Albus C, Ladwig KH, Herrmann-Lingen C. [Psychocardiology: clinically relevant recommendations regarding selected cardiovascular diseases]. Dtsch Med Wochenschr 2014;139:596-601.

248. Ladwig KH, Lederbogen F, Albus C, Angermann C, Borggrefe M, Fischer D, Fritzsche K, Haass M, Jordan J, Junger J, Kindermann I, Kollner V, Kuhn B, Scherer M, Seyfarth M, Voller H, Waller C, Herrmann-Lingen C. Position paper on the importance of psychosocial factors in cardiology: update 2013. Ger Med Sci 2014;12:Doc09.

249. Huffman JC, Niazi SK, Rundell JR, Sharpe M, Katon WJ. Essential articles on collaborative care models for the treatment of psychiatric disorders in medical settings: a publication by the academy of psychosomatic medicine research and evidence-based practice committee. Psychosomatics 2014;55:109-122.

250. Katon WJ, Lin EH, Von Korff M, Ciechanowski P, Ludman EJ, Young B, Peterson D, Rutter CM, McGregor M, McCulloch D. Collaborative care for patients with depression and chronic illnesses. N Engl J Med 2010;363:2611-2620.

251. Blumenthal JA, Sherwood A, Babyak MA, Watkins LL, Smith PJ, Hoffman BM, O'Hayer CV, Mabe S, Johnson J, Doraiswamy PM, Jiang W, Schocken DD, Hinderliter AL. Exercise and pharmacological treatment of depressive symptoms in patients with coronary heart disease: results from the UPBEAT (Understanding the Prognostic Benefits of Exercise and Antidepressant Therapy) study. J Am Coll Cardiol 2012;60:1053-1063.

252. Orth-Gomer K, Schneiderman N, Wang HX, Walldin C, Blom M, Jernberg T. Stress reduction prolongs life in women with coronary disease: the Stockholm Women's Intervention Trial for Coronary Heart Disease (SWITCHD). Circ Cardiovasc Qual Outcomes 2009;2:25-32.

253. Gulliksson M, Burell G, Vessby B, Lundin L, Toss H, Svardsudd K. Randomized controlled trial of cognitive behavioral therapy vs standard treatment to prevent recurrent cardiovascular events in patients with coronary heart disease: Secondary Prevention in Uppsala Primary Health Care project (SUPRIM). Arch Intern Med 2011;171:134-140.

254. Lie I, Arnesen H, Sandvik L, Hamilton G, Bunch EH. Effects of a home-based intervention program on anxiety and depression 6 months after coronary artery bypass grafting: a randomized controlled trial. J Ppsychosom Res 2007;62:411-418.

255. Page T, Lockwood C, Conroy-Hiller T. Effectiveness of nurse-led cardiac clinics in adult patients with a diagnosis of coronary heart disease. Int J Evid Based Healthcare 2005;3:2-26.

256. Bishop GD, Kaur D, Tan VL, Chua YL, Liew SM, Mak KH. Effects of a psychosocial skills training workshop on psychophysiological and psychosocial risk in patients undergoing coronary artery bypass grafting. Am Heart J 2005;150:602-609.

257. Theorell T, Emdad R, Arnetz B, Weingarten AM. Employee effects of an educational program for managers at an insurance company. Psychosom Med 2001;63: 724-733.

258. Lollgen H, Bockenhoff A, Knapp G. Physical activity and all-cause mortality: an updated meta-analysis with different intensity categories. Int J Sports Med 2009;30: 213-224.

259. Sattelmair J, Pertman J, Ding EL, Kohl HW 3rd, Haskell W, Lee IM. Dose response between physical activity risk of coronary heart disease: a meta-analysis. Circulation 2011;124:789-795.

260. Moore SC, Patel AV, Matthews CE, Berrington de Gonzalez A, Park Y, Katki HA, Linet MS, Weiderpass E, Visvanathan K, Helzlsouer KJ, Thun M, Gapstur SM, Hartge $P$, Lee IM. Leisure time physical activity of moderate to vigorous intensity and mortality: a large pooled cohort analysis. PLoS Med 2012;9:e1001335.

261. Samitz G, Egger M, Zwahlen M. Domains of physical activity and all-cause mortality: systematic review and dose-response meta-analysis of cohort studies. Int J Epidemiol 2011;40:1382-1400.

262. Campbell F BL, Messina J, Day M, Buckley Wood H, Payne N, Goyder E, Armitage C. National Institute for Health and Clinical Excellence (NICE) public health intervention guidance physical activity: BA for adults in primary care. Review of effectiveness evidence. London: National Institute for Health and Clinical Excellence, 2012.

263. Elley CR, Kerse N, Arroll B, Robinson E. Effectiveness of counselling patients on physical activity in general practice: cluster randomised controlled trial. BMJ 2003; 326:793.

264. Garrett S, Elley CR, Rose SB, O'Dea D, Lawton BA, Dowell AC. Are physical activity interventions in primary care and the community cost-effective? A systematic review of the evidence. Br J Gen Pract 2011;61:e125-e133.

265. Borjesson M, Urhausen A, Kouidi E, Dugmore D, Sharma S, Halle M, Heidbuchel H, Bjornstad HH, Gielen S, Mezzani A, Corrado D, Pelliccia A, Vanhees L. Cardiovascular evaluation of middle-aged/senior individuals engaged in leisure-time sport activities: position stand from the sections of exercise physiology and sports cardiology of the European Association of Cardiovascular Prevention and Rehabilitation. Eur J Cardiovasc Prev Rehabil 2011;18:446-458.

266. Fletcher GF, Ades PA, Kligfield P, Arena R, Balady GJ, Bittner VA, Coke LA, Fleg JL, Forman DE, Gerber TC, Gulati M, Madan K, Rhodes J, Thompson PD, Williams MA. Exercise standards for testing and training: a scientific statement from the American Heart Association. Circulation 2013;128:873-934.

267. Physical Activity Guidelines Advisory Committee. Physical Activity Guidelines Advisory Committee Report, 2008. Washington, DC: U.S. Department of Health and Human Services, 2008.

268. Lee DC, Pate RR, Lavie CJ, Sui X, Church TS, Blair SN. Leisure-time running reduces all-cause and cardiovascular mortality risk. J Am Coll Cardiol 2014;64: $472-481$.

269. Talbot LA, Morrell CH, Fleg JL, Metter EJ. Changes in leisure time physical activity and risk of all-cause mortality in men and women: the Baltimore Longitudinal Study of Aging. Prev Med 2007;45:169-176. 
270. Piepoli MF, Davos C, Francis DP, Coats AJ, ExTra MC. Exercise training meta-analysis of trials in patients with chronic heart failure (ExTraMATCH). BMJ 2004;328:189.

271. Lee IM, Shiroma EJ, Lobelo F, Puska P, Blair SN, Katzmarzyk PT. Effect of physical inactivity on major non-communicable diseases worldwide: an analysis of burden of disease and life expectancy. Lancet 2012;380:219-229.

272. Department of Health, Physical Activity, Health Improvement and Protection. Stay Active: A report on physical activity for health from the four home countries' Chief Medical Officers. https://www.sportengland.org/media/388152/dh_128210.pdf.

273. Vanhees L, Geladas N, Hansen D, Kouidi E, Niebauer J, Reiner Z, Cornelissen V, Adamopoulos S, Prescott E, Borjesson M, Bjarnason-Wehrens B, Bjornstad HH, Cohen-Solal A, Conraads V, Corrado D, De Sutter J, Doherty P, Doyle F, Dugmore D, Ellingsen O, Fagard R, Giada F, Gielen S, Hager A, Halle M, Heidbuchel H, Jegier A, Mazic S, McGee H, Mellwig KP, Mendes M, Mezzani A, Pattyn N, Pelliccia A, Piepoli M, Rauch B, Schmidt-Trucksass A, Takken T, van Buuren F, Vanuzzo D. Importance of characteristics and modalities of physical activity and exercise in the management of cardiovascular health in individuals with cardiovascular risk factors: recommendations from the EACPR. Part II. Eur J Prev Cardiol 2012;19:1005-1033.

274. Ainsworth BE, Haskell WL, Herrmann SD, Meckes N, Bassett DR Jr, Tudor-Locke C, Greer JL, Vezina J, Whitt-Glover MC, Leon AS. 2011 Compendium of Physical Activities: a second update of codes and MET values. Med Sci Sports Exerc 2011;43:1575-1581.

275. Howley ET. Type of activity: resistance, aerobic and leisure versus occupational physical activity. Med Sci Sports Exerc 2001;33(6 Suppl):S364-S369; discussion S419-S420.

276. Garber CE, Blissmer B, Deschenes MR, Franklin BA, Lamonte MJ, Lee IM, Nieman DC, Swain DP. American College of Sports Medicine position stand. Quantity and quality of exercise for developing and maintaining cardiorespiratory, musculoskeletal, and neuromotor fitness in apparently healthy adults: guidance for prescribing exercise. Med Sci Sports Exerc 2011;43:1334-1359.

277. Glazer NL, Lyass A, Esliger DW, Blease SJ, Freedson PS, Massaro JM, Murabito JM, Vasan RS. Sustained and shorter bouts of physical activity are related to cardiovascular health. Med Sci Sports Exerc 2013;45:109-15.

278. Donnelly JE, Blair SN, Jakicic JM, Manore MM, Rankin JW, Smith BK. American College of Sports Medicine position stand. Appropriate physical activity intervention strategies for weight loss and prevention of weight regain for adults. Med Sci Sports Exerc 2009;41:459-471.

279. Schwingshackl L, Missbach B, Dias S, Konig J, Hoffmann G. Impact of different training modalities on glycaemic control and blood lipids in patients with type 2 diabetes: a systematic review and network meta-analysis. Diabetologia 2014;57: 1789-1797.

280. American College of Sports Medicine. ACSM's Guidelines for Exercise Testing and Prescription. Philadelphia: Wolters Kluwer/Lippincott Williams \& Wilkins Health, 2014.

281. Marijon E, Tafflet M, Celermajer DS, Dumas F, Perier MC, Mustafic H, Toussaint JF, Desnos M, Rieu M, Benameur N, Le Heuzey JY, Empana JP, Jouven X. Sportsrelated sudden death in the general population. Circulation 2011;124:672-681.

282. Thompson PD, Franklin BA, Balady G], Blair SN, Corrado D, Estes NA 3rd, Fulton JE, Gordon NF, Haskell WL, Link MS, Maron BJ, Mittleman MA, Pelliccia A, Wenger NK, Willich SN, Costa F. Exercise and acute cardiovascular events placing the risks into perspective: a scientific statement from the American Heart Association Council on Nutrition, Physical Activity, and Metabolism and the Council on Clinical Cardiology. Circulation 2007;115:2358-2368.

283. Cahill K, Stevens S, Perera R, Lancaster T. Pharmacological interventions for smoking cessation: an overview and network meta-analysis. Cochrane Database Syst Rev 2013;5:CD009329.

284. Hughes JR, Stead LF, Lancaster T. Antidepressants for smoking cessation. Cochrane Database Syst Rev 2007;1:CD000031.

285. Cahill K, Stead LF, Lancaster T. Nicotine receptor partial agonists for smoking cessation. Cochrane Database Syst Rev 2012;4:CD006103.

286. Hughes JR, Stead LF, Hartmann-Boyce J, Cahill K, Lancaster T. Antidepressants for smoking cessation. Cochrane Database Syst Rev 2014;1:CD000031.

287. Doll R, Peto R, Boreham J, Sutherland I. Mortality in relation to smoking: 50 years' observations on male British doctors. BMJ 2004;328:1519.

288. Kiiskinen U, Vartiainen E, Puska P, Aromaa A. Long-term cost and life-expectancy consequences of hypertension. J Hypertens 1998;16:1103-1112.

289. Prescott E, Hippe M, Schnohr P, Hein HO, Vestbo J. Smoking and risk of myocardial infarction in women and men: longitudinal population study. BMJ 1998;316: 1043-1047.

290. Taylor T LD, Bryant A, Keyse L, Joloza MT Smoking-related behaviour and attitudes, 2005. London: Office for National Statistics, 2006.

291. West R. Key performance indicators: findings from the Smoking Toolkit Study. http:/l www.smokinginengland.info.
292. He J, Vupputuri S, Allen K, Prerost MR, Hughes J, Whelton PK. Passive smoking and the risk of coronary heart disease - a meta-analysis of epidemiologic studies. N Engl J Med 1999;340:920-926.

293. Law MR, Morris JK, Wald NJ. Environmental tobacco smoke exposure and ischaemic heart disease: an evaluation of the evidence. BMJ 1997;315:973-980.

294. Prescott E, Scharling H, Osler M, Schnohr P. Importance of light smoking and inhalation habits on risk of myocardial infarction and all cause mortality. A 22 year follow up of 12149 men and women in the Copenhagen City Heart Study. J Epidemiol Community Health 2002;56:702-706.

295. Kotseva K, Wood D, De Backer G, De Bacquer D, Pyorala K, Keil U, Group ES. EUROASPIRE III: a survey on the lifestyle, risk factors and use of cardioprotective drug therapies in coronary patients from 22 European countries. Eur J Cardiovasc Prev Rehabil 2009;16:121-137.

296. Centers for Disease Control and Prevention. How Tobacco Smoke Causes Disease: The Biology and Behavioural Basis for Smoking-attributable Disease 2010. A Report of the Surgeon General. http://www.surgeongeneral.gov/library/tobaccosmoke/ index.html.

297. Joseph AM, Norman SM, Ferry LH, Prochazka AV, Westman EC, Steele BG, Sherman SE, Cleveland M, Antonuccio DO, Hartman N, McGovern PG. The safety of transdermal nicotine as an aid to smoking cessation in patients with cardiac disease. N Engl J Med 1996;335:1792-1798.

298. Critchley J, Capewell S. Smoking cessation for the secondary prevention of coronary heart disease. Cochrane Database Syst Rev 2004;1:CD003041.

299. Woolf KJ, Zabad MN, Post JM, McNitt S, Williams GC, Bisognano JD. Effect of nicotine replacement therapy on cardiovascular outcomes after acute coronary syndromes. Am J Cardiol 2012;110:968-970.

300. Chow CK, Jolly S, Rao-Melacini P, Fox KA, Anand SS, Yusuf S. Association of diet, exercise, and smoking modification with risk of early cardiovascular events after acute coronary syndromes. Circulation 2010;121:750-758.

301. Stead LF, Bergson G, Lancaster T. Physician advice for smoking cessation. Cochrane Database Syst Rev 2008;2:CD000165.

302. Heatherton TF, Kozlowski LT, Frecker RC, Fagerstrom KO. The Fagerstrom Test for Nicotine Dependence: a revision of the Fagerstrom Tolerance Questionnaire. BrJ Addict 1991;86:1119-1127.

303. Stead LF, Perera R, Bullen C, Mant D, Hartmann-Boyce J, Cahill K, Lancaster T. Nicotine replacement therapy for smoking cessation. Cochrane Database Syst Rev 2012;11:CD000146.

304. Eisenberg MJ, Windle SB, Roy N, Old W, Grondin F, Bata I, Iskander A, Lauzon C, Srivastava N, Clarke A, Cassavar D, Dion D, Haught H, Mehta SR, Baril JF, Lambert CR, Madan M, Abramson B, Dehghani P. Varenicline for smoking cessation in hospitalized patients with acute coronary syndrome. Circulation 2016;133 $21-30$.

305. Pisinger C, Dossing M. A systematic review of health effects of electronic cigarettes. Prev Med 2014;69:248-260.

306. McRobbie H, Bullen C, Hartmann-Boyce J, Hajek P. Electronic cigarettes for smoking cessation and reduction. Cochrane Database Syst Rev 2014;12:CD010216.

307. Bullen C, Howe C, Laugesen M, McRobbie H, Parag V, Williman J, Walker N. Elec tronic cigarettes for smoking cessation: a randomised controlled trial. Lancet 2013; 382:1629-1637.

308. Henningfield JE. Nicotine medications for smoking cessation. N Engl J Med 1995; 333:1196-1203.

309. Etter JF, Bullen C. A longitudinal study of electronic cigarette users. Addict Behav 2014:39:491-494

310. Kalkhoran S, Glantz SA. E-cigarettes and smoking cessation in real-world and clinical settings: a systematic review and meta-analysis. Lancet Respir Med 2016;4 $116-128$.

311. European Heart Network. Diet, Physical Activity and Cardiovascular Disease Prevention in Europe. Brussels, Belguim: European Heart Network, 2011.

312. Astrup A, Dyerberg J, Elwood P, Hermansen K, Hu FB, Jakobsen MU, Kok FJ, Krauss RM, Lecerf JM, LeGrand P, Nestel P, Riserus U, Sanders T, Sinclair A, Stender S, Tholstrup T, Willett WC. The role of reducing intakes of saturated fat in the prevention of cardiovascular disease: where does the evidence stand in 2010? Am J Clin Nutr 2011;93:684-688.

313. Mensink RP, Katan MB. Effect of dietary fatty acids on serum lipids and lipoproteins. A meta-analysis of 27 trials. Arterioscler Thromb 1992;12:911-919.

314. Wen YT, Dai JH, Gao Q. Effects of omega-3 fatty acid on major cardiovascular events and mortality in patients with coronary heart disease: a meta-analysis of randomized controlled trials. Nutrition, metabolism, and cardiovascular diseases. Nutr Metab Cardiovasc Dis 2014;24:470-475.

315. Rizos EC, Ntzani EE, Bika E, Kostapanos MS, Elisaf MS. Association between omega-3 fatty acid supplementation and risk of major cardiovascular disease events: a systematic review and meta-analysis. JAMA 2012;308:1024-1033.

316. Mozaffarian D, Katan MB, Ascherio A, Stampfer MJ, Willett WC. Trans fatty acids and cardiovascular disease. N Engl J Med 2006;354:1601-1613. 
317. He FJ, MacGregor GA. Effect of modest salt reduction on blood pressure: a meta-analysis of randomized trials. Implications for public health. J Hum Hypertens 2002; 16:761-770.

318. Sacks FM, Svetkey LP, Vollmer WM, Appel LJ, Bray GA, Harsha D, Obarzanek E, Conlin PR, Miller ER 3rd, Simons-Morton DG, Karanja N, Lin PH. Effects on blood pressure of reduced dietary sodium the Dietary Approaches to Stop Hypertension (DASH) diet. DASH-Sodium Collaborative Research Group. N Engl J Med 2001;344:3-10.

319. Aburto NJ, Hanson S, Gutierrez H, Hooper L, Elliott P, Cappuccio FP. Effect of increased potassium intake on cardiovascular risk factors and disease: systematic review and meta-analyses. BMJ 2013;346:f1378.

320. Chowdhury R, Stevens S, Gorman D, Pan A, Warnakula S, Chowdhury S, Ward H, Johnson L, Crowe F, Hu FB, Franco OH. Association between fish consumption, long chain omega 3 fatty acids, and risk of cerebrovascular disease: systematic review and meta-analysis. BMJ 2012;345:e6698.

321. Schottker B, Jorde R, Peasey A, Thorand B, Jansen EH, Groot L, Streppel M, Gardiner J, Ordonez-Mena JM, Perna L, Wilsgaard T, Rathmann W, Feskens E, Kampman E, Siganos G, Njolstad I, Mathiesen EB, Kubinova R, Pajak A, Topor-Madry R, Tamosiunas A, Hughes M, Kee F, Bobak M, Trichopoulou A, Boffetta P, Brenner H. Vitamin D and mortality: meta-analysis of individual participant data from a large consortium of cohort studies from Europe and the United States. BMJ 2014;348:g3656.

322. Threapleton DE, Greenwood DC, Evans CE, Cleghorn CL, Nykjaer C, Woodhead C, Cade JE, Gale CP, Burley VJ. Dietary fibre intake and risk of cardiovascular disease: systematic review and meta-analysis. BMJ 2013;347:f6879.

323. Zhang Z, Xu G, Liu D, Zhu W, Fan X, Liu X. Dietary fiber consumption and risk of stroke. Eur J Epidemiol 2013;28:119-130.

324. Yao B, Fang H, Xu W, Yan Y, Xu H, Liu Y, Mo M, Zhang H, Zhao Y. Dietary fiber intake and risk of type 2 diabetes: a dose-response analysis of prospective studies. Eur J Epidemiol 2014;29:79-88.

325. Wang X, Ouyang Y, Liu J, Zhu M, Zhao G, Bao W, Hu FB. Fruit and vegetable consumption and mortality from all causes, cardiovascular disease, and cancer: systematic review and dose-response meta-analysis of prospective cohort studies. BMJ 2014;349:g4490.

326. He FJ, Nowson CA, MacGregor GA. Fruit and vegetable consumption and stroke: meta-analysis of cohort studies. Lancet 2006;367:320-326.

327. Dauchet L, Amouyel P, Hercberg S, Dallongeville J. Fruit and vegetable consumption and risk of coronary heart disease: a meta-analysis of cohort studies. J Nutr 2006;136:2588-2593.

328. Luo C, Zhang Y, Ding Y, Shan Z, Chen S, Yu M, Hu FB, Liu L. Nut consumption and risk of type 2 diabetes, cardiovascular disease, and all-cause mortality: a systematic review and meta-analysis. Am J Clin Nutr 2014;100:256-269.

329. Zheng J, Huang T, Yu Y, Hu X, Yang B, Li D. Fish consumption and CHD mortality: an updated meta-analysis of seventeen cohort studies. Public Health Nutr 2012;15: 725-737.

330. Chowdhury R, Kunutsor S, Vitezova A, Oliver-Williams C, Chowdhury S, Kiefte-de-Jong JC, Khan H, Baena CP, Prabhakaran D, Hoshen MB, Feldman BS, Pan A, Johnson L, Crowe F, Hu FB, Franco OH. Vitamin D and risk of cause specific death: systematic review and meta-analysis of observational cohort and randomised intervention studies. BMJ 2014;348:g1903.

331. Ronksley PE, Brien SE, Turner BJ, Mukamal KJ, Ghali WA. Association of alcohol consumption with selected cardiovascular disease outcomes: a systematic review and meta-analysis. BMJ 2011;342:d671.

332. Holmes MV, Dale CE, Zuccolo L, Silverwood RJ, Guo Y, Ye Z, Prieto-Merino D, Dehghan A, Trompet S, Wong A, Cavadino A, Drogan D, Padmanabhan S, Li S, Yesupriya A, Leusink M, Sundstrom J, Hubacek JA, Pikhart H, Swerdlow DI, Panayiotou AG, Borinskaya SA, Finan C, Shah S, Kuchenbaecker KB, Shah T, Engmann J, Folkersen L, Eriksson P, Ricceri F, Melander O, Sacerdote C, Gamble DM, Rayaprolu S, Ross OA, McLachlan S, Vikhireva O, Sluijs I, Scott RA, Adamkova V, Flicker L, Bockxmeer FM, Power C, Marques-Vidal P, Meade T, Marmot MG, Ferro JM, Paulos-Pinheiro S, Humphries SE, Talmud PJ, Mateo Leach I, Verweij N, Linneberg A, Skaaby T, Doevendans PA, Cramer MJ, van der Harst P, Klungel OH, Dowling NF, Dominiczak AF, Kumari M, Nicolaides AN, Weikert C, Boeing H, Ebrahim S, Gaunt TR, Price JF, Lannfelt L, Peasey A, Kubinova R, Pajak A, Malyutina S, Voevoda MI, Tamosiunas A, Maitland-van der Zee AH, Norman PE, Hankey G], Bergmann MM, Hofman A, Franco OH, Cooper J, Palmen J, Spiering W, de Jong PA, Kuh D, Hardy R, Uitterlinden AG, Ikram MA, Ford I, Hypponen E, Almeida OP, Wareham NJ, Khaw KT, Hamsten A, Husemoen LL, Tjonneland A, Tolstrup JS, Rimm E, Beulens JW, Verschuren WM, Onland-Moret NC, Hofker MH, Wannamethee SG, Whincup PH, Morris R, Vicente AM, Watkins H, Farrall M, Jukema JW, Meschia J, Cupples LA, Sharp SJ, Fornage M, Kooperberg C, LaCroix AZ, Dai JY, Lanktree MB, Siscovick DS, Jorgenson E, Spring B, Coresh J, Li YR, Buxbaum SG, Schreiner PJ, Ellison RC, Tsai MY, Patel SR, Redline S, Johnson AD, Hoogeveen RC, Hakonarson H, Rotter JI, Boerwinkle E, de
Bakker PI, Kivimaki M, Asselbergs FW, Sattar N, Lawlor DA, Whittaker J, Davey Smith G, Mukamal K, Psaty BM, Wilson JG, Lange LA, Hamidovic A, Hingorani AD, Nordestgaard BG, Bobak M, Leon DA, Langenberg C, Palmer TM, Reiner AP Keating BJ, Dudbridge F, Casas JP. Association between alcohol and cardiovascular disease: Mendelian randomisation analysis based on individual participant data. BMJ 2014;349:g4164.

333. de Ruyter JC, Olthof MR, Seidell JC, Katan MB. A trial of sugar-free or sugar-sweetened beverages and body weight in children. N Engl J Med 2012; 367:1397-1406.

334. World Health Organization. Guideline: Sugars Intake for Adults and Children. Geneva: World Health Organization, 2015.

335. Ras RT, Geleijnse JM, Trautwein EA. LDL-cholesterol-lowering effect of plant sterols and stanols across different dose ranges: a meta-analysis of randomised controlled studies. Br J Nutr 2014;112:214-219.

336. Sofi F, Abbate R, Gensini GF, Casini A. Accruing evidence on benefits of adherence to the Mediterranean diet on health: an updated systematic review and meta-analysis. Am J Clin Nutr 2010;92:1189-1196.

337. Estruch R, Ros E, Salas-Salvado J, Covas MI, Corella D, Aros F, Gomez-Gracia E, Ruiz-Gutierrez V, Fiol M, Lapetra J, Lamuela-Raventos RM, Serra-Majem L, Pinto X, Basora J, Munoz MA, Sorli JV, Martinez JA, Martinez-Gonzalez MA. Primary prevention of cardiovascular disease with a Mediterranean diet. N Engl / Med 2013;368:1279-1290.

338. Oreopoulos A, Padwal R, Norris CM, Mullen JC, Pretorius V, Kalantar-Zadeh K. Effect of obesity on short- and long-term mortality postcoronary revascularization: a meta-analysis. Obesity 2008;16:442-450.

339. Berrington de Gonzalez A, Hartge P, Cerhan JR, Flint AJ, Hannan L, Maclnnis RJ, Moore SC, Tobias GS, Anton-Culver H, Freeman LB, Beeson WL, Clipp SL, English DR, Folsom AR, Freedman DM, Giles G, Hakansson N, Henderson KD, Hoffman-Bolton J, Hoppin JA, Koenig KL, Lee IM, Linet MS, Park Y, Pocobelli G, Schatzkin A, Sesso HD, Weiderpass E, Willcox BJ, Wolk A, Zeleniuch-Jacquotte A, Willett WC, Thun MJ. Body-mass index and mortality among 1.46 million white adults. N Engl J Med 2010;363:2211-2219.

340. Stewart ST, Cutler DM, Rosen AB. Forecasting the effects of obesity and smoking on U.S. life expectancy. N Engl J Med 2009;361:2252-2260.

341. Poirier P, Alpert MA, Fleisher LA, Thompson PD, Sugerman HJ, Burke LE, Marceau P, Franklin BA. Cardiovascular evaluation and management of severely obese patients undergoing surgery: a science advisory from the American Heart Association. Circulation 2009;120:86-95.

342. Emerging Risk Factors Collaboration, Wormser D, Kaptoge S, Di Angelantonio E, Wood AM, Pennells L, Thompson A, Sarwar N, Kizer JR, Lawlor DA Nordestgaard BG, Ridker P, Salomaa V, Stevens J, Woodward M, Sattar N Collins R, Thompson SG, Whitlock G, Danesh J. Separate and combined associations of body-mass index and abdominal adiposity with cardiovascular disease: collaborative analysis of 58 prospective studies. Lancet 2011;377:1085-1095.

343. Kramer CK, Zinman B, Retnakaran R. Are metabolically healthy overweight and obesity benign conditions?: a systematic review and meta-analysis. Ann Intern Med 2013;159:758-769.

344. van der AD, Nooyens AC, van Duijnhoven FJ, Verschuren MM, Boer JM. All-cause mortality risk of metabolically healthy abdominal obese individuals: the EPICMORGEN study. Obesity 2014;22:557-564.

345. Bell JA, Hamer M, Sabia S, Singh-Manoux A, Batty GD, Kivimaki M. The natural course of healthy obesity over 20 years. J Am Coll Cardiol 2015;65:101-102.

346. Romero-Corral A, Montori VM, Somers VK, Korinek J, Thomas RJ, Allison TG Mookadam F, Lopez-Jimenez F. Association of bodyweight with total mortality and with cardiovascular events in coronary artery disease: a systematic review of cohort studies. Lancet 2006;368:666-678.

347. Barry VW, Baruth M, Beets MW, Durstine JL, Liu J, Blair SN. Fitness vs. fatness on all-cause mortality: a meta-analysis. Prog Cardiovasc Dis 2014;56:382-390.

348. Ekelund U, Ward HA, Norat T, Luan J, May AM, Weiderpass E, Sharp SJ, Overvad K, Ostergaard JN, Tjonneland A, Johnsen NF, Mesrine S, Fournier A, Fagherazzi G, Trichopoulou A, Lagiou P, Trichopoulos D, Li K, Kaaks R, Ferrari P, Licaj I, Jenab M, Bergmann M, Boeing H, Palli D, Sieri S, Panico S, Tumino R, Vineis P, Peeters PH, Monnikhof E, Bueno-de-Mesquita HB, Quiros JR, Agudo A, Sanchez MJ, Huerta JM, Ardanaz E, Arriola L, Hedblad B, Wirfalt E, Sund M, Johansson M, Key TJ, Travis RC, Khaw KT, Brage S, Wareham NJ, Riboli E. Physical activity and all-cause mortality across levels of overall and abdominal adiposity in European men and women: the European Prospective Investigation into Cancer and Nutrition Study (EPIC). Am J Clin Nutr 2015; 101:613-621.

349. Kwok CS, Pradhan A, Khan MA, Anderson SG, Keavney BD, Myint PK, Mamas MA, Loke YK. Bariatric surgery and its impact on cardiovascular disease and mortality: a systematic review and meta-analysis. Int J Cardiol 2014;173:20-28.

350. Cholesterol Treatment Trialists' Collaboration, Mihaylova B, Emberson J, Blackwell L, Keech A, Simes J, Barnes EH, Voysey M, Gray A, Collins R, Baigent $C$. The effects of lowering LDL cholesterol with statin therapy in people 
at low risk of vascular disease: meta-analysis of individual data from 27 randomised trials. Lancet 2012;380:581-590.

351. Robinson JG, Wang S, Smith BJ, Jacobson TA. Meta-analysis of the relationship between non-high-density lipoprotein cholesterol reduction and coronary heart disease risk. J Am Coll Cardiol 2009;53:316-322.

352. Nordestgaard BG, Chapman MJ, Humphries SE, Ginsberg HN, Masana L, Descamps OS, Wiklund O, Hegele RA, Raal FJ, Defesche JC, Wiegman A, Santos RD, Watts GF, Parhofer KG, Hovingh GK, Kovanen PT, Boileau C, Averna M, Boren J, Bruckert E, Catapano AL, Kuivenhoven JA, Pajukanta P, Ray K, Stalenhoef AF, Stroes E, Taskinen MR, Tybjaerg-Hansen A. Familial hypercholesterolaemia is underdiagnosed and undertreated in the general population: guidance for clinicians to prevent coronary heart disease: consensus statement of the European Atherosclerosis Society. Eur Heart J 2013;34:3478-3490a.

353. Cannon CP, Blazing MA, Giugliano RP, McCagg A, White JA, Theroux P, Darius H, Lewis BS, Ophuis TO, Jukema JW, De Ferrari GM, Ruzyllo W, De Lucca P, Im K, Bohula EA, Reist C, Wiviott SD, Tershakovec AM, Musliner TA, Braunwald E, Califf RM. Ezetimibe added to statin therapy after acute coronary syndromes. N Engl J Med 2015;372:2387-2397.

354. Neaton JD, Blackburn H, Jacobs D, Kuller L, Lee DJ, Sherwin R, Shih J, Stamler J, Wentworth D. Serum cholesterol level and mortality findings for men screened in the Multiple Risk Factor Intervention Trial. Multiple Risk Factor Intervention Trial Research Group. Arch Intern Med 1992;152:1490-1500.

355. Thompson A, Danesh J. Associations between apolipoprotein B, apolipoprotein $\mathrm{Al}$, the apolipoprotein $\mathrm{B} / \mathrm{Al}$ ratio and coronary heart disease: a literature-based meta-analysis of prospective studies. J Intern Med 2006;259:481-492.

356. McQueen MJ, Hawken S, Wang X, Ounpuu S, Sniderman A, Probstfield J, Steyn K, Sanderson JE, Hasani M, Volkova E, Kazmi K, Yusuf S. Lipids, lipoproteins, and apolipoproteins as risk markers of myocardial infarction in 52 countries (the INTERHEART study): a case-control study. Lancet 2008;372:224-233.

357. Emerging Risk Factors Collaboration, Di Angelantonio E, Sarwar N, Perry P, Kaptoge S, Ray KK, Thompson A, Wood AM, Lewington S, Sattar N, Packard CJ, Collins R, Thompson SG, Danesh J. Major lipids, apolipoproteins, and risk of vascular disease. JAMA 2009;302:1993-2000.

358. Sarwar N, Danesh J, Eiriksdottir G, Sigurdsson G, Wareham N, Bingham S, Boekholdt SM, Khaw KT, Gudnason V. Triglycerides and the risk of coronary heart disease: 10,158 incident cases among 262,525 participants in 29 Western prospective studies. Circulation 2007;115:450-458.

359. Chapman MJ, Ginsberg HN, Amarenco P, Andreotti F, Boren J, Catapano AL, Descamps OS, Fisher E, Kovanen PT, Kuivenhoven JA, Lesnik P, Masana L, Nordestgaard BG, Ray KK, Reiner Z, Taskinen MR, Tokgozoglu L, Tybjaerg-Hansen A, Watts GF. Triglyceride-rich lipoproteins and high-density lipoprotein cholesterol in patients at high risk of cardiovascular disease: evidence and guidance for management. Eur Heart J 2011;32:1345-1361.

360. Fruchart JC, Sacks F, Hermans MP, Assmann G, Brown WV, Ceska R, Chapman MJ, Dodson PM, Fioretto P, Ginsberg HN, Kadowaki T, Lablanche JM, Marx N, Plutzky J, Reiner Z, Rosenson RS, Staels B, Stock JK, Sy R, Wanner C, Zambon A, Zimmet P. The Residual Risk Reduction Initiative: a call to action to reduce residual vascular risk in patients with dyslipidemia. Am J Cardiol 2008;102(10 Suppl):1K-34K.

361. Voight BF, Peloso GM, Orho-Melander M, Frikke-Schmidt R, Barbalic M, Jensen MK, Hindy G, Holm H, Ding EL, Johnson T, Schunkert H, Samani NJ, Clarke R, Hopewell JC, Thompson JF, Li M, Thorleifsson G, Newton-Cheh C, Musunuru K, Pirruccello JP, Saleheen D, Chen L, Stewart A, Schillert A, Thorsteinsdottir U, Thorgeirsson G, Anand S, Engert JC, Morgan T, Spertus J, Stoll M, Berger K, Martinelli N, Girelli D, McKeown PP, Patterson CC, Epstein SE, Devaney J, Burnett MS, Mooser V, Ripatti S, Surakka I, Nieminen MS, Sinisalo J, Lokki ML, Perola M, Havulinna A, de Faire U, Gigante B, Ingelsson E, Zeller T, Wild P, de Bakker PI, Klungel OH, Maitland-van der Zee AH, Peters BJ, de Boer A, Grobbee DE, Kamphuisen PW, Deneer VH, Elbers CC, Onland-Moret NC, Hofker MH, Wijmenga C, Verschuren WM, Boer JM, van der Schouw YT, Rasheed A, Frossard P, Demissie S, Willer C, Do R, Ordovas JM, Abecasis GR, Boehnke M, Mohlke KL, Daly MJ, Guiducci C, Burtt NP, Surti A, Gonzalez E, Purcell S, Gabriel S, Marrugat J, Peden J, Erdmann J, Diemert P, Willenborg C, Konig IR, Fischer M, Hengstenberg C, Ziegler A, Buysschaert I, Lambrechts D, Van de Werf F, Fox KA, El Mokhtari NE, Rubin D, Schrezenmeir J, Schreiber S, Schafer A, Danesh J, Blankenberg S, Roberts R, McPherson R, Watkins H, Hall AS, Overvad K, Rimm E, Boerwinkle E, Tybjaerg-Hansen A, Cupples LA, Reilly MP, Melander O, Mannucci PM, Ardissino D, Siscovick D, Elosua R, Stefansson K, O’Donnell C], Salomaa V, Rader DJ, Peltonen L, Schwartz SM, Altshuler D, Kathiresan S. Plasma HDL cholesterol and risk of myocardial infarction: a mendelian randomisation study. Lancet 2012;380:572-580.

362. Nordestgaard BG, Chapman MJ, Ray K, Boren J, Andreotti F, Watts GF, Ginsberg H, Amarenco P, Catapano A, Descamps OS, Fisher E, Kovanen PT, Kuivenhoven JA, Lesnik P, Masana L, Reiner Z, Taskinen MR, Tokgozoglu L,
Tybjaerg-Hansen A. Lipoprotein(a) as a cardiovascular risk factor: current status. Eur Heart J 2010;31:2844-2853.

363. Friedewald WT, Levy RI, Fredrickson DS. Estimation of the concentration of lowdensity lipoprotein cholesterol in plasma, without use of the preparative ultracentrifuge. Clin Chem 1972;18:499-502.

364. Boekholdt SM, Arsenault BJ, Mora S, Pedersen TR, LaRosa JC, Nestel PJ, Simes RJ, Durrington P, Hitman GA, Welch KMA, DeMicco DA, Zwinderman AH, Clearfield MB, Downs JR, Tonkin AM, Colhoun HM, Gotto AM, Ridker PM, Kastelein JJP. Association of LDL cholesterol, non-HDL cholesterol, and apolipoprotein $B$ levels with risk of cardiovascular events among patients treated with statins. JAMA 2012;307:1302-1309.

365. Cholesterol Treatment Trialists' Collaboration, Baigent C, Blackwell L, Emberson J, Holland LE, Reith C, Bhala N, Peto R, Barnes EH, Keech A, Simes J, Collins R. Efficacy and safety of more intensive lowering of LDL cholesterol: a meta-analysis of data from 170,000 participants in 26 randomised trials. Lancet 2010;376:1670-1681.

366. Preis SR, Hwang SJ, Coady S, Pencina MJ, D’Agostino RB Sr, Savage PJ, Levy D, Fox CS. Trends in all-cause and cardiovascular disease mortality among women and men with and without diabetes mellitus in the Framingham Heart Study, 1950 to 2005. Circulation 2009;119:1728-1735.

367. Kwan BC, Kronenberg F, Beddhu S, Cheung AK. Lipoprotein metabolism and lipid management in chronic kidney disease. J Am Soc Nephrol 2007;18:1246-1261.

368. Sharp Collaborative Group. Study of Heart and Renal Protection (SHARP): randomized trial to assess the effects of lowering low-density lipoprotein cholesterol among 9,438 patients with chronic kidney disease. Am Heart J 2010;160:p785794.e10.

369. Fellstrom BC, Jardine AG, Schmieder RE, Holdaas H, Bannister K, Beutler J, Chae DW, Chevaile A, Cobbe SM, Gronhagen-Riska C, De Lima JJ, Lins R, Mayer G, McMahon AW, Parving HH, Remuzzi G, Samuelsson O, Sonkodi S, Sci D, Suleymanlar G, Tsakiris D, Tesar V, Todorov V, Wiecek A, Wuthrich RP, Gottlow M, Johnsson E, Zannad F. Rosuvastatin and cardiovascular events in patients undergoing hemodialysis. N Engl J Med 2009;360:1395-1407.

370. Palmer SC, Navaneethan SD, Craig JC, Johnson DW, Perkovic V, Hegbrant J, Strippoli GF. HMG CoA reductase inhibitors (statins) for people with chronic kidney disease not requiring dialysis. Cochrane Database Syst Rev 2014;5:CD007784.

371. Colhoun HM, Betteridge DJ, Durrington PN, Hitman GA, Neil HA, Livingstone SJ, Thomason MJ, Mackness MI, Charlton-Menys V, Fuller JH. Primary prevention of cardiovascular disease with atorvastatin in type 2 diabetes in the Collaborative Atorvastatin Diabetes Study (CARDS): multicentre randomised placebocontrolled trial. Lancet 2004;364:685-696.

372. Collins R, Armitage J, Parish S, Sleigh P, Peto R. MRC/BHF Heart Protection Study of cholesterol-lowering with simvastatin in 5963 people with diabetes: a randomised placebo-controlled trial. Lancet 2003;361:2005-2016.

373. Nissen SE, Nicholls SJ, Sipahi I, Libby P, Raichlen JS, Ballantyne CM, Davignon J, Erbel R, Fruchart JC, Tardif JC, Schoenhagen P, Crowe T, Cain V, Wolski K, Goormastic M, Tuzcu EM. Effect of very high-intensity statin therapy on regression of coronary atherosclerosis: the ASTEROID trial. JAMA 2006;295 1556-1565.

374. Preiss D, Tikkanen MJ, Welsh P, Ford I, Lovato LC, Elam MB, LaRosa JC, DeMicco DA, Colhoun HM, Goldenberg I, Murphy MJ, MacDonald TM, Pedersen TR, Keech AC, Ridker PM, Kjekshus J, Sattar N, McMurray JJ. Lipidmodifying therapies and risk of pancreatitis: a meta-analysis. JAMA 2012;308 804-811.

375. Robinson JG, Smith B, Maheshwari N, Schrott H. Pleiotropic effects of statins: benefit beyond cholesterol reduction? A meta-regression analysis. J Am Coll Cardiol 2005; 46:1855-1862.

376. Stroes ES, Thompson PD, Corsini A, Vladutiu GD, Raal FJ, Ray KK, Roden M, Stein E, Tokgozoglu L, Nordestgaard BG, Bruckert E, De Backer G, Krauss RM, Laufs U, Santos RD, Hegele RA, Hovingh GK, Leiter LA, Mach F, Marz W, Newman CB, Wiklund O, Jacobson TA, Catapano AL, Chapman MJ, Ginsberg HN. Statin-associated muscle symptoms: impact on statin therapyEuropean Atherosclerosis Society Consensus Panel Statement on Assessment, Aetiology and Management. Eur Heart J 2015;36:1012-1022.

377. Reiner Z, Galic M, Hanzevacki M, Tedeschi-Reiner E. [Concomitant use of statins and cytochrome P 450 inhibitors in Croatia]. Lijecnicki vjesnik 2005;127:65-68.

378. Cholesterol Treatment Trialists' Collaboration, Emberson JR, Kearney PM, Blackwell L, Newman C, Reith C, Bhala N, Holland L, Peto R, Keech A, Collins R, Simes J, Baigent C. Lack of effect of lowering LDL cholesterol on cancer: meta-analysis of individual data from 175,000 people in 27 randomised trials of statin therapy. PLoS One 2012; 7:e29849.

379. Waters DD, Ho JE, DeMicco DA, Breazna A, Arsenault BJ, Wun CC, Kastelein J, Colhoun $\mathrm{H}$, Barter P. Predictors of new-onset diabetes in patients treated with atorvastatin: results from 3 large randomized clinical trials. J Am Coll Cardiol 2011:57:1535-1545. 
380. Culver AL, Ockene IS, Balasubramanian R, Olendzki BC, Sepavich DM, Wactawski-Wende J, Manson JE, Qiao Y, Liu S, Merriam PA, Rahilly-Tierny C, Thomas F, Berger JS, Ockene JK, Curb JD, Ma Y. Statin use and risk of diabetes mellitus in postmenopausal women in the Women's Health Initiative. Arch Intern Med 2012;172:144-152.

381. Sattar N, Preiss D, Murray HM, Welsh P, Buckley BM, de Craen AJ, Seshasai SR, McMurray JJ, Freeman DJ, Jukema JW, Macfarlane PW, Packard CJ, Stott DJ, Westendorp RG, Shepherd J, Davis BR, Pressel SL, Marchioli R, Marfisi RM, Maggioni AP, Tavazzi L, Tognoni G, Kjekshus J, Pedersen TR, Cook TJ, Gotto AM, Clearfield MB, Downs JR, Nakamura H, Ohashi Y, Mizuno K, Ray KK, Ford I. Statins and risk of incident diabetes: a collaborative meta-analysis of randomised statin trials. Lancet 2010;375:735-742.

382. Swerdlow DI, Preiss D, Kuchenbaecker KB, Holmes MV, Engmann JE, Shah T, Sofat R, Stender S, Johnson PC, Scott RA, Leusink M, Verweij N, Sharp SJ, Guo Y, Giambartolomei C, Chung C, Peasey A, Amuzu A, Li K, Palmen J, Howard P, Cooper JA, Drenos F, Li YR, Lowe G, Gallacher J, Stewart MC, Tzoulaki I, Buxbaum SG, van der AD, Forouhi NG, Onland-Moret NC, van der Schouw YT, Schnabel RB, Hubacek JA, Kubinova R, Baceviciene M, Tamosiunas A, Pajak A, Topor-Madry R, Stepaniak U, Malyutina S, Baldassarre D, Sennblad B, Tremoli E, de Faire U, Veglia F, Ford I, Jukema JW, Westendorp RG, de Borst GJ, de Jong PA, Algra A, Spiering W, Maitland-van $\operatorname{der}$ Zee AH, Klungel OH, de Boer A, Doevendans PA, Eaton CB, Robinson JG, Duggan D, DIAGRAM Consortium, MAGIC Consortium, InterAct Consortium, Kjekshus J, Downs JR, Gotto AM, Keech AC, Marchioli R, Tognoni G, Sever PS, Poulter NR, Waters DD, Pedersen TR, Amarenco P, Nakamura $H$, McMurray JJ, Lewsey JD, Chasman DI, Ridker PM, Maggioni AP, Tavazzi L, Ray KK, Seshasai SR, Manson JE, Price JF, Whincup PH, Morris RW, Lawlor DA, Smith GD, Ben-Shlomo Y, Schreiner PJ, Fornage M, Siscovick DS, Cushman M, Kumari M, Wareham NJ, Verschuren WM, Redline S, Patel SR, Whittaker JC, Hamsten A, Delaney JA, Dale C, Gaunt TR, Wong A, Kuh D, Hardy R, Kathiresan S, Castillo BA, van der Harst P, Brunner EJ, Tybjaerg-Hansen A, Marmot MG, Krauss RM, Tsai M, Coresh J, Hoogeveen RC, Psaty BM, Lange LA, Hakonarson H, Dudbridge F, Humphries SE, Talmud PJ, Kivimaki M, Timpson NJ, Langenberg C, Asselbergs FW, Voevoda M, Bobak M, Pikhart H, Wilson JG, Reiner AP, Keating BJ, Hingorani AD, Sattar N. HMG-coenzyme A reductase inhibition, type 2 diabetes, and bodyweight: evidence from genetic analysis and randomised trials. Lancet 2015;385:351-361.

383. Robinson JG, Farnier M, Krempf M, Bergeron J, Luc G, Averna M, Stroes ES, Langslet G, Raal FJ, El Shahawy M, Koren MJ, Lepor NE, Lorenzato C, Pordy R, Chaudhari U, Kastelein J. Efficacy and safety of alirocumab in reducing lipids and cardiovascular events. N Engl J Med 2015;372:1489-1499.

384. Sabatine MS, Giugliano RP, Wiviott SD, Raal FJ, Blom DJ, Robinson J, Ballantyne CM, Somaratne R, Legg J, Wasserman SM, Scott R, Koren MJ, Stein EA. Efficacy and safety of evolocumab in reducing lipids and cardiovascular events. N Engl J Med 2015;372:1500-1509.

385. Ballantyne CM, Neutel J, Cropp A, Duggan W, Wang EQ, Plowchalk D, Sweeney K, Kaila N, Vincent J, Bays H. Results of bococizumab, a monoclonal antibody against proprotein convertase subtilisin/kexin type 9 , from a randomized, placebo-controlled, dose-ranging study in statin-treated subjects with hypercholesterolemia. Am J Cardiol 2015;115:1212-1221.

386. AIM-HIGH Investigators, Boden WE, Probstfield JL, Anderson T, Chaitman BR, Desvignes-Nickens P, Koprowicz K, McBride R, Teo K, Weintraub W. Niacin in patients with low HDL cholesterol levels receiving intensive statin therapy. $N$ EnglJ Med 2011;365:2255-2267.

387. Ryden L, Grant PJ, Anker SD, Berne C, Cosentino F, Danchin N, Deaton C, Escaned J, Hammes HP, Huikuri H, Marre M, Marx N, Mellbin L, Ostergren J, Patrono C, Seferovic P, Uva MS, Taskinen MR, Tendera M, Tuomilehto J, Valensi P, Zamorano JL, Achenbach S, Baumgartner H, Bax JJ, Bueno H, Dean V, Deaton C, Erol C, Fagard R, Ferrari R, Hasdai D, Hoes AW, Kirchhof P, Knuuti J, Kolh P, Lancellotti P, Linhart A, Nihoyannopoulos P, Piepoli MF, Ponikowski P, Sirnes PA, Tamargo JL, Tendera M, Torbicki A, Wijns W, Windecker S, De Backer G, Sirnes PA, Ezquerra EA, Avogaro A, Badimon L, Baranova E, Baumgartner H, Betteridge J, Ceriello A, Fagard R, Funck-Brentano C, Gulba DC, Hasdai D, Hoes AW, Kjekshus JK, Knuuti J, Kolh P, Lev E, Mueller C, Neyses L, Nilsson PM, Perk J, Ponikowski P, Reiner Z, Sattar N, Schachinger V, Scheen A, Schirmer H, Stromberg A, Sudzhaeva S, Tamargo JL, Viigimaa M, Vlachopoulos C, Xuereb RG. ESC guidelines on diabetes, pre-diabetes, and cardiovascular diseases developed in collaboration with the EASD: the Task Force on diabetes, pre-diabetes, and cardiovascular diseases of the European Society of Cardiology (ESC) and developed in collaboration with the European Association for the Study of Diabetes (EASD). Eur Heart J 2013; 34:3035-3087.

388. UK Prospective Diabetes Study (UKPDS) Group. Intensive blood-glucose control with sulphonylureas or insulin compared with conventional treatment and risk of complications in patients with type 2 diabetes (UKPDS 33). Lancet 1998;352 837-853.

389. The ADVANCE Collaborative Group, Patel A, MacMahon S, Chalmers J, Neal B, Billot L, Woodward M, Marre M, Cooper M, Glasziou P, Grobbee D, Hamet P, Harrap S, Heller S, Liu L, Mancia G, Mogensen CE, Pan C, Poulter N, Rodgers A, Williams B, Bompoint S, de Galan BE, Joshi R, Travert F. Intensive blood glucose control and vascular outcomes in patients with type 2 diabetes. N Engl J Med 2008;358:2560-2572.

390. Sattar N, Preiss D. HbA1c in type 2 diabetes diagnostic criteria: addressing the right questions to move the field forwards. Diabetologia 2012;55:1564-1567.

391. UK Prospective Diabetes Study (UKPDS) Group. Effect of intensive bloodglucose control with metformin on complications in overweight patients with type 2 diabetes (UKPDS 34). Lancet 1998;352:854-865.

392. Heidenreich PA, Trogdon JG, Khavjou OA, Butler J, Dracup K, Ezekowitz MD, Finkelstein EA, Hong Y, Johnston SC, Khera A, Lloyd-Jones DM, Nelson SA, Nichol G, Orenstein D, Wilson PW, Woo YJ. Forecasting the future of cardiovascular disease in the United States: a policy statement from the American Heart Association. Circulation 2011;123:933-944.

393. Duckworth W, Abraira C, Moritz T, Reda D, Emanuele N, Reaven PD, Zieve FJ, Marks J, Davis SN, Hayward R, Warren SR, Goldman S, McCarren M, Vitek ME, Henderson WG, Huang GD, Investigators V. Glucose control and vascular complications in veterans with type 2 diabetes. N Engl J Med 2009;360:129-139.

394. Zinman B, Wanner C, Lachin JM, Fitchett D, Bluhmki E, Hantel S, Mattheus M, Devins T, Johansen OE, Woerle HJ, BroedI UC, Inzucchi SE. Empagliflozin, cardiovascular outcomes, and mortality in type 2 diabetes. N Engl J Med 2015;373: 2117-2128.

395. Shepherd J, Barter P, Carmena R, Deedwania P, Fruchart JC, Haffner S, Hsia J, Breazna A, LaRosa J, Grundy S, Waters D. Effect of lowering LDL cholesterol substantially below currently recommended levels in patients with coronary heart disease and diabetes: the Treating to New Targets (TNT) study. Diabetes Care 2006;29:1220-1226.

396. Hansson L, Zanchetti A, Carruthers SG, Dahlof B, Elmfeldt D, Julius S, Menard J, Rahn $\mathrm{KH}$, Wedel $\mathrm{H}$, Westerling S. Effects of intensive blood-pressure lowering and low-dose aspirin in patients with hypertension: principal results of the Hypertension Optimal Treatment (HOT) randomised trial. HOT Study Group. Lancet 1998;351:1755-1762

397. UK Prospective Diabetes Study Group. Tight blood pressure control and risk of macrovascular and microvascular complications in type 2 diabetes: UKPDS 38 BMJ 1998;317:703-713.

398. De Berardis G, Sacco M, Strippoli GF, Pellegrini F, Graziano G, Tognoni G, Nicolucci A. Aspirin for primary prevention of cardiovascular events in people with diabetes: meta-analysis of randomised controlled trials. BMJ 2009;339: b4531.

399. Emerging Risk Factors Collaboration, Sarwar N, Gao P, Seshasai SR, Gobin R, Kaptoge S, Di Angelantonio E, Ingelsson E, Lawlor DA, Selvin E, Stampfer M, Stehouwer CD, Lewington S, Pennells L, Thompson A, Sattar N, White IR, Ray KK, Danesh J. Diabetes mellitus, fasting blood glucose concentration, and risk of vascular disease: a collaborative meta-analysis of 102 prospective studies. Lancet 2010;375:2215-2222.

400. Lindstrom J, Tuomilehto J. The diabetes risk score: a practical tool to predict type 2 diabetes risk. Diabetes Care 2003;26:725-731.

401. Inzucchi SE, Bergenstal RM, Buse JB, Diamant M, Ferrannini E, Nauck M, Peters AL, Tsapas A, Wender R, Matthews DR. Management of hyperglycemia in type 2 diabetes, 2015: a patient-centered approach: update to a position statement of the American Diabetes Association and the European Association for the Study of Diabetes. Diabetes Care 2015;38:140-149.

402. Constantino MI, Molyneaux L, Limacher-Gisler F, Al-Saeed A, Luo C, Wu T, Twigg SM, Yue DK, Wong J. Long-term complications and mortality in youngonset diabetes: type 2 diabetes is more hazardous and lethal than type 1 diabetes. Diabetes Care 2013;36:3863-3869.

403. Pan A, Wang Y, Talaei M, Hu FB, Wu T. Relation of active, passive, and quitting smoking with incident type 2 diabetes: a systematic review and meta-analysis. Lancet Diabetes Endocrinol 2015;3:958-967.

404. Li G, Zhang P, Wang J, An Y, Gong Q, Gregg EW, Yang W, Zhang B, Shuai Y, Hong J, Engelgau MM, Li H, Roglic G, Hu Y, Bennett PH. Cardiovascular mortality, all-cause mortality, and diabetes incidence after lifestyle intervention for people with impaired glucose tolerance in the Da Qing Diabetes Prevention Study: a 23-year follow-up study. Lancet Diabetes Endocrinol 2014;2:474-480.

405. Evans JM, Wang J, Morris AD. Comparison of cardiovascular risk between patients with type 2 diabetes and those who had had a myocardial infarction: cross sectional and cohort studies. BMJ 2002;324:939-942.

406. Wannamethee SG, Shaper AG, Whincup PH, Lennon L, Sattar N. Impact of diabetes on cardiovascular disease risk and all-cause mortality in older men: influence of age at onset, diabetes duration, and established and novel risk factors. Arch Intern Med 2011;171:404-410. 
407. Preiss D, Sattar N, McMurray Jj. A systematic review of event rates in clinical trials in diabetes mellitus: the importance of quantifying baseline cardiovascular disease history and proteinuria and implications for clinical trial design. Am Heart J 2011; 161:p210-219.e1.

408. Tonelli M, Muntner P, Lloyd A, Manns BJ, Klarenbach S, Pannu N, James MT, Hemmelgarn BR. Risk of coronary events in people with chronic kidney disease compared with those with diabetes: a population-level cohort study. Lancet 2012; 380:807-814.

409. Emerging Risk Factors Collaboration, Di Angelantonio E, Kaptoge S, Wormser D, Willeit P, Butterworth AS, Bansal N, O'Keeffe LM, Gao P, Wood AM, Burgess S, Freitag DF, Pennells L, Peters SA, Hart CL, Haheim LL, Gillum RF, Nordestgaard BG, Psaty BM, Yeap BB, Knuiman MW, Nietert PJ, Kauhanen J, Salonen JT, Kuller LH, Simons LA, van der Schouw YT, Barrett-Connor E, Selmer R, Crespo C], Rodriguez B, Verschuren WM, Salomaa V, Svardsudd K, van der Harst $P$, Bjorkelund $C$, Wilhelmsen $L$, Wallace RB, Brenner $H$, Amouyel P, Barr EL, Iso H, Onat A, Trevisan M, D'Agostino RB Sr, Cooper C, Kavousi M, Welin L, Roussel R, Hu FB, Sato S, Davidson KW, Howard BV, Leening MJ, Rosengren A, Dorr M, Deeg DJ, Kiechl S, Stehouwer CD, Nissinen A, Giampaoli S, Donfrancesco C, Kromhout D, Price JF, Peters A, Meade TW, Casiglia E, Lawlor DA, Gallacher J, Nagel D, Franco OH, Assmann G, Dagenais GR, Jukema JW, Sundstrom J, Woodward M, Brunner EJ, Khaw KT, Wareham NJ, Whitsel EA, Njolstad I, Hedblad B, Wassertheil-Smoller S, Engstrom G, Rosamond WD, Selvin E, Sattar N, Thompson SG, Danesh J. Association of cardiometabolic multimorbidity with mortality. JAMA 2015;314:52-60.

410. Action to Control Cardiovascular Risk in Diabetes Study Group, Gerstein HC, Miller ME, Byington RP, Goff DC Jr, Bigger JT, Buse JB, Cushman WC, Genuth S, Ismail-Beigi F, Grimm RH Jr, Probstfield JL, Simons-Morton DG, Friedewald WT. Effects of intensive glucose lowering in type 2 diabetes. N Engl J Med 2008;358:2545-2559.

411. Ray KK, Seshasai SR, Wijesuriya S, Sivakumaran R, Nethercott S, Preiss D, Erqou S, Sattar N. Effect of intensive control of glucose on cardiovascular outcomes and death in patients with diabetes mellitus: a meta-analysis of randomised controlled trials. Lancet 2009;373:1765-1772.

412. Dormandy JA, Charbonnel B, Eckland DJ, Erdmann E, Massi-Benedetti M, Moules IK, Skene AM, Tan MH, Lefebvre PJ, Murray GD, Standl E, Wilcox RG, Wilhelmsen L, Betteridge J, Birkeland K, Golay A, Heine RJ, Koranyi L, Laakso M, Mokan M, Norkus A, Pirags V, Podar T, Scheen A, Scherbaum W, Schernthaner G, Schmitz O, Skrha J, Smith U, Taton J. Secondary prevention of macrovascular events in patients with type 2 diabetes in the PROactive Study (PROspective pioglitAzone Clinical Trial In macroVascular Events): a randomised controlled trial. Lancet 2005;366:1279-1289.

413. Kelly TN, Bazzano LA, Fonseca VA, Thethi TK, Reynolds K, He J. Systematic review: glucose control and cardiovascular disease in type 2 diabetes. Ann Intern Med 2009:151:394-403.

414. Green JB, Bethel MA, Armstrong PW, Buse JB, Engel SS, Garg J, Josse R, Kaufman KD, Koglin J, Korn S, Lachin JM, McGuire DK, Pencina MJ, Standl E, Stein PP, Suryawanshi S, Van de Werf F, Peterson ED, Holman RR. Effect of sitagliptin on cardiovascular outcomes in type 2 diabetes. N Engl J Med 2015;373: 232-242.

415. Pfeffer MA, Claggett B, Diaz R, Dickstein K, Gerstein HC, Kober LV, Lawson FC, Ping L, Wei X, Lewis EF, Maggioni AP, McMurray JJ, Probstfield JL, Riddle MC, Solomon SD, Tardif JC. Lixisenatide in patients with type 2 diabetes and acute coronary syndrome. N Engl J Med 2015;373:2247-2257.

416. Scirica BM, Bhatt DL, Braunwald E, Steg PG, Davidson J, Hirshberg B, Ohman P, Frederich R, Wiviott SD, Hoffman EB, Cavender MA, Udell JA, Desai NR, Mosenzon O, McGuire DK, Ray KK, Leiter LA, Raz I. Saxagliptin and cardiovascular outcomes in patients with type 2 diabetes mellitus. N Engl J Med 2013;369: 1317-1326.

417. White WB, Cannon CP, Heller SR, Nissen SE, Bergenstal RM, Bakris GL, Perez AT, Fleck PR, Mehta CR, Kupfer S, Wilson C, Cushman WC, Zannad F. Alogliptin after acute coronary syndrome in patients with type 2 diabetes. N Engl J Med 2013;369:1327-1335.

418. Emdin CA, Rahimi K, Neal B, Callender T, Perkovic V, Patel A. Blood pressure lowering in type 2 diabetes: a systematic review and meta-analysis. JAMA 2015;313: 603-615.

419. Baigent C, Keech A, Kearney PM, Blackwell L, Buck G, Pollicino C, Kirby A, Sourjina T, Peto R, Collins R, Simes R. Efficacy and safety of cholesterol-lowering treatment: prospective meta-analysis of data from 90,056 participants in 14 randomised trials of statins. Lancet 2005;366:1267-1278.

420. Goldfine AB, Kaul S, Hiatt WR. Fibrates in the treatment of dyslipidemias-time for a reassessment. N Engl J Med 2011;365:481-484.

421. Antiplatelet Trialists' Collaboration. Collaborative overview of randomised trials of antiplatelet therapy-l: Prevention of death, myocardial infarction, and stroke by prolonged antiplatelet therapy in various categories of patients. BMJ 1994;308 $81-106$.

422. Schernthaner G, Sattar N. Lessons from SAVOR and EXAMINE: some important answers, but many open questions. J Diabetes Complic 2014;28:430-433.

423. Livingstone SJ, Looker HC, Hothersall EJ, Wild SH, Lindsay RS, Chalmers J, Cleland S, Leese GP, McKnight J. Morris AD, Pearson DW, Peden NR, Petrie JR, Philip S, Sattar N, Sullivan F, Colhoun HM. Risk of cardiovascular disease and total mortality in adults with type 1 diabetes: Scottish registry linkage study. PLoS Med 2012;9:e1001321.

424. Livingstone SJ, Levin D, Looker HC, Lindsay RS, Wild SH, Joss N, Leese G, Leslie $P$, McCrimmon RJ, Metcalfe W, McKnight JA, Morris AD, Pearson DW, Petrie JR, Philip S, Sattar NA, Traynor JP, Colhoun HM. Estimated life expectancy in a Scottish cohort with type 1 diabetes, 2008-2010. JAMA 2015;313:37-44.

425. Lind M, Svensson AM, Kosiborod M, Gudbjornsdottir S, Pivodic A, Wedel H, Dahlqvist S, Clements M, Rosengren A. Glycemic control and excess mortality in type 1 diabetes. N Engl J Med 2014;371:1972-1982.

426. Writing Group for the DCCT/EDIC Research Group, Orchard T], Nathan DM, Zinman B, Cleary P, Brillon D, Backlund JY, Lachin JM. Association between 7 years of intensive treatment of type 1 diabetes and long-term mortality. JAMA 2015;313:45-53.

427. Cholesterol Treatment Trialists' Collaboration, Kearney PM, Blackwell L, Collins R, Keech A, Simes J, Peto R, Armitage J, Baigent C. Efficacy of cholesterollowering therapy in 18,686 people with diabetes in 14 randomised trials of statins: a meta-analysis. Lancet 2008;371:117-125.

428. Cook NR, Cutler JA, Obarzanek E, Buring JE, Rexrode KM, Kumanyika SK, Appel LJ, Whelton PK. Long term effects of dietary sodium reduction on cardiovascular disease outcomes: observational follow-up of the trials of hypertension prevention (TOHP). BMJ 2007;334:885-888.

429. Fagard RH. Exercise therapy in hypertensive cardiovascular disease. Prog Cardiovasc Dis 2011:53:404-411.

430. Doll R, Peto R, Wheatley K, Gray R, Sutherland I. Mortality in relation to smoking: 40 years' observations on male British doctors. BMJ 1994;309:901-911.

431. Law MR, Morris JK, Wald NJ. Use of blood pressure lowering drugs in the prevention of cardiovascular disease: meta-analysis of 147 randomised trials in the context of expectations from prospective epidemiological studies. BMJ 2009;338: b1665.

432. Zanchetti A, Mancia G. Longing for clinical excellence: a critical outlook into the NICE recommendations on hypertension management-is nice always good? J Hypertens 2012;30:660-668.

433. Mancia G, Fagard R, Narkiewicz K, Redon J, Zanchetti A, Bohm M, Christiaens T, Cifkova R, De Backer G, Dominiczak A, Galderisi M, Grobbee DE, Jaarsma T, Kirchhof P, Kjeldsen SE, Laurent S, Manolis AJ, Nilsson PM, Ruilope LM, Schmieder RE, Sirnes PA, Sleight P, Viigimaa M, Waeber B, Zannad F. 2013 ESH/ESC practice guidelines for the management of arterial hypertension. Blood Pressure 2014:23:3-16.

434. Zanchetti A, Grassi G, Mancia G. When should antihypertensive drug treatment be initiated and to what levels should systolic blood pressure be lowered? A critical reappraisal. J Hypertens 2009;27:923-934.

435. SPRINT Research Group. A randomized trial of intensive versus standard bloodpressure control. N Engl J Med 2015;373:2103-2116.

436. Beckett NS, Peters R, Fletcher AE, Staessen JA, Liu L, Dumitrascu D, Stoyanovsky V, Antikainen RL, Nikitin Y, Anderson C, Belhani A, Forette F, Rajkumar C, Thijs L, Banya W, Bulpitt C). Treatment of hypertension in patients 80 years of age or older. N Engl J Med 2008;358:1887-1898.

437. Gupta AK, Arshad S, Poulter NR. Compliance, safety, and effectiveness of fixeddose combinations of antihypertensive agents: a meta-analysis. Hypertension 2010; 55:399-407.

438. Elliott WJ, Meyer PM. Incident diabetes in clinical trials of antihypertensive drugs: a network meta-analysis. Lancet 2007;369:201-207.

439. Lim SS, Vos T, Flaxman AD, Danaei G, Shibuya K, Adair-Rohani H, Amann M, Anderson HR, Andrews KG, Aryee M, Atkinson C, Bacchus LJ, Bahalim AN, Balakrishnan K, Balmes J, Barker-Collo S, Baxter A, Bell ML, Blore JD, Blyth F, Bonner C, Borges G, Bourne R, Boussinesq M, Brauer M, Brooks P, Bruce NG Brunekreef B, Bryan-Hancock C, Bucello C, Buchbinder R, Bull F, Burnett RT, Byers TE, Calabria B, Carapetis J, Carnahan E, Chafe Z, Charlson F, Chen H, Chen JS, Cheng AT, Child JC, Cohen A, Colson KE, Cowie BC, Darby S, Darling S, Davis A, Degenhardt L, Dentener F, Des Jarlais DC, Devries K, Dherani M, Ding EL, Dorsey ER, Driscoll T, Edmond K, Ali SE, Engell RE, Erwin PJ, Fahimi S, Falder G, Farzadfar F, Ferrari A, Finucane MM, Flaxman S, Fowkes FG, Freedman G, Freeman MK, Gakidou E, Ghosh S, Giovannucci E, Gmel G, Graham K, Grainger R, Grant B, Gunnell D, Gutierrez HR, Hall W, Hoek HW, Hogan A, Hosgood HD 3rd, Hoy D, Hu H, Hubbell BJ, Hutchings SJ, Ibeanusi SE, Jacklyn GL, Jasrasaria R, Jonas JB, Kan H, Kanis JA, Kassebaum N, Kawakami N, Khang YH, Khatibzadeh S, Khoo JP, Kok C, Laden F, Lalloo R, Lan Q, Lathlean T, Leasher JL, Leigh J, Li Y, Lin JK, 
Lipshultz SE, London S, Lozano R, Lu Y, Mak J, Malekzadeh R, Mallinger L, Marcenes W, March L, Marks R, Martin R, McGale P, McGrath J, Mehta S, Mensah GA, Merriman TR, Micha R, Michaud C, Mishra V, Mohd Hanafiah K, Mokdad AA, Morawska L, Mozaffarian D, Murphy T, Naghavi M, Neal B, Nelson PK, Nolla JM, Norman R, Olives C, Omer SB, Orchard J, Osborne R, Ostro B, Page A, Pandey KD, Parry CD, Passmore E, Patra J, Pearce N, Pelizzari PM, Petzold M, Phillips MR, Pope D, Pope CA 3rd, Powles J, Rao M, Razavi H, Rehfuess EA, Rehm JT, Ritz B, Rivara FP, Roberts T, Robinson C, Rodriguez-Portales JA, Romieu I, Room R, Rosenfeld LC, Roy A, Rushton L, Salomon JA, Sampson U, Sanchez-Riera L, Sanman E, Sapkota A, Seedat S, Shi P, Shield K, Shivakoti R, Singh GM, Sleet DA, Smith E, Smith KR, Stapelberg NJ, Steenland K, Stockl H, Stovner LJ, Straif K, Straney L, Thurston GD, Tran JH, Van Dingenen R, van Donkelaar A, Veerman JL, Vijayakumar L, Weintraub R, Weissman MM, White RA, Whiteford $H$, Wiersma ST, Wilkinson JD, Williams HC, Williams W, Wilson N, Woolf AD, Yip P, Zielinski JM, Lopez AD, Murray C], Ezzati M, AIMazroa MA, Memish ZA. A comparative risk assessment of burden of disease and injury attributable to 67 risk factors and risk factor clusters in 21 regions, 1990-2010: a systematic analysis for the Global Burden of Disease Study 2010. Lancet 2012;380:2224-2260.

440. Lewington S, Clarke R, Qizilbash N, Peto R, Collins R. Age-specific relevance of usual blood pressure to vascular mortality: a meta-analysis of individual data for one million adults in 61 prospective studies. Lancet 2002;360:1903-1913.

441. O’Brien E, Waeber B, Parati G, Staessen J, Myers MG. Blood pressure measuring devices: recommendations of the European Society of Hypertension. BMJ 2001; 322:531-536.

442. Myers MG, Godwin M, Dawes M, Kiss A, Tobe SW, Kaczorowski J. Measurement of blood pressure in the office: recognizing the problem and proposing the solution. Hypertension 2010;55:195-200.

443. Parati G, Stergiou GS, Asmar R, Bilo G, de Leeuw P, Imai Y, Kario K, Lurbe E, Manolis A, Mengden T, O'Brien E, Ohkubo T, Padfield P, Palatini P, Pickering T, Redon J, Revera M, Ruilope LM, Shennan A, Staessen JA, Tisler A, Waeber B, Zanchetti A, Mancia G. European Society of Hypertension guidelines for blood pressure monitoring at home: a summary report of the Second International Consensus Conference on Home Blood Pressure Monitoring. J Hypertens 2008;26: 1505-1526.

444. Mancia G, Facchetti R, Bombelli M, Grassi G, Sega R. Long-term risk of mortality associated with selective and combined elevation in office, home, and ambulatory blood pressure. Hypertension 2006;47:846-853.

445. Sehestedt T, Jeppesen J, Hansen TW, Wachtell K, Ibsen H, Torp-Pedersen C, Hildebrandt $\mathrm{P}$, Olsen $\mathrm{MH}$. Risk prediction is improved by adding markers of subclinical organ damage to SCORE. Eur Heart J 2010;31:883-891.

446. Pascual JM, Rodilla E, Costa JA, Garcia-Escrich M, Gonzalez C, Redon J. Prognostic value of microalbuminuria during antihypertensive treatment in essential hypertension. Hypertension 2014;64:1228-1234.

447. ESH/ESC Task Force for the Management of Arterial Hypertension. 2013 Practice guidelines for the management of arterial hypertension of the European Society of Hypertension (ESH) and the European Society of Cardiology (ESC): ESH/ESC Task Force for the Management of Arterial Hypertension. J Hypertens 2013;31: 1925-1938.

448. O'Rourke MF, Adji A. Guidelines on guidelines: focus on isolated systolic hypertension in youth. J Hypertens 2013;31:649-654.

449. Blood Pressure Lowering Treatment Trialists' Collaboration, Turnbull F, Neal B, Ninomiya T, Algert C, Arima H, Barzi F, Bulpitt C, Chalmers J, Fagard R, Gleason A, Heritier S, Li N, Perkovic V, Woodward M, MacMahon S. Effects of different regimens to lower blood pressure on major cardiovascular events in older and younger adults: meta-analysis of randomised trials. BMJ 2008;336: $1121-1123$.

450. Wald DS, Law M, Morris JK, Bestwick JP, Wald NJ. Combination therapy versus monotherapy in reducing blood pressure: meta-analysis on 11,000 participants from 42 trials. Am J Med 2009;122:290-300.

451. Jamerson K, Weber MA, Bakris GL, Dahlof B, Pitt B, Shi V, Hester A, Gupte J, Gatlin M, Velazquez EJ. Benazepril plus amlodipine or hydrochlorothiazide for hypertension in high-risk patients. N Engl J Med 2008;359:2417-2428.

452. ONTARGET Investigators, Yusuf S, Teo KK, Pogue J, Dyal L, Copland I, Schumacher H, Dagenais G, Sleight P, Anderson C. Telmisartan, ramipril, or both in patients at high risk for vascular events. N Engl J Med 2008;358: 1547-1559.

453. Daugherty SL, Powers JD, Magid DJ, Tavel HM, Masoudi FA, Margolis KL, O'Connor PJ, Selby JV, Ho PM. Incidence and prognosis of resistant hypertension in hypertensive patients. Circulation 2012;125:1635-1642.

454. Wachtell K, Okin PM, Olsen MH, Dahlof B, Devereux RB, Ibsen H, Kjeldsen SE, Lindholm LH, Nieminen MS, Thygesen K. Regression of electrocardiographic left ventricular hypertrophy during antihypertensive therapy and reduction in sudden cardiac death: the LIFE Study. Circulation 2007;116:700-705.
455. Yusuf S, Zhao F, Mehta SR, Chrolavicius S, Tognoni G, Fox KK. Effects of clopidogrel in addition to aspirin in patients with acute coronary syndromes without ST-segment elevation. N Engl J Med 2001;345:494-502.

456. Wiviott SD, Braunwald E, McCabe CH, Montalescot G, Ruzyllo W, Gottlieb S, Neumann FJ, Ardissino D, De Servi S, Murphy SA, Riesmeyer J, Weerakkody G, Gibson CM, Antman EM. Prasugrel versus clopidogrel in patients with acute coronary syndromes. N Engl J Med 2007;357:2001-2015.

457. Wallentin L, Becker RC, Budaj A, Cannon CP, Emanuelsson H, Held C, Horrow J, Husted S, James S, Katus H, Mahaffey KW, Scirica BM, Skene A, Steg PG, Storey RF, Harrington RA, Freij A, Thorsen M. Ticagrelor versus clopidogrel in patients with acute coronary syndromes. N Engl J Med 2009;361:1045-1057.

458. Kim BK, Hong MK, Shin DH, Nam CM, Kim JS, Ko YG, Choi D, Kang TS, Park BE, Kang WC, Lee SH, Yoon JH, Hong BK, Kwon HM, Jang Y. A new strategy for discontinuation of dual antiplatelet therapy: the RESET Trial (REal Safety and Efficacy of 3-month dual antiplatelet Therapy following Endeavor zotarolimus-eluting stent implantation). J Am Coll Cardiol 2012;60:1340-1348.

459. Feres F, Costa RA, Abizaid A, Leon MB, Marin-Neto JA, Botelho RV, King SB 3rd, Negoita M, Liu M, de Paula JE, Mangione JA, Meireles GX, Castello HJ Jr, Nicolela EL Jr, Perin MA, Devito FS, Labrunie A, Salvadori D Jr, Gusmao M, Staico R, Costa JR Jr, de Castro JP, Abizaid AS, Bhatt DL. Three vs twelve months of dual antiplatelet therapy after zotarolimus-eluting stents: the OPTIMIZE randomized trial. JAMA 2013;310:2510-2522.

460. Gwon HC, Hahn JY, Park KW, Song YB, Chae IH, Lim DS, Han KR, Choi JH, Choi SH, Kang HJ, Koo BK, Ahn T, Yoon JH, Jeong MH, Hong TJ, Chung WY, Choi YJ, Hur SH, Kwon HM, Jeon DW, Kim BO, Park SH, Lee NH, Jeon HK, Jang Y, Kim HS. Six-month versus 12-month dual antiplatelet therapy after implantation of drug-eluting stents: the Efficacy of Xience/Promus Versus Cypher to Reduce Late Loss After Stenting (EXCELLENT) randomized, multicenter study. Circulation 2012;125:505-513.

461. Schulz-Schupke S, Byrne RA, Ten Berg JM, Neumann FJ, Han Y, Adriaenssens T, Tolg R, Seyfarth M, Maeng M, Zrenner B, Jacobshagen C, Mudra H, von Hodenberg E, Wohrle J, Angiolillo DJ, von Merzljak B, Rifatov N, Kufner S, Morath T, Feuchtenberger A, Ibrahim T, Janssen PW, Valina C, Li Y, Desmet W, Abdel-Wahab M, Tiroch K, Hengstenberg C, Bernlochner I, Fischer M, Schunkert H, Laugwitz KL, Schomig A, Mehilli J, Kastrati A. ISAR-SAFE: a randomized, double-blind, placebo-controlled trial of 6 vs. 12 months of clopidogrel therapy after drug-eluting stenting. Eur Heart J 2015;36:1252-1263.

462. Mauri L, Kereiakes DJ, Yeh RW, Driscoll-Shempp P, Cutlip DE, Steg PG, Normand SL, Braunwald E, Wiviott SD, Cohen DJ, Holmes DR Jr, Krucoff MW, Hermiller J, Dauerman HL, Simon DI, Kandzari DE, Garratt KN, Lee DP, Pow TK, Ver Lee P, Rinaldi MJ, Massaro JM. Twelve or 30 months of dual antiplatelet therapy after drug-eluting stents. N Engl J Med 2014;371: 2155-2166.

463. Bonaca MP, Bhatt DL, Cohen M, Steg PG, Storey RF, Jensen EC, Magnani G, Bansilal S, Fish MP, Im K, Bengtsson O, Oude Ophuis T, Budaj A, Theroux P, Ruda M, Hamm C, Goto S, Spinar J, Nicolau JC, Kiss RG, Murphy SA, Wiviott SD, Held P, Braunwald E, Sabatine MS. Long-term use of ticagrelor in patients with prior myocardial infarction. N Engl J Med 2015;372:1791-1800.

464. Antithrombotic Trialists' Collaboration, Baigent C, Blackwell L, Collins R, Emberson J, Godwin J, Peto R, Buring J, Hennekens C, Kearney P, Meade T, Patrono C, Roncaglioni MC, Zanchetti A. Aspirin in the primary and secondary prevention of vascular disease: collaborative meta-analysis of individual participant data from randomised trials. Lancet 2009;373:1849-1860.

465. De Schryver EL, Algra A, van Gijn J. Dipyridamole for preventing stroke and other vascular events in patients with vascular disease. Cochrane Database Syst Rev 2007; 3:CD001820.

466. Sacco RL, Diener HC, Yusuf S, Cotton D, Ounpuu S, Lawton WA, Palesch Y, Martin RH, Albers GW, Bath P, Bornstein N, Chan BP, Chen ST, Cunha L, Dahlof B, De Keyser J, Donnan GA, Estol C, Gorelick P, Gu V, Hermansson K, Hilbrich L, Kaste M, Lu C, Machnig T, Pais P, Roberts R, Skvortsova V, Teal P, Toni D, Vandermaelen C, Voigt T, Weber M, Yoon BW. Aspirin and extended-release dipyridamole versus clopidogrel for recurrent stroke. N Engl J Med 2008;359:1238-1251.

467. Farrell B, Godwin J, Richards S, Warlow C. The United Kingdom transient ischaemic attack (UK-TIA) aspirin trial: final results. J Neurol Neurosurg Psychiatry 1991; 54:1044-1054.

468. Mohr JP, Thompson JL, Lazar RM, Levin B, Sacco RL, Furie KL, Kistler JP, Albers GW, Pettigrew LC, Adams HP Jr, Jackson CM, Pullicino P. A comparison of warfarin and aspirin for the prevention of recurrent ischemic stroke. N Engl J Med 2001;345:1444-1451.

469. Liu M, Counsell C, Sandercock P. Anticoagulants for preventing recurrence following ischaemic stroke or transient ischaemic attack. Cochrane Database Syst Rev 2000;2:CD000248.

470. Ikeda Y, Shimada K, Teramoto T, Uchiyama S, Yamazaki T, Oikawa S, Sugawara M, Ando K, Murata M, Yokoyama K, Ishizuka N. Low-dose aspirin for primary 
prevention of cardiovascular events in Japanese patients 60 years or older with atherosclerotic risk factors: a randomized clinical trial. JAMA 2014;312: 2510-2520.

471. Bhatt DL, Fox KA, Hacke W, Berger PB, Black HR, Boden WE, Cacoub P, Cohen EA, Creager MA, Easton JD, Flather MD, Haffner SM, Hamm CW, Hankey GJ, Johnston SC, Mak KH, Mas JL, Montalescot G, Pearson TA, Steg PG, Steinhubl SR, Weber MA, Brennan DM, Fabry-Ribaudo L, Booth J, Topol EJ. Clopidogrel and aspirin versus aspirin alone for the prevention of atherothrombotic events. N Engl J Med 2006;354:1706-1717.

472. ASCEND. A Study of Cardiovascular Events in Diabetes. http://www.ctsu.ox.ac.uk/ ascend.

473. De Berardis G, Sacco M, Evangelista V, Filippi A, Giorda CB, Tognoni G, Valentini U, Nicolucci A. Aspirin and Simvastatin Combination for Cardiovascular Events Prevention Trial in Diabetes (ACCEPT-D): design of a randomized study of the efficacy of low-dose aspirin in the prevention of cardiovascular events in subjects with diabetes mellitus treated with statins. Trials 2007;8:21.

474. Nelson MR, Reid CM, Ames DA, Beilin LJ, Donnan GA, Gibbs P, Johnston Cl, Krum H, Storey E, Tonkin A, Wolfe R, Woods R, McNeil JJ. Feasibility of conducting a primary prevention trial of low-dose aspirin for major adverse cardiovascular events in older people in Australia: results from the ASPirin in Reducing Events in the Elderly (ASPREE) pilot study. Med J Aust 2008;189:105-109.

475. Aspirin to Reduce Risk of Initial Vascular Events (ARRIVE) Trial. http://www.arrivestudy.com.

476. Chen ZM, Sandercock P, Pan HC, Counsell C, Collins R, Liu LS, Xie JX, Warlow C, Peto R. Indications for early aspirin use in acute ischemic stroke: a combined analysis of 40000 randomized patients from the Chinese Acute Stroke Trial and the International Stroke Trial. On behalf of the CAST and IST collaborative groups. Stroke 2000;31:1240-1249.

477. CAPRIE Steering Committee. A randomised, blinded, trial of clopidogrel versus aspirin in patients at risk of ischaemic events (CAPRIE). Lancet 1996;348: $1329-1339$.

478. Diener HC, Bogousslavsky J, Brass LM, Cimminiello C, Csiba L, Kaste M, Leys D, Matias-Guiu J, Rupprecht HJ. Aspirin and clopidogrel compared with clopidogrel alone after recent ischaemic stroke or transient ischaemic attack in high-risk patients (MATCH): randomised, double-blind, placebo-controlled trial. Lancet 2004; 364:331-337.

479. Wang Y, Pan Y, Zhao X, Li H, Wang D, Johnston SC, Liu L, Meng X, Wang A, Wang C, Wang Y. Clopidogrel with aspirin in acute minor stroke or transient ischemic attack (CHANCE) trial: one-year outcomes. Circulation 2015;132:40-46.

480. Morrow DA, Braunwald E, Bonaca MP, Ameriso SF, Dalby AJ, Fish MP, Fox KA, Lipka LJ, Liu X, Nicolau JC, Ophuis AJ, Paolasso E, Scirica BM, Spinar J, Theroux P, Wiviott SD, Strony J, Murphy SA. Vorapaxar in the secondary prevention of atherothrombotic events. N Engl J Med 2012;366:1404-1413.

481. Kripalani S, Yao X, Haynes RB. Interventions to enhance medication adherence in chronic medical conditions: a systematic review. Arch Intern Med 2007;167: 540-550.

482. Chowdhury R, Khan H, Heydon E, Shroufi A, Fahimi S, Moore C, Stricker B, Mendis S, Hofman A, Mant J, Franco $\mathrm{OH}$. Adherence to cardiovascular therapy: a meta-analysis of prevalence and clinical consequences. Eur Heart J 2013;34: 2940-2948.

483. Ho PM, Bryson CL, Rumsfeld JS. Medication adherence: its importance in cardiovascular outcomes. Circulation 2009;119:3028-3035.

484. Osterberg L, Blaschke T. Adherence to medication. N Engl ] Med 2005;353: 487-497.

485. de Cates AN, Farr MR, Wright N, Jarvis MC, Rees K, Ebrahim S, Huffman MD. Fixed-dose combination therapy for the prevention of cardiovascular disease. Cochrane Database Syst Rev 2014;4:CD009868.

486. Castellano JM, Sanz G, Penalvo JL, Bansilal S, Fernandez-Ortiz A, Alvarez L, Guzman L, Linares JC, Garcia F, D’Aniello F, Arnaiz JA, Varea S, Martinez F, Lorenzatti A, Imaz I, Sanchez-Gomez LM, Roncaglioni MC, Baviera M, Smith SC Jr, Taubert K, Pocock S, Brotons C, Farkouh ME, Fuster V. A polypill strategy to improve adherence: results from the FOCUS project. J Am Coll Cardiol 2014;64: 2071-2082

487. Simpson SH, Eurich DT, Majumdar SR, Padwal RS, Tsuyuki RT, Varney J, Johnson JA. A meta-analysis of the association between adherence to drug therapy and mortality. BM/ 2006;333:15.

488. Doshi JA, Zhu J, Lee BY, Kimmel SE, Volpp KG. Impact of a prescription copayment increase on lipid-lowering medication adherence in veterans. Circulation 2009;119:390-397.

489. Gehi A, Haas D, Pipkin S, Whooley MA. Depression and medication adherence in outpatients with coronary heart disease: findings from the Heart and Soul Study. Arch Intern Med 2005; 165:2508-2513.

490. Tarn DM, Heritage J, Paterniti DA, Hays RD, Kravitz RL, Wenger NS. Physician communication when prescribing new medications. Arch Intern Med 2006;166: 1855-1862.
491. Santschi V, Chiolero A, Burnand B, Colosimo AL, Paradis G. Impact of pharmacist care in the management of cardiovascular disease risk factors: a systematic review and meta-analysis of randomized trials. Arch Intern Med 2011;171:1441-1453.

492. Mamudu HM, Paul TK, Veeranki SP, Budoff M. The effects of coronary artery calcium screening on behavioral modification, risk perception, and medication adherence among asymptomatic adults: a systematic review. Atherosclerosis 2014; 236:338-350.

493. Wald NJ, Law MR. A strategy to reduce cardiovascular disease by more than $80 \%$. BMJ 2003;326:1419.

494. Lonn E, Bosch J, Teo KK, Pais P, Xavier D, Yusuf S. The polypill in the prevention of cardiovascular diseases: key concepts, current status, challenges, and future directions. Circulation 2010;122:2078-2088.

495. Jorgensen T, Capewell S, Prescott E, Allender S, Sans S, Zdrojewski T, De Bacquer D, de Sutter J, Franco OH, Logstrup S, Volpe M, Malyutina S, Marques-Vidal P, Reiner Z, Tell GS, Verschuren WM, Vanuzzo D. Populationlevel changes to promote cardiovascular health. Eur J Prev Cardiol 2013;20: 409-421.

496. Mozaffarian D, Afshin A, Benowitz NL, Bittner V, Daniels SR, Franch HA, Jacobs DR Jr, Kraus WE, Kris-Etherton PM, Krummel DA, Popkin BM, Whitsel LP, Zakai NA. Population approaches to improve diet, physical activity, and smoking habits: a scientific statement from the American Heart Association. Circulation 2012;126:1514-1563.

497. National Institute for Health and Care Excellence. Prevention of cardiovascular disease at the population level. London: National Institute for Health and Care Excellence, 2010.

498. EU platform on diet, physical activity and health. European Union, 2005. http://ec. europa.eu/health/archive/ph_determinants/life_style/nutrition/platform/docs/ platform_charter.pdf

499. Bureau Europe'en des Unions de Consommateurs. The consumer case for EU legal restrictions on the use of artificial trans-fats in food. Position paper. Brussels: European Union, 2014. http://www.beuc.eu/publications/beuc-x-2014-010_the_ consumer_case_for_eu_legal_restrictions_on_the_use_of_artificial_trans.pdf.

500. Webster J, Trieu K, Dunford E, Hawkes C. Target salt 2025: a global overview of national programs to encourage the food industry to reduce salt in foods. Nutrients 2014:6:3274-87.

501. He FJ, Pombo-Rodrigues S, Macgregor GA. Salt reduction in England from 2003 to 2011: its relationship to blood pressure, stroke and ischaemic heart disease mortality. BMJ Open 2014;4:e004549.

502. Romon M, Lommez A, Tafflet M, Basdevant A, Oppert JM, Bresson JL, Ducimetiere P, Charles MA, Borys JM. Downward trends in the prevalence of childhood overweight in the setting of 12-year school- and community-based programmes. Public Health Nutr 2009;12:1735-1742.

503. Veerman JL, Van Beeck EF, Barendregt JJ, Mackenbach JP. By how much would limiting TV food advertising reduce childhood obesity? Eur J Public Health 2009;19: 365-39.

504. Hawkes C, Smith TG, Jewell J, Wardle J, Hammond RA, Friel S, Thow AM, Kain J. Smart food policies for obesity prevention. Lancet 2015;385:2410-2421.

505. Wakefield MA, Loken B, Hornik RC. Use of mass media campaigns to change health behaviour. Lancet 2010;376:1261-1271.

506. Grunert KG, Wills JM. A review of European research on consumer response to nutrition information on food labels. J Public Health 2007;15:385-399.

507. Eyles H, Ni Mhurchu C, Nghiem N, Blakely T. Food pricing strategies, population diets, and non-communicable disease: a systematic review of simulation studies. PLoS Med 2012;9:e1001353.

508. Powell LM, Chriqui JF, Khan T, Wada R, Chaloupka FJ. Assessing the potential effectiveness of food and beverage taxes and subsidies for improving public health: a systematic review of prices, demand and body weight outcomes. Obesity Rev 2013; 14:110-128.

509. Geaney F, Kelly C, Greiner BA, Harrington JM, Perry IJ, Beirne P. The effectiveness of workplace dietary modification interventions: a systematic review. Prev Med 2013;57:438-447

510. Capewell S, O'Flaherty M. Rapid mortality falls after risk-factor changes in populations. Lancet 2011;378:752-753.

511. Kriemler S, Zahner L, Schindler C, Meyer U, Hartmann T, Hebestreit H, BrunnerLa Rocca HP, van Mechelen W, Puder JJ. Effect of school based physical activity programme (KISS) on fitness and adiposity in primary schoolchildren: cluster randomised controlled trial. BMJ 2010;340:c785.

512. Global Advocacy Council for Physical Activity, International Society for Physical Activity and Health. The Toronto Charter for Physical Activity: a global call for action. J Physical Activity Health 2010;7(Suppl 3):S370-S385.

513. Hillman CH, Pontifex MB, Castelli DM, Khan NA, Raine LB, Scudder MR, Drollette ES, Moore RD, Wu CT, Kamijo K. Effects of the FITKids randomized controlled trial on executive control and brain function. Pediatrics 2014;134 e1063-e1071. 
514. Mendoza JA, Levinger DD, Johnston BD. Pilot evaluation of a walking school bus program in a low-income, urban community. BMC Public Health 2009;9:122.

515. Patel MS, Asch DA, Volpp KG. Wearable devices as facilitators, not drivers, of health behavior change. JAMA 2015;313:459-460.

516. Kerr J, Eves F, Carroll D. Six-month observational study of prompted stair climbing. Prev Med 2001;33:422-427.

517. Exercise prescription for health — the green prescription. Dublin: RCSI House, 2013.

518. Mitchell MS, Goodman JM, Alter DA, John LK, Oh PI, Pakosh MT, Faulkner GE. Financial incentives for exercise adherence in adults: systematic review and meta-analysis. Am J Prev Med 2013;45:658-667.

519. Huhman ME, Potter LD, Duke JC, Judkins DR, Heitzler CD, Wong FL. Evaluation of a national physical activity intervention for children: VERB campaign, 20022004. Am J Prev Med 2007;32:38-43.

520. American College of Sports Medicine. ACSM's guidelines for exercise testing and prescription. 9th ed. Baltimore: Wolters Kluwer/Lippincott, 2014.

521. Colcombe SJ, Kramer AF, Erickson KI, Scalf P, McAuley E, Cohen NJ, Webb A, Jerome GJ, Marquez DX, Elavsky S. Cardiovascular fitness, cortical plasticity, and aging. Proc Natl Acad Sci USA 2004;101:3316-3321

522. Leyk D, Rohde U, Hartmann ND, Preuss PA, Sievert A, Witzki A. Results of a workplace health campaign: what can be achieved? Dtsch Arztebl Int 2014;111: 320-327.

523. World Health Organization. Guidelines for implementation. WHO Framework Convention on Tobacco Control. Articles 5.3, 8-14. Geneva: World Health Organization, 2011.

524. Lochen ML, Henrichsen SH, Grimsrud TK, Holmen TL, Gallefoss F. Use of snus during pregnancy is not without risk. Tidsskrift for den Norske laegeforening : tidsskrift for praktisk medicin, ny raekke 2012;132:932-933.

525. Arefalk G, Hambraeus K, Lind L, Michaelsson K, Lindahl B, Sundstrom J. Discontinuation of smokeless tobacco and mortality risk after myocardial infarction. Circulation 2014:130:325-332.

526. Hansson J, Galanti MR, Hergens MP, Fredlund P, Ahlbom A, Alfredsson L, Bellocco R, Eriksson M, Hallqvist J, Hedblad B, Jansson JH, Nilsson P, Pedersen N, Trolle Lagerros Y, Ostergren PO, Magnusson C. Use of snus and acute myocardial infarction: pooled analysis of eight prospective observational studies. Eur J Epidemiol 2012;27:771-779.

527. International Agency for Research on Cancer. Monographs on the evaluation of carcinogenic risks to humans. Volume 100E. Personal Habits and Indoor Combustions. Smokeless Tabacco. 2012 [http://monographs.iarc.fr/ENG/Monographs/vol100E/ mono100E-8.pdf].

528. Grana R, Benowitz N, Glantz SA. E-cigarettes: a scientific review. Circulation 2014; 129:1972-1986.

529. Iversen B, Jacobsen BK, Lochen ML. Active and passive smoking and the risk of myocardial infarction in 24,968 men and women during 11 year of follow-up: the Tromso Study. Eur J Epidemiol 2013;28:659-667.

530. Gallefoss F, Holmen T, Grimsrud T, Henrichsen S, Løchen M-L. Snus under svangerskap er ikke ufarlig. Tidsskrift for Den norske legeforening 2012;132:932-933.

531. Lochen ML, Gram IT, Skattebo S, Kolstrup N. Tobacco images and texts in Norwegian magazines and newspapers. Scand J Public Health 2007;35:31-38.

532. Anderson P. Global alcohol policy and the alcohol industry. Curr Opin Psychiatry 2009;22:253-257.

533. Wagenaar AC, Salois MJ, Komro KA. Effects of beverage alcohol price and tax levels on drinking: a meta-analysis of 1003 estimates from 112 studies. Addiction 2009:104:179-190.

534. World Health Organization. Global status report on alcohol and health. http://apps. who.int/iris/bitstream/10665/112736/1/9789240692763_eng.pdf.

535. National Institute for Health and Care Excellence. Alcohol-use disorders: preventing the development of hazardous and harmful drinking. https://www.nice.org.uk/ guidance/ph24.

536. Her M, Giesbrecht N, Room R, Rehm J. Privatizing alcohol sales and alcohol consumption: evidence and implications. Addiction 1999;94:1125-1139.

537. Mann RE, Macdonald S, Stoduto LG, Bondy S, Jonah B, Shaikh A. The effects of introducing or lowering legal per se blood alcohol limits for driving: an international review. Accid Anal Prev 2001;33:569-583.

538. Stockwell T. A review of research into the impacts of alcohol warning labels on attitudes and behaviour. British Colombia, Canada: Center for Addiction Research of BC, University of Victoria, 2006.

539. Kaner EF, Beyer F, Dickinson HO, Pienaar E, Campbell F, Schlesinger C, Heather N, Saunders J, Burnand B. Effectiveness of brief alcohol interventions in primary care populations. Cochrane Database Syst Rev 2007;2:CD004148.

540. Brien SE, Ronksley PE, Turner BJ, Mukamal KJ, Ghali WA. Effect of alcohol consumption on biological markers associated with risk of coronary heart disease: systematic review and meta-analysis of interventional studies. BMJ 2011;342:d636.

541. Mukamal KJ, Chen CM, Rao SR, Breslow RA. Alcohol consumption and cardiovascular mortality among U.S. adults, 1987 to 2002. J Am Coll Cardiol 2010;55) $1328-1335$.
542. Klatsky AL. Alcohol and cardiovascular mortality: common sense and scientific truth. J Am Coll Cardiol 2010;55:1336-1338.

543. Britton A, McKee M. The relation between alcohol and cardiovascular disease in Eastern Europe: explaining the paradox. J Epidemiol Community Health 2000;54 $328-332$.

544. Newby DE, Mannucci PM, Tell GS, Baccarelli AA, Brook RD, Donaldson K, Forastiere F, Franchini M, Franco OH, Graham I, Hoek G, Hoffmann B, Hoylaerts MF, Kunzli N, Mills N, Pekkanen J, Peters A, Piepoli MF, Rajagopalan S, Storey RF. Expert position paper on air pollution and cardiovascular disease. Eur Heart J 2015;36:83-93b.

545. Murphy AW, Cupples ME, Smith SM, Byrne M, Byrne MC, Newell J. Effect of tailored practice and patient care plans on secondary prevention of heart disease in general practice: cluster randomised controlled trial. BMJ 2009;339:b4220.

546. Brotons C, Lobos JM, Royo-Bordonada MA, Maiques A, de Santiago A, Castellanos A, Diaz S, Obaya JC, Pedro-Botet J, Moral I, Lizarbe V, Moreno R, Perez A, Cordero A, Fornes-Ubeda F, Serrano-Saiz B, Camafort-Babkowski M, Elosua R, Sans S, de Pablo C, Gil-Nunez A, de Alvaro-Moreno F, Armario P. Rico OC, Villar F, Lizcano A. Implementation of Spanish adaptation of the European guidelines on cardiovascular disease prevention in primary care. BMC Fam Pract 2013;14:36.

547. Reiner Z, Sonicki Z, Tedeschi-Reiner E. Physicians' perception, knowledge and awareness of cardiovascular risk factors and adherence to prevention guidelines: the PERCRO-DOC survey. Atherosclerosis 2010;213:598-603.

548. Dallongeville J, Banegas JR, Tubach F, Guallar E, Borghi C, De Backer G, Halcox JP, Masso-Gonzalez EL, Perk J, Sazova O, Steg PG, Artalejo FR. Survey of physicians' practices in the control of cardiovascular risk factors: the EURIKA study. Eur J Prev Cardiol 2012;19:541-550.

549. Byrne D, O'Connor L, Jennings S, Bennett K, Murphy AW. A survey of GPs awareness and use of risk assessment tools and cardiovascular disease prevention guidelines. Irish Med J 2015;108:204-207.

550. Wood DA, Kotseva K, Connolly S, Jennings C, Mead A, Jones J, Holden A, De Bacquer D, Collier T, De Backer G, Faergeman O. Nurse-coordinated multidisciplinary, family-based cardiovascular disease prevention programme (EUROAC$T I O N$ ) for patients with coronary heart disease and asymptomatic individuals at high risk of cardiovascular disease: a paired, cluster-randomised controlled trial. Lancet 2008:371:1999-2012.

551. Voogdt-Pruis HR, Beusmans GH, Gorgels AP, Kester AD, Van Ree JW. Effectiveness of nurse-delivered cardiovascular risk management in primary care: a randomised trial. BrJ Gen Pract 2010;60:40-46.

552. Allen JK, Dennison-Himmelfarb CR, Szanton SL, Bone L, Hill MN, Levine DM, West M, Barlow A, Lewis-Boyer L, Donnelly-Strozzo M, Curtis C, Anderson K. Community Outreach and Cardiovascular Health $(\mathrm{COACH})$ Trial: a randomized, controlled trial of nurse practitioner/community health worker cardiovascular disease risk reduction in urban community health centers. Circ Cardiovasc Qual Outcomes 2011:4:595-602

553. Bramlage P, Messer C, Bitterlich N, Pohlmann C, Cuneo A, Stammwitz E, Tebbenjohanns J, Gohlke H, Senges J, Tebbe U. The effect of optimal medical therapy on 1-year mortality after acute myocardial infarction. Heart 2010;96:604-609.

554. Andrikopoulos G, Tzeis S, Nikas N, Richter D, Pipilis A, Gotsis A, Tsaknakis T, Kartalis A, Kitsiou A, Toli K, Mantas I, Olympios C, Pras A, Lampropoulos S, Oikonomou K, Pappas C, Kranidis A, Anastasiou-Nana M. Triposkiadis F, Goudevenos I, Theodorakis G, Vardas P. Short-term outcome and attainment of secondary prevention goals in patients with acute coronary syndrome-results from the countrywide TARGET study. Int J Cardiol 2013;168:922-927.

555. Anderson L, Taylor RS. Cardiac rehabilitation for people with heart disease: an overview of Cochrane systematic reviews. Cochrane Database Syst Rev 2014;12 CD011273.

556. Anderson L, Oldridge N, Thompson DR, Zwisler A-D, Rees K, Martin N, Taylor RS. Exercise-based cardiac rehabilitation for coronary heart disease. J Am Coll Cardiol 2016;67:1-12.

557. Clark RA, Conway A, Poulsen V, Keech W, Tirimacco R, Tideman P. Alternative models of cardiac rehabilitation: a systematic review. Eur J Prev Cardiol 2015;22 $35-74$.

558. Karmali KN, Davies P, Taylor F, Beswick A, Martin N, Ebrahim S. Promoting patient uptake and adherence in cardiac rehabilitation. Cochrane Database Syst Rev 2014;6:CD007131.

559. McAlister FA, Lawson FM, Teo KK, Armstrong PW. Randomised trials of secondary prevention programmes in coronary heart disease: systematic review. $B M]$ 2001;323:957-962.

560. Murchie P, Campbell NC, Ritchie LD, Simpson JA, Thain J. Secondary prevention clinics for coronary heart disease: four year follow up of a randomised controlled trial in primary care. BMJ 2003;326:84.

561. Jorstad HT, von Birgelen C, Alings AM, Liem A, van Dantzig JM, Jaarsma W, Lok DJ, Kragten HJ, de Vries K, de Milliano PA, Withagen AJ, Scholte Op Reimer WJ, Tijssen JG, Peters RJ. Effect of a nurse-coordinated prevention programme on 
cardiovascular risk after an acute coronary syndrome: main results of the RESPONSE randomised trial. Heart 2013;99:1421-1430.

562. Piepoli MF, Corra U, Adamopoulos S, Benzer W, Bjarnason-Wehrens B, Cupples M, Dendale P, Doherty P, Gaita D, Hofer S, McGee H, Mendes M, Niebauer J, Pogosova N, Garcia-Porrero E, Rauch B, Schmid JP, Giannuzzi P. Secondary prevention in the clinical management of patients with cardiovascular diseases. Core components, standards and outcome measures for referral and delivery: a policy statement from the cardiac rehabilitation section of the European Association for Cardiovascular Prevention \& Rehabilitation. Endorsed by the Committee for Practice Guidelines of the European Society of Cardiology. Eur J Prev Cardiol 2014;21:664-681.

563. Bjarnason-Wehrens B, McGee H, Zwisler AD, Piepoli MF, Benzer W, Schmid JP, Dendale P, Pogosova NG, Zdrenghea D, Niebauer J, Mendes M. Cardiac rehabilitation in Europe: results from the European Cardiac Rehabilitation Inventory Survey. Eur J Cardiovasc Prev Rehabil 2010;17:410-418.

564. Kotseva K, Wood D, De Backer G, De Bacquer D. Use and effects of cardiac rehabilitation in patients with coronary heart disease: results from the EUROASPIRE III survey. Eur J Prev Cardiol 2013;20:817-826.

565. Gravely-Witte S, Leung YW, Nariani R, Tamim H, Oh P, Chan VM, Grace SL. Effects of cardiac rehabilitation referral strategies on referral and enrollment rates. Nat Rev Cardiol 2010;7:87-96.
566. Taylor RS, Dalal H, Jolly K, Moxham T, Zawada A. Home-based versus centre-based cardiac rehabilitation. Cochrane Database Syst Rev 2010;1 CD007130.

567. Neubeck L, Redfern J, Fernandez R, Briffa T, Bauman A, Freedman SB. Telehealth interventions for the secondary prevention of coronary heart disease: a systematic review. Eur J Cardiovasc Prev Rehabil 2009;16:281-289.

568. Piotrowicz E, Korzeniowska-Kubacka I, Chrapowicka A, Wolszakiewicz J, Dobraszkiewicz-Wasilewska B, Batogowski M, Piotrowski W, Piotrowicz R. Feasibility of home-based cardiac telerehabilitation: results of TelelnterMed study. Cardiol J 2014;21:539-546.

569. Varnfield M, Karunanithi M, Lee CK, Honeyman E, Arnold D, Ding H, Smith C, Walters DL. Smartphone-based home care model improved use of cardiac rehabilitation in postmyocardial infarction patients: results from a randomised controlled trial. Heart 2014:100:1770-1779.

570. Giannuzzi P, Temporelli PL, Marchioli R, Maggioni AP, Balestroni G, Ceci V, Chieffo C, Gattone M, Griffo R, Schweiger C, Tavazzi L, Urbinati S, Valagussa F, Vanuzzo $D$. Global secondary prevention strategies to limit event recurrence after myocardial infarction: results of the GOSPEL study, a multicenter, randomized controlled trial from the Italian Cardiac Rehabilitation Network. Arch Intern Med 2008;168:2194-2204. 